\title{
FEEDSTOCK-FLEXIBLE REFORMER SYSTEM (FFRS) FOR SOLID OXIDE FUEL CELL (SOFC)- QUALITY SYNGAS
}

\section{Final Scientific/Technical Project Report}

\author{
Reporting Period Start Date: October 1, 2006
}

Reporting Period End Date: July 31, 2010

Principal Authors:

*Kelly Jezierski, Manager, Alternative Fuel Based Energy Programs ${ }^{a}$

Dr. Andrew Tadd, Assistant Research Scientist ${ }^{\mathrm{b}}$

Dr. Johannes Schwank, Principal Investigator, Professor of Chemical Engineering ${ }^{b}$

Date of Issuance: August 2010

DOE Award Number DE-FC26-06NT42813

\author{
Submitted by:

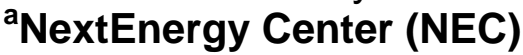 \\ 461 Burroughs Street \\ Detroit, Ml 48202
}

Project Partners:

bUniversity of Michigan (UM), Transportation Energy Center (TEC), Ann Arbor, MI

'Energy Technology Components (ETC), LLC, Ann Arbor, MI

${ }^{\mathrm{d}}$ Faubert \& Associates, LLC, South Lyon, MI

Co-authors and Team Members:

Roland Kibler, Director of Generation, Storage \& Fuels Programs ${ }^{a}$

David McLean, Vice President, Technology Programs \& Chief Operating Officer ${ }^{a}$

Mahesh Samineni, Sr. Project Engineer ${ }^{a}$

Ryan Smith, Project Engineer ${ }^{a}$

Sameer Parvathikar, Graduate Student Research Assistant ${ }^{\mathrm{b}}$

Joe Mayne, Graduate Student Research Assistant ${ }^{\mathrm{b}}$

Tom Westrich, Graduate Student Research Assistant ${ }^{b}$ Jerry Mader, President ${ }^{\mathrm{C}}$

Dr. F. Michael Faubert, Ph. D., P.E ${ }^{d}$ 


\section{DISCLAIMER}

This report was prepared as an account of work sponsored by an agency of the United States Government. Neither the United States Government nor any agency thereof, nor any of their employees, makes any warranty, express or implied, or assumes any legal liability or responsibility for the accuracy, completeness, or usefulness of any information, apparatus, product, or process disclosed, or represents that its use would not infringe privately owned rights. Reference herein to any specific commercial product, process, or service by trade name, trademark, manufacturer, or otherwise does not necessarily constitute or imply its endorsement, recommendation, or favoring by the United States Government or any agency thereof. The views and opinions of authors expressed herein do not necessarily state or reflect those of the United States Government or any agency thereof. 


\section{ABSTRACT}

The U.S. Department of Energy National Energy Technology Laboratory funded this research collaboration effort between NextEnergy and the University of Michigan, who successfully designed, built, and tested a reformer system, which produced highquality syngas for use in SOFC and other applications, and a novel reactor system, which allowed for facile illumination of photocatalysts. Carbon and raw biomass gasification, sulfur tolerance of non-Platinum Group Metals (PGM) based $\left(\mathrm{Ni} / \mathrm{CeZrO}_{2}\right)$ reforming catalysts, photocatalysis reactions based on $\mathrm{TiO}_{2}$, and mild pyrolysis of biomass in ionic liquids (ILs) were investigated at low and medium temperatures (primarily 450 to $850^{\circ} \mathrm{C}$ ) in an attempt to retain some structural value of the starting biomass. Despite a wide range of processes and feedstock composition, a literature survey showed that, gasifier products had narrow variation in composition, a restriction used to develop operating schemes for syngas cleanup. Three distinct reaction conditions were investigated: equilibrium, autothermal reforming of hydrocarbons, and the addition of $\mathrm{O}_{2}$ and steam to match the final $(\mathrm{C} / \mathrm{H} / \mathrm{O})$ composition.

Initial results showed rapid and significant deactivation of $\mathrm{Ni} / \mathrm{CeZrO}_{2}$ catalysts upon introduction of thiophene, but both stable and unstable performance in the presence of sulfur were obtained. The key linkage appeared to be the hydrodesulfurization activity of the $\mathrm{Ni}$ reforming catalysts. For feed stoichiometries where high $\mathrm{H}_{2}$ production was thermodynamically favored, stable, albeit lower, $\mathrm{H}_{2}$ and $\mathrm{CO}$ production were obtained; but lower thermodynamic $\mathrm{H}_{2}$ concentrations resulted in continued catalyst deactivation and eventual poisoning. High $\mathrm{H}_{2}$ levels resulted in thiophene converting to $\mathrm{H}_{2} \mathrm{~S}$ and $\mathrm{S}$ surface desorption, leading to stable performance; low $\mathrm{H}_{2}$ levels resulted in unconverted $\mathrm{S}$ and loss in $\mathrm{H}_{2}$ and $\mathrm{CO}$ production, as well as loss in thiophene conversion. Bimetallic catalysts did not outperform Ni-only catalysts, and small Ni particles were found to have lower activities under S-free conditions, but did show less effect of $S$ on performance, in this study.

Imidazolium-based ILs, choline chloride compounds and low-melting eutectics of metal nitrates were evaluated, and it was found that, ILs have some capacity to dissolve cellulose and show thermal stability to temperatures where pyrolysis begins, have no vapor pressure, (simplifying product recoveries), and can dissolve ionic metal salts, allowing for the potential of catalytic reactions on breakdown intermediates. Clear evidence of photoactive commercial $\mathrm{TiO}_{2}$ was obtained, but in-house synthesis of photoactive $\mathrm{TiO}_{2}$ proved difficult, as did fixed-bed gasification, primarily due to the challenge of removing the condensable products from the reaction zone quickly enough to prevent additional reaction. Further investigation into additional non-PGM catalysts and ILs is recommended as a follow-up to this work. 


\section{TABLE OF CONTENTS}

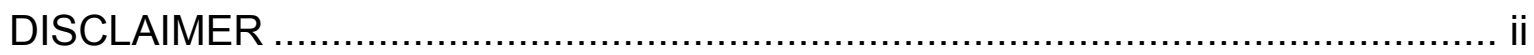

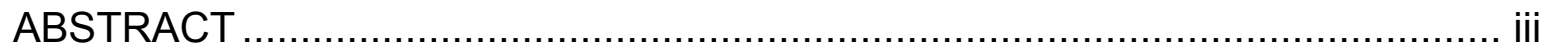

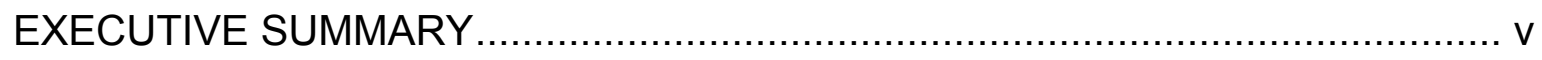

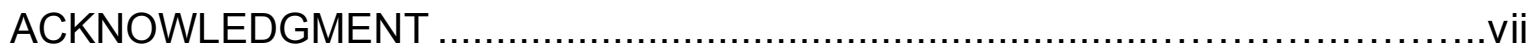

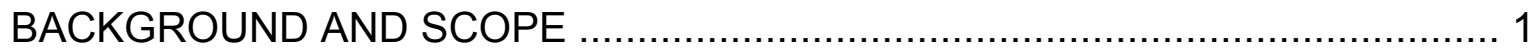

TASK 1.0: Research Management Plan.......................................................... 3

TASK 2.0: Survey and Review of Fossil and Non-fossil Feedstock Gasification Methods 14

TASK 3.0: Evaluation of Existing Commercial Flex-Feedstock Gasification Technologies

TASK 4.0: Design of Compact, Feedstock-Flexible Syngas System ..................... 32

TASK 5.0: Construction of Prototype Reformer Unit ........................................ 50

TASK 6.0: Benchmarking of Reformer Catalyst Performance .............................. 56

TASK 7.0: Post-Reaction Characterization of Catalysts ................................... 127

TASK 8.0: Demonstration of Reforming of a Simulated Flexible-Feedstock Derived Gasifier Product Stream 128

TASK 9.0: SOFC Testing 150 


\section{EXECUTIVE SUMMARY}

This serves as the final report on the Feedstock-Flexible Reformer System (FFRS) project, as administered by U.S. DOE-NETL under contract number DE-FC2606NT42813. The goal of the project was to perform laboratory-scale design and testing of a fuel flexible syngas reforming system that can produce SOFC-quality syngas. More specifically, NextEnergy, in collaboration with the University of Michigan and as guided by DOE-NETL, successfully designed, built, and tested a reformer system, which made high-quality producer gas for use in solid oxide fuel cell (SOFC) and other applications.

The accomplishments of the project are summarized and the scientific knowledge generated are highlighted. Analysis of published gasification data showed that, despite a wide range of processes and feedstock composition, gasifier products had narrow variation in composition. This restriction on composition was used to develop operating schemes for reformers to clean up remaining hydrocarbons in the gasifier product. Further, it appears that a simple physical property, such as the thermal conductivity of the gas, can be used to estimate the reformer feed composition and set the reformer feed parameters.

After a subcontract was signed by the partners, a reformer test system was designed and constructed to allow for evaluation of catalysts under reforming conditions. This consisted of a complete reactant feed system for delivering gas and liquid phase reactants, preheating, and reactor temperature control. A control system executed in LabVIEW and allowing for remote operation of the system was developed.

Carbon gasification, sulfur tolerance of reforming catalysts, and raw biomass gasification were investigated. Enhancement of low temperature carbon gasification using photocatalysts based on $\mathrm{TiO}_{2}$ was studied. As part of that effort, a novel 2D reactor system allowing for facile illumination of the photocatalysts was designed, built, and tested. Clear evidence of photoactive commercial $\mathrm{TiO}_{2}$ was obtained, but in-house synthesis of photoactive $\mathrm{TiO}_{2}$ proved difficult.

The sulfur tolerance of $\mathrm{Ni} / \mathrm{CeZrO}_{2}$ reforming catalysts was evaluated. Initial results showed rapid and significant deactivation of catalysts upon introduction of thiophene, a S-containing hydrocarbon. Following adjustment of experimental protocols, results showing both stable and unstable performance in presence of $S$ were obtained. It is the reaction conditions that determine whether the catalyst will deactivate catastrophically or not. For those feed stoichiometries where high $\mathrm{H}_{2}$ production is thermodynamically favored, stable, albeit lower, $\mathrm{H}_{2}$ and $\mathrm{CO}$ production are obtained. When thermodynamic $\mathrm{H}_{2}$ concentrations are lower, continued deactivation and eventual loss of activity are observed. The key linkage appears to be the hydrodesulfurization activity of the $\mathrm{Ni}$ reforming catalysts. When $\mathrm{H}_{2}$ levels are high, thiophene is converted to $\mathrm{H}_{2} \mathrm{~S}$ and $\mathrm{S}$ is removed from the catalyst surface, leading to stable performance. At low $\mathrm{H}_{2}$ levels, $\mathrm{S}$ accumulates on the surface, deactivating the catalyst and leading to not only a loss in $\mathrm{H}_{2}$ and $\mathrm{CO}$ production, but also a loss of thiophene conversion. Bimetallic catalysts in general were not found to outperform Ni-only catalysts. Very small nickel 
particles were found to have lower activities under S-free conditions, but did show less effect of $S$ on performance.

Biomass gasification is usually performed at high temperature with a goal of yielding small molecule products. Here, low and medium temperature gasification was studied, with the goal of obtaining products that retain some of the structural value of the starting biomass. Fixed bed gasification proved difficult, primarily due to the challenge of removing the condensable products from the reaction zone quickly enough to prevent additional reaction. A new concept was formulated and explored, namely mild pyrolysis and gasification of biomass in ionic liquids. Ionic liquids have some capacity to dissolve cellulose, and show thermal stability to temperatures where pyrolysis begins. As ionic liquids, they have no vapor pressure, simplifying product recoveries, and can dissolve ionic metal salts, allowing for the potential of catalytic reactions on breakdown intermediates. In addition to typical imidazolium-based ionic liquids, less expensive materials including choline chloride and low-melting eutectics of metal nitrates were evaluated.

$\mathrm{Ni} / \mathrm{CeZrO}_{2}$ catalysts were tested for the reforming of simulated gasifier product mixtures. Both $\mathrm{Ni}$ and $\mathrm{Ni}$-Sn catalysts were evaluated, with no S-tolerance being impacted by $\mathrm{Sn}$-doping. Under S-free conditions, $\mathrm{Ni} / \mathrm{CeZrO}{ }_{2}$ performed better than $\mathrm{Ni}-$ $\mathrm{Sn}$, although both showed relatively stable performance. The addition of $250 \mathrm{ppm} \mathrm{\textrm {H } _ { 2 } \mathrm { S }}$ to the reformer feed resulted in immediate drops in performance, but afterwards $\mathrm{H}_{2}$ and $\mathrm{CO}$ production remained stable at the lower levels. Longer duration operation (to 25 hours) showed that there is a gradual loss in $\mathrm{H}_{2}$ production, with $\mathrm{H}_{2} \mathrm{~S}$ present in the feed. Upon removing $\mathrm{H}_{2} \mathrm{~S}$, some $\mathrm{H}_{2}$ production is regained, but there is some unrecoverable loss in performance. 


\section{ACKNOWLEDGMENT}

This material is based upon work supported by the Department of Energy National Energy Technology Laboratory under Award Number DE-FC26-06NT42813.

The authors would like to express gratitude to the Department of Energy National Energy Technology Laboratory (DOE-NETL) for supporting this work, especially to Mr. Arthur L. Baldwin and Dr. Daniel J. Driscoll for their expertise and guidance on this project and to Ms. Mary Beth Pearse for her assistance in the administration of this project. 


\section{BACKGROUND AND SCOPE}

The period of performance (POP) for the project was October 1, 2006 thru July 31,2010 . The initial program was setup for a glycerol study with STM Power, wherein glycerol, a byproduct in a certain biodiesel production process, would be used to run a Stirling engine customized to accept glycerol as a fuel. However, in 2007, STM Power filed for bankruptcy. The program was then refocused to a new effort for the development of a feedstock-flexible reformer system. NextEnergy partnered with the University of Michigan in mid-2007, and refined the new scope of work for the program, including new tasks and cost share amounts.

In September 2007, the project was kicked-off with the University of Michigan I Energy Technology Components (ETC), LLC, to begin the development of the reformer system. One year later, a modified agreement between DOE-NETL and NextEnergy was reached, with the revised scope of work, budget, and management plan. The period of performance was extended through July 31, 2010, and appropriate tasks were approved.

The sections in this report are broken down by task number for this project. All tasks, with the exception of Task 9, which was optional, were successfully demonstrated or completed. It was advised by DOE-NETL not to pursue Task 9 . The Tasks are numbered and titled as follows:

1. Research Management Plan

2. Survey and Review of Fossil and Non-fossil Feedstock Gasification Methods

3. Evaluation of Existing Commercial Flex-Feedstock Gasification Technologies

4. Design of Compact, Feedstock-Flexible Syngas System

5. Construction of Prototype Reformer Unit

6. Benchmarking of Reformer Catalyst Performance

7. Post-Reaction Characterization of Catalysts

8. Demonstration of Reforming of a Simulated Flexible-Feedstock Derived Gasifier Product Stream

9. SOFC Testing

The budget for this program included $\$ 1,843,768$ funded by DOE-NETL. It was originally planned that, the amount co-funded in the form of cost share by the partners (NextEnergy and University of Michigan / ETC) would be $\$ 370,865$. However, the cost share exceeded this amount. The cost share amount as at July 26, 2010 was: $\$ 511,619$. More details are provided in the attached financial reports.

Drs. Andrew Tadd and Johannes Schwank from the University of Michigan were the principal investigators for this research \& development effort. Mr. Jerry Mader from ETC also assisted in the R\&D efforts made by Drs. Tadd and Schwank. Mr. Arthur Baldwin from DOE-NETL served as the Government Task Leader (GTL). Kelly Jezierski served as the project engineer from NextEnergy, acting as successor after Ryan Smith and Mahesh Samineni. NextEnergy also utilized the services of Dr. F. Michael ("Mike") Faubert to assist with the R\&D and project management efforts, 
especially for Tasks 2 and 3 . The contractual flow down structure is shown below as Figure B.1.

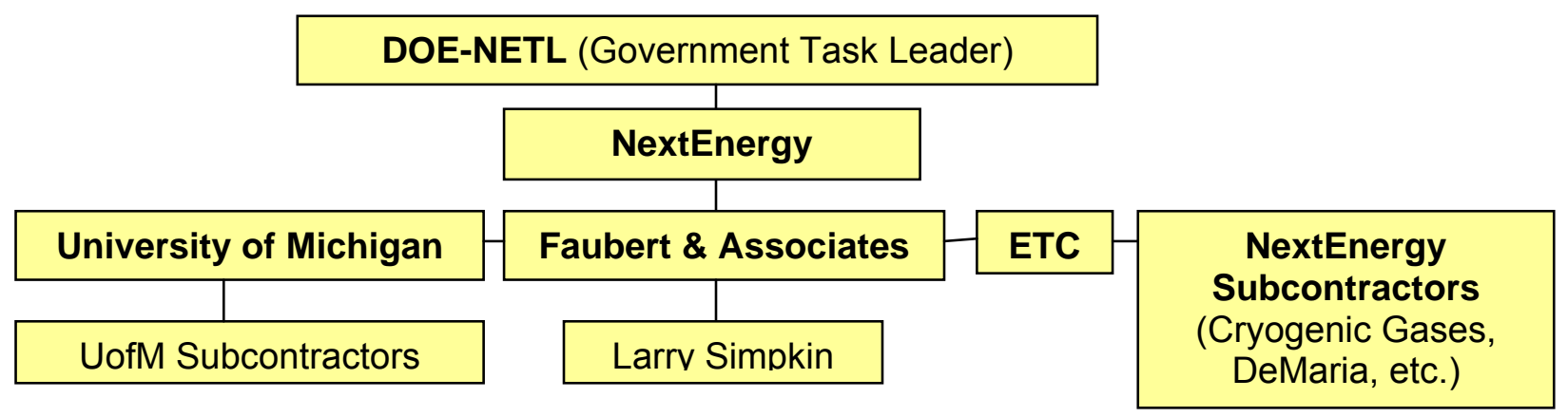

Figure B.1. Contractual Flow Chart for FFRS Project. 


\section{TASK 1.0: RESEARCH MANAGEMENT PLAN}

Task1.0 - Recipient shall develop a work breakdown structure and supporting narrative that concisely addresses the overall project as set forth in the agreement. Recipient will provide a concise summary of the technical objectives and technical approach for each Task and, where appropriate, for each subtask, including detailed schedules and planned expenditures for each Task including any necessary charts and tables, and all major milestones, deliverables and decision points. The plan will include a graphical depiction of anticipated expenditures (DOE and total costs). This report will be submitted within 30 days of the agreement modification. The DOE Contracting Officer's Technical Representative (COR) will, within 20 calendar days from receipt of the Research Management Plan, review it and provide comments to the Recipient. Within 15 calendar days after receipt of DOE's comments, Recipient will submit a final Research Management Plan to the DOE COR for review and approval to DOE.

Task 1 was completed at the start of the project. The statement of project objectives and work breakdown is described below. Planned timeline and budget is also compared to the actual timeline and budget at the close of the program.

\section{STATEMENT OF PROJECT OBJECTIVES}

\section{A. OBJECTIVES}

The project "Feedstock-flexible Reformer System for SOFC-quality Syngas" that is the subject of this Work Statement represents the first phase of an overall long-term program objective (see B, below).

The specific objectives of this first phase are:

* To develop, design, construct and operate a prototype modular reforming reactor configuration capable of converting gasifier product streams of varying composition into SOFC-quality syngas.

* To develop a conceptual design of a small-scale, compact, modular reactor system integrating the reforming reactor with upstream components capable of converting feedstocks from a wide variety of locally-accessible sources (e.g., lignitic and brown coals, peat, wood, purpose-grown energy crops, solid waste, agricultural waste, and animal waste) into a relatively clean product stream containing combustible gases with condensables as minor products.

\section{B. LONG-TERM PROJECT OBJECTIVES}

Long-term Program Objective

The utilization of widely-variable and even mixed fossil and non-fossil feedstocks could be greatly facilitated by developing methods for small-scale, distributed conversion of carbonaceous feedstocks including coal, biomass, solid waste and their blends, into syngas. An important requirement for smaller scale, distributed systems is that they must be capable of converting biomass and non-biomass feedstocks, including 
mixed wastes that vary widely in composition, in a steam/oxygen gasifier. The partially enriched fuel gas produced in these feedstock-flexible gasifiers, after downstream processing determined by the product gas composition, will be suitable for a number of applications. The gasifier output can be directly used as fuel for heating, steam production, and crop drying. The output can also be blended with digester methane from animal waste or landfills for use as a fuel for internal combustion engines (see Figure 1).

The gasifier output can also be passed through a downstream fuel-processing unit, to generate a relatively pure syngas (mixture of hydrogen plus carbon monoxide) suitable for powering solid oxide fuel cells for distributed electricity generation. This syngas can also serve as feedstock for advanced Fischer-Tropsch synthesis, providing for the conversion of a variety of carbonaceous feedstocks into liquid transportation fuels.

The long-term program objective for this partnership between NextEnergy, Energy Technology Consultants (ETC), and the $\mathrm{U}$ of M Transportation Energy Center (TEC) is to analyze and develop a fully-integrated and self-sufficient distributed energy system. The ultimate fully-integrated and self-sufficient (bio)-energy system could have wide ranging applications ranging from farm complexes to military bases to remote communities. A conceptual sketch of such a system is given in Figure 1.1 below. The segment shown in purple is the subject of this work statement. Future segments requiring additional funding are shown in green or blue. The segment shown in orange requires no attention as part of this program.

Specifically, this project (the purple segment in Figure 1.1) will demonstrate the production of SOFC-quality syngas produced on site from locally available mixtures of feedstocks. The total technology demonstration program, containing an integrated gasifier and reformer system, will require a sustained research and development effort over approximately five years, with resource requirements in the range of $\$ 8-10$ million. Ultimately, it is envisioned that the technology that is developed would be transferred to industry, serving as key components of a self-sufficient distributed electricity generation system that could be used on farms, in remote populated areas, military bases and combat zones. 


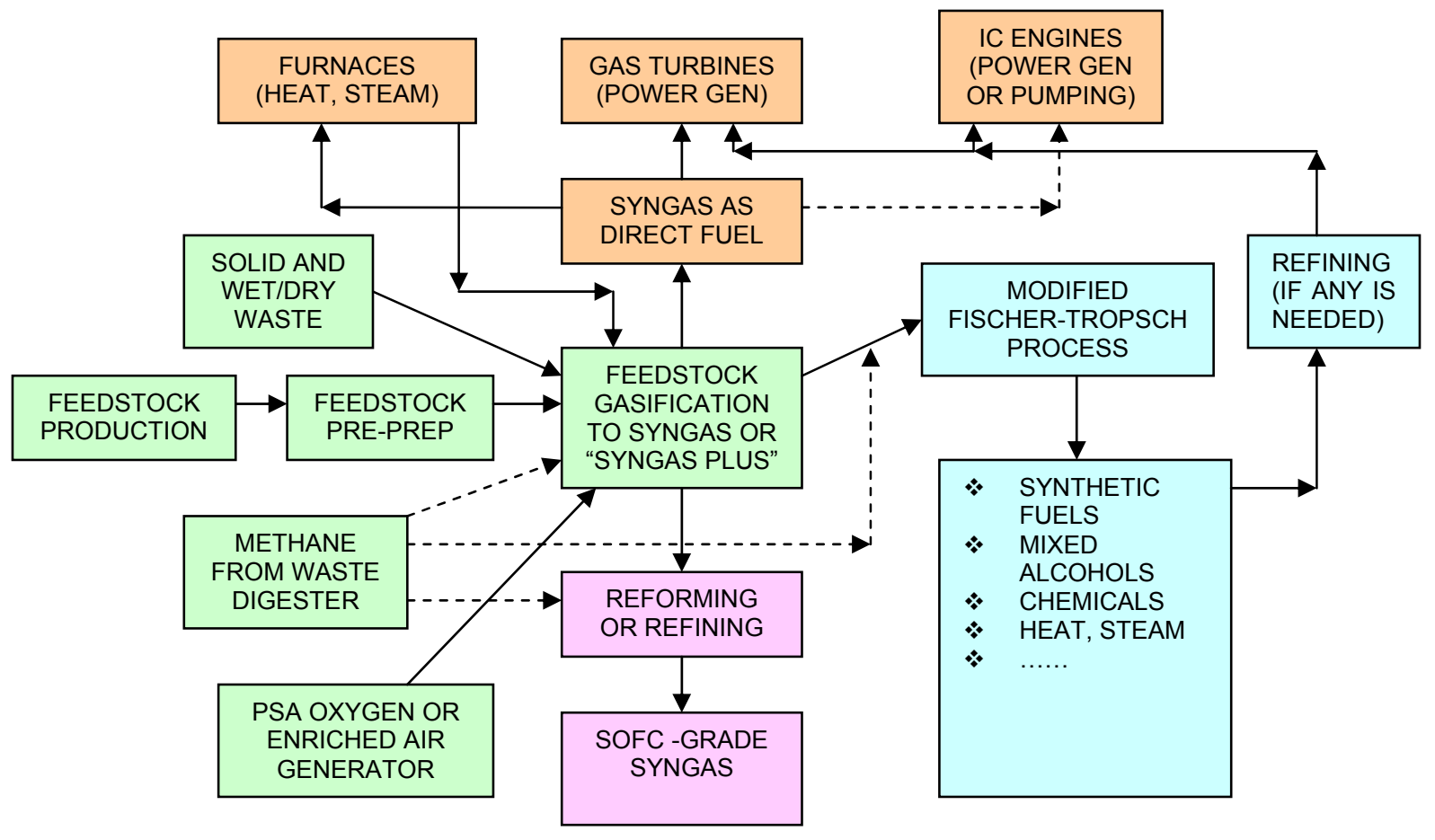

Figure 1.1. Conceptual Sketch of Self-sufficient Bioenergy System

\section{TECHNICAL BACKGROUND}

Syngas is a mixture of carbon monoxide and hydrogen that often contains high levels of nitrogen. It is typically made by gasifying carbonaceous feedstocks in air. A higher-BTU product can be produced by using oxygen and/or steam as the oxidizer in the gasification process. Syngas produced with air has a combustion energy of about $130-150 \mathrm{BTU} / \mathrm{ft}^{3}$. Steam/oxygen gasification methods can produce a variety of gases extending from carbon monoxide (CO) and hydrogen $\left(\mathrm{H}_{2}\right)$ mixtures at 250-300 BTU/ $\mathrm{ft}^{3}$ to a range of synthetic natural gas (SNG) products with combustion energies in the 950$1000 \mathrm{BTU} / \mathrm{ft}^{3}$ range.

Mixtures of $\mathrm{CO}$ and $\mathrm{H}_{2}$ are sometimes used directly as a fuel gas, although at lower BTU levels supplementary fuel is typically required to maintain stable combustion and to minimize combustion emissions. Alternatively, most of the $\mathrm{CO}$ can be removed by reacting the gas with steam using the so-called water gas shift reaction $\left[\left(\mathrm{CO}+\mathrm{H}_{2}\right)+\right.$ $\mathrm{H}_{2} \mathrm{O} \rightarrow \mathrm{CO}_{2}+2 \mathrm{H}_{2}$ ], followed by $\mathrm{CO}_{2}$-stripping using the Sulfinol process or equivalent. The result is relatively pure hydrogen that may be suitable for use in hydrogenation processes or in SOFCs or, after further refining to at least "five 9s" grade, for PEM fuel cells.

A SOFC is a highly efficient direct generator of electricity that is operated at high temperature. It is compatible with a variety of primary fuels, and it has less stringent requirements for fuel quality since $\mathrm{CO}$ can be used directly as a fuel, along with $\mathrm{H} 2$. 
SOFCs have less sensitivity to contaminants, such as sulfur ${ }^{1}$. In SOFCs, oxygen ions are the primary charge carriers and since they diffuse slowly at room temperature, operating temperatures of $800^{\circ} \mathrm{C}$ to $1000^{\circ} \mathrm{C}$ are typically required ${ }^{2}$. An attractive feature of SOFCs is that they produce not only electricity, but also high temperature waste heat, whereas most other fuel cell types produce electricity and low temperature waste heat. The residual fuel and high temperature waste heat can be used in bottoming cycles such as gas turbines, or as a heat source for fuel reforming. Thus, as a total system, SOFCs can achieve higher efficiency than low-temperature fuel cells. ${ }^{3}$ The state-of-theart SOFC reformers can handle natural gas, gasoline and diesel fuels, but impurities in the fuels can cause catastrophic failures due to deactivation of the catalysts in the fuel cell.

Due to their high temperature of operation, SOFCs can operate on syngas (a mixture of carbon monoxide and hydrogen) produced from natural gas, liquid transportation fuels or solid fuels such as coal or biomass. To date, the majority of syngas for SOFCs has been generated by reforming natural gas, which is a relatively mature technology. Fuel reforming of natural gas can take place in three different ways: external reforming in separate reactor systems, indirect internal reforming, where the reformer is thermally coupled to the SOFC, and direct internal reforming, where the anode of the SOFC also serves as reforming catalyst. In all cases, sulfur compounds must be removed prior to fuel reforming. The high sulfur levels typically encountered in syngas derived from fossil sources or biomass $(>100 \mathrm{ppm})$ would result in irreversible performance loss. One of the reasons for this phenomenon is that at these high levels, sulfur penetrates into the electrolyte and poisons it.

There is a great deal of on-going effort in fuel processing to produce hydrogen from various primary fuels via steam reforming, partial oxidation, or autothermal reforming $4,5,6,7,8,9$. At the University of Michigan (UM), a DoE-funded project led to the development of a prototype compact gasoline reformer ${ }^{10}$. A groundbreaking insight gained in this research is that reforming of hydrocarbon mixtures is much more complex

1 James Zizelman, Steven Shaffer and Subhasish Mukerjee, Solid Oxide Fuel Cell Auxiliary Power UnitA Development Update, SAE Technical Paper Series, March 4-7, 2002.

2 Sandrine Colson-Inam, Solid Oxide Fuel Cells-Ready to Market?, Fuel Cell Today, January 7, 2004.

3 X. Ma, L. Sun, C. Song, A new approach to deep desulfurization of gasoline, diesel fuel and jet fuel by selective adsorption for ultra-clean fuels and for fuel cell applications, Catal. Today 77 (2002) 107-116

4 X. Wang, R. J. Gorte, A study of steam reforming of hydrocarbon fuels on Pd/ceria, Appl. Catal. A: Gen. 224 (2002) 209-218.

5 J. Lampert, Selective catalytic oxidation: a new catalytic approach to the desulfurization of natural gas and liquid petroleum gas for fuel reformer applications, J. of Power Sources 131 (2004) 27-34.

6 Q. Ming, T. Healey, L. Allen, P. Irving, Steam reforming of hydrocarbon fuels, Catal. Today 77 (2002) 51-64.

7 L. J. Petterson, R. Westerholm, State of the art of multi-fuel reformers for fuel cell vehicles: problem identification and research needs, Int. J. of Hydrogen Energy 26 (2001), 243-264.

8 C. Song, Fuel processing for low-temperature and high-temperature fuel cells challenges, and opportunities for sustainable development in the $21^{\text {st }}$ century, Catal. Today 77 (2002) 17-49.

9 T. Luo, J. M. Vohs, and R. J. Gorte, An examination of Sulfur Poisoning on Pd/Ceria Catalysts, J. of Catalysis 210 (2002) 397-404.

10 "Fuel Processor for PEM Fuel Cells", DoE Contract DE-FC04-02AL67630 
than dealing with individual components ${ }^{11}$. In mixtures, synergistic effects start to appear, which lead to changes in chemical mechanisms and thus influence the quality of the reformate. The non-linear behavior of hydrocarbon mixtures provides a complexity that investigations of single component model compounds are not able to properly capture.

The complexities involved in generating SOFC-grade syngas have important ramifications for utilization of either coals or biomass as a feedstock. For example, a DOE study examined the composition of gasifier products obtained from three different sources of biomass, poplar, switch grass, and mixed wood (Table 1). ${ }^{12}$ The results show that in addition to the expected mixture of $\mathrm{H} 2, \mathrm{CO}$, and $\mathrm{CO} 2$, a variety of other chemical species is formed, including methane, ethylene, benzene, and toluene. Furthermore, varying amounts of $\mathrm{H} 2 \mathrm{~S}$ and $\mathrm{NH} 3$ are formed. The relative amounts of the products depend on the biomass type. Most notably, the H2S concentration in switch grass is well beyond the sulfur tolerance limits of SOFCs, and switch grass leads to large amounts of cyanide formation.

If coal feedstocks alone are used, the results are similar but present different challenges. Gasification of coal under similar conditions using oxygen-steam mixtures (often called "hydrogasification") produces a somewhat similar gas (see the first column in Table 1.1). Of course, coals vary widely and thus the gas composition also varies widely. Although no data are shown here, coals can also result in high benzene, toluene, ammonia and cyanide levels.

\begin{tabular}{|l|l|l|l|l|}
\hline \multicolumn{5}{|c|}{ Table 1.1. Typical Gas Yields from Biomass and Coal. } \\
\hline $\begin{array}{l}\text { Feedstock } \\
\text { Type }\end{array}$ & $\begin{array}{l}\text { Typical } \\
\text { Midwestern } \\
\text { Coal }\end{array}$ & $\begin{array}{l}\text { Hybrid } \\
\text { poplar }\end{array}$ & $\begin{array}{l}\text { Switch } \\
\text { grass }\end{array}$ & $\begin{array}{l}\text { Mixed } \\
\text { Woods }\end{array}$ \\
\hline $\mathrm{H} 2$, vol \% & 22.8 & 33.99 & 24.31 & 31.82 \\
\hline $\mathrm{CO}$ & 18.0 & 36.67 & 39.47 & 31.59 \\
\hline $\mathrm{CO} 2$ & 18.5 & 17.91 & 14.97 & 17.96 \\
\hline $\mathrm{CH} 4$ & 14.1 & 12.56 & 13.77 & 11.73 \\
\hline $\mathrm{C} 2 \mathrm{H} 4$ & 0.5 & 4.41 & 5.86 & 4.50 \\
\hline Benzene & $\mathrm{NA}$ & 1.35 & 0.96 & 1.06 \\
\hline Toluene & $\mathrm{NA}$ & 0.31 & 0.20 & 0.24 \\
\hline
\end{tabular}

${ }^{11}$ Gould, Benjamin D.; Tadd, Andrew R.; Schwank, Johannes W.. "Nickel-catalyzed autothermal reforming of jet fuel surrogates: n-Dodecane, tetralin, and their mixture",Journal of Power Sources, 164(1), (2007) 344-350.

12 Richard Bain, "Biomass Gasification Overview", January 28,2004, NREL; see also http://www.msenergy.ms/Gasification\%20-\%20Mississippi\%20Presentation\%20v2.pdf 


\begin{tabular}{|l|l|l|l|l|}
\hline $\mathrm{H} 2 / \mathrm{CO}$ & 1.27 & 0.93 & 0.62 & 1.01 \\
\hline $\mathrm{H} 2 \mathrm{~S}, \mathrm{ppmv}$ & 9,000 & $64-72$ & $323-396$ & $36-63$ \\
\hline $\begin{array}{l}\text { Ammonia, } \\
\mathrm{ppmv}\end{array}$ & $\begin{array}{l}\text { Always } \\
\text { present }\end{array}$ & $290 \mathrm{max}$ & $760 \mathrm{max}$ & $339-369$ \\
\hline $\begin{array}{l}\mathrm{Cl}^{-} \text {cond, } \\
\mathrm{ppm}-\mathrm{m} / \mathrm{v}\end{array}$ & $\mathrm{NA}$ & 0 & $486 \mathrm{max}$ & $4 \mathrm{max}$ \\
\hline $\begin{array}{l}\mathrm{K}^{+} \text {cond, ppm- } \\
\mathrm{m} / \mathrm{v}\end{array}$ & $\mathrm{NA}$ & $10 \mathrm{max}$ & 208 max & 7 max \\
\hline $\begin{array}{l}\text { Tot org. C } \\
\text { cond ppm-m/v }\end{array}$ & NA & 2060 max & 2320 max & 2480 max \\
\hline $\begin{array}{l}\text { Cyanide, } \\
\text { ppm-m/v }\end{array}$ & $\begin{array}{l}\text { Always } \\
\text { present }\end{array}$ & 37 & $1442-1472$ & $\mathrm{ND}$ \\
\hline
\end{tabular}

None of these four gasifier product streams would be suitable as direct feed for an SOFC, because of the presence of sulfur and nitrogen containing contaminants, as well as benzene and toluene. And, it is reasonable to expect that other types of feedstocks would lead to similar, unsuitable gasifier product streams. Converting each of these three gasifier product streams into SOFC-grade syngas would require the development of feedstock-specific reforming methods. This is certainly an option for large-scale facilities, where the process can be optimized for one specific feedstock. But for distributed generation of electricity on a smaller scale, it would be much more advantageous to make use of mixtures of locally available flexible feedstocks, such as peat, agricultural waste, corn stover, wood products, etc. In such a case, the gasifier product stream would vary considerably depending on whatever feedstock type is available at a given location or time. Consequently, the downstream processing unit that makes SOFC-grade syngas must be able to accommodate fluctuations in the composition of the gasifier output. This represents a major challenge for the design of a fuel processing system downstream of such a gasifier.

\section{SCOPE OF WORK AND TASK SUMMARY}

NextEnergy, as Recipient and Program Manager, will develop and submit a research management plan with the assistance of Energy Technology Consultants and the University of Michigan Transportation Energy Center (Johannes Schwank and Jerry Mader). Together, these entities are hereafter referred to as "The Partners".

- Because there is extensive, if often old, prior art in this field, the partners will undertake an in-depth review of prior art in this field going back to the earliest examples of variable-feedstock gasification and syngas reforming.

- Based in part on extensive personal experience, the partners will evaluate all existing designs of gasifier used for both fossil and non-fossil feedstocks. They will then develop and model a gasifier design that reflects the best prior 
work and incorporates innovations already conceptualized by the partners. This will involve gasification of biomass or other feedstocks to produce a high hydrogen content fuel gas of about 300-350 BTU/ $/ \mathrm{ft}^{3}$ net (lower) heating value. Past experience with both fossil and renewable feedstock gasification indicates that this gas will contain $10-15$ vol\% of hydrocarbon, mostly methane.

- The partners will design, build and operate a reformer that will convert this hydrogen-rich syngas containing methane and other contaminants into a relatively pure syngas containing only hydrogen and carbon monoxide. Other than reforming, it is expected that additional refining may be needed to remove sulfur compounds.

- The partners already have available to them a solid oxide fuel cell prototype that was built at $U$ of $M$ and used in a prior program. The design will be revised based on this prior experience and, if possible, a new version will be built (or acquired) and used to evaluate the reformed syngas produced in this program. The focus will be on optimizing thermodynamic efficiency (including both electrical and thermal energy contributions) and the sensitivity of the SOFC electrolyte and catalyst(s) to poisoning or other adverse effects as a consequence of any remaining contaminants in the gas stream.

- Individual tasks are discussed in greater detail in Section E, below.

\section{E. TASKS TO BE PERFORMED}

Task 1: Survey and review of fossil and non-fossil feedstock gasification methods

Since the design of the reformer unit will critically depend on the steady-state and transient performance of upstream gasifier units, a comprehensive survey of the existing scientific literature on carbonaceous feedstock gasification will be conducted. The mechanistic aspects of feedstock gasification will be investigated, with emphasis on the effect of feedstock type, blend (where applicable) and reaction conditions on product composition. Special attention will be paid to the details of heteroatom chemistry and the mechanistic aspects of tar formation.

\section{Task 2: Evaluation of existing commercial flex-feedstock gasification technologies}

Current gasifier units are based on several different reactor configurations, including but not limited to updraft gasifiers, downdraft gasifiers, fluid-bed gasifiers, circulating fluid-bed gasifiers, and entrained flow gasifiers. Each of these reactor types has its own technical challenges regarding feed pretreatment, feeder reliability, and heat integration. A critical question is which of these reactor technologies lends itself best for scaling down to the small, compact size required for this project. The goal of this task is to determine the most promising reactor configuration for a small-scale, flexible-feed gasifier unit, with special emphasis on operability and optimization of the BTU content of the product gas over a wide range of feedstocks. 
Task 3: Design of compact, feedstock-flexible syngas-system.

A conceptual design of a small-scale, compact, modular reactor system will be carried out. The overall design will integrate reforming reactor modules with upstream components capable of converting feedstocks from a wide variety of locally-accessible sources (e.g., lignitic and brown coals, peat, wood, purpose-grown energy crops, solid waste, agricultural waste, and animal waste) into a relatively clean product stream containing combustible gases with condensables as minor products.

The performance of the compact reformer modules will be simulated using software such as ASPEN Plus ${ }^{\mathrm{TM}}$, with the imposed design constraints that the reformer must be able to convert typical gasifier output streams derived from variable and mixed fossil and non-fossil feedstocks into SOFC-grade syngas. The reformer design will build on already existing expertise in design of modular reformer systems for gasoline and kerosene-type fuels. The reformer will be sized accordingly to accommodate the anticipated flow rates of product gas coming from gasifier units

To optimize the reformer design, it is necessary to consider the performance of upstream gasifier units, and if needed, incorporate some recycle streams linking the reformer with the gasifier. This strategy may prove beneficial fro achieving uniform gasifier output streams, independent of gasifier feedstocks. Alternative strategies for maintaining the correct $\mathrm{CO}: \mathrm{H}_{2}$ balance in the gasifier output stream may include the use of auxiliary fuel. This fuel could be a bio-based product such as digester methane, thus ensuring that as far as possible any $\mathrm{CO}_{2}$ produced will be from non-fossil sources. The design will incorporate widely-used zeolite or CMS pressure-swing absorption (PSA) processes to provide oxygen with only a minor energy input.

The initial focus will be on utilizing wastes based on wood, paper, or corrugated board. However, the design will be expanded to consider agricultural waste of all kinds (including wet waste streams) and to purpose-grown biomass crops in addition to lignitic and western coals and even peat.

A unique aspect of the design of the reformer will be to adapt a feed manipulation technique recently developed in the context of a U.S. Army synfuel project undertaken at the University of Michigan. This new method is essential in achieving the required flexibility for dealing with gasifier output streams of varying composition. The design of the reformer unit will not only contain catalytic reactor modules, but also mass flow controllers for mixing together synthetic feed streams simulating gasifier outputs expected for different types of feedstock, and pressure-swing adsorption (PSA) hardware for enriched air production.

Included in this task will be the identification of suitable catalyst materials, followed by synthesis and characterization of catalysts. This effort will build on existing catalyst development work undertaken over the past several years in the context of the Army and DOE funded fuel processing projects.

Task 4: Construction of prototype reformer unit

Based on the design effort in Task 3 , the required components for construction of a compact prototype reformer unit will be procured. The prototype reformer system will be assembled along with a set of vaporizers and mass flow controllers permitting the feeding of a wide range of gas and condensable mixtures that closely resemble typical 
gasifier outputs. The system will also be equipped with a pressure-swing adsorption (PSA) unit for enriched air production, and with suitable heteroatom removal systems, to guard against sulfur poisoning of the catalyst bed. The prototype reformer system, once completely assembled, will be tested for safety and operability, and system operators will be trained.

Task 5: Benchmarking of reformer catalyst performance

The performance of the catalyst and reactor system will be benchmarked by using pure model compounds found in typical mixed feedstock gasifier products under autothermal reforming, steam reforming, and partial oxidation conditions. The reforming characteristics of compounds such as benzene or toluene will be systematically studied, followed by reforming of mixtures of increasing complexity. These mixtures will be obtained from bottled gases, including $\mathrm{CO}, \mathrm{CO}_{2}, \mathrm{H}_{2}, \mathrm{H}_{2} \mathrm{~S}$, cyanide, and hydrocarbon gases (the latter being one or more of methane, ethane, propane and butane); and benzene and toluene vapors generated in saturators. An important aspect of this task will be to develop a good understanding of the sulfur-tolerance of the reformer system, and, if needed, optimize the catalyst formulations to impart better resistance to sulfur. The reactor will be operated under conventional reaction conditions to determine product baseline selectivity and yield of $\mathrm{CO}$ and $\mathrm{H}_{2}$.

Task 6: Post-reaction characterization of catalysts

Should significant catalyst deactivation occur, the causes for the deactivation will be diagnosed by examining the catalyst using a wide range of state-of-the-art catalyst characterization methods available at the $U$ of $M$, including thermogravimetric analysis, surface area analysis, pore size analysis, electron microscopy, X-ray photoelectron spectroscopy, and so on.

Task 7: Demonstration of reforming of a simulated flexible-feedstock-derived gasifier product stream.

Based on insights gained from Tasks 6 and 7, the reforming of simulated gasifier product streams will be demonstrated by reforming gas and condensable mixtures with compositions as shown in Table 1. The purpose of this task is to evaluate feedstock sensitivities, operability, and other parameters. The stability and reliability of the system will be tested by keeping the catalyst on stream over extended periods of time, and the composition of the syngas product will be continuously monitored to assure SOFCgrade quality.

\section{Task 8: Design and Evaluation of a Suitable SOFC}

If the available funding permits, which it did not, the $U$ of M's substantial experience and expertise in the area of SOFC design, development and operation will be used to design, model, develop and build a solid oxide fuel cell for use in this program (see Fig. 1). The objective will be to evaluate efficiencies of operation and to identify any problems associated with contaminants in the syngas generated by the proposed reformer. Alternatively, a SOFC might be acquired from a local outside vendor.

Task 9: Documentation and Reporting

The results of Tasks 1-9 will be documented and reported as delineated below under deliverables. 


\section{F. CRITICAL PATH PROJECT MILESTONES (Milestone Plan/Status) NextEnergy has developed a Milestone Plan for the project that is shown below.}

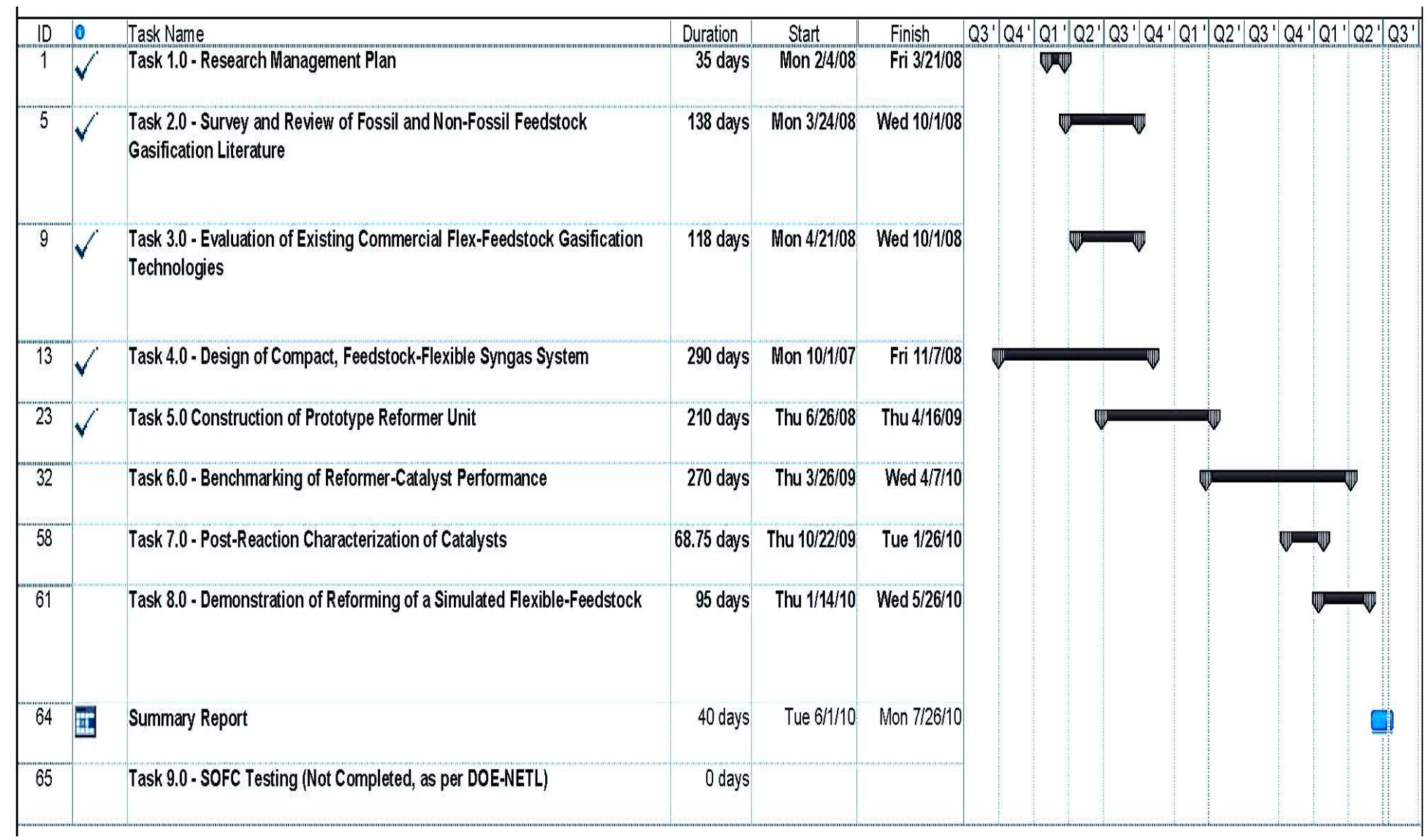




\section{G. DELIVERABLES}

1. Report containing a survey and review of flexible-feedstock gasification methods, and evaluation of existing commercial gasification technologies (Month 3 of contract).

2. ASPEN simulation of integrated reformer system (Month 6 of contract)

3. Design specifications of integrated reformer system, with capital cost and operation cost estimation. (Month 10 of contract)

4. Detailed technical drawings and operation manual of the reformer unit. (Month 15 of contract)

5. Report on benchmarking results and post-reaction characterization of reformer catalyst (Month 19 of contract)

6. Final report with documentation of the demonstration results of the reformer (Month 24 of contract).

H. Budget (See Table below):

Proposed vs. Actual Budget for NETL Program

Total NETL Award: $\quad \$ \$ 1,843,780$

\begin{tabular}{|c|c|c|c|c|}
\hline Participants & Function & $\begin{array}{l}\text { Actual DOE } \\
\text { Funding (\$) }\end{array}$ & $\begin{array}{c}\text { Planned Cost } \\
\text { Share (\$) }\end{array}$ & $\begin{array}{c}\text { Actual Cost } \\
\text { Share (\$) }\end{array}$ \\
\hline $\begin{array}{r}\text { University of } \\
\text { Michigan (U } \\
\text { of } M)\end{array}$ & \begin{tabular}{lrr} 
Develop a flexible & \multicolumn{2}{c}{ a foedstock reformer r to } \\
feeds & produce a syngas for \\
fuelling a solid oxide fuel \\
cell
\end{tabular} & $1,118,403$ & 287,865 & 338,895 \\
\hline $\begin{array}{r}\text { Energy } \\
\text { Technology } \\
\text { Consultants } \\
\text { (ETC) }\end{array}$ & $\begin{array}{l}\text { Provide energy technical } \\
\text { expertise to } U \text { of } M \text { for the } \\
\text { project. }\end{array}$ & 151,800 & 21,000 & $32,249.47$ \\
\hline $\begin{array}{r}\text { NextEnergy } \\
\text { Center (NEC) }\end{array}$ & $\begin{array}{l}\text { Project manager, lab } \\
\text { manager, demonstration } \\
\text { testing location provider, } \\
\text { fuels and fuel cell expertise }\end{array}$ & 573,565 & 62,000 & 90,000 \\
\hline Totals & & $1,843,768$ & *370,865 & $511,619.47$ \\
\hline $\begin{array}{l}\% \text { of funded } \\
\text { portion }\end{array}$ & & - & $20 \%$ & $28 \%$ \\
\hline
\end{tabular}

*NOTE: This amount was later revised to $\$ 460,942.00$ in September 2008 and agreed to by DOE-NETL and NEC. 


\title{
TASK 2.0: SURVEY AND REVIEW OF FOSSIL AND NON-FOSSIL FEEDSTOCK GASIFICATION METHODS
}

Task 2.0 -Recipient shall conduct a comprehensive survey of the existing scientific literature on carbonaceous feedstock gasification. Design of the reformer unit will critically depend on the steady-state and transient performance of upstream gasifier units. The mechanistic aspects for feedstock gasification will be investigated with emphasis on the effect of feedstock type, blend (where applicable) and reaction conditions on product composition. Special attention will be paid to the details of heteroatom chemistry and the mechanistic aspects of tar formation.

Tasks 2.0 and 3.0 have been combined in this report and the associated literature survey is appended below and starting on page 18.

\section{Task 3.0 - Evaluation of Existing Commercial Flex-Feedstock Gasification Technologies}

\begin{abstract}
Task 3.0 - Recipient shall conduct a comprehensive evaluation of existing commercial flexible feedstock gasification technologies to identify the appropriate reactor technology for scaling down to the small, compact size required for this project. Current gasifier units are based on several different reactor configurations, including, but not limited to, updraft gasifiers, downdraft gasifiers, fluid-bed gasifiers, circulating fluid-bed gasifiers, and entrained flow gasifiers. Each of these reactor types has its own technical challenges regarding feed pretreatment, feeder reliability, and heat integration. The goal of this task is to determine the promising reactor configuration for a small-scale, flexible-feed gasifier unit, with special emphasis on operability and optimization of the BTU content of the product gas over a wide range of feedstocks.
\end{abstract}

Tasks 2.0 and 3.0 have been combined in this report and the associated literature survey is appended below.

\section{Literature Survey to Address Tasks 2.0 and 3.0}

Principal Investigators

F. Michael Faubert, Ph. D. P.E. Larry J. Simpkin, P.E.

13 October 2008 
Table of Contents for Tasks 2.0 and 3.0 (Literature Study) Report

\begin{tabular}{|c|c|c|}
\hline & SECTION & PAGE NO. \\
\hline 1.0 & STATEMENT OF WORK & 20 \\
\hline 2.0 & METHODOLOGY FOR INVESTIGATION & 20 \\
\hline 3.0 & INTRODUCTION & 21 \\
\hline 4.0 & THE BASIC GASIFICATION PROCESS & 21 \\
\hline 5.0 & GASIFIER TYPES & 23 \\
\hline 6.0 & TARS AND HETEROATOMS & 29 \\
\hline 7.0 & CONCLUSION & 32 \\
\hline 8.0 & GASIFIER SUPPLIERS & 34 \\
\hline 9.0 & REFERENCES & 34 \\
\hline
\end{tabular}


This report serves as the deliverable for Tasks 2.0 and 3.0 of "Feedstock-flexible Reformer System for Solid-Oxide Fuel Cell (SOFC)-Quality Syngas", Contract Number DE-FC26-06NT42813.

\subsection{METHODOLOGY FOR INVESTIGATION}

The investigators utilized the Internet as the principal tool for conducting the literature search. An effort was made to include both research programs and operating facilities in the study. Manufacturers, consultants, professional organizations, Department Of Energy, National Renewable Energy Laboratory, National Energy Technology Laboratory, European Coalitions on Research, Chinese Laboratories, Universities, and International Council on Large Electric Systems (CIGRE) papers were queried.

Manufacturing sites were sparse with real technical information or operating data, but they were abundant with accomplishments (perhaps inflated), which provided a guide to what systems are working and what systems are likely to be real players in the next few years. Approximately fifty such sites were reviewed.

Technical papers from the American Institute of Chemical Engineers (AICHE), American Society of Mechanical Engineers (ASME), CIGRE, and Science Direct were limited to gleaning value from over 35 abstracts. A number (8-10) of available publications by consultants and U.S. Universities were studied, and digested findings are included. A small number (8) of patent claims and applications were available and also reviewed. With the help of the Google Search Engine, searches were conducted on categories including coal gasification, fixed bed gasification, biomass gasification, fluidized bed gasification, bubble bed fluidized bed gasification, circulating fluidized bed gasification, entrained flow gasification, solid oxide fuel cells, tar removal systems, sulfur removal methods in gas, gasifiers in the U.S. and gasifier manufactures worldwide. This account is reasonably complete, and each query resulted in tens of thousands of returns. The first fifty or so were scanned with the more pertinent ones read completely. More than 200 of these were studied. 
In some cases the principal investigators were shown with email addresses and sometimes phone numbers. Where prudent, contacts were made by email and by phone. Very few of these inquiries were returned when no commercial potential was apparent.

\section{0}

\section{INTRODUCTION}

Coal gasification accounts for 85 percent of solids gasification and is well established in South Africa. Biomass gasification has existed in developing countries for decades and is expanding rapidly worldwide. Biomass is the fourth largest primary energy source behind fossil fuels worldwide, and accounts for about 11 percent of the world's primary use. [1]

Biomass gasification development is largely centered in Europe, China, and India where biomass gas has been used for decades. Many programs in the United States have been set aside or downscaled due to lack of funding. As was found during the search of technical literature, detailed reporting on operating units or development projects is sparse to non-existent in the USA.

\subsection{THE GASIFICATION PROCESS}

There are multiple designs of gasifiers presently in existence. Regardless of the specific type, they all include these basic steps.

- Preparation of the biomass can include shredding, compressing, and pelletizing to achieve a uniform feedstock size. Uniformity of size is of critical importance to ensure a steady, uninterrupted flow of biomass into the gasifer.

- Introduction of the feedstock into the gasifier, which includes the following processes: feedstock drying; flaming pyrolysis; char oxidation or gasification; and char reduction.

- Syngas cleanup, which may include filtering, heating or cooling, particulate removal, desulfurization, tar removal, reforming, and possibly compression. 
Feedstock drying is of critical importance to ensure that it does not jam the system feeding the gasifier. It can be effected using energy created in the gasification process, or from an external heat source.

The pyrolysis (or devolatilization) process takes place between $200^{\circ} \mathrm{C}$ and $500^{\circ} \mathrm{C}$, and liberates complex hydrocarbons and some gaseous inorganic compounds. The char that remains after pyrolysis undergoes the following reactions: [2]

Combustion

Partial Oxidation

Methanation

Water-gas Shift

CO Methanation
$\{$ biomass volatiles/char $\}+\mathrm{O}_{2} \rightarrow \mathrm{CO}_{2}$

\{biomass volatiles/char $\}+\mathrm{O}_{2} \rightarrow \mathrm{CO}$ \{biomass volatiles/char\} $+\mathrm{H}_{2} \rightarrow \mathrm{CH}_{4}$

$$
\mathrm{CO}+\mathrm{H}_{2} \mathrm{O} \rightarrow \mathrm{CO}_{2}+\mathrm{H}_{2}
$$$$
\mathrm{CO}+3 \mathrm{H}_{2} \rightarrow \mathrm{CH}_{4}+\mathrm{H}_{2} \mathrm{O}
$$

There are also a myriad of potential reactions that may occur due to thermal cracking of the pyrolysis compounds. Heteroatoms are included in this group of products and some likely compounds are sulfur dioxide, hydrogen sulfide, carbonyl sulfide, hydrogen cyanide, ammonia and alkali metal radicals locked into complex hydrocarbon rings. Removal of these can be accomplished with various methodologies presently available. Any of the gasifier types can accomplish coal or biomass gasification, hence choosing a given technology is dependant on the feedstock properties and the gasifier's end product use.

To supply a $1 \mathrm{~kW}$ solid-oxide fuel cell (SOFC), the gasifier will need to handle approximately 1.5-2.5 pounds of biomass per hour and generate 60-100 cubic feet of gas per hour, depending on gas quality. It should be recognized that gasifiers have poor transient performance, and many of the cleanup systems share that characteristic [3] Turn-down ratios are in the order of 2-2.5, which relegate fuel cells to having limited load swings unless multiple units are used. In industrial operations, constant pressure gasholders are used to provide a buffer on the gas supply for variable volumetric demands. 


\subsection{GASIFIER TYPES}

There are several types of solid fuel gasifiers being used or under development at present. Each has their own peculiarities in design, ease of operation, fuel flexibility and product gas quality. [2] During this investigation the principal focus was on supplying a solid-oxide fuel cell (SOFC) with a gasifier capable of processing a spectrum of fuels derived from wood waste, agricultural waste, and sewage sludge with varying moisture content. Coal will work as a feedstock but is not a likely candidate for producing gas for a fuel cell which would not compete economically with integrated combined cycle plants.

Biomass will generally be limited to fueling small plants $100 \mathrm{MW}$ or less. Unlike coal, it is subject to a larger variability in chemical composition, moisture content, ash content and heteroatom variability. This will present a greater challenge than coal for the gasifier fuel cell system. Refuse derived fuel (RDF) will provide an exception to the 100MW limit due to central collection sites for RDF in large municipalities. While less popular in the United States than in Europe, RDF is being used to produce thermal energy for heating, air conditioning, and steam power plants. Smaller communities may find gasification a viable alternative and perhaps use fuel cells for producing electrical output.

Four general types of solid fuel gasifiers have been produced with a number of variants within the four types. The four types are batch, fixed bed, fluidized bed and entrained flow. Batch units have been used for coke ovens or charcoal retorts, and are not competitors for a gasifier fuel cell combination, hence no further discussion is pursued.

Fixed bed gasifiers have a number of variants, including updraft, downdraft, rotating grate, throated design, etc. However the important differences are updraft versus downdraft fixed bed units. The updraft fixed bed gasifier has been in use for well over a century. In the United States these units used coal to produce a low to medium BTU gas, which was supplied to distribution systems for cooking, refrigeration, illumination and some heating. The plants were run at essentially base load, with load variations being handled by large gas holders, which were a common structure on 
municipal landscapes up through the 1950's. Natural gas distribution displaced the plants and gasholders were demolished. [4]

In South Africa the original Sasol Plant was commissioned in 1955, gasifying a low rank coal, and up until 1975 produced $40 \%$ of the motor fuel for all of South Africa along with 1500 other chemical products ranging from aspirin to dynamite. [5] The Secunda Plant, commissioned in 1980, is the largest synthetic fuel plant in the world. It produces $150,000 \mathrm{bbl} /$ day and accounts for $35 \%$ of all of South Africa's liquid fuel needs today. It is currently being expanded by $20 \%$. Both coal gas and natural gas are used as feedstock for the liquid production. The gasifiers are LURGI fixed bed updraft units operating with low rank coal, however their use has been minimized in the past two years, due to displacement by natural gas from Kenya. [6]

Based on a host of experimental work conducted at Sasol, the updraft fixed bed gasifier can handle highly variable feedstock composition, wide size range in the feedstock, and wide variations in moisture content while maintaining an easily controlled process. It has high tar production with low particulate carry over.

An enormous amount of theoretical and practical expertise exists at the South African facilities, which have now become a product for sale in conjunction with LURGI GESELLSCHAFT. As a result not much is available in the literature to benefit this search.

The LURGI gasifier operates with a fixed grate at the bottom with lock-hoppers at both the bottom and top of the unit. Fuel is fed from the top of the unit in a batch mode and falls through exiting gas on its way to the flaming bed above the grate. As material is reduced to ash, the ash is removed through the lower lock-hopper. Gas exiting the top of the unit is rich in tars but very low in particulate. Heteroatom compounds existing in the gas are a function of the feedstock and will not differ significantly from gasifier to gasifier using the same feedstock.

The fixed bed updraft gasifier has a bed of fuel undergoing pyrolysis and glowing char below that fuel. The updraft of oxidant, usually air and/or steam, passes through the entire bed exiting with pyrolysis products, hydrogen, carbon monoxide and carbon dioxide along with contaminants. Exit temperature is in the $300^{\circ} \mathrm{C}$ range; hence tars remain in quantities up to $20 \%$. Tars represent a significant energy fraction of the 
gasifier output, which encourages a subsequent cracking process or separation and reinjection to the gasifier.

Both RECTISOL and SELEXOL processes have been used for tar separation in the past. [7] For a SOFC, the gasifier tar output can be disposed of by thermal cracking at temperatures in the $1000^{\circ} \mathrm{C}$ range. This is not a deterrent since the SOFC operates in the $1000^{\circ} \mathrm{C}$ range. There are reports from the Netherlands that indicate a substantial amount of tar can be fed to a SOFC at temperatures of $800^{\circ} \mathrm{C}$. However, inquiries regarding the validity of that claim received no response. [8]

Advantages of updraft fixed bed gasifiers include:

- $\quad$ Simple \& low cost

- $\quad$ Proven technology

- Handles high moisture \& high ash feedstock

- $\quad$ Can handle a wide spectrum of fuels

- $\quad$ Accepts large variance of fuel sizing

Disadvantages include:

- High tar content in gas

Downdraft gasifiers are an important variant of the venerable updraft fixed bed gasifier. Feedstock enters the gasifier from above the fuel bed, which is supported by a grate. Oxidant is supplied from above the bed, flows downward through the bed, and exits at a high temperature $\left(900^{\circ} \mathrm{C}-1000^{\circ} \mathrm{C}\right)$. A lock-hopper below the grate facilitates ash removal. However, some of the smaller ash particles are entrained in the off-gas and require removal for most applications. Low tar content is assured in the output by virtue of the high outlet temperature, which promotes cracking as long as the gasifier is working properly. Very low tar levels have been attained at various sites using a variety of feedstocks, which is a significant plus when supplying a SOFC. However, both gas energy content and tar content are sensitive to moisture percent in the feedstock. 
An important parameter affecting gasifier performance is the superficial velocity at which it operates. This parameter is defined as the gas production rate $\left(\mathrm{m}^{3} / \mathrm{sec}\right)$ divided by the cross sectional hearth area $\left(\mathrm{m}^{2}\right)$. The quotient has the dimensions of velocity $(\mathrm{m} / \mathrm{s})$. In fixed bed gasifiers, this parameter can be varied in a range of one to three, which impacts a downdraft gasifier's tar performance, char production, gas energy content, gas production rate, and fuel consumption. Generally, lowering the superficial velocity will increase tar production and increase char production. Increasing superficial velocity will cause tar and char production decrease and gas outlet temperature increase, while gas energy content decreases. The loss in gas energy content results from char combustion rather than gasification. [9] Note that both high temperature and low tar are desirable when supplying a SOFC.

Fuel bridging or arching, which forms a void in the fuel bed, is a problem with certain feedstocks. This is exacerbated by feedstock size and moisture content. One approach to mitigating this difficulty employs a rotating grate, which mechanically breaks the bridge but introduces a moving part into a high temperature, abrasive environment, which results in high maintenance. A second problem is channeling or blowout at high superficial velocities that can be minimized by the rotating grate. Utilizing both size control and moisture control on the feedstock has been effective in minimizing bridging. Both of the preceding problems will cause degradation in gas quality and increased particulate carryover if not corrected.

Removal of particulate carryover can be accomplished with cyclone separators or high temperature fabric filters. They are used together in series when very high removal efficiency is required.

While nothing was found in the literature regarding in-bed sulfur removal, it would appear that the downdraft bed might be a candidate for in-bed dry sulfur capture using limestone mixed with the fuel. Subsequent capture would be made in the gas particulate cleanup system already in place or in the bottom ash.

Advantages of downdraft gasifiers include:

- Proven process

- Low cost 
- Mineral content stays as ash

- Very low tar in gas

Disadvantages include:

- Does not handle high moisture feedstock

- Poor carbon conversion (4-7 \% of carbon is not converted [2])

- High temperature output (but an advantage for the SOFC application)

NOTEWORTHY

In August, 2002, Community Power Corporation (CPC) of Littleton, CO, in conjunction with ITN Energy Systems, also of Littleton, put on a demonstration of their technologies resulting in a $10 \mathrm{~W}$ SOFC (supplied by ITN) operating on syngas produced by a fixed bed downflow gasifier (supplied by CPC). The system operated for a total of 6 hours using three separate biomass feeds: pecan shells ( 2 hours); coconut shells ( 2 hours); and pinewood chips ( 2 hours). The power was used to drive a model electric train. NBC did a video of the demonstration, which the authors are seeking to obtain. [10]

Fluidized combustion and gasification has enjoyed the attention of researchers and some constructors for the past 35 years. The technology offers high energy per unit reactor volume, low ash carryover in off-gas, and the ability to capture sulfur in the ash without the use of a wet system. [11] The power production in a fluidized bed unit is as high as 4 million BTU per hour per square foot of bed area. This contrasts with about one million BTU per hour per square foot for a fixed bed gasifier.

Fluidized-bed gasifiers come in two major variants, named "bubbling fluidizedbed" and "circulating fluidized-bed". In a bubbling fluidized-bed, the gaseous oxidizer is of sufficient velocity to create a drag force on the bed particles to suspend them in the gaseous media. It follows from simple physics that the particles in the bed must be 
uniform in density and size, since drag force at any velocity is proportional to cross sectional area, while particle weight is proportional to volume. Hence for a given material density, small particles are suspended at a lower velocity than larger ones. A properly operating fluidized-bed will appear to be bubbling when one observes the surface, hence the name bubbling fluidized-bed. As the velocity is increased above the ideal fluidizing rate, entrainment and channeling occur. [12] Both phenomena are detrimental to gas quality.

To mitigate channeling and entrainment, distributor plates or nozzles are used to maintain a uniform velocity profile over the grate area. Feedstock is sized carefully and moisture content is controlled to maintain the fuel pellets' cross-sectional area and weight. When feedstock is low density, a higher density inert material (sand or pebbles) with smaller particle size is added to the bed to mitigate channeling. This also provides scrubbing action on the feedstock surface, exposing fresh material, accelerating the pyrolysis rate.

High temperatures are attained in the compact bed, which results in lower values of tar than the updraft fixed-bed gasifier. Fluidized-beds also have a much higher energy per unit volume than that of fixed beds, which reduces the size of these fluidized-bed units. They tend to function best as medium-size units since small units show significant wall effects, while large units are prone to channeling. Compartmentalization has been used to reduce this difficulty in large fluidized bed boilers.

Advantages of bubbling bed gasifiers include:

- Can handle fuel over a wide size range if size variability is controlled

- Yields uniform product gas

- Low tar in gas

- High carbon conversion

Disadvantages include:

- Bed channeling \& large bubble formation which cause bypassing 
The circulating fluidized-bed gasifier operates at a much higher superficial velocity than the bubbling bed gasifier. [13] It works well with small size feedstock in the range of $0.5 \mathrm{~mm}$ because this size-velocity combination results in char entrainment that can be recirculated. The recirculation rate may be 25 times the feed rate for the gasifier. Residence time is increased due to the recirculation, leading to improved gas production and higher overall efficiency. This, coupled with small sized feedstock, promotes complete carbon energy conversion and facilitates low tar content in the product gas. A major drawback with the circulating bed is high temperature erosion in the circulation path.

Advantages of circulating bed gasifiers include:

- High carbon conversion

- Low tar in product gas

- Fast reaction in bed

Disadvantages include:

- Fuel size dictate minimum transport velocity

- Lower heat exchange rate in bed when compared to bubbling bed

- Higher particulate entrainment in product gas

\subsection{TARS AND HETEROATOMS}

The bulk of a commercial gasification has been devoted to coal as a feedstock, with petro-coke being the next largest feedstock. Biomass is a relatively new entry in the feedstock menu and has gained the central focus in development projects. Biomass has an energy density less than half of coal and is widely distributed, which provides impetus for smaller energy-conversion facilities than the central stations of today.

The gasification process consists of a pyrolysis stage followed by a gasification stage, and then some form of gas clean up. Pyrolysis temperatures usually are in the $200^{\circ} \mathrm{C}$ $500^{\circ} \mathrm{C}$ range and occur in an oxygen-deficient atmosphere. Heating can be internal or external. If internal, some of the feedstock is consumed by oxidation. Pyrolytic 
products include volatiles and thermally-cracked, higher ranked hydrocarbons, leaving a residual char (carbon and inorganic compounds). For the most part the pyrolytic products do not enter the gasification reactions per se; however the transition of these compounds to other species is affected by gasification zone residence time and temperature. The organic compounds liberated during pyrolysis are tars or precursors to tar and can be classified as shown in Table 1 below. [14]

A simplistic description of the tar production follows:

Class I tars are dominant below $750^{\circ} \mathrm{C}$ and decrease steadily after undergoing temperature increases up to $1000^{\circ} \mathrm{C}$. Class II is the second highest at $750^{\circ} \mathrm{C}$ and decreases drastically as temperature is raised to $1000^{\circ} \mathrm{C}$. Class III, while slightly less than class II at $750^{\circ} \mathrm{C}$, also decreases as temperature increases to $1000^{\circ} \mathrm{C}$. Class IV concentration is affected by increasing temperature but not drastically. Class V shows a reverse response to increasing temperature and becomes much larger as temperature is increased to $1000^{\circ} \mathrm{C}$. This latter effect is caused by heavy tar production from class I tars, which show a marked decrease in this temperature range. [14]

Tars may not be a great deterrent to successful Solid Oxide Fuel Cell (SOFC) operation if they are reduced to approximately $10 \%$ of the original value. A system which is reported to essentially remove $100 \%$ of all tars has been used in the Netherlands and christened OLGA, an acronym for Oil Gas Absorption System. This system is quite simple in that it uses oil scrubbing to absorb tars. The principle here is "like dissolves like". Tars remain in gaseous form in the oil, and are removed in a stripper unit through which the air to the gasifier is channeled. This allows the tar to produce heat for the processes in the gasifier, or undergoes an additional gasification attempt to further reduce it. The inherent advantage this system has is complete tar usage and zero waste streams. [15]

Tar is a catch-all umbrella for a host of complex organic volatiles that appear in the pyrolysis gas evolution. Table 3.1 below lists a number of potential tar products in ascending molecular weight classes: 
TABLE 3.1. TARS CLASSIFICATION.

\begin{tabular}{|l|l|l|}
\hline CLASS & CHEMICAL GROUP & COMPOUND NAMES \\
\hline I & $\begin{array}{l}\text { Compounds not detectable } \\
\text { by gas chromatograph }\end{array}$ & $\begin{array}{l}\text { Net of total minus sum of classes II } \\
-\mathrm{V}\end{array}$ \\
\hline II & Heterocyclic Aromatics & Cresol, Phenol, Pyridine, Quinoline \\
\hline III & Single Ring Aromatics & Styrene, Toluene, Xylene \\
\hline IV & $\begin{array}{l}2-3 \quad \text { Ring Poly-aromatic } \\
\text { hydrocarbons }\end{array}$ & $\begin{array}{l}\text { Acenaphtylene, Anthracene, } \\
\text { Biphenyls, } \\
\text { Phenanthrene }\end{array}$ \\
\hline V & $\begin{array}{l}4-7 \quad \text { Ring Poly-aromatic } \\
\text { hydrocarbons }\end{array}$ & $\begin{array}{l}\text { Benzopyrene, Chrysene, Perylene, } \\
\text { Pyrene }\end{array}$ \\
\hline
\end{tabular}

Compounds shown in class II and III are typical of those found in the dark, brownish-black deposit on glass fireplace doors. The deposit occurs mostly at the beginning and end of fireplace use, which is in part due to glass presenting a condensation site during these parts of the cycle. Such an event is undesirable in a gasifier and in end-use equipment.

In steam power applications theses tars can be burned in the boiler with little to no detrimental effects. This is not likely to be the case for an SOFC. However, given enough residence time at $800^{\circ} \mathrm{C}$ to $900^{\circ} \mathrm{C}$ inlet temperatures, tars will have cracked to lighter noncondensables that can be consumed by the fuel cell. In any event there are a variety of methods to handle tars in gaseous media that have been used commercially for decades. [16]

In addition to tar products in the gasifier output, a number of heteroatom compounds occur, depending on feedstock. Of particular interest are the sulfur compounds hydrogen sulfide and carbonyl sulfide, both of which poison many catalysts. A level of $10 \mathrm{ppm}$ of hydrogen sulfide in the supply gas will cause about a 15 percent drop in cell voltage and damage contacts between cells. However there are established commercial methods for removing sulfur compounds from gases.

Inorganic compounds containing sulfur, calcium, sodium or potassium can be problematic for catalysts, as well as for structural components. They appear as particulates for the alkali metals, but more often gaseous SOx or H2S for sulfur contaminants. Particulates can be removed by filters or precipitators, but gaseous 
contaminants are more difficult to remove. Each of the inorganic compounds needs to be removed since they will either plug the fuel cell electrolyte or poison the catalyst.

Hydrogen cyanide can be formed with ammonia and steam at high temperature $\left(1200^{\circ} \mathrm{C}\right)$, which is above the temperature of most gasification processes. Ammonia usually forms from nitrogen bound in the feedstock at temperatures between $500^{\circ} \mathrm{C}$ $600^{\circ} \mathrm{C}$ and no hot gas method was found in the literature for its removal. If present it may decompose to nitrogen oxides and water in the fuel cell.

Alkali metals, particularly sodium, calcium, and potassium, will probably be present to some degree in various feedstocks. A portion of the amount present will appear as ash along with silicon compounds. Small amounts may carryover as particulate or perhaps gaseous phase. Data regarding this phenomenon was not discovered in the literature search.

\subsection{CONCLUSION}

With the information obtained during this investigation, it appears that any of the gasifier technologies are viable candidates for supplying an SOFC. To obtain a definitive conclusion, a matrix was been prepared wherein the individual gasifier technologies are rated on how well they meet what are believed to be important characteristics on a scale of one to three. A second multiplier of one to three to each rating based the importance of that characteristic. This process provides flexibility for the user to change characteristics and importance to fit their individual needs and technical opinions.

\section{DECISION MATRIX}

\begin{tabular}{|c|c|c|c|}
\hline $\begin{array}{l}\text { Desired } \\
\text { Parameter }\end{array}$ & Gasifier Type & $\begin{array}{l}\text { Relative } \\
\text { Importance }\end{array}$ & Adjusted Score \\
\hline & UFB DFB BFB CFB & & UFB DFB BFB CFB \\
\hline $\begin{array}{l}\text { Ability To } \\
\text { Process } \\
\text { A Variety Of } \\
\text { Fuels } \\
\end{array}$ & $\begin{array}{llll}3 & 3 & 2 & 2\end{array}$ & 2 & $\begin{array}{ll}6 & 6\end{array}$ \\
\hline
\end{tabular}




\begin{tabular}{|c|c|c|c|c|c|c|c|c|c|}
\hline \begin{tabular}{|l} 
Ability To \\
Accept \\
Various Fuel \\
Sizing \\
\end{tabular} & 3 & 2 & 1 & 1 & 2 & 6 & 4 & 2 & 1 \\
\hline $\begin{array}{l}\text { Ability To } \\
\text { Accept A } \\
\text { Range Of } \\
\text { Moisture } \\
\end{array}$ & 3 & 2 & 2 & 2 & 2 & 6 & 4 & 4 & 4 \\
\hline \begin{tabular}{|l|} 
Ability To \\
Minimize \\
Tar Content \\
\end{tabular} & 1 & 3 & 3 & 3 & 3 & 3 & 9 & 9 & 9 \\
\hline \begin{tabular}{|l} 
Ease Of \\
Control
\end{tabular} & 3 & 3 & 3 & 2 & 2 & 9 & 9 & 9 & 6 \\
\hline \multirow[t]{2}{*}{$\begin{array}{l}\text { Gas Energy } \\
\text { Content }\end{array}$} & 1 & 3 & 3 & 3 & 1 & 1 & 3 & 3 & 3 \\
\hline & & & & & $\begin{array}{l}\text { TOTAL } \\
\text { SCORE }\end{array}$ & 31 & 35 & 33 & 27 \\
\hline
\end{tabular}

UFB - Upflow fluidized-bed; DFB - Downflow fluidized-bed

BFB - Bubbling fluidized-bed; CFB - Circulating fluidized-bed 


\subsection{GASIFIER SUPPLIERS}

During the course of the search, the authors uncovered three companies with substantial experience in the manufacture of gasifier systems. They include the following:

- Primenergy, 3171 N. Toledo Ave, Tulsa, OK 74115-1804, (918) 835-1011. They offer engineering, procurement and construction of biomass-fueled systems. They use an air-blown updraft fixed bed. They have a test facility including a gasifier and an IC engine. They have built gasifier systems that operate on rice hulls, straw, sugarcane bagasse, poultry litter, refuse derived fuel and sewage sludge.

- Olan Group, 333 Northwood Way, Palisades Park, NJ 07650. They build fixedbed downflow gasifiers systems, ranging from $35 \mathrm{kWe}$ to $2 \mathrm{MWe}$. They have built systems that operate on wood chips, rice husks, sawdust and agricultural waste.

- Community Power Corporation (CPC), 8110 Shaffer Parkway, Suite 120, Littleton, CO 80127, (303) 933-3135. They use fixed-bed down flow gasifier systems, ranging in size from $5 \mathrm{kWe}$ to $100 \mathrm{kWe}$. They have built systems to operate on wood chips, walnut shells, pecan shells, coconut husks and shells, office waste, and military encampment waste.

\subsection{REFERENCES}

1. "A Review of Fixed Bed Gasification Systems for Biomass", S. Chopra and A. Kr Jain, 2007.

2. "Benchmarking Biomass Gasification Technologies for Fuels, Chemicals and Hydrogen Production", Prepared for U.S. Department of Energy, National Energy Technology Laboratory, Jared P. Ciferno and John J. Marano, June 2002.

3. Personal experience of the authors.

4. Con Edison Public Issues - Manufactured Gas Plants, Google Search. 
5. "South Africa Has Ways to Make Oil From Coal", Google Search, 2006.

6. "Sasol to Expand Secunda Plant", African Info, Google Search, 2007.

7. "Thermal Processing of Unused Products: The Sasol Perspective", Sastech Technology. Transfer Division, J. Slaghaus, A. M. Ooms, H. B. Erasmus, 1995.

8. Energy Council of the Netherlands, Google Search.

9. Superficial Velocity-The Key to Downdraft Gasification", T. Reed et al, 1999.

10. Personal communication with Rob Walt, President of Community Power Corporation, Littleton Colorado, on Wednesday, 3 September 2008.

11. “Final Report: Testing a New Type of Fixed-Bed Gasifier”, DOE Database, Carl Bielenberg, 2006.

12. "Circulating Fluidized-Bed Gasifier for Biomass", X. Bingyan et al, Google Search.

13. "Combustion and Gasification in Fluidized Beds", Prabir Basu, Taylor and Francis Group, 2006.

14. "Tar Formation in Fluidized Bed Gasification-Impact of Gasifier Operating Conditions, Energy Council of the Netherlands, S.V.B. Van Paasen and J.H.A. Kiel, May, 2004.

15. Energy Research Center of the Netherlands; Biomass, Coal, and Environmental Research - Bivkin (OLGA), Google Search.

16. "Biomass Gasifier "Tars"; Their Nature, Formation and Conversion, T.A. Milne and R. J. Evans, NREL, and N. Abatzoglou, Kemstrie, Inc., NREL/TP-57025357, Nov. 1998.

17. "A Survey of Biomass Gasification" (book), Biomass Energy Foundation, circa 2001. 


\section{TASK 4.0: DESIGN OF COMPACT, FEEDSTOCK-FLEXIBLE SYNGAS SYSTEM}

Task 4.0 - Recipient shall develop a conceptual design for the small-scale, compact, modular reactor system. The overall design will integrate reforming reactor modules with upstream components capable of converting feedstocks from a wide variety of locally-accessible sources...Performance of the compact reformer modules will be simulated using software such as ASPEN Plus ${ }^{T M}$, with the imposed design constraints that the reformer must be able to convert typical gasifier output streams derived from variable and mixed fossil and non-fossil feedstocks into SOFC-grade syngas. The reformer design will build on already existing expertise in design of modular reformer systems for gasoline and kerosene-type fuels. The reformer will be sized accordingly to accommodate the anticipated flow rates of product gas coming from gasifier units.

To optimize the reformer design, performance of the upstream gasifier unit will be maximized. If necessary, the design will incorporate recycle streams linking the reformer with the gasifier to achieve uniform gasifier output, independent of gasifier feedstocks. Alternative strategies for maintaining the correct $\mathrm{CO}: \mathrm{H}_{2}$ balance in the gasifier output stream may include the use of auxiliary fuel. This fuel could be a bio-based product such as digester methane, thus ensuring that as far as possible any $\mathrm{CO}_{2}$ produced will be from non-fossil sources. The design will incorporate widely-used zeolite or CMS pressure-swing absorption (PSA) processes to provide oxygen with only a minor energy input.

The initial focus will be on utilizing wastes based on wood, paper, or corrugated board. However, the design will be expanded to consider agricultural waste of all kinds (including wet waste streams) and to purpose-grown biomass crops in addition to lignitic and western coals and peat.

The design will adapt a feed manipulation technique recently developed...This new method is essential in achieving the required flexibility for dealing with gasifier output streams of varying composition.

Included in this task will be the identification of suitable catalyst materials, followed by synthesis and characterization of catalysts.

\section{Investigation of process considerations}

\section{Introduction}

The development of a flexible feedstock reformer requires both an active, durable reforming catalyst and a robust process design. Several key challenges must be solved at the system level. For instance, since the reformer input is envisioned as flexible, how will the system measure and adapt to that variation? What is the likely range of variation as the feedstock is change? How can a process be envisioned which accepts variable input composition but yields a less-variable output composition?

Table 4.1 summarizes the reported syngas compositions from various gasifier designs and feedstocks, including coal, biomass, and hydrocarbons. ${ }^{2}$ Different combinations of gasification process and feedstock type lead to very different syngas compositions. For example, oxygen-blown systems have very low $\mathrm{N}_{2}$ contamination in the product, while air blown systems can have in excess of 40 mole $\% \mathrm{~N}_{2}$ in the dry product. Comparison of the different processes can be simplified by comparing the 
ratios of different elements in the syngas product, such as the $\mathrm{C} / \mathrm{O}$ or $\mathrm{H} / \mathrm{C}$ ratio. (Nitrogen is neglected in this comparison as it is present in small quantities except for the air-blown processes, and even then will not participate in chemical equilibrium reactions during syngas reforming and clean-up.) Figure 4.1 shows the $\mathrm{H} / \mathrm{C}, \mathrm{C} / \mathrm{O}$, and $\mathrm{H} / \mathrm{O}$ ratios as well as the process steam feed rate for the process/feedstock combinations given in Table 4.1. There is very little variation in the $\mathrm{C} / \mathrm{O}$ ratio across all processes, despite the use of different techniques and feedstocks. The average $\mathrm{C} / \mathrm{O}$ ratio is 0.93 with a standard deviation of 0.103 . This tight grouping is a result of using a carbonaceous feedstock and the desire to produce syngas. Product $\mathrm{C} / \mathrm{O}$ ratios much lower than 1.0 would result in an undesirable shift to $\mathrm{CO}_{2}$. The $\mathrm{H} / \mathrm{C}$ and $\mathrm{H} / \mathrm{O}$ ratios show much more variability, but move in concert with each other as only one is independent (since $\mathrm{H} / \mathrm{C}{ }^{*} \mathrm{C} / \mathrm{O}=\mathrm{H} / \mathrm{O}$ ). In fact, plotting the $\mathrm{H} / \mathrm{C}$ versus the $\mathrm{H} / \mathrm{O}$ yields a straight line with slope $=1$ and shows air blown systems are no different than oxygen blown systems (see Figure 4.2). Returning to Table 4.1, it can be seen that the while the $\mathrm{H}$ content of the syngas varies substantially, there are trends. The fixed bed processes using steam have $\mathrm{H} / \mathrm{C}$ ratios of $1.25-2.0$. Fluidized bed systems have lower ratios $(1.0-1.25)$ with the use of steam increasing the $\mathrm{H}$ content. The entrained flow processes have some of the lowest $\mathrm{H} / \mathrm{C}$ ratios $(0.75-1.0)$. In gasification of natural gas and petroleum, one can see that feedstock plays an important role, with natural gas having the highest $\mathrm{H}$ content in the product $(\mathrm{H} / \mathrm{C}=3.25$, where pure methane would have $\mathrm{H} / \mathrm{C}=4.0$ ). Essentially, the variability in the elemental composition of syngas from different sources lies in the hydrogen content; the $\mathrm{C} / \mathrm{O}$ ratio will be approximately 0.9 regardless of source.

One potential approach to achieving constant reformer output composition under variable input composition might be to use long residence times and allow the system to come to equilibrium. Clearly the success of this strategy will be dependent on catalyst activity, contact times, and reaction engineering. 
Table 4.1. Syngas composition from different feedstocks and gasification processes, in dry mole \%.

Data from Higman and van der Burgt (2008).

\begin{tabular}{|c|c|c|c|c|c|c|c|c|c|c|c|}
\hline \multirow[b]{2}{*}{ Process } & \multicolumn{11}{|c|}{ Mole percent, in dry synthesis gas product } \\
\hline & $\mathrm{CO}_{2}$ & $\mathrm{CO}$ & $\mathrm{H}_{2}$ & $\mathrm{CH}_{4}$ & $\mathrm{C}_{\mathrm{n}} \mathrm{H}_{\mathrm{m}}$ & $\mathrm{C}_{2} \mathrm{H}_{4}$ & $\mathrm{C}_{2} \mathrm{H}_{6}$ & Ar & $\mathbf{N}_{2}$ & $\begin{array}{l}\mathrm{H}_{2} \mathrm{~S}+ \\
\mathrm{COS}\end{array}$ & $\mathrm{NH}_{3}$ \\
\hline Lurgi dry bottom coal & 30.89 & 15.18 & 42.15 & 8.64 & 0.79 & 0 & 0 & 0 & 0.68 & 1.31 & 0.36 \\
\hline BGL coal & 3.46 & 54.96 & 31.54 & 4.54 & 0.48 & 0 & 0 & 0 & 3.35 & 1.31 & 0.36 \\
\hline Ruhr 100 coal & 29.52 & 18.15 & 35.11 & 15.78 & 1.02 & 0 & 0 & 0 & 0.35 & $\begin{array}{l}0 \\
\left(H_{2} \mathbf{S}\right)\end{array}$ & 0 \\
\hline Fluid bed, biomass Air & 6.7 & 31 & 18.9 & 2.1 & 0 & 0 & 0 & 0.5 & 40.8 & 0.03 & 0 \\
\hline Fluid bed, lignite $\mathrm{O}_{2} /$ steam & 6.2 & 56.7 & 32.8 & 2.6 & 0 & 0 & 0 & 0.6 & 0.9 & 0.2 & 0 \\
\hline Fluid bed, Bit. $\mathrm{O}_{2} /$ steam & 5.3 & 52 & 37.3 & 3.5 & 0 & 0 & 0 & 0.6 & 1 & 0.3 & 0 \\
\hline Fluid bed, Bit. Air & 1.9 & 30.7 & 18.7 & 0.9 & 0 & 0 & 0 & 0.6 & 47 & 0.2 & 0 \\
\hline Entrained flow, browncoal & 8 & 61 & 29 & 0 & 0 & 0 & 0 & 1 & 1 & 0.2 & 0 \\
\hline Entrained flow, lignite & 10 & 62 & 26 & 0 & 0 & 0 & 0 & 1 & 1 & 0.1 & 0 \\
\hline Entrained flow, anthracite & 1 & 65 & 31 & 0 & 0 & 0 & 0 & 1 & 1 & 0.2 & 0 \\
\hline GEE Oil gasification, NG & 2.6 & 35 & 61.1 & 0.3 & 0 & 0 & 0 & 1 & 0 & 0 & 0 \\
\hline $\begin{array}{l}\text { GEE Oil gasification, } \\
\text { Naphtha }\end{array}$ & 2.7 & 45.3 & 51.2 & 0.7 & 0 & 0 & 0 & 0.1 & 0 & 0 & 0 \\
\hline $\begin{array}{l}\text { GEE Oil gasification, } \\
\text { Heavy oil }\end{array}$ & 5.7 & 47.5 & 45.8 & 0.5 & 0 & 0 & 0 & 0.3 & 0.3 & 0 & 0 \\
\hline GEE Oil gasification, Tar & 5.7 & 54.3 & 38.9 & 0.1 & 0 & 0 & 0 & 0.8 & 0.2 & 0 & 0 \\
\hline $\begin{array}{l}\text { SilvaGas } \\
\text { biomass }\end{array}$ & 12.2 & 44.4 & 22 & 15.6 & 0 & 5.1 & 0.7 & 0 & 0 & 0 & 0 \\
\hline FICFB & 20 & 25 & 37.5 & 10 & 0 & 0 & 0 & 0 & 4 & 0 & 0 \\
\hline
\end{tabular}




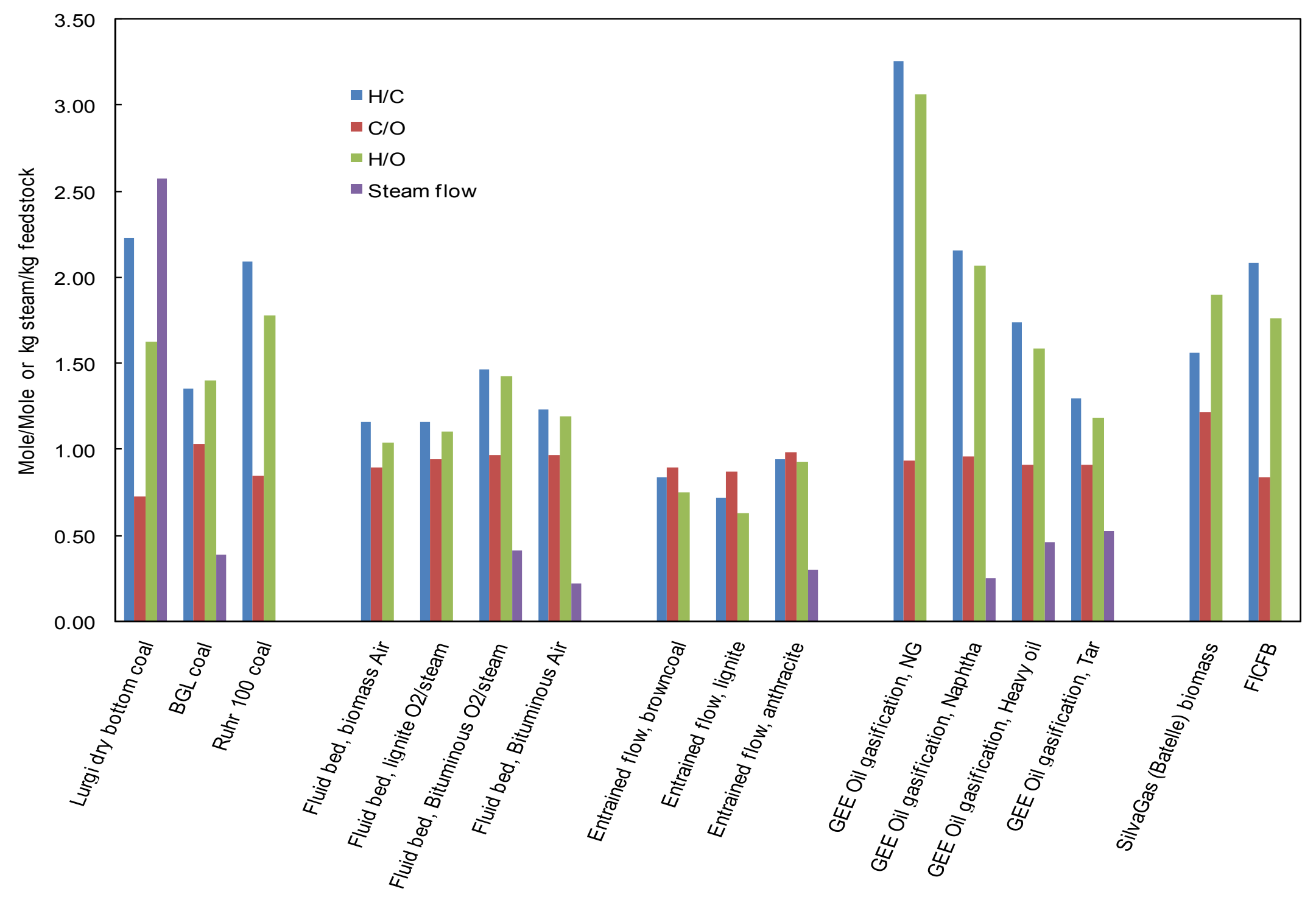

Figure 4.1. Atomic ratios of $\mathrm{C}, \mathrm{H}$, and $\mathrm{O}$ as well as steam feed rates for various gasification 


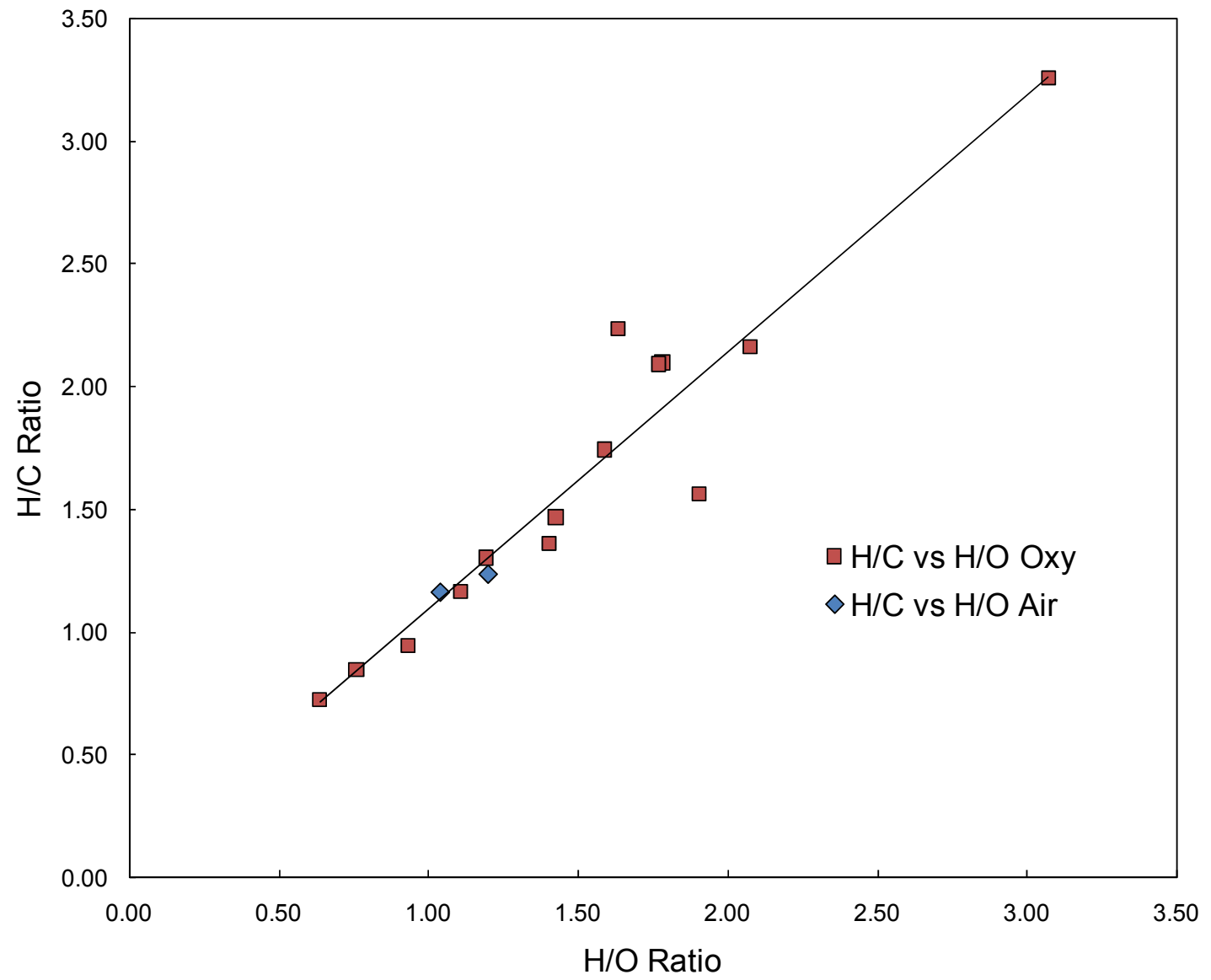

Figure 4.2. Correlation between the $\mathrm{H} / \mathrm{C}$ ratio and the $\mathrm{H} / \mathrm{O}$ ratio in product syngas from different gasification process/feedstock combinations.

\section{Current progress}

Representation of the various gasifier output compositions (Table 4.1) on a ternary $\mathrm{C} / \mathrm{H} / \mathrm{O}$

Figure 4.3) diagram revealed that all gasifiers yield outputs which close to the line of equal $\mathrm{C}-\mathrm{O}$ composition. The only variable in the atomic composition is the $\mathrm{H}$ content, which is linked to the gasification feedstock. Natural gas has the highest $\mathrm{H}$ content, coals have the lowest $\mathrm{H}$ content. The addition of $\mathrm{O}_{2}$ or $\mathrm{H}_{2} \mathrm{O}$ represents moving along a straight line on the ternary diagram toward the oxygen vertex or a point of $\mathrm{H}: \mathrm{O}$ equal to $2: 1$. Since chemical equilibrium depends on the overall $\mathrm{C}-\mathrm{H}-\mathrm{O}$ composition of the mixture and the equilibration temperature, a constant output from the reformer could theoretically be assured by addition of the appropriate amounts of steam or oxygen and control of the exit temperature.

Two modes of reformer operation may be envisioned: reforming of trace hydrocarbons with pre-determined $\mathrm{O} / \mathrm{C}$ and $\mathrm{H}_{2} \mathrm{O} / \mathrm{C}$ ratios or addition of $\mathrm{H}_{2} \mathrm{O}$ and $\mathrm{O}_{2}$ to reach a specified $\mathrm{C} / \mathrm{H} / \mathrm{O}$ atomic composition. The results of using each approach have been determined using $\mathrm{ASPEN}^{\circledR}$ simulation software. 


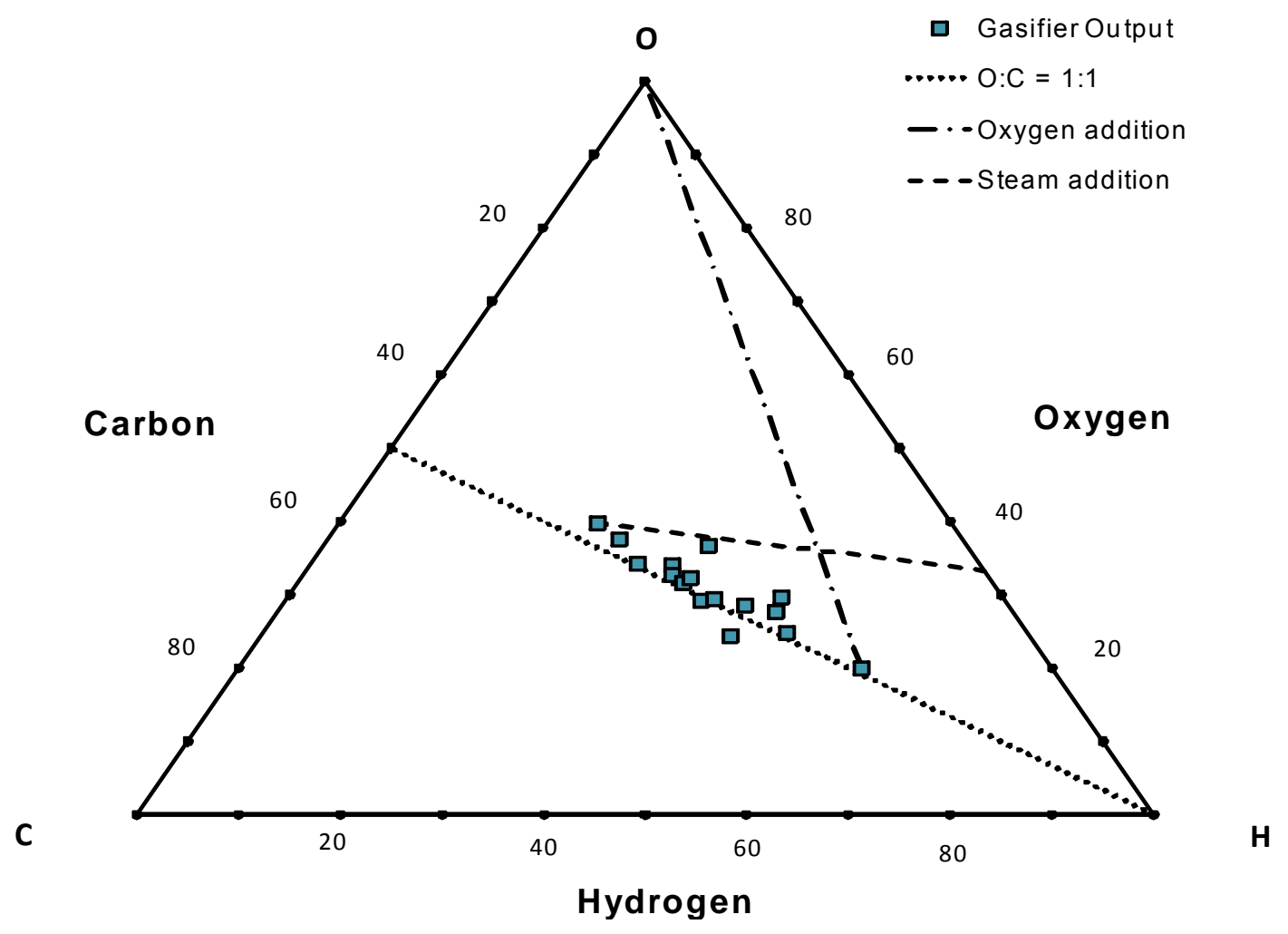

Figure 4.3. $\mathrm{C} / \mathrm{H} / \mathrm{O}$ composition of gasifier products from processes in Table 4.1.

\section{Experimental/Methodological Considerations}

In order to carry out reforming experiments, a gas mixture was purchased to match a typical composition described in the original project proposal (Table 4.2). The gas compositions used in the equilibrium calculations were based on adding $\mathrm{H}_{2}$ or $\mathrm{CO}$ to this mixture to produce input streams which had different $\mathrm{C}$ $\mathrm{H}-\mathrm{O}$ ratios and which could be easily produced with the experimental facilities available at UM. The input compositions used for equilibrium calculations are presented in Table 4.3, and are plotted on the $\mathrm{C} / \mathrm{H} / \mathrm{O}$ ternary diagram in

Figure 4.4.

Table 4.2. Composition of simulated gasifier product available for UM reforming tests.

$\begin{array}{ll}\text { Component } & \text { Volume percent } \\ \mathrm{H}_{2} & 29.0 \\ \mathrm{CH}_{4} & 13.0 \\ \mathrm{C}_{2} \mathrm{H}_{4} & 5.0 \\ \mathrm{CO} & 36.0 \\ \mathrm{CO}_{2} & 17.0\end{array}$


Table 4.3. Mole fractions of model gasifier output compositions used for equilibrium calculations.

\begin{tabular}{llllll} 
& Base & $4: 1 \mathrm{CO}$ & $2: 1 \mathrm{CO}$ & $4: 1 \mathrm{H}_{2}$ & $2: 1 \mathrm{H}_{2}$ \\
\hline $\mathrm{H}_{2}$ & 0.290 & 0.232 & 0.193 & 0.432 & 0.527 \\
$\mathrm{CH}_{4}$ & 0.130 & 0.104 & 0.87 & 0.104 & 0.87 \\
$\mathrm{C}_{2} \mathrm{H}_{4}$ & 0.50 & 0.40 & 0.33 & 0.40 & 0.33 \\
$\mathrm{CO}$ & 0.360 & 0.488 & 0.573 & 0.288 & 0.240 \\
$\mathrm{CO}_{2}$ & 0.170 & 0.136 & 0.113 & 0.136 & 0.113 \\
& & & & & \\
$\mathrm{C}$ & 0.275 & 0.310 & 0.335 & 0.233 & 0.202 \\
$\mathrm{H}$ & 0.471 & 0.399 & 0.346 & 0.552 & 0.612 \\
$\mathrm{O}$ & 0.254 & 0.291 & 0.319 & 0.215 & 0.186
\end{tabular}

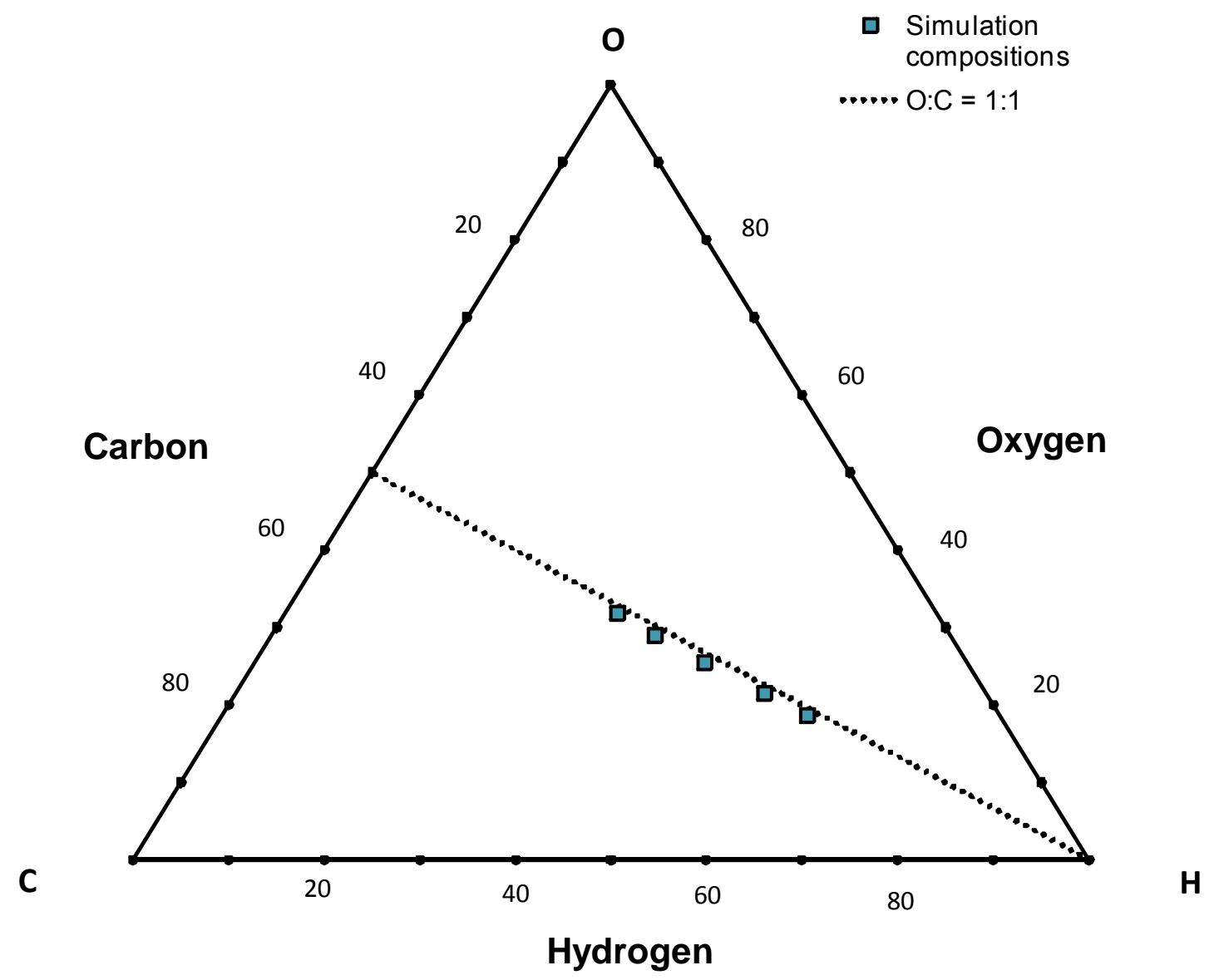

Figure 4.4. $\mathrm{C} / \mathrm{H} / \mathrm{O}$ positions of the model gasifier product compositions.

Equilibrium calculations were performed using ASPEN ${ }^{\circledR}$ software and the simple flowsheet in Figure 4.5. In the simulation, a model gasifier product 
(Stream 1) is mixed with an air/steam feed (Stream 2) and allowed to come to chemical and thermal equilibrium before exiting the reactor (Stream 3). The Gibbs reactor block is used to represent the flexible feedstock reformer and the exit temperature is specified (as opposed to adiabatic operation). The software calculates the exit composition and temperature by minimizing the Gibbs free energy of the system.

Each of the gasifier input streams was equilibrated at 5 atm pressure, a feed temperature of $500{ }^{\circ} \mathrm{C}$, and exit temperatures from 500 to $1000{ }^{\circ} \mathrm{C}$ under three scenarios. The first was simple chemical equilibrium of the feed gas with no steam or oxygen addition. The second was a reforming scenario where oxygen and steam were added to each of the feeds in Table 4.3 to achieve an $\mathrm{O} / \mathrm{C}$ and $\mathrm{H}_{2} \mathrm{O} / \mathrm{C}$ ratio of 0.5 and 1.0 (based on $\mathrm{CH}_{4}$ and $\mathrm{C}_{2} \mathrm{H}_{4}$ ). The third scenario was the addition of oxygen and steam to reach a specified $\mathrm{C} / \mathrm{H} / \mathrm{O}$ composition. The overall reformer feeds (Stream 1 plus Stream 2) are given in Table 4.4 and Table 4.5 below.

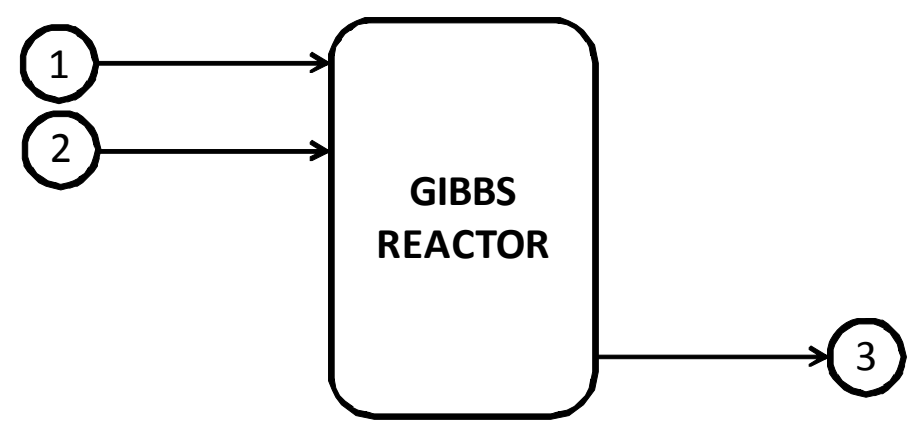

Figure 4.5. ASPEN model flowsheet used for equilibrium calculations. Stream 1: gasifier product. Stream 2: $\mathrm{O}_{2} / \mathrm{H}_{2} \mathrm{O}$ (for reforming or $\mathrm{C} / \mathrm{H} / \mathrm{O}$ matching). Stream 3: product.

Table 4.4. Feed compositions (mole fraction) for the reforming scenario.

\begin{tabular}{llllll} 
Component & Base Case & $4: 1 \mathrm{CO}$ & $2: 1 \mathrm{CO}$ & $4: 1 \mathrm{H}_{2}$ & $2: 1 \mathrm{H}_{2}$ \\
\hline $\mathrm{H}_{2}$ & 0.193 & 0.165 & 0.145 & 0.308 & 0.394 \\
$\mathrm{CH}_{4}$ & 0.086 & 0.074 & 0.065 & 0.074 & 0.065 \\
$\mathrm{C}_{2} \mathrm{H}_{4}$ & 0.033 & 0.029 & 0.025 & 0.029 & 0.025 \\
$\mathrm{CO}$ & 0.239 & 0.348 & 0.429 & 0.205 & 0.180 \\
$\mathrm{CO}_{2}$ & 0.113 & 0.097 & 0.085 & 0.097 & 0.085 \\
$\mathrm{~N}_{2}$ & 0.144 & 0.123 & 0.108 & 0.123 & 0.108 \\
$\mathrm{O}_{2}$ & 0.038 & 0.033 & 0.029 & 0.033 & 0.029 \\
$\mathrm{H}_{2} \mathrm{O}$ & 0.153 & 0.131 & 0.115 & 0.131 & 0.115
\end{tabular}


Table 4.5. Feed compositions (mole fraction) for the $\mathrm{C} / \mathrm{H} / \mathrm{O}$ matching scenario.

\begin{tabular}{llllll} 
Component & Base Case & $4: 1 \mathrm{CO}$ & $2: 1 \mathrm{CO}$ & $4: 1 \mathrm{H}_{2}$ & $2: 1 \mathrm{H}_{2}$ \\
\hline $\mathrm{H}_{2}$ & 0.134 & 0.118 & 0.104 & 0.200 & 0.236 \\
$\mathrm{CH}_{4}$ & 0.060 & 0.053 & 0.046 & 0.048 & 0.039 \\
$\mathrm{C}_{2} \mathrm{H}_{4}$ & 0.023 & 0.020 & 0.018 & 0.019 & 0.015 \\
$\mathrm{CO}$ & 0.166 & 0.249 & 0.307 & 0.133 & 0.107 \\
$\mathrm{CO}_{2}$ & 0.078 & 0.069 & 0.061 & 0.063 & 0.051 \\
$\mathrm{~N}_{2}$ & 0.237 & 0.097 & 0.000 & 0.336 & 0.436 \\
$\mathrm{O}_{2}$ & 0.063 & 0.026 & 0.000 & 0.089 & 0.116 \\
$\mathrm{H}_{2} \mathrm{O}$ & 0.240 & 0.367 & 0.464 & 0.111 & 0.000
\end{tabular}

Comparison of equilibrium results under different reaction scenarios

\section{Simple Equilibrium}

The first question which should be posed is whether the model gasifier product compositions used in the simulations are already at equilibrium. To evaluate this each of the five compositions was allowed to come to equilibrium at different reformer exit temperatures. Figure 4.6 presents the equilibrium composition for the base case feed mixture from Table 4.3 at exit temperatures in the range of $500-1000{ }^{\circ} \mathrm{C}$ and at $5 \mathrm{~atm}$ pressure. The feed composition is noted at the left hand axis. Note that the feed mixture is not at equilibrium, as there is no temperature at which the equilibrium composition matches the feed composition. High temperatures favor low methane content and high $\mathrm{CO}$ and $\mathrm{H}_{2}$ content. There is negligible ethylene content at any temperature. Since the feed $\mathrm{C} / \mathrm{O}$ ratio is slightly greater than 1.0 , methane cannot be completely converted as there is not enough oxygen in the mixture. The trends seen for the base case are representative of those observed in all feed mixtures. In all cases higher temperatures are best cue to the lower methane content.

Since the exit temperature is specified, one of the calculation outputs is the reactor heat duty. Figure 4.7 shows the energy duty on the reactor for the different feed mixtures from Table 4.3 at different exit temperatures. High temperatures are desirable, but achieving these temperatures would require additional energy input. The shape of the curves is largely determined by the chemical composition of the feed, but the position relative to zero duty is determined by the feed temperature. Higher feed temperatures would shift the curves downward and the adiabatic equilibrium temperature to a higher value. So simple equilibration may be a useful approach, but only if high feed temperatures can be maintained and the reformer operated nearly adiabatically. 


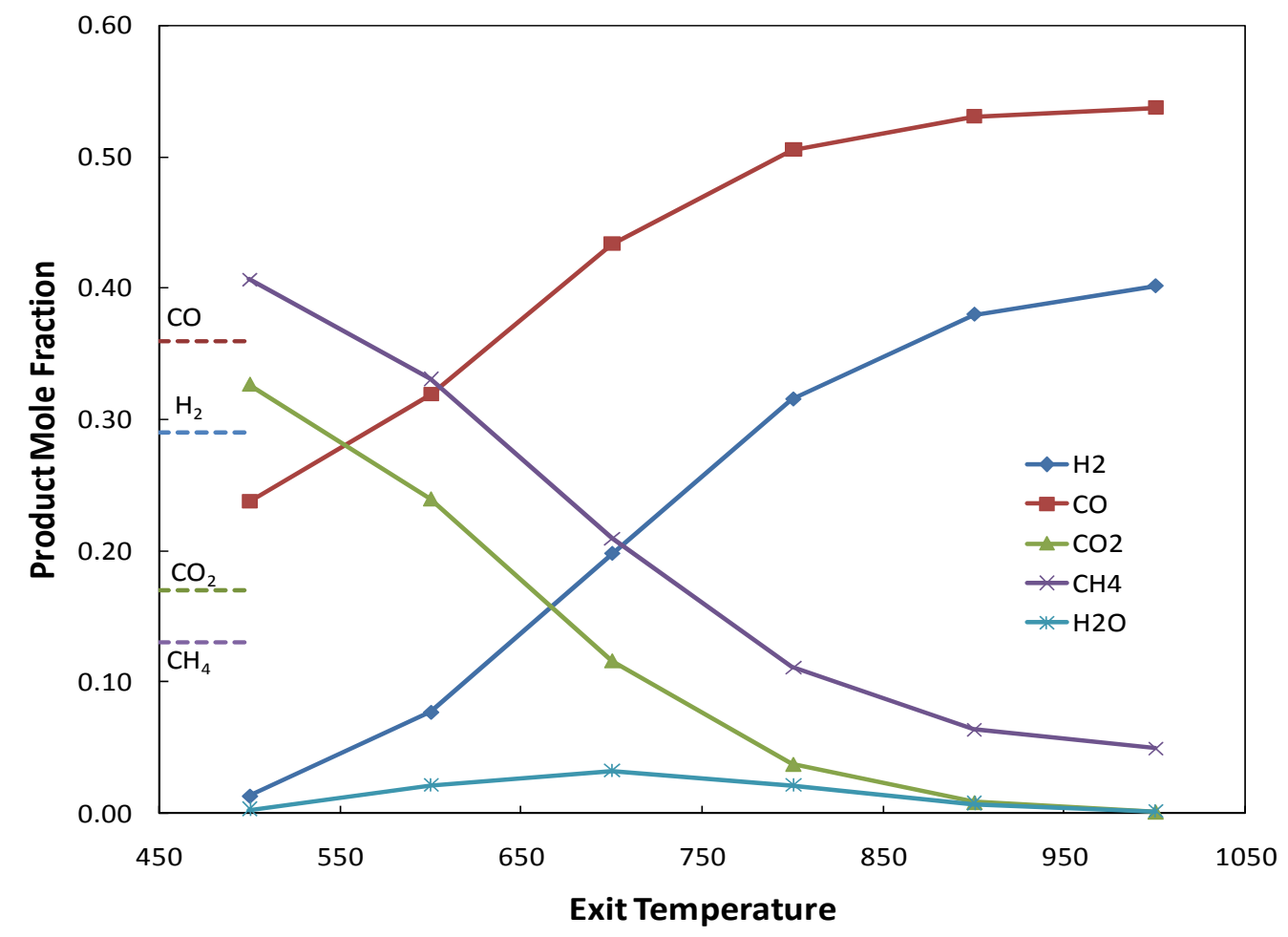

Figure 4.6. Mole fractions in equilibrium product distribution for base case feed (Table 4.3).

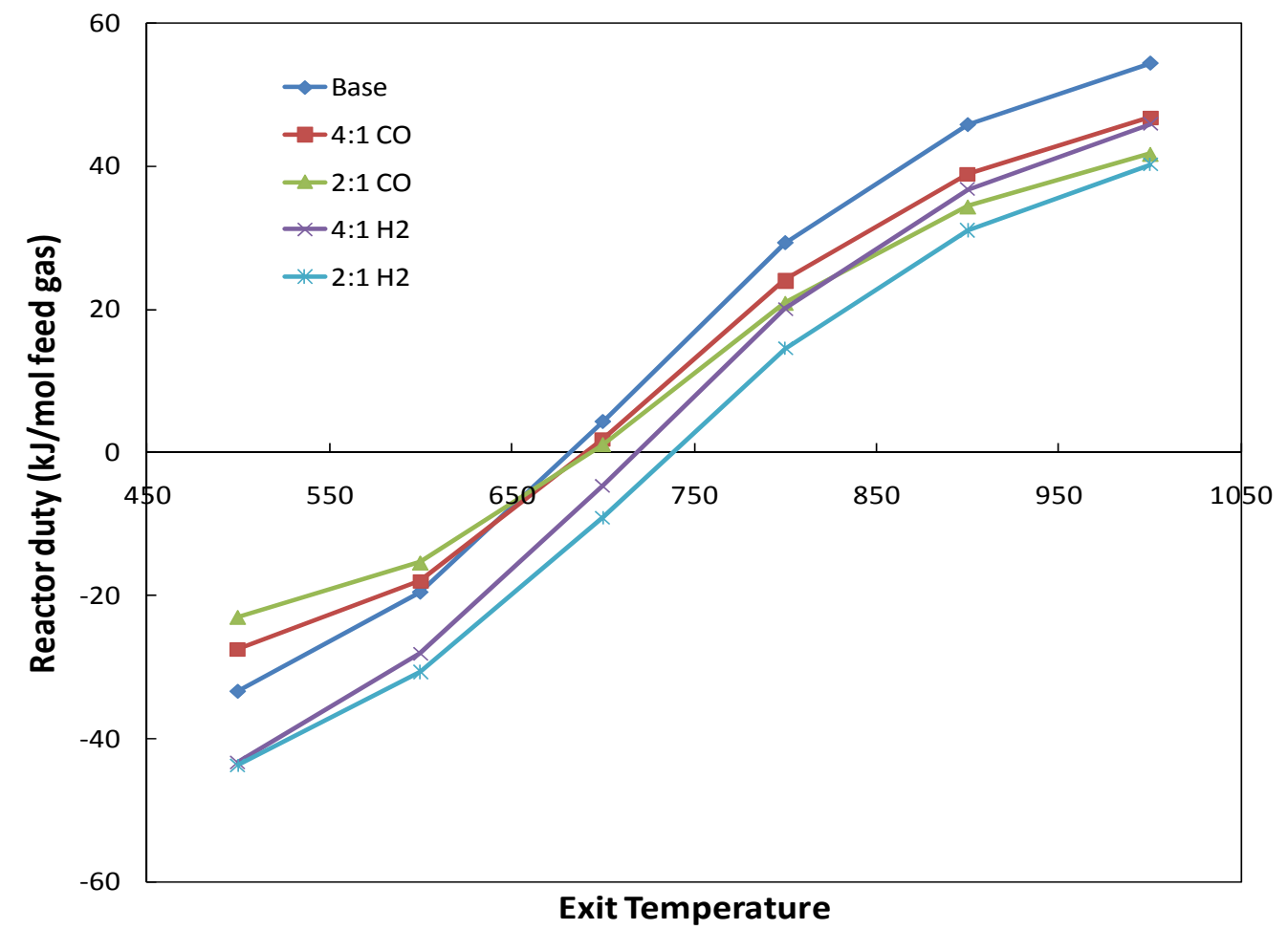

Figure 4.7. Reformer duty for equilibration of model gasifier products from Table 4.3. 


\section{Autothermal Reforming of Hydrocarbons}

Autothermal reforming of the hydrocarbons in the model gasifier products was the second scenario examined. $\mathrm{O}_{2}$ and $\mathrm{H}_{2} \mathrm{O}$ were added to the model gasifier feeds to achieve an $\mathrm{O} / \mathrm{C}$ ratio of 0.5 and $\mathrm{a} \mathrm{H}_{2} \mathrm{O} / \mathrm{C}$ ratio of 1.0 (based on $\mathrm{C}$ in $\mathrm{CH}_{4}$ and $\mathrm{C}_{2} \mathrm{H}_{4}$ ). The overall feed compositions are given above in Table 4.4 and the equilibrium product distributions at various exit temperatures are given in Figure 4.8. As with the simple equilibrium case, high temperatures give low $\mathrm{CH}_{4}$ and high $\mathrm{H}_{2}$ and $\mathrm{CO}$ content. Unlike the previous case, however, temperatures between 900 and $1000{ }^{\circ} \mathrm{C}$ can almost completely convert methane. This is a result of the higher oxygen content of the overall mixture.

The reactor duties for the reforming scenario are given in Figure 4.9. The trends are similar to the simple equilibrium case given above. The main difference is that the reforming scenario is more exothermic at low temperatures. The goal of post-gasifier reforming is two-fold: to convert hydrocarbons to $\mathrm{CO}$ and $\mathrm{H}_{2}$ to facilitate SOFC and to reduce product variation due to varying feedstocks. Figure 4.10 shows the product composition for each model gasifier product following reforming at an exit temperature of $1000{ }^{\circ} \mathrm{C}$. There is small variation in water and $\mathrm{CO}_{2}$ content, while methane content is low across all feed mixtures (due to the high exit temperature). As would be expected, the greatest variation is in $\mathrm{H}_{2}$ and $\mathrm{CO}$ content. This is a result of the varying $\mathrm{C} / \mathrm{H} / \mathrm{O}$ composition of the different feeds. The combined $\mathrm{H}_{2}$ and $\mathrm{CO}$ content (the fuel portion for an SOFC) shows a maximum at the base case feed composition. Each case considered the same molar feed rate of gasifier product to the reformer. The base case contains more $\mathrm{CH}_{4}$ and $\mathrm{C}_{2} \mathrm{H}_{4}$ than the other cases, and it yields the highest $\mathrm{H}_{2}$ and $\mathrm{CO}$ output. 


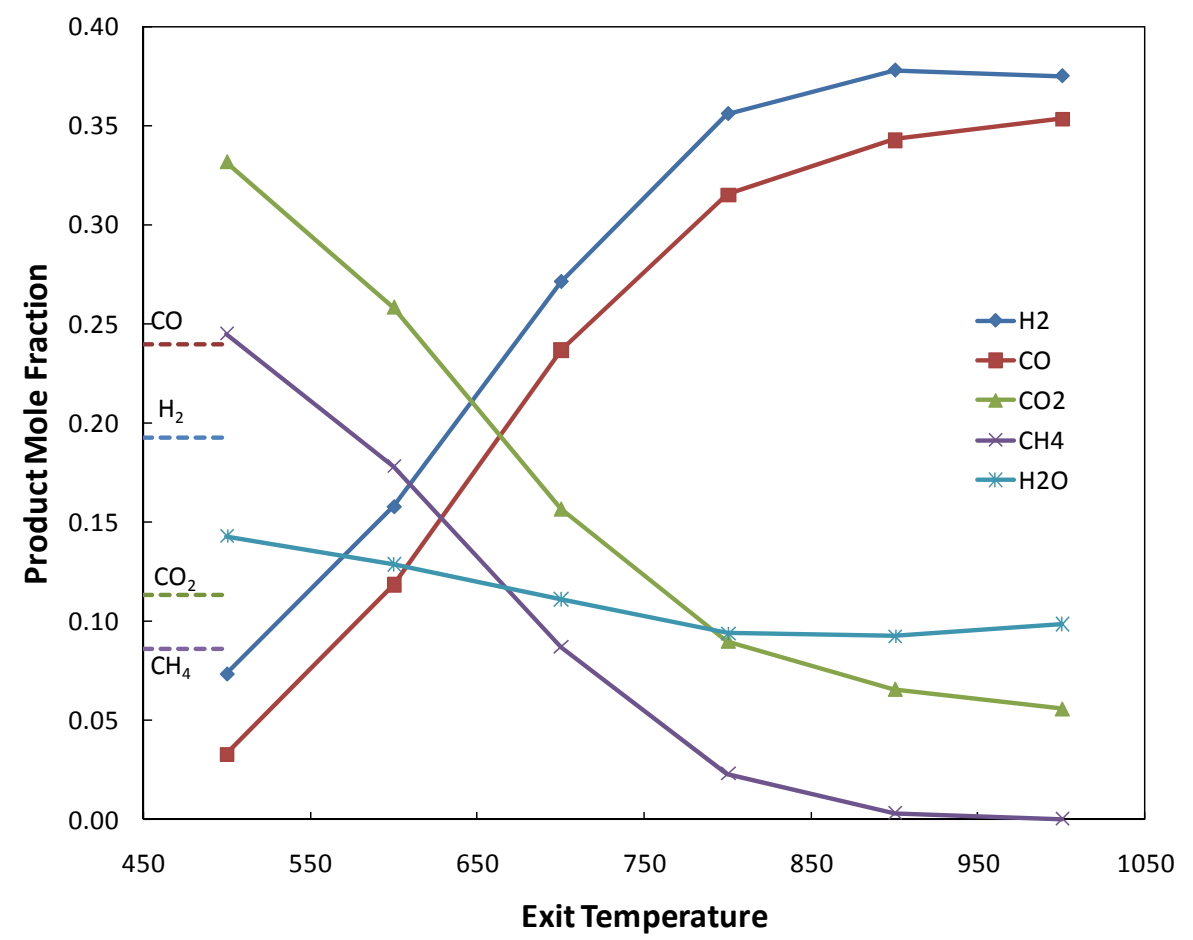

Figure 4.8. Equilibrium product composition under reforming scenario of base case model gasifier product.

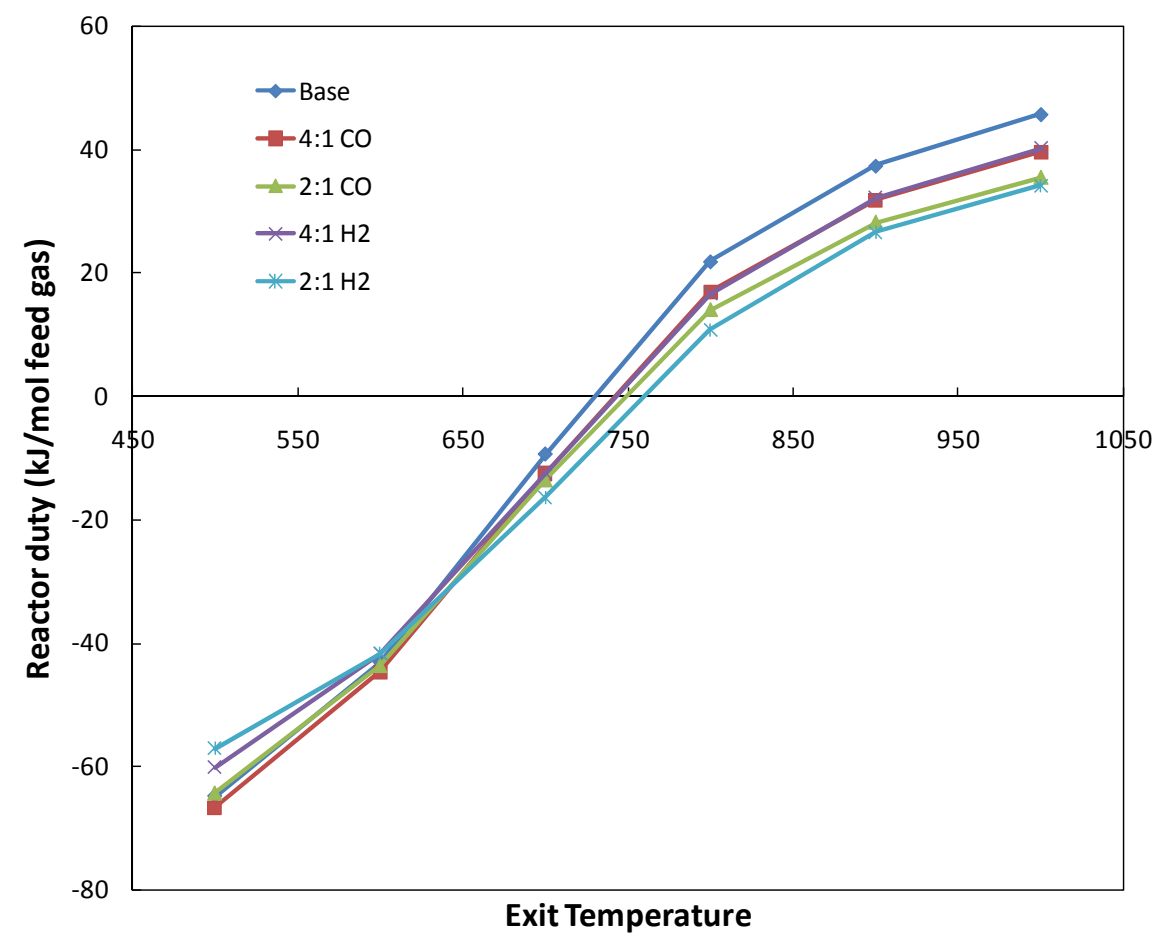

Figure 4.9. Reactor duty for autothermal reforming of model gasifier products. 


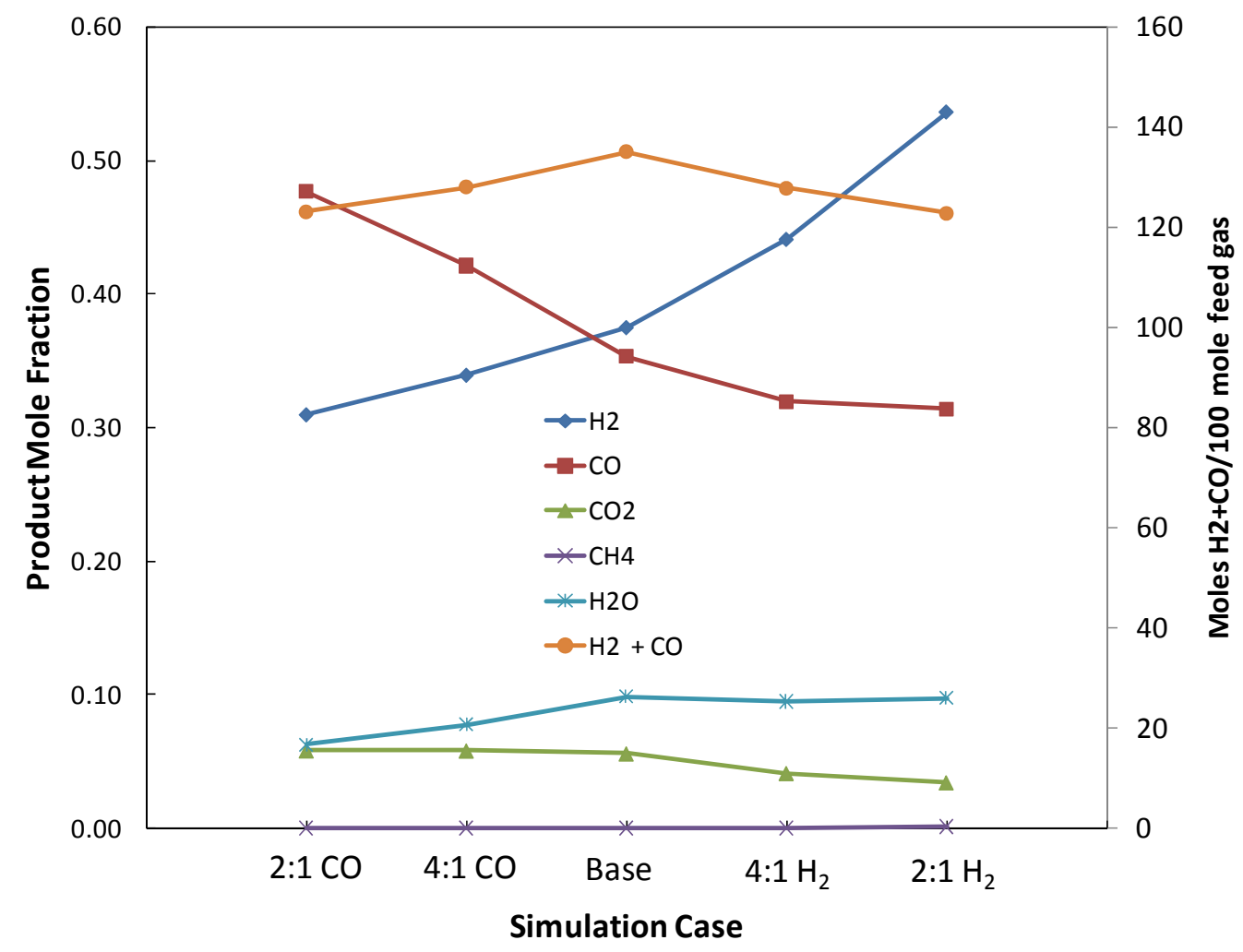

Figure 4.10. Product composition and SOFC fuel content $\left(\mathrm{H}_{2}+\mathrm{CO}\right)$ at $1000{ }^{\circ} \mathrm{C}$ exit temperature for model gasifier outputs.

\section{C/H/O matching}

The third and final scenario examined was the reaction to equilibrium of each of the model gasifier products when $\mathrm{O}_{2}$ and $\mathrm{H}_{2} \mathrm{O}$ were added to match the final $\mathrm{C} / \mathrm{H} / \mathrm{O}$ composition. The $\mathrm{C} / \mathrm{H} / \mathrm{O}$ target was set at the intersection of pure $\mathrm{H}_{2} \mathrm{O}$ addition to the 2:1 CO case and pure $\mathrm{O}_{2}$ addition to the $2: 1 \mathrm{H}_{2}$ case. The other cases were mixed with a combination of steam and $\mathrm{O}_{2}$. Figure 4.11 presents the equilibrium reformer output as a function of temperature for the base case feed. As with the other scenarios, high exit temperatures decrease the $\mathrm{CH}_{4}$ content and increase the $\mathrm{H}_{2}$ and $\mathrm{CO}$ content. The $\mathrm{C} / \mathrm{H} / \mathrm{O}$ scenario, however, leads to the lowest exit temperatures required for minimal $\mathrm{CH}_{4}$ content.

Figure 4.12 presents the reformer duty for all reformer feed cases. The curves have shapes similar to those found for the simple equilibrium and reforming cases. They are less sigmoidal and in general less energy is required - that is, more exit temperatures lead to exothermic operation. This is a result of the significant input of oxygen to the system. The high $\mathrm{H}_{2}$ cases essentially undergo some combustion in order to arrive at the final equilibrium composition. These high exotherms indicate a loss of energy, which indicates that the overall reformer efficiency will be lower in these cases. A quick estimate of efficiency can be made by dividing the lower heating value (LHV) of the reformer product by the LHV of the reformer feed. These results are given in Figure 4.13. This 
calculation shows the much lower efficiency of the $\mathrm{C} / \mathrm{H} / \mathrm{O}$ strategy when adding $\mathrm{O}_{2}$ as compared to adding $\mathrm{H}_{2} \mathrm{O}$. This simple estimate, however, neglects overall system efficiency which must account for the energy required to achieve exit temperature under pure $\mathrm{H}_{2} \mathrm{O}$ addition. This is the origin of efficiencies beyond $100 \%$.

Figure 4.14 shows the equilibrium reformer product distribution for each feed mixture. The mole fractions of all components decrease as the $\mathrm{H}_{2}$ content in the feed increases. This is due to the diluent effect of $\mathrm{N}_{2}$, which is added along with $\mathrm{O}_{2}$, which in turn is added in the greatest amounts to the high $\mathrm{H}_{2}$ cases. When the product distributions are shown on an $\mathrm{N}_{2}$-free basis, the compositions are identical amongst all cases (Figure 4.15). These figures also show the SOFC fuel content, $\mathrm{H}_{2}$ and $\mathrm{CO}$, which decreases as more $\mathrm{O}_{2}$ is added. This is the origin of the drop in efficiency noted above.

Optimal reforming scenario

Selection of the optimal reforming scenario will depend on the specific requirements of the downstream system and the desired or acceptable system efficiency. Practical application of any scenario will also require a catalyst which can effectively catalyze the necessary reactions without deactivation due to either carbon deposition or other catalytic poisons. 


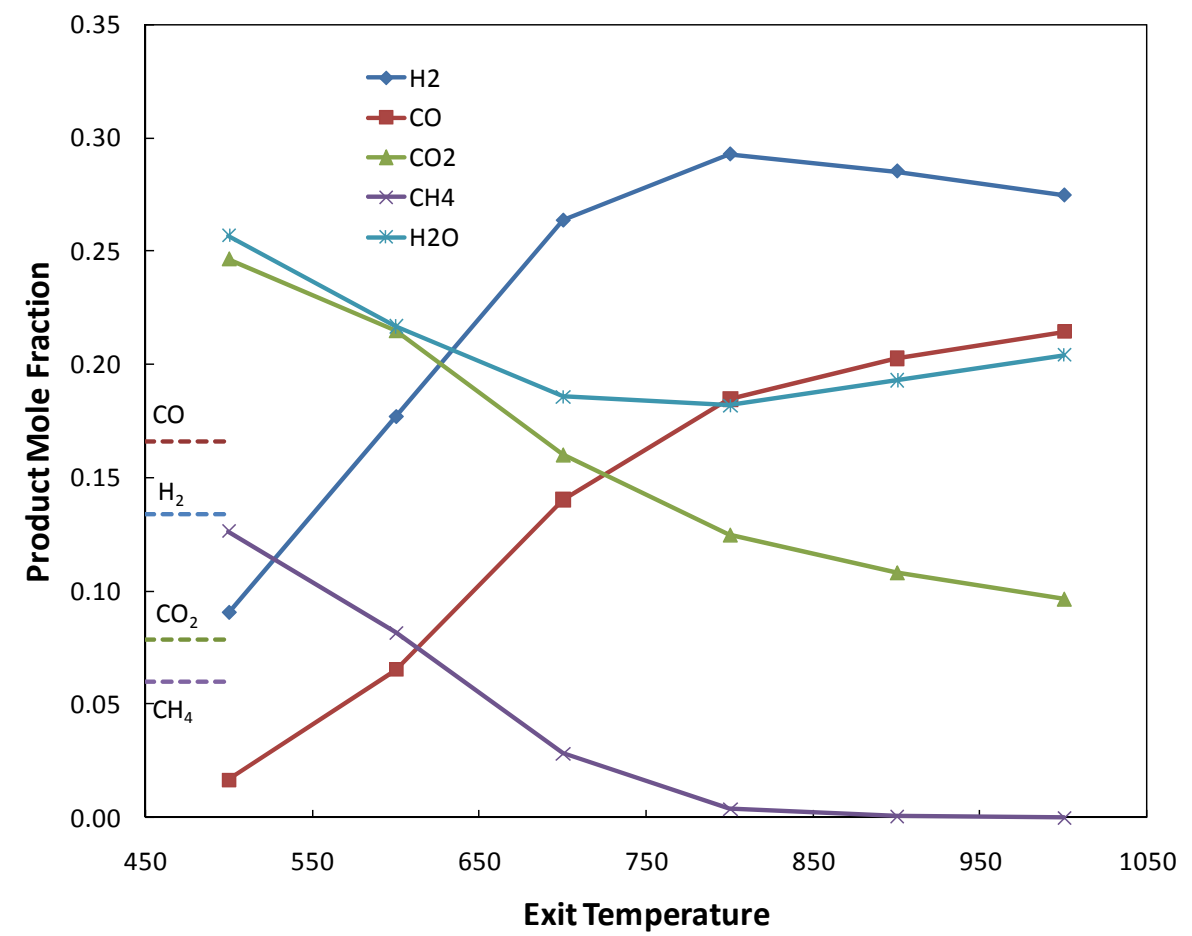

Figure 4.11. Equilibrium product composition of base case model gasifier product under $\mathrm{C} / \mathrm{H} / \mathrm{O}$ matching scenario.

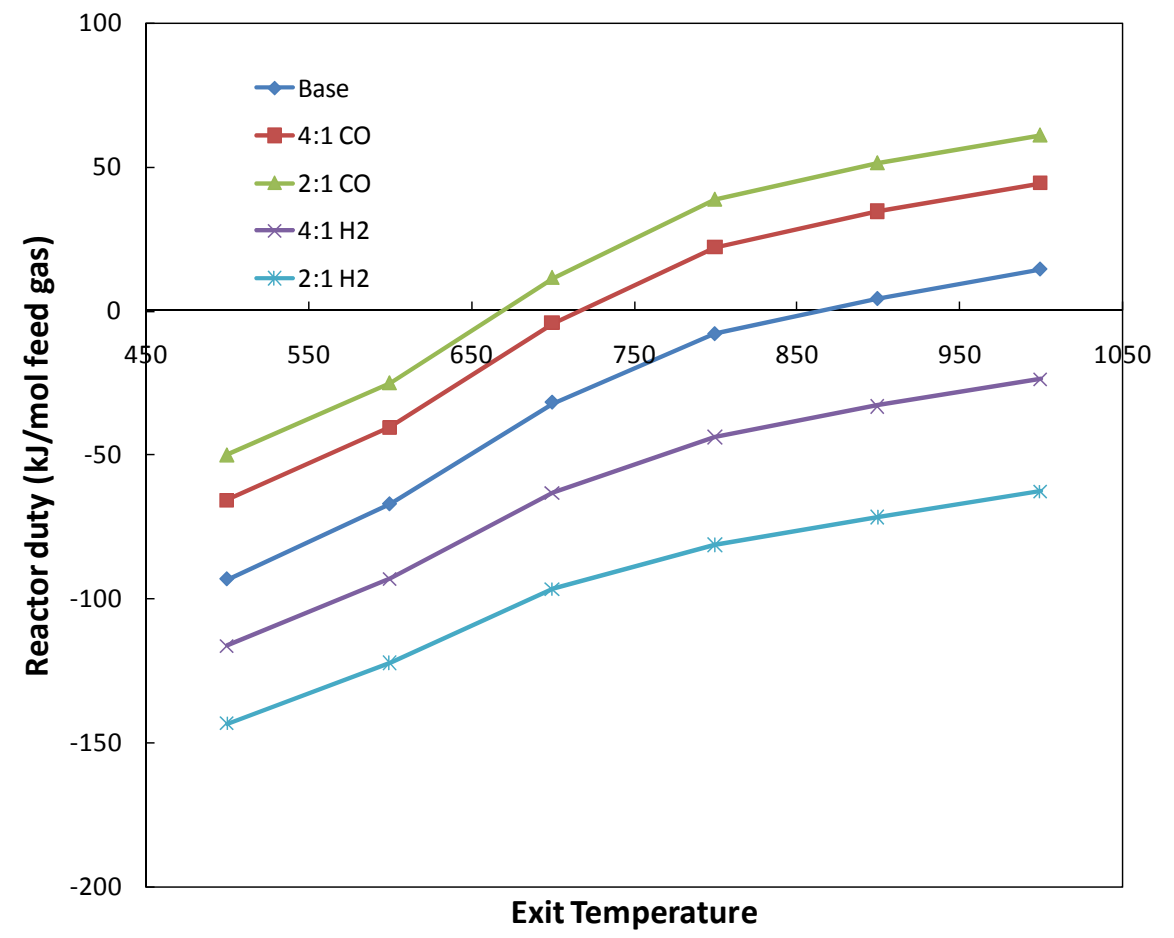

Figure 4.12. Reactor duty for autothermal reforming of model gasifier products. 


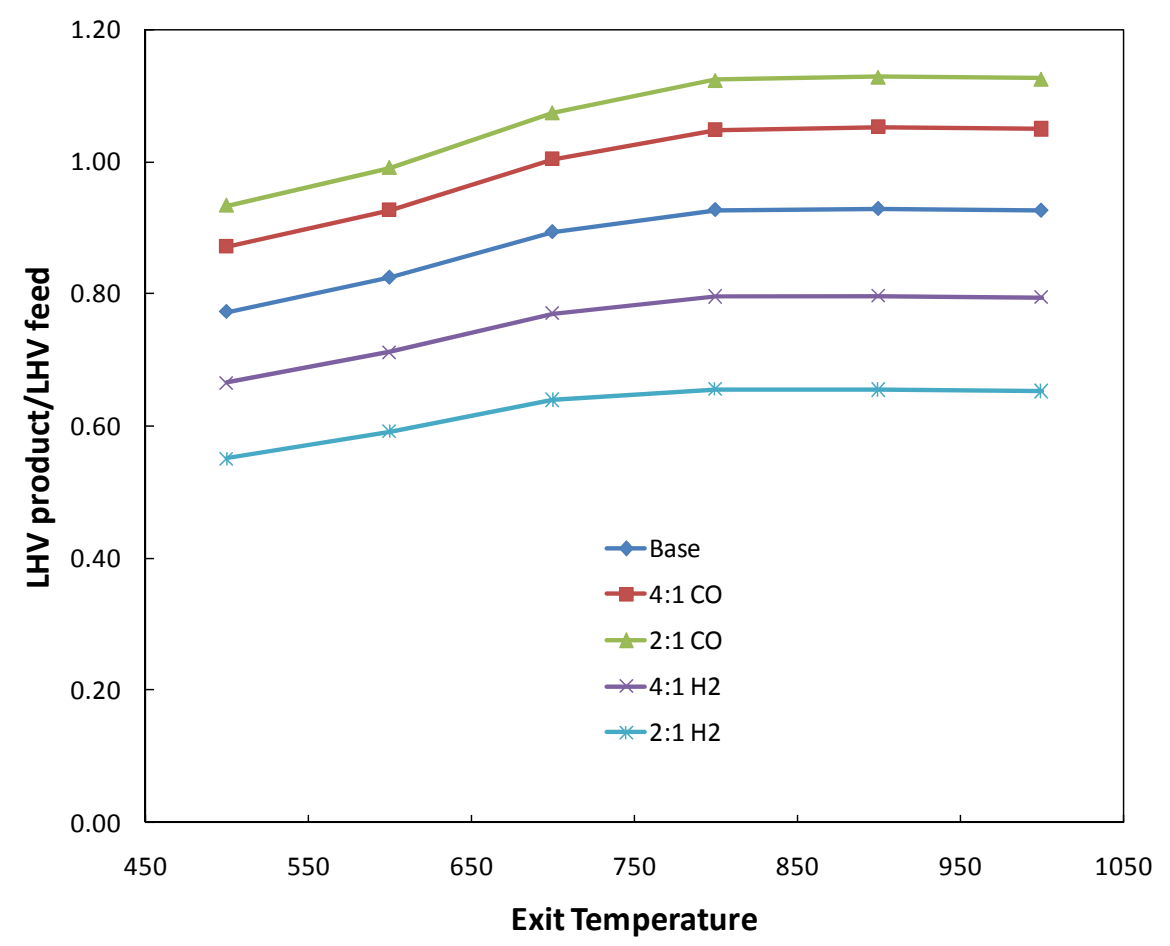

Figure 4.13. Reformer efficiency calculated as $L H V_{\text {out }} / L H V_{\text {in }}$.

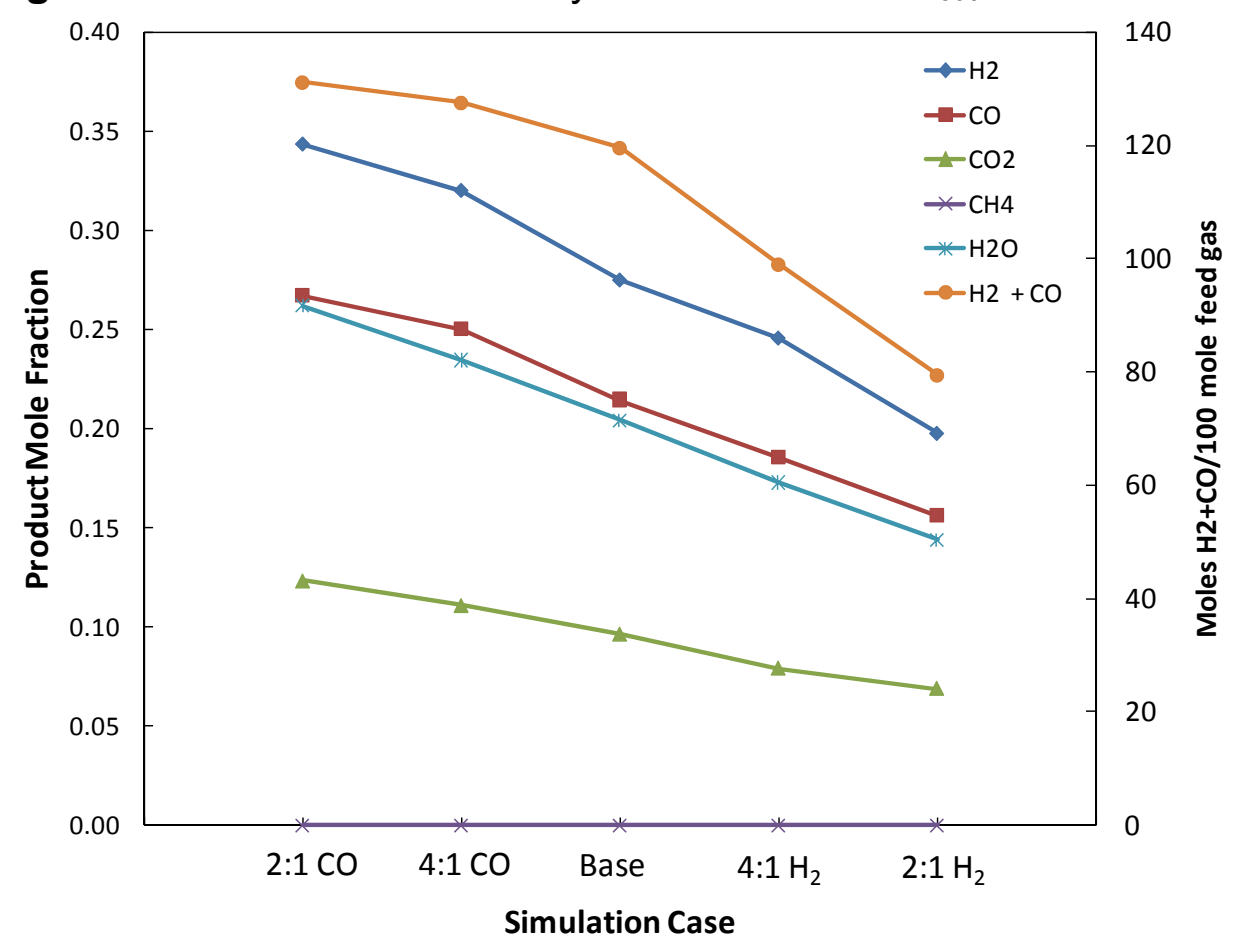

Figure 4.14. Product composition and SOFC fuel content $\left(\mathrm{H}_{2}+\mathrm{CO}\right)$ at $1000{ }^{\circ} \mathrm{C}$ exit temperature for model gasifier outputs. 


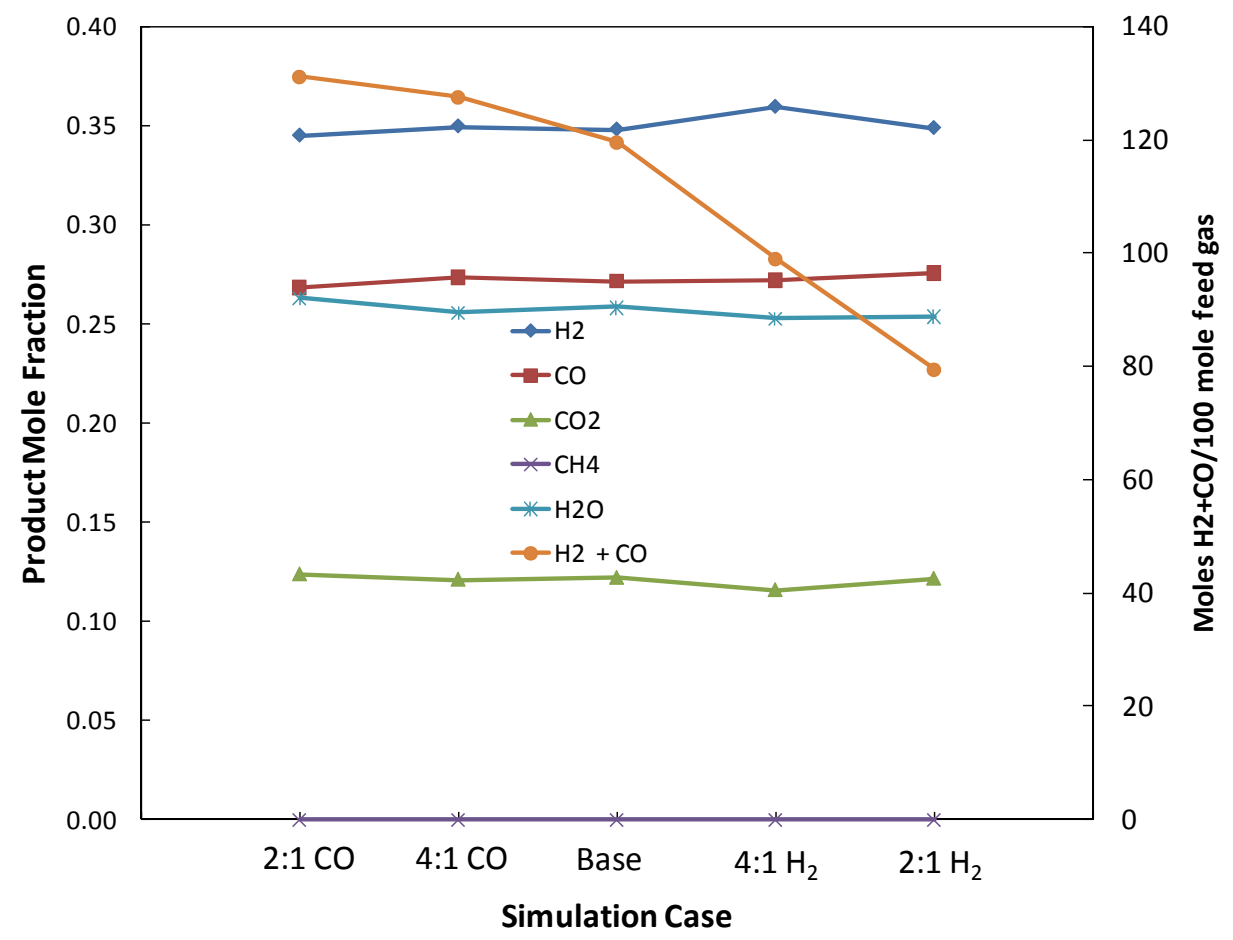

Figure 4.15. Product composition and SOFC fuel content $\left(\mathrm{H}_{2}+\mathrm{CO}\right)$ at $1000{ }^{\circ} \mathrm{C}$ exit temperature for model gasifier outputs.

Can $\mathrm{C} / \mathrm{H} / \mathrm{O}$ be measured?

While it may be attractive to design a reforming process based on gross composition mapping, to be useful the control scheme must be implementable in some fashion. Mixture composition can be measured through the use of gas chromatography, but this would result in discrete measurements of composition on the order of minutes apart, at best. Gas chromatography, however, is a relatively complex analytical tool, and at a minimum would require the supply of additional gases to the reformer system to the instrumentation. An ideal measurement would be continuous as well as robust, cheap, and based on a simple principle of detection. To this end, we have investigated whether any physical properties of the gasifier product mixtures might be used to determine the feed $\mathrm{C} / \mathrm{H} / \mathrm{O}$ composition.

As discussed above, inspection of

Figure 4.3 shows that the $\mathrm{C} / \mathrm{O}$ ratio of the different gasifier outputs is very close to 1.0. To determine the $\mathrm{C} / \mathrm{H} / \mathrm{O}$ ratio, then, only the $\mathrm{H}$ content must be measured. Figure 4.16 shows the dependence of feed gas heat capacity, thermal conductivity, and density on the $\mathrm{H}$ component of the $\mathrm{C}_{\mathrm{x}} \mathrm{H}_{\mathrm{y}} \mathrm{O}_{\mathrm{z}}$ composition. Each of these properties shows a reasonable correlation with $\mathrm{H}$ composition. Thermal conductivity is a simple measurement to make, and could provide a method to estimate the $\mathrm{C} / \mathrm{H} / \mathrm{O}$ composition of reformer feed gas in a continuous, real-time manner. This would be a key component of a reforming system coupled to a flexible feedstock reformer. 


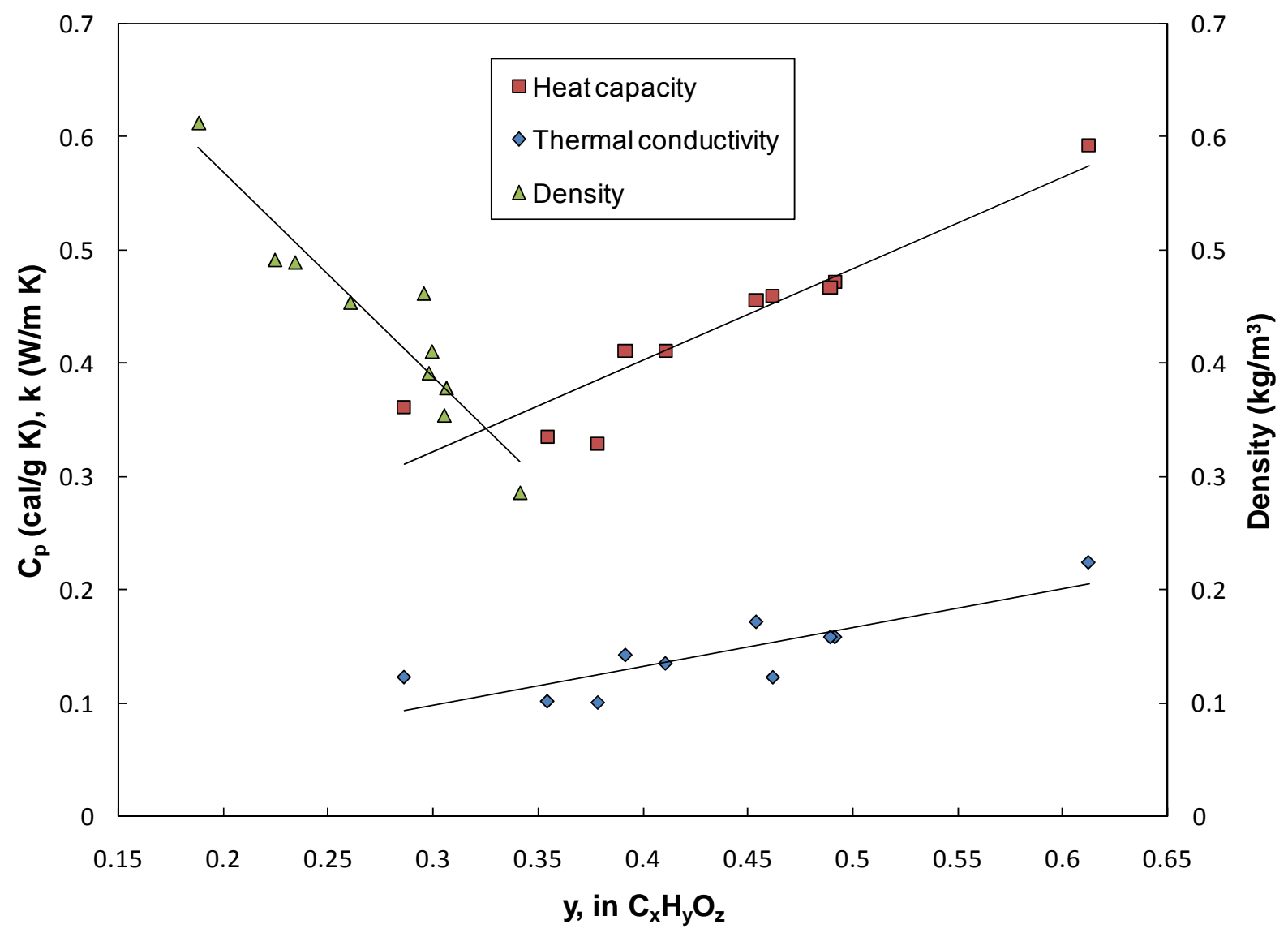

Figure 4.16. Dependence of heat capacity, thermal conductivity, and density on $\mathrm{H}$ content of gasifier product. 
TASK 5.0: CONSTRUCTION OF PROTOTYPE REFORMER UNIT

Task 5.0 - Based on the Task 4.0 design effort, recipient will assist in the procurement of the required components for construction of a compact prototype reformer unit. The prototype reformer system will be assembled along with a set of vaporizers and mass flow controllers permitting the feeding of a wide range of gas and condensable mixtures that closely resemble typical gasifier outputs. The system will also be equipped with a pressure-swing adsorption (PSA) unit for enriched air production, and with suitable heteroatom removal systems, to guard against sulfur poisoning of the catalyst bed. The prototype reformer system, once completely assembled, will be tested for safety and operability, and system

The first steps in the construction of the prototype reformer unit were to refine the process flow diagrams and physical layouts for the experimental reforming test system. This included calculations of required reactant flowrates and likely reactions occurring in the reformer, as well as review of commercially available process and analytical equipment which could be used in the experimental system.

Materials lists were developed for the reformer system and the lab space at NextEnergy, including parts and equipment to build the reformer, chemicals and lab supplies to support experimentation and catalyst synthesis, and suggested infrastructure for the lab space. This included securing quotations for a mass spectrometer, gas chromatograph, furnaces, mass flow controllers, lab benches and hoods, chemicals, solvents, and miscellaneous lab supplies such as glassware, a laboratory balance, personal protective equipment, etc. These materials lists were organized and transmitted to NextEnergy.

The process flow diagrams were finalized and a preliminary physical layout was designed using AutoCAD. Fittings, tubing, mass flow controllers, and a physical support structure were laid out in 3-dimensional CAD using dimensionally correct templates from Swagelok. This allowed for multiple design iterations which resulted in a simple, easily constructed system with excellent component access.

Figure 5.17 through Figure 5.19 present the process flow diagrams for the reformer system. Figure 5.20 through Figure 5.22 show several views of the completed reformer system. 


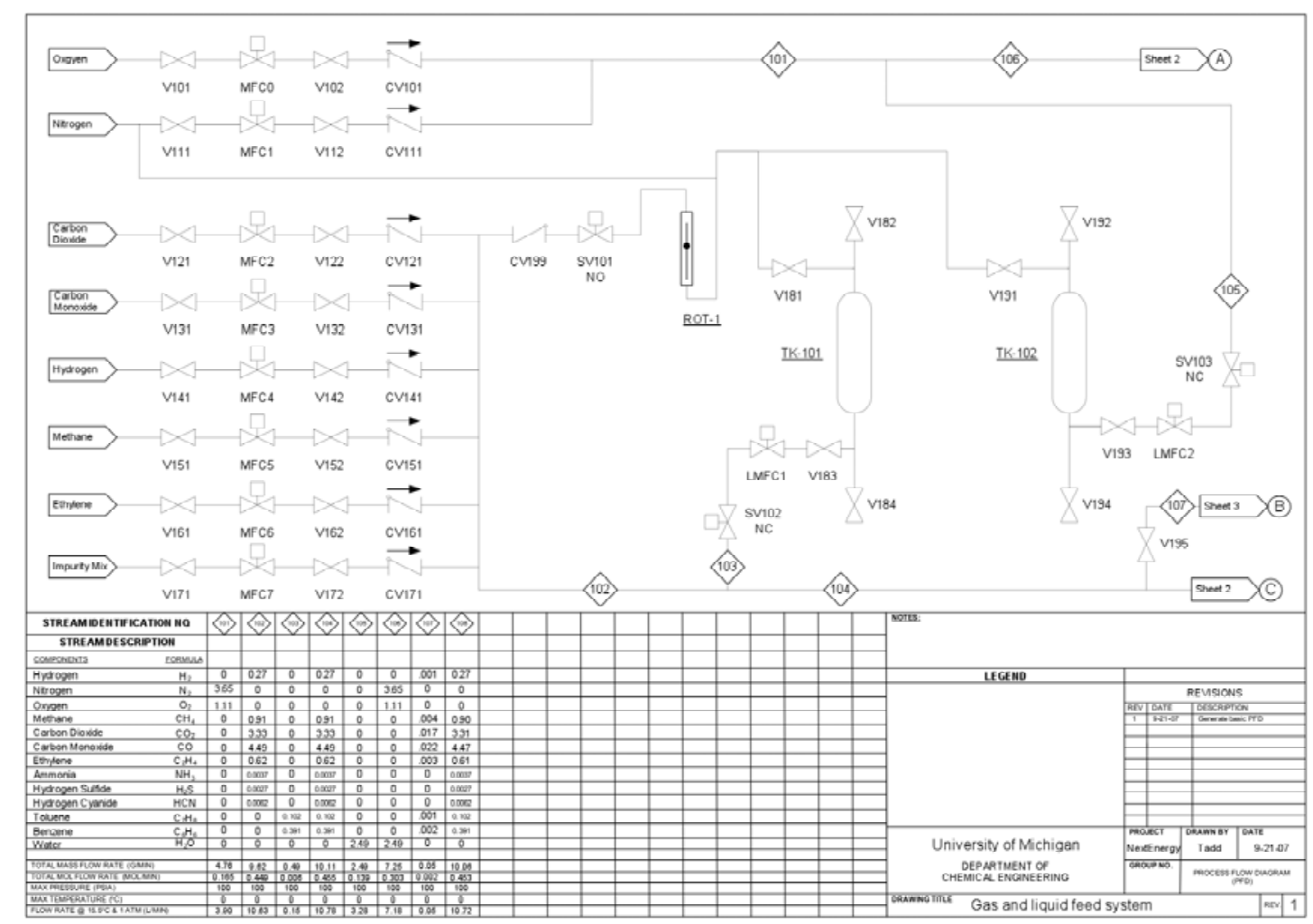

Figure 5.17. Process flow diagram for reformer system.

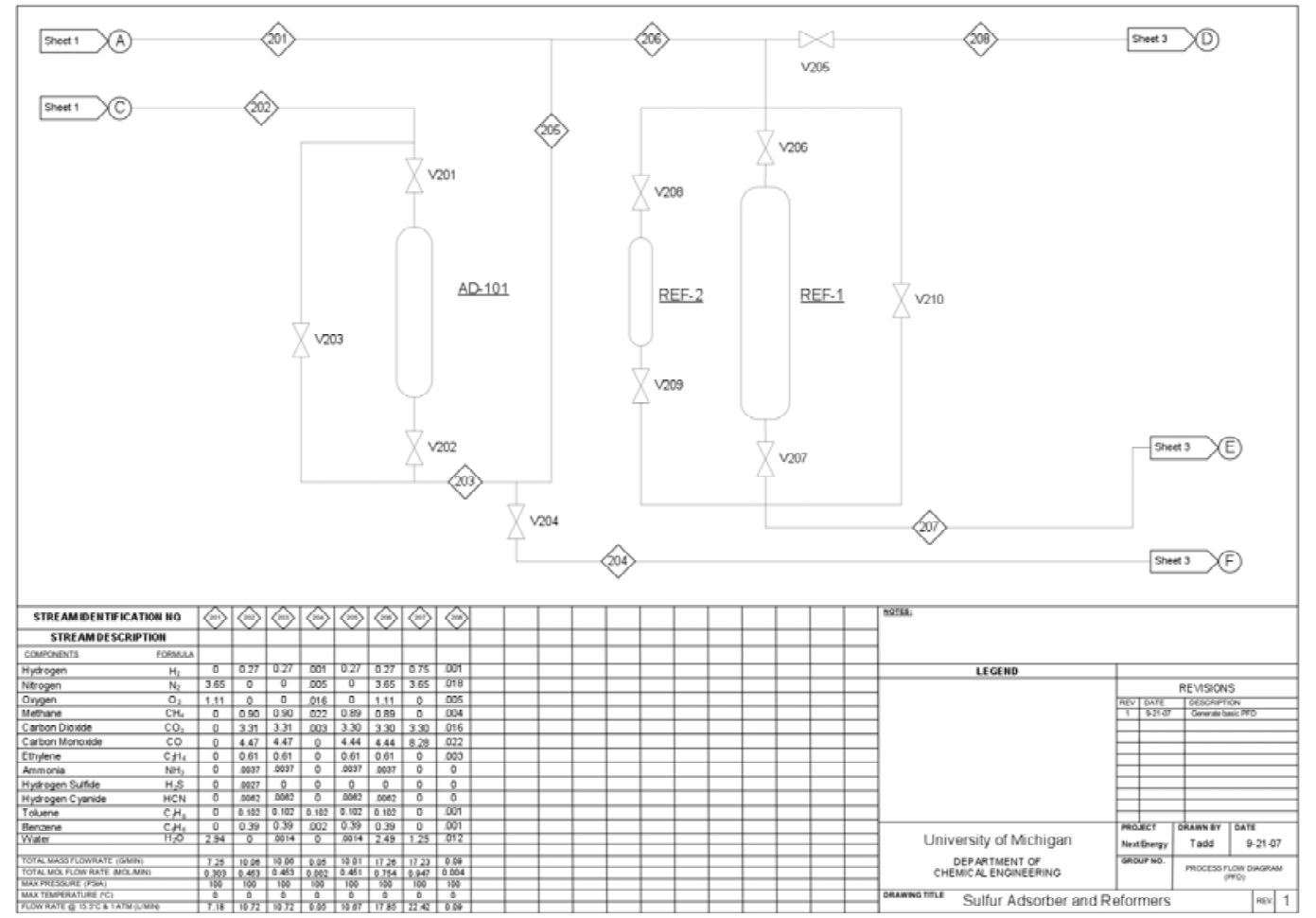

Figure 5.18. Process flow diagram for reformer system. 


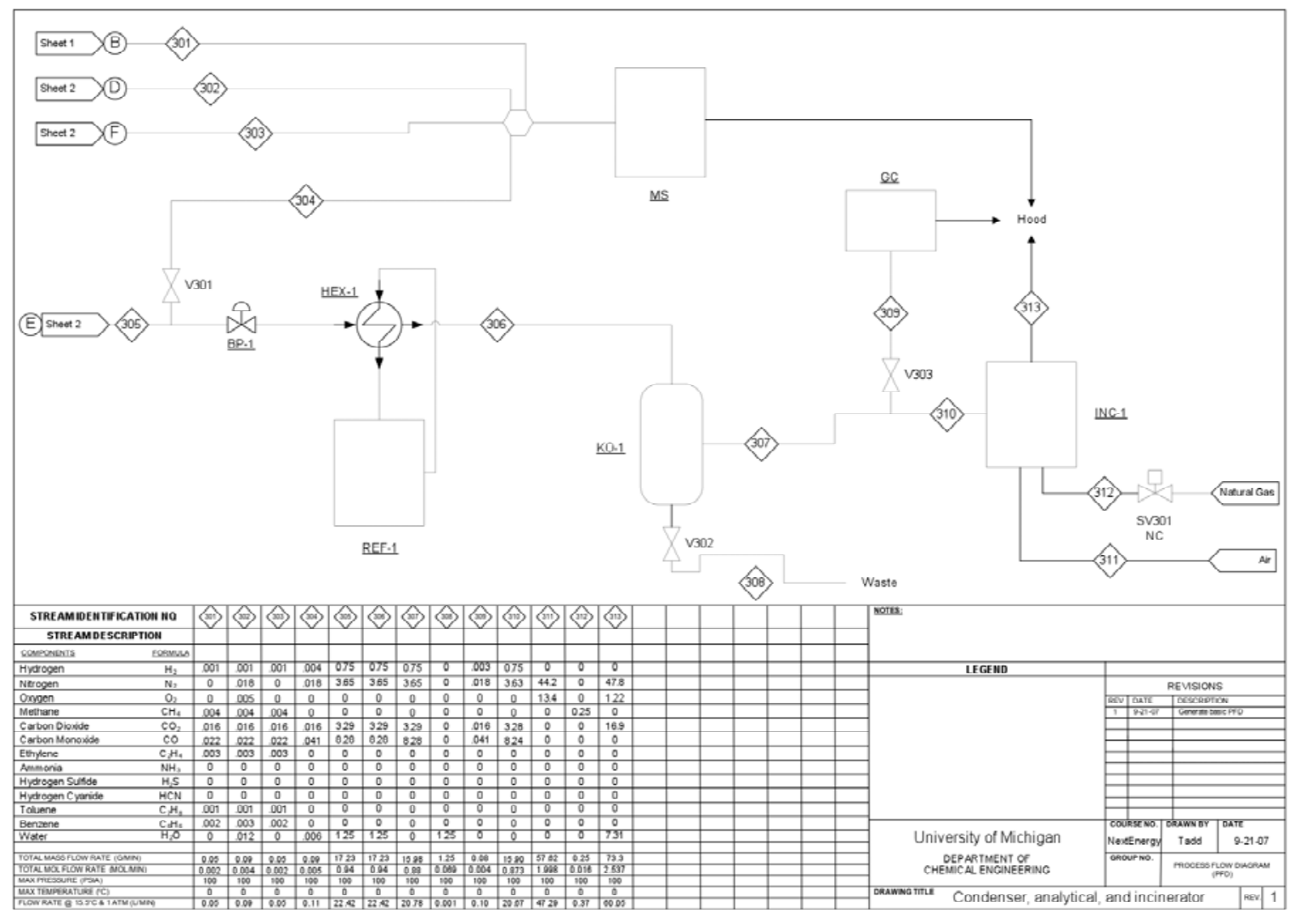

Figure 5.19. Process flow diagram for reformer system. 


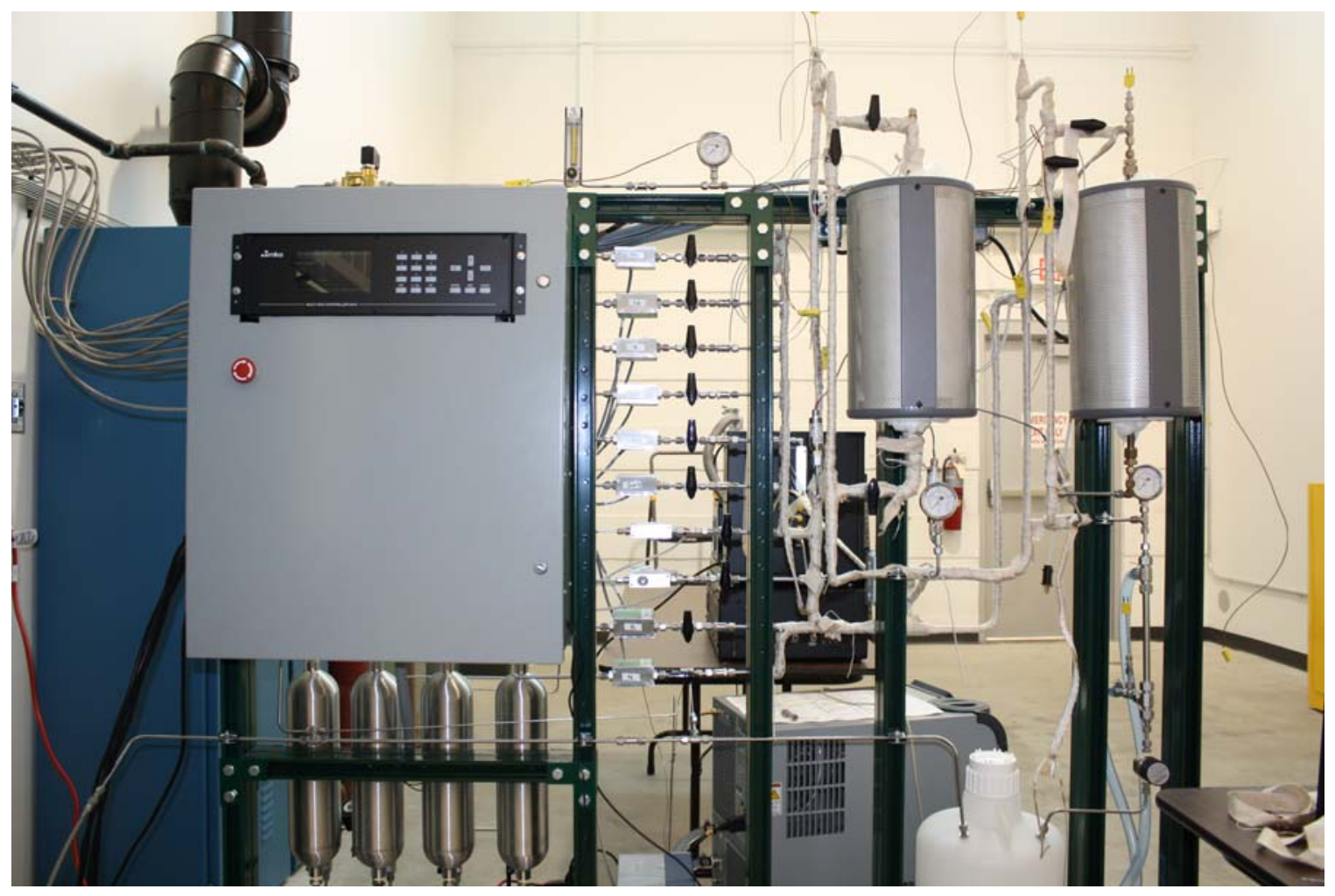

Figure 5.20. Front view of completed reformer system. 


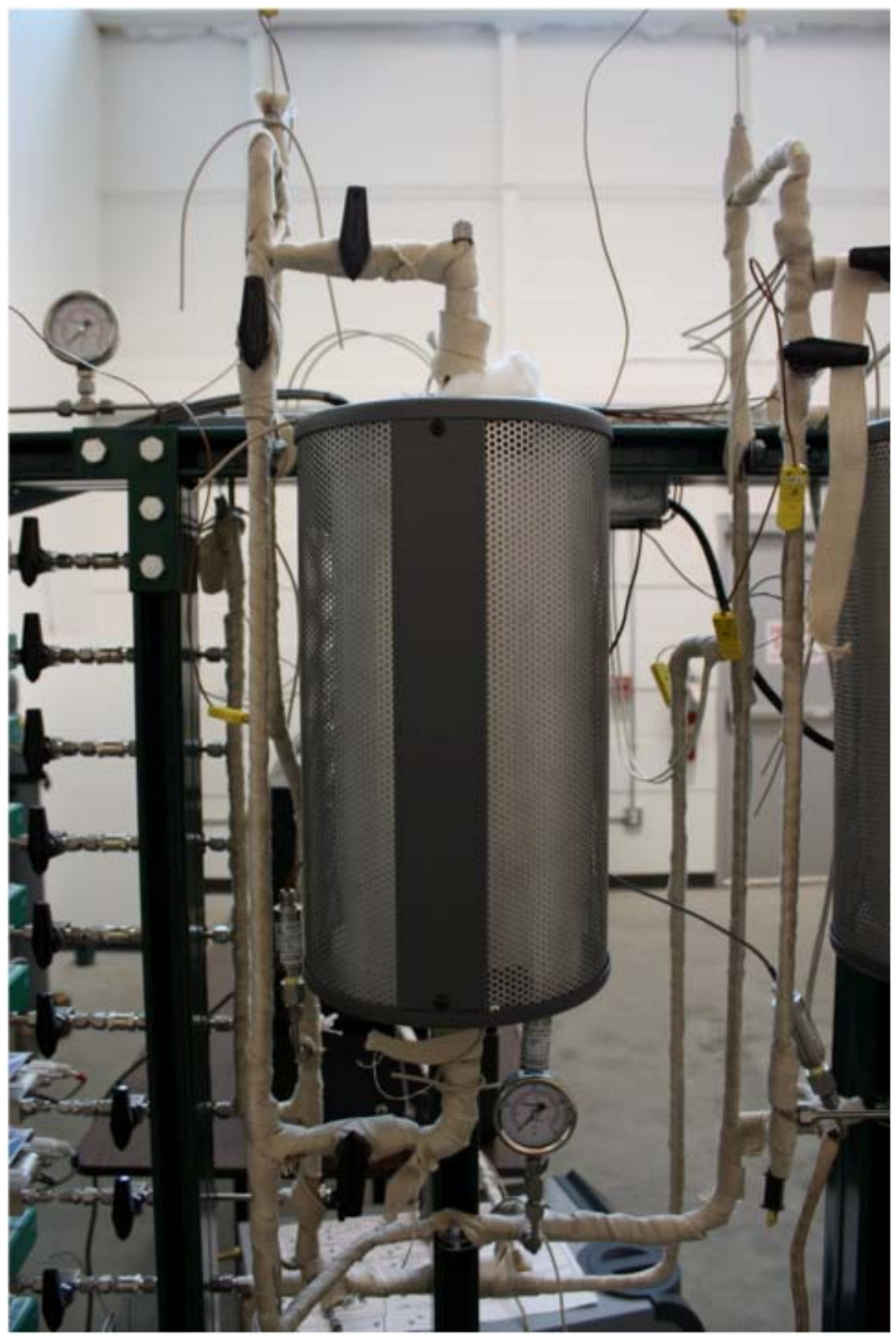

Figure 5.21. Close up of furnace housing catalytic reactor. 


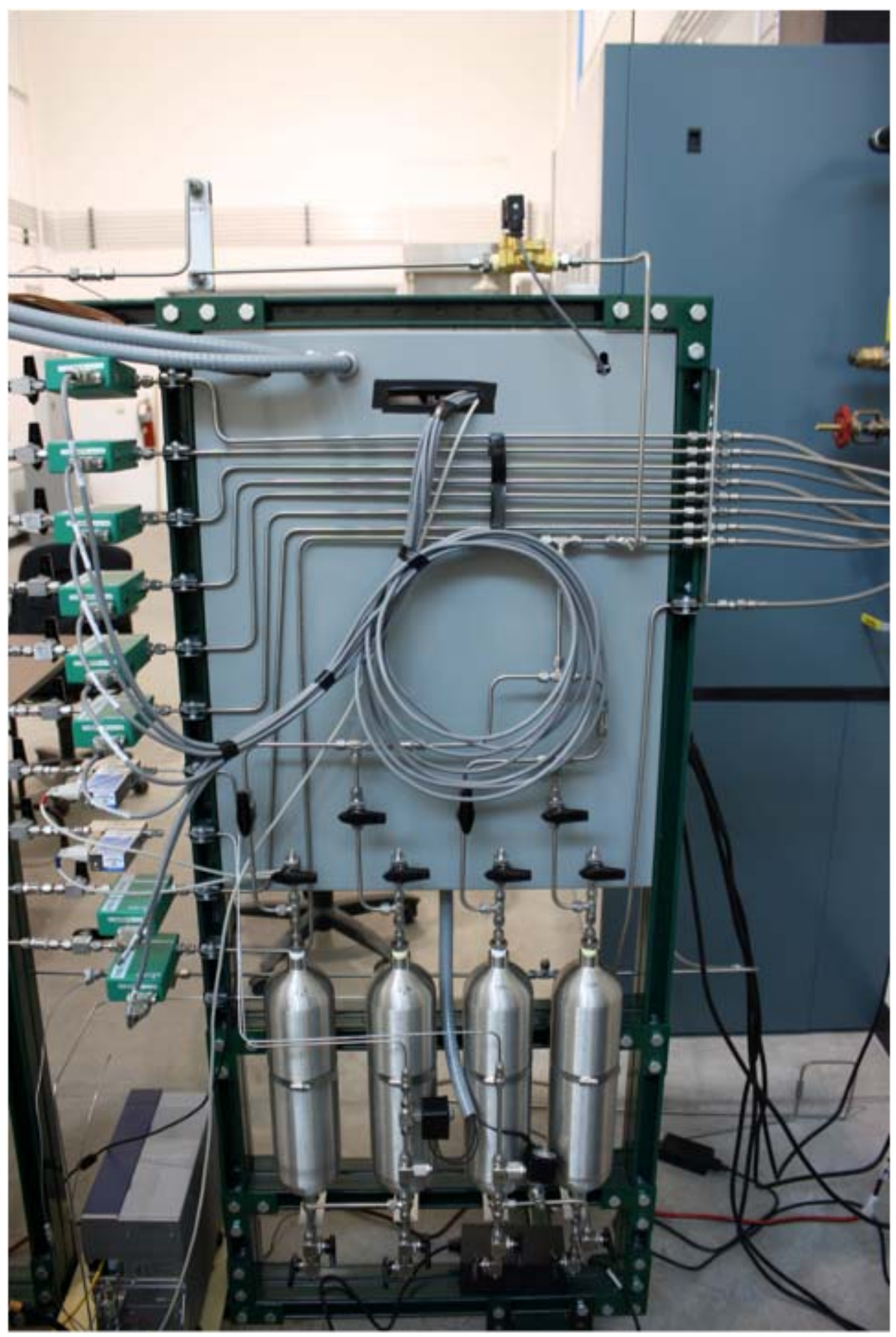

Figure 5.22. View of rear of completed reformer system. 
TASK 6.0: BENCHMARKING OF REFORMER CATALYST PERFORMANCE

Recipient shall test and evaluate the performance of the catalyst and reactor system using pure model compounds found in typical mixed feedstock gasifier products under autothermal reforming, steam reforming, and partial oxidation conditions. The reforming characteristics of compounds such as benzene or toluene will be systematically studied, followed by reforming of mixtures of increasing complexity. These mixtures will be obtained from bottled gases, including $\mathrm{CO}, \mathrm{CO}_{2}, \mathrm{H}_{2}, \mathrm{H}_{2} \mathrm{~S}$, cyanide, and hydrocarbon gases (the latter being one or more of methane, ethane, propane and butane); and benzene and toluene vapors generated in saturators. An important aspect of this task will be to develop a good understanding of the sulfur-tolerance of the reformer system, and, if needed, optimize the catalyst formulations to impart better resistance to sulfur. The reactor will be operated under conventional reaction conditions to determine product baseline selectivity and yield of $\mathrm{CO}$ and $\mathrm{H}_{2}$.

\section{Carbon Gasification}

Similar to hydrocarbon reforming, carbon gasification produces hydrogen, carbon monoxide and carbon dioxide from high temperature steam and a large hydrocarbon (in this case, coal or carbon). Although gasification technology has been studied for the better part of a century, its use as an industrially relevant source of energy and synthetic fuels has been limited in large part by the availability of crude oil. As demand - and in turn, price - of crude increases, alternative energy sources must be sought.

Coal gasification is one of the best short-term options toward this end. Alternative energy technologies, such as photovoltaics, wind energy, and fuel cells remain decades away from large-scale use. However, current estimates of coal reserves within the United States predict a supply on the order of 300-500 years. In addition, many new power plants - coal gasification power plants - are currently being built that offer superior efficiency and emissions to traditional coal fired power plants.

Further research into gasification catalysts could further reduce cost and improve emissions and efficiencies of these new gasification plants. In addition, development of cheap coal-based alternatives to crude oil would dramatically lower energy costs and relieve dependence on foreign energy.

For the initial gasification experiments (EXP\#1), activated carbon (SigmaAldrich, Norit) was placed into a $1 / 2$ inch (OD) quartz reactor tube. This tube was heated to $1100^{\circ} \mathrm{C}$ at a constant ramp rate of $5^{\circ} \mathrm{C} / \mathrm{min}$. When the temperature ramp began, water (flow rate of $\sim 0.1 \mathrm{~mL} / \mathrm{min}$ ) was pumped into heated lines $\left(\sim 160^{\circ} \mathrm{C}\right)$ in order to vaporize the water in the inert nitrogen stream flowing in the heated zone. A portion of the effluent gas was routed into the mass spectrometer (Hiden Analytical Systems, PIC MS) where the partial pressures of the following gases were measured: $\mathrm{N}_{2}, \mathrm{CO}, \mathrm{CO}_{2}, \mathrm{H}_{2}$. From these measurements, it is possible to determine the temperatures at which activated carbon reacts with water, via the gasification reaction.

In a later experimental procedure (EXP\#2), several changes were made. In place of a constant temperature ramp under steam/inert $\left(\mathrm{N}_{2}\right)$ flow, the temperature was ramped to a constant value $\left(800^{\circ} \mathrm{C}\right.$ on the furnace controller, 
$815^{\circ} \mathrm{C}$ on the thermocouple in the reactor). Once the temperature in the reactor stabilized and constant mass spectrometer readings were achieved, the water flow was introduced to an argon inert flow. Argon was used because, at molecular mass $=40$ atomic mass units (amu), it does not overlap signals with anything else in the mass spectrometer, as nitrogen does $\left(\mathrm{N}_{2}=28 \mathrm{amu} \& \mathrm{CO}=\right.$ $28 \mathrm{amu}$ ).

Initial results from the first experimental procedure, EXP\#1, show that nitrogen is the wrong inert carrier gas for this quantification technique: mass spectrometry. Figure 6.23 depicts typical data recorded from experiments done under EXP\#1 conditions. Consistently, nitrogen composition percentages were too large, while carbon monoxide values were too small. Deconvolution of the mass peak at 28 amu is theoretically sound, but experimentally difficult.

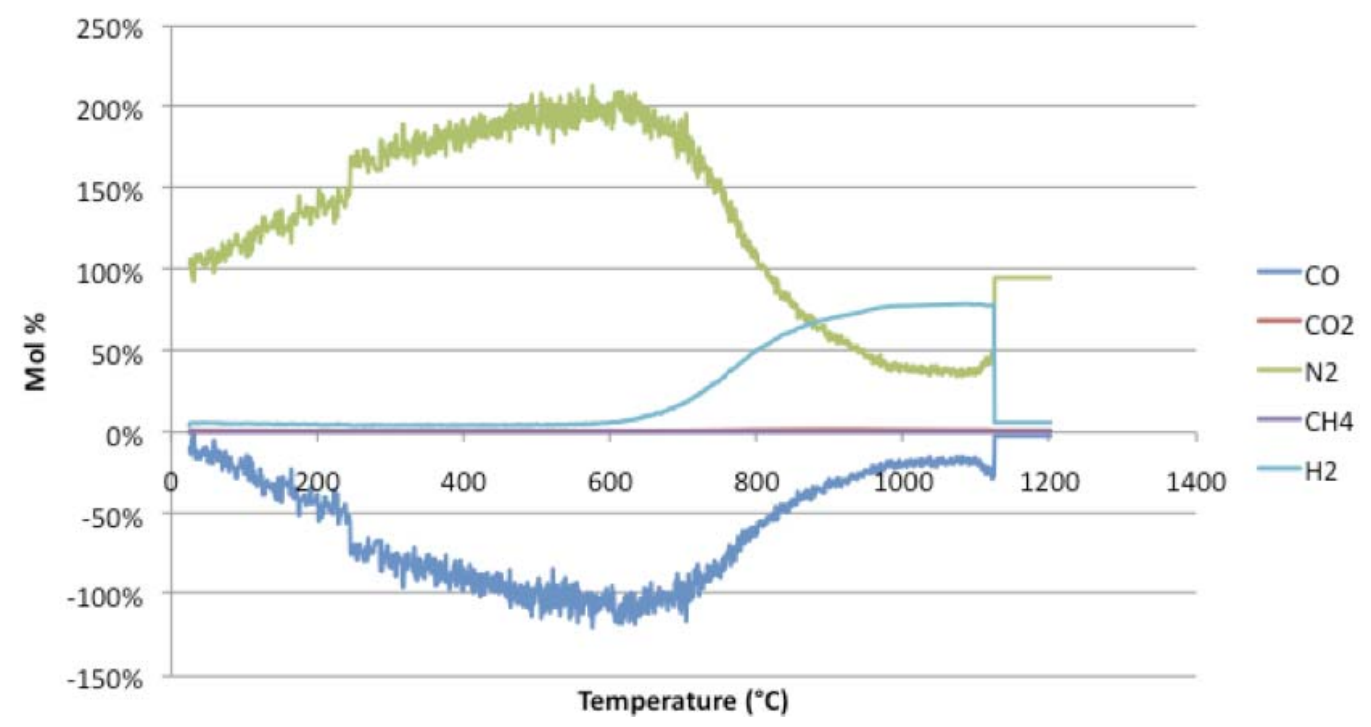

Figure 6.23. Gasification effluent gas composition for EXP\#1 procedure in the gasification of activated carbon (Norit, pelletized carbon). Even with calibration, gas composition values are erroneous (as seen by mole percents $>100$ and $<0$ ).

Therefore, experimental conditions were adjusted to EXP\#2, as described previously. After these changes were made, much more consistent and reasonable values were measured. Measurement repeatability was also tested for EXP\#2 (results shown in Figure 6.24); these results were much more acceptable than those from EXP\#1.

Regardless of which experimental procedure is used, hydrogen production via the gasification of carbon with water has been shown. These results serve to confirm the ability of the analytical system and basic protocols to characterize carbon gasification. 


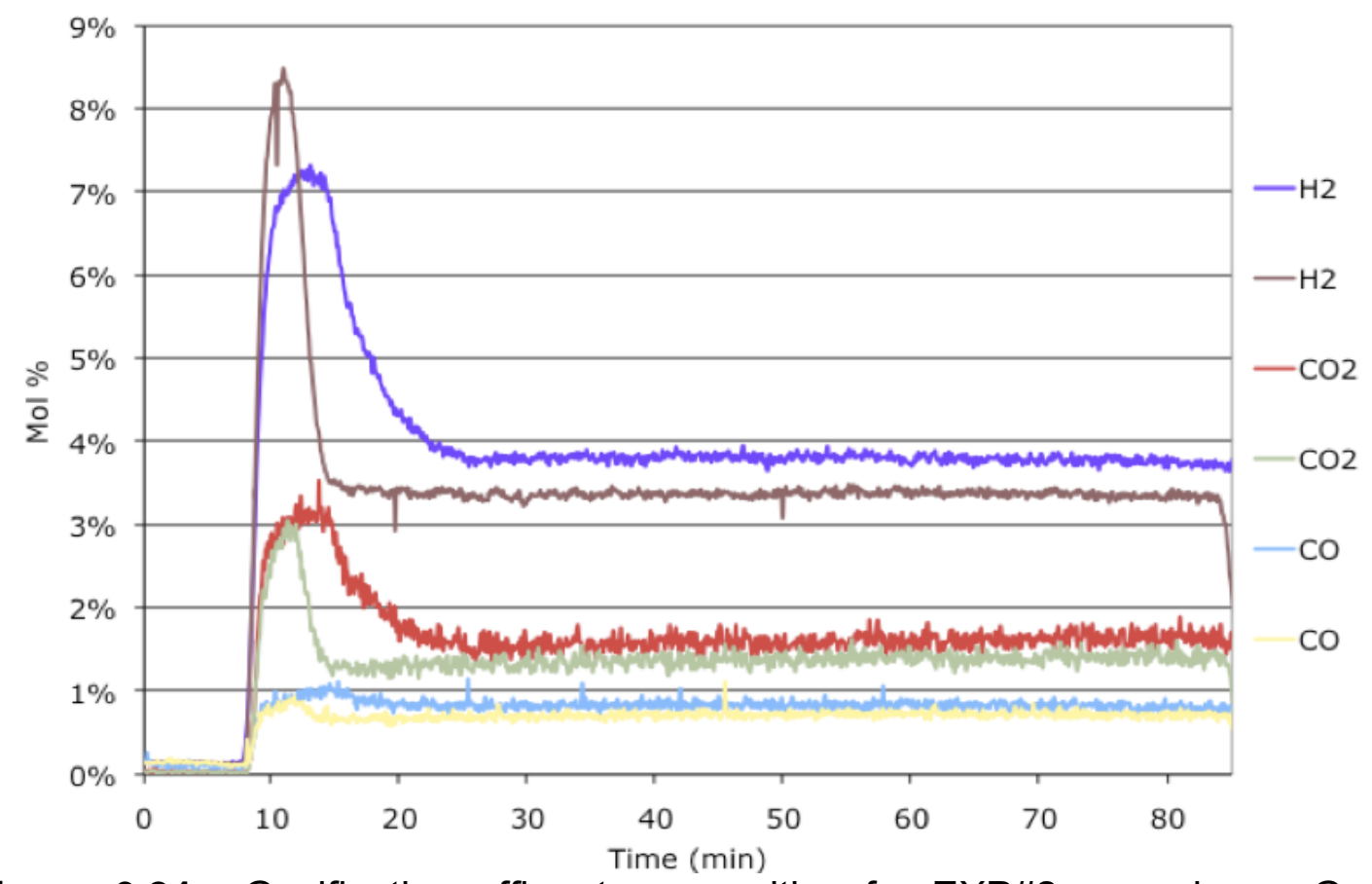

Figure 6.24. Gasification effluent composition for EXP\#2 procedure. Gases shown are: $\mathrm{H}_{2}, \mathrm{CO}$, and $\mathrm{CO}_{2}$. This test was repeated to verify results and repeatability. It can be seen that this reaction procedure produces repeatable results.

\section{Use of photocatalysts in assisting carbon gasification}

Photooxidation (photobleaching) rates of methylene blue dye using UVirradiated titanium dioxide power is a common method to determine photocatalytic activity. Therefore, photobleaching of methylene blue resting in the catalyst bed position would prove that UV light is, in fact, illuminating the catalyst bed. In addition, the UV-lamp power incident on the catalyst bed might also be determined, based on other published experimental observations. Although this test has not been completed, preliminary photobleaching studies have been completed on methylene blue dye using the current UV lamp.

As the aqueous solution of methylene blue and titanium dioxide is illuminated using a UV lamp, the dye degrades over time (modeled using common batch reactor models). If the solution is removed from the lamp at recorded time intervals and the concentration of methylene blue is measured, it is possible to determine reaction rate constants. In order to measure the methylene blue concentration, the solution was placed in a UV-Vis spectrometer and the solutions absorbance at $654 \mathrm{~nm}$ was measured. 


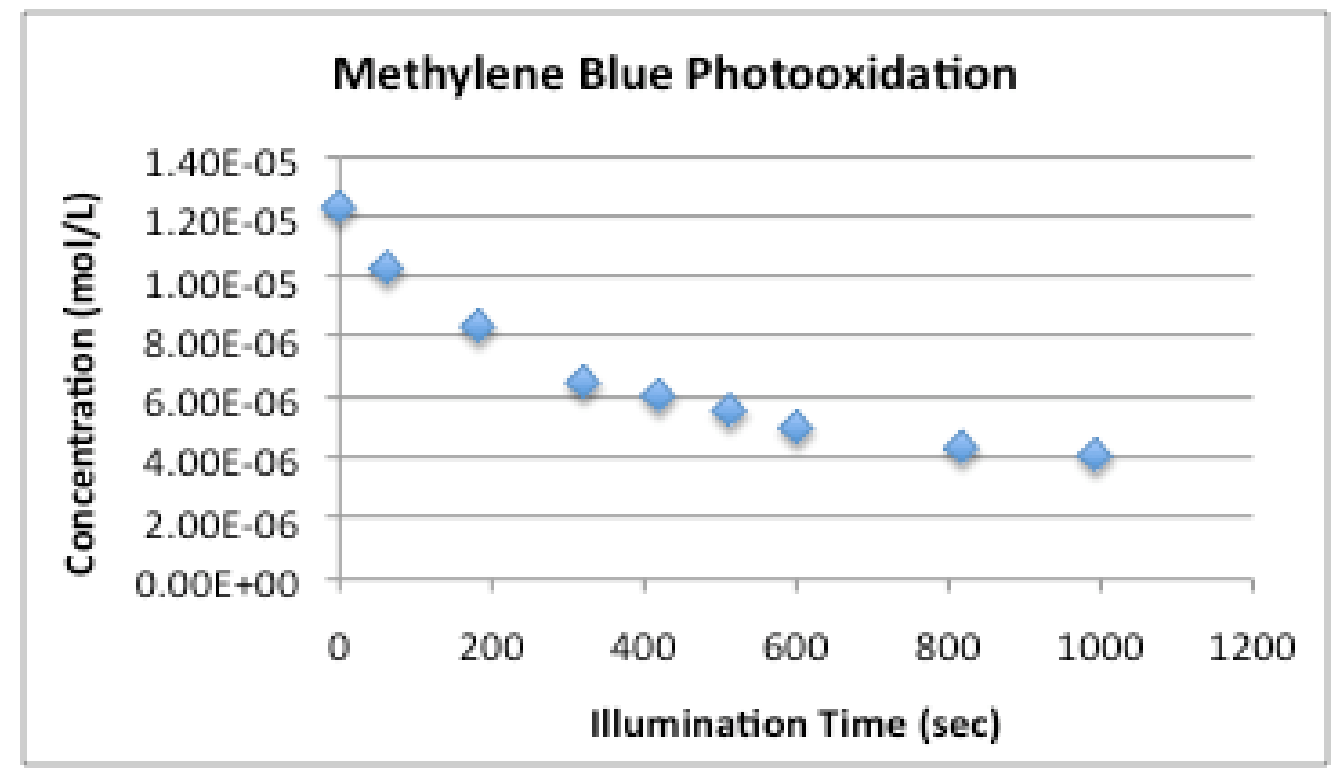

Figure 6.25. Photooxidation of methylene blue. Concentrations were calculated using UV-Vis spectrometer, calibrated with known methylene blue concentrations.

As shown in Figure 6.25, methylene blue concentrations follow an exponential decrease as a function of time. This result is expected, however, this data has not been fully compared to published work in order to assure that this experimental determination of UV lamp power is adequate. Initial results from this work suggest a rate constant of about $10^{7} \mathrm{~mol} \mathrm{~L}^{-1} \mathrm{~s}^{-1}$ of methylene blue degraded. Published data for this reaction rate can be as high as $10^{9} \mathrm{~mol} \mathrm{~L}^{-1} \mathrm{~s}^{-1}$ and vary with respect to experimental conditions.

One of the key challenges in testing photocatalysts, and more so in applying them, is achieving good illumination of the catalyst. In an effort to eliminate the problem of illumination of the catalyst bed, a pseudo-2D reactor was built. This type of reaction vessel orients a very thin catalyst bed over a large area. This is achieved via a thin milled surface in a stainless steel block, covered by a thick piece if quartz.

Several plate reactor designs were investigated in an effort to minimize construction cost, maximize ease of assembly \& disassembly, and improve reaction performance. COMSOL (a finite element modeling software) was used to investigate thermal loads under heating and reaction conditions, in addition to various flow schemes. It is necessary to maintain a uniform temperature profile on the catalyst bed. It is also necessary to have a uniform flow distribution across the catalyst bed. COMSOL modeling can show variations in both flow and temperature profiles.

The results of the COMSOL modeling show that the $2 \mathrm{D}$ plate reactor is designed to have very uniform temperature profiles along the catalyst bed. In addition, flow modeling suggests that various packing materials in the catalyst bed determine the uniformity of the flow velocity within the bed. Specifically, the addition of glass wool packing material before and after the catalyst bed produces the most uniform velocities throughout the bed. 


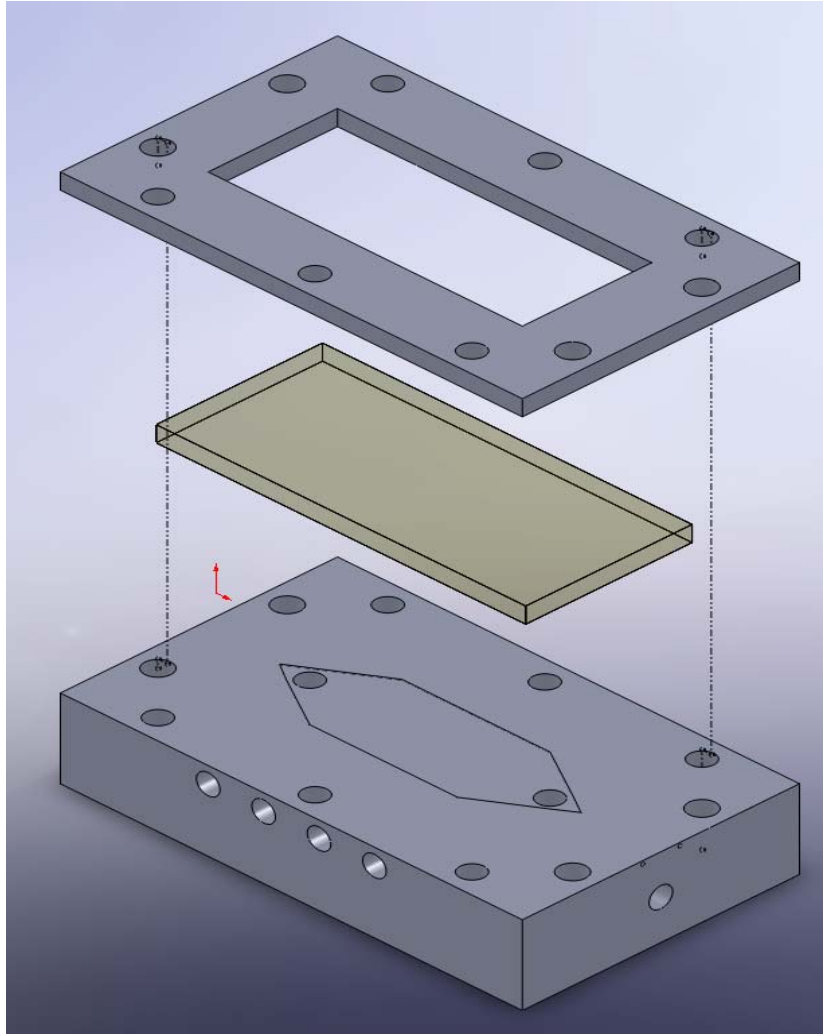

Figure 6.26. Exploded CAD view of the constructed plate reactor used for photocatalytic reforming experiments.

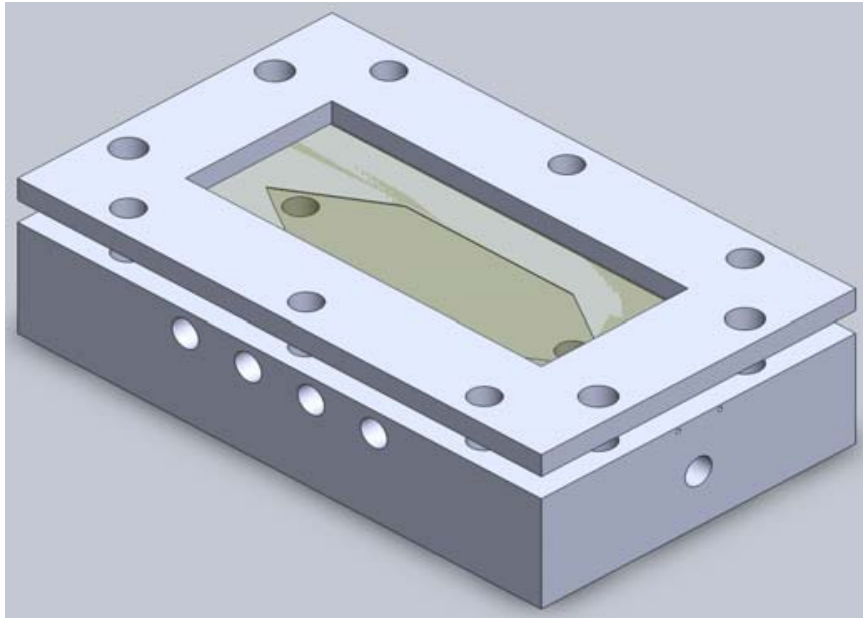

Figure 6.27. Collapsed CAD model of the constructed plate reactor. 


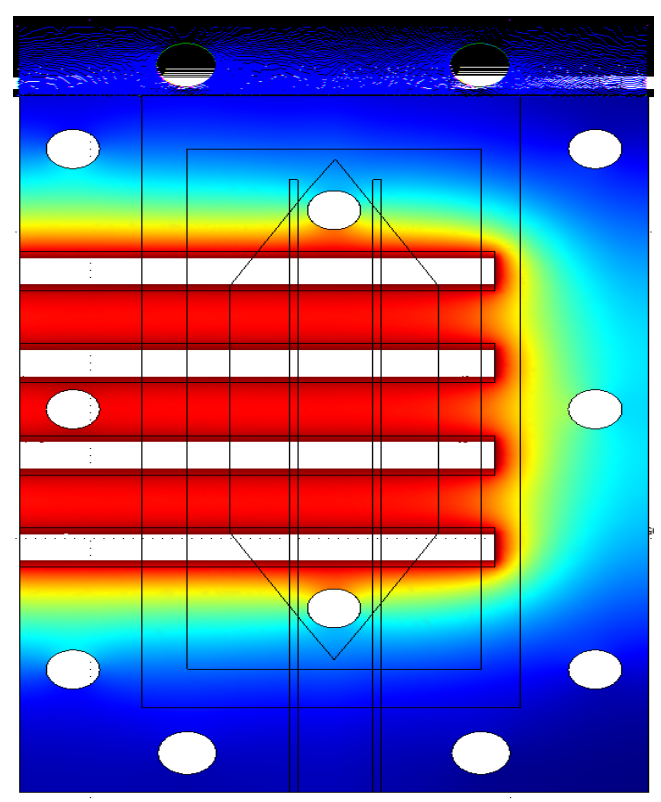

Figure 6.28. COMSOL thermal modeling of the plate reactor. Deep red areas indicate high temperature $\left(\sim 500^{\circ} \mathrm{C}\right)$, while the deep blue areas are $\sim 50^{\circ} \mathrm{C}$. Even heat distribution across the catalyst bed is of utmost importance.

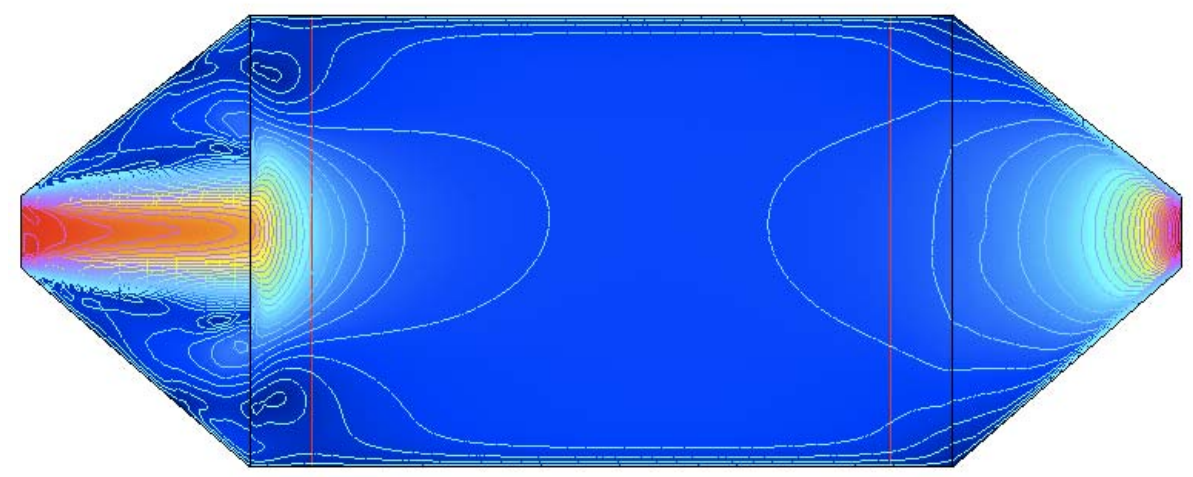

Figure 6.29. COMSOL fluid flow modeling of plate reactor. Red areas represent large flow velocities, while blue regions represent low flow velocities; light blue lines are lines of constant flow velocity. Uniform velocity fields across the catalyst bed are very important for reaction analysis. COMSOL allows various catalyst parameters to be changed, such as powder porosity and permeability when using porous flow governing equations. 
Another interesting design feature is the quartz cover plate and gasket material. The quartz window must be transparent to UV wavelengths, to allow photocatalytic reactions to take place. The quartz plate used is a GE type 124 material from Technical Glass, Inc. UV transmission experiments on this quartz show that it transmits more than $90 \%$ of the incident UV light at $365 \mathrm{~nm}$; this is acceptable for this application.

(Includes Surface Reflection Losses - Samples Tested 10mm Thick)

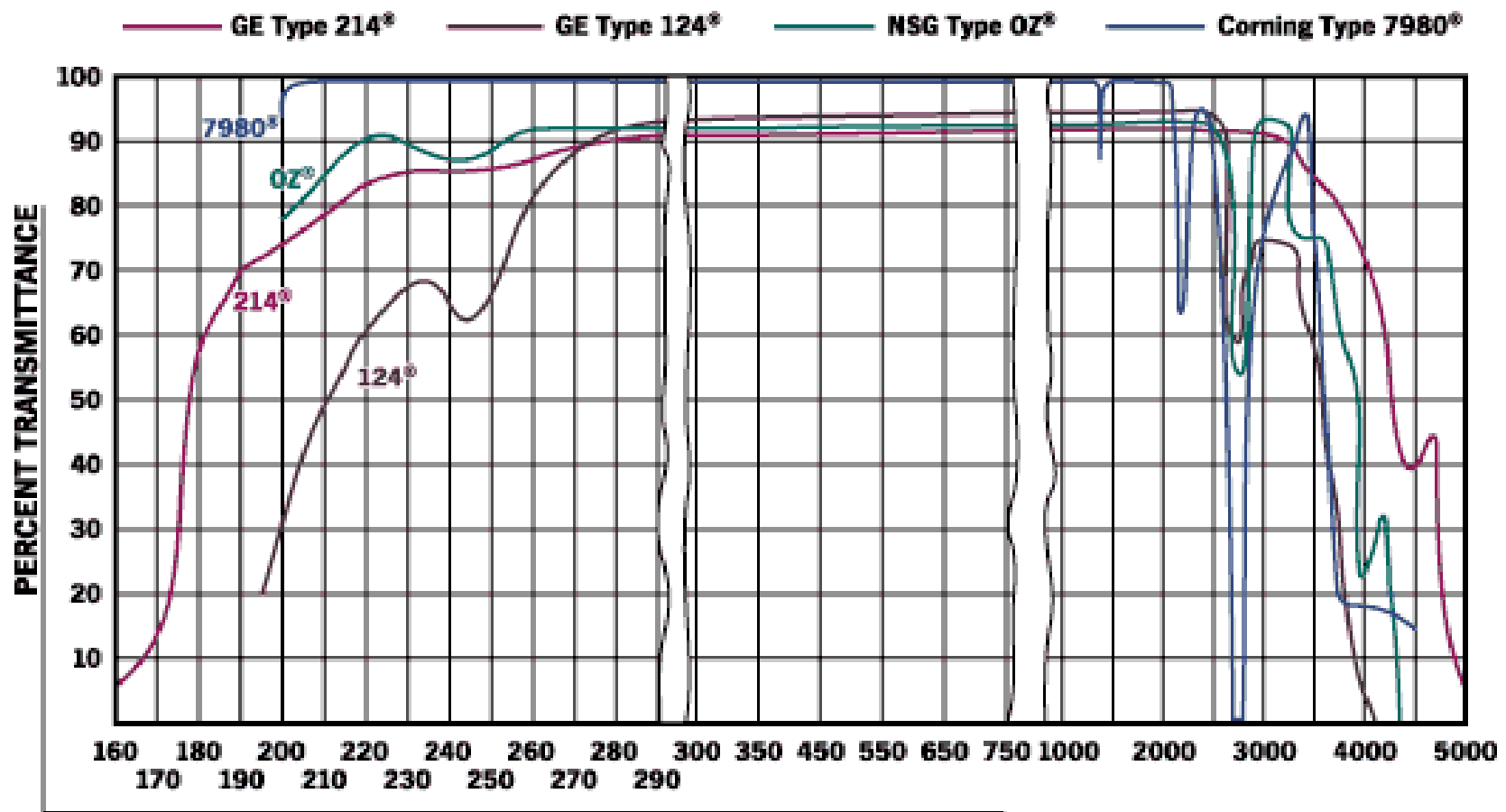

\section{WAVE LENGTH, NANOMETERS}

Figure 6.30. Transmission data for various quartz materials ${ }^{13}$.

The finished reactor has proven to be capable of reaching temperatures in excess of $700^{\circ} \mathrm{C}$ - far higher than anticipated. Methane autothermal reforming reactions were successfully performed in this $2 \mathrm{D}$ reactor at $600^{\circ} \mathrm{C}$. Although further changes and minor alterations have been envisioned, the initial build of this reactor has proved to be a viable option for studying photocatalytic systems.

In order to demonstrate such a photocatalytic process, one fundamental reaction was chosen: carbon monoxide oxidation (CO-Ox). Photocatalytic $\mathrm{CO}-\mathrm{Ox}$ is a reaction that has demanded considerable attention in the past decade ${ }^{14,15,16,17}$. In the presence of UV-light, titanium dioxide $\left(\mathrm{TiO}_{2}\right)$ acts as a low temperature catalyst for the oxidation of carbon monoxide and oxygen into carbon dioxide. Several experiments were conducted in the 2D reactor using a

\footnotetext{
${ }^{13}$ Image courtesy of Technical Glass Products: www.technicalglass.com

${ }_{14}^{14}$ Bosc, F., Ayral, A., Keller, N., Keller, V. Applied Catalysis B: Environmental. 69 (2007) 133-137.

${ }^{15}$ Dai, W., et al. ChemPhysChem. 10 (2009) 411-419.

${ }^{16}$ Kamegawa, T., et al. Catalysis Letters. 129 (2009) 7-11

${ }^{17}$ Ho, K. Y., Yeung, K. L. Gold Bulletin. 40 (2007).
} 
commercially available $\mathrm{TiO}_{2}$ (Degussa P25) as a catalyst. These experiments will be used to compare the baseline photocatalytic activity of $\mathrm{TiO}_{2}$ synthesized inhouse.

Synthesis of photoactive $\mathrm{TiO}_{2}$ was also conducted. Using a commercially available titanium precursor, titanium butoxide, several batches of $\mathrm{TiO}_{2}$ were synthesized. However, many of these batches failed to produce a uniform photocatalyst. The $\mathrm{TiO}_{2}$ photocatalyst batches that were successfully synthesized were characterized by Raman spectroscopy and Differential Scanning Calorimetry (DSC) to determine crystalinity and crystal phase - important factors for photocatalysts. For example, the anatase structure for $\mathrm{TiO}_{2}$ has a large bandgap $(3.2 \mathrm{eV})$, but another structure, rutile, has a smaller band gap (3.0 eV). Although the rutile form is able to use more of the solar spectrum, because of its smaller band gap, it has lower photocatalytic efficiency than anatase due to lower surface area. Each of these phases has significantly different vibrational structures in Raman spectroscopy. Raman can also be used to quantitatively determine the relative weight fractions of anatase and rutile $\mathrm{TiO}_{2}$ in a sample. However, Raman is useful only for crystalline structures. DSC is used to determine the weight fraction of amorphous $\mathrm{TiO}_{2}$ present in each sample ${ }^{18}$. DSC monitors the 'heat flow' in and out of a sample as it undergoes a temperature ramp in a furnace. When amorphous $\mathrm{TiO}_{2}$ undergoes a phase change into anatase $\mathrm{TiO}_{2}$ at $400^{\circ} \mathrm{C}$, a large amount of heat is released from the sample. This exothermic event can be monitored using a DSC. Further, this heat of crystallization is a known value; combined with the sample mass, one can calculate the weight of $\mathrm{TiO}_{2}$ that was crystallized from the DSC information. Therefore, the composition of $\mathrm{TiO}_{2}$ can be very accurately determined from these two techniques.

The oxidation of carbon monoxide is a bimolecular reaction whose product is carbon dioxide. The results from this test can be seen from the $\mathrm{CO}_{2}$ concentration in the reactor effluent stream. This data is presented in Figure 6.31 , below. The reactor temperature was ramped at $10^{\circ} \mathrm{C} / \mathrm{min}$ to $100,150,200$, and $250^{\circ} \mathrm{C}$ and held at each temperature for 2.5 hours. At each temperature increment, the UV-lamp was left off for the first hour, turned on for the second hour (indicated by black brackets in Figure 6.31), then turned off again for 0.5 hours. With this procedure, it is very easy to see periods of photoactivity of the $\mathrm{TiO}_{2}$ catalyst. Above $200^{\circ} \mathrm{C}$, the stainless steel $2 \mathrm{D}$ reactor began to catalyze the CO-oxidation reaction, which is evident by the large increase in baseline $\mathrm{CO}_{2}$ concentration.

${ }^{18}$ Ohtani, B., et al. J. Phys. Chem. B. 101 (1997) 3746-3752 


\section{CO Photocatalytic Oxidation}

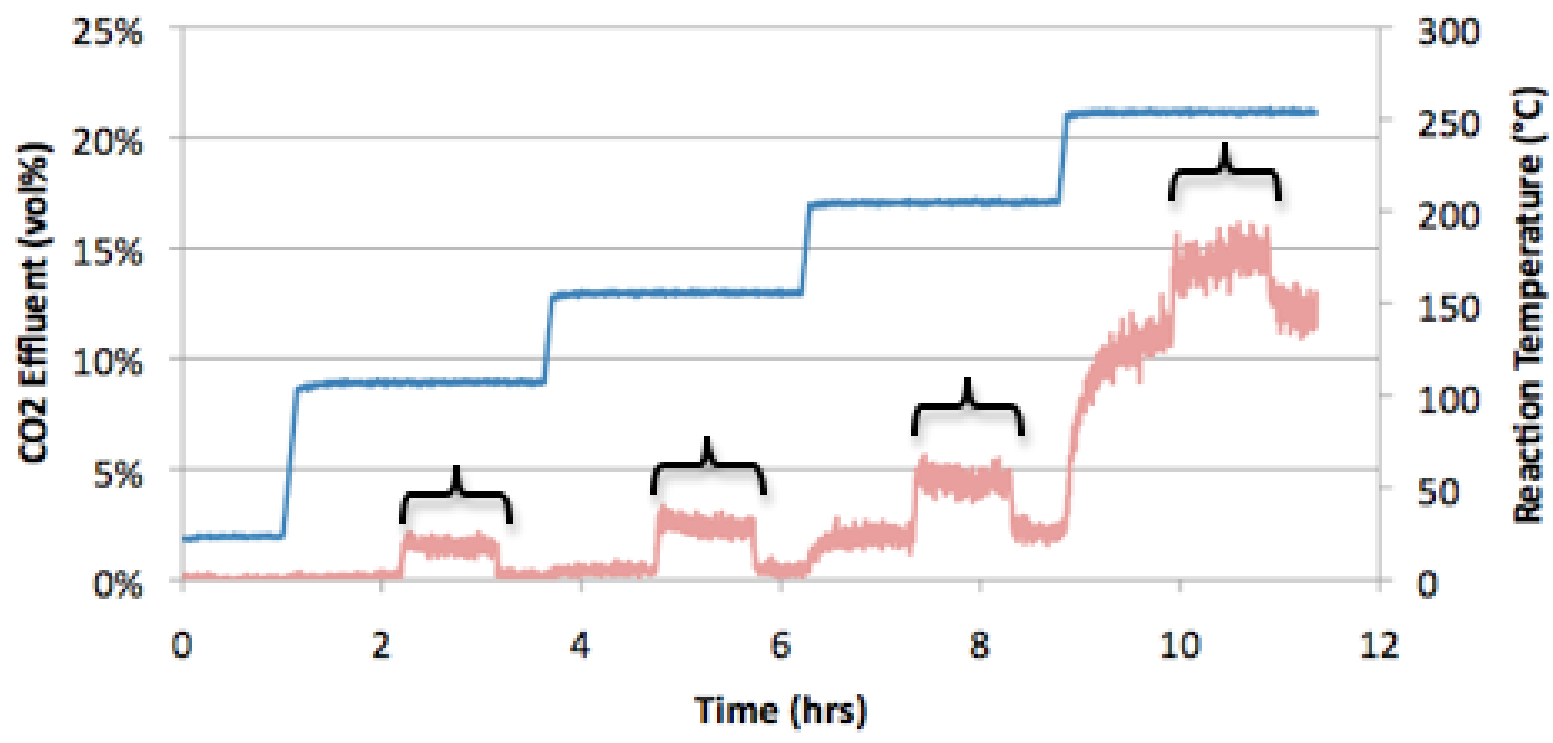

Figure 6.31. Photocatalytic CO-oxidation over Degussa P25 in the 2D reactor. Periods of photocatalytic activity are marked by the black brackets. The $\mathrm{CO}_{2}$ concentration is shown in red, while the temperature is shown in blue.

The Raman analysis performed on the synthesized $\mathrm{TiO}_{2}$ shows that the largest crystalline phase present is anatase - a very photoactive phase of $\mathrm{TiO}_{2}$. After calcination at $700^{\circ} \mathrm{C}$ for 5 hours, much of the fluorescence (associated with amorphous $\mathrm{TiO}_{2}$ and residual precursor material) is gone, and some rutile formation is observed. Figure 6.32 shows these two spectra; vibrational modes for anatase and rutile crystal phases are marked with 'A' and ' $R$ ', respectively. The regions of the pre-calcination sample that are marked with a star are possibly attributed to a third phase of $\mathrm{TiO}_{2}$ : brookite. However, these vibrational modes are not observed in the samples after calcination. 


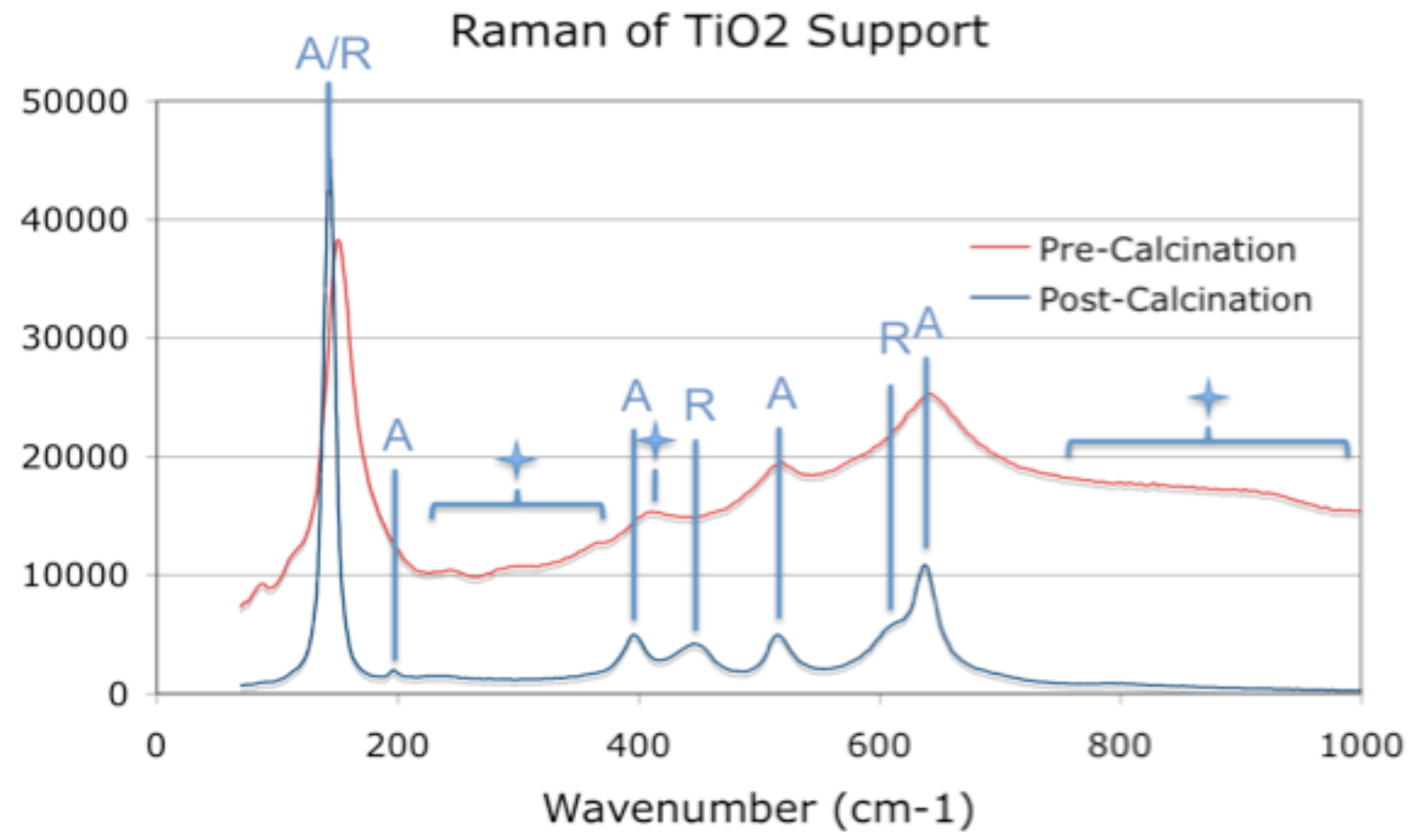

Figure 6.32. Raman spectra of the synthesized $\mathrm{TiO}_{2}$ photocatalyst before and after calcination at $700^{\circ} \mathrm{C}$ in air.

Differential Scanning Calorimetry reveals what fraction of the synthesized $\mathrm{TiO}_{2}$ is amorphous $\mathrm{TiO}_{2}$. Figure 6.33 shows the data from these two experiments. In the pre-calcination sample, two peaks can be readily seen (as indicated by the downward-pointing arrows). The left-most peak (at $400^{\circ} \mathrm{C}$ ) indicates the transformation of amorphous $\mathrm{TiO}_{2}$ into anatase $\mathrm{TiO}_{2}$, while the higher temperature peak represents a phase change from anatase to rutile $\mathrm{TiO}_{2}$. It is apparent that the pre-calcination sample contains amorphous $\mathrm{TiO}_{2}$ while the post-calcination sample does not. By integrating the $400^{\circ} \mathrm{C}$ peak in Figure 6.33, one can calculate the mass fraction of amorphous $\mathrm{TiO}_{2}$ present in the precalcination sample. From these two analytical techniques, the weight fractions of amorphous, anatase, and rutile $\mathrm{TiO}_{2}$ were calculated and presented in Table 6.6. 


\section{TiO2 Crystallization}

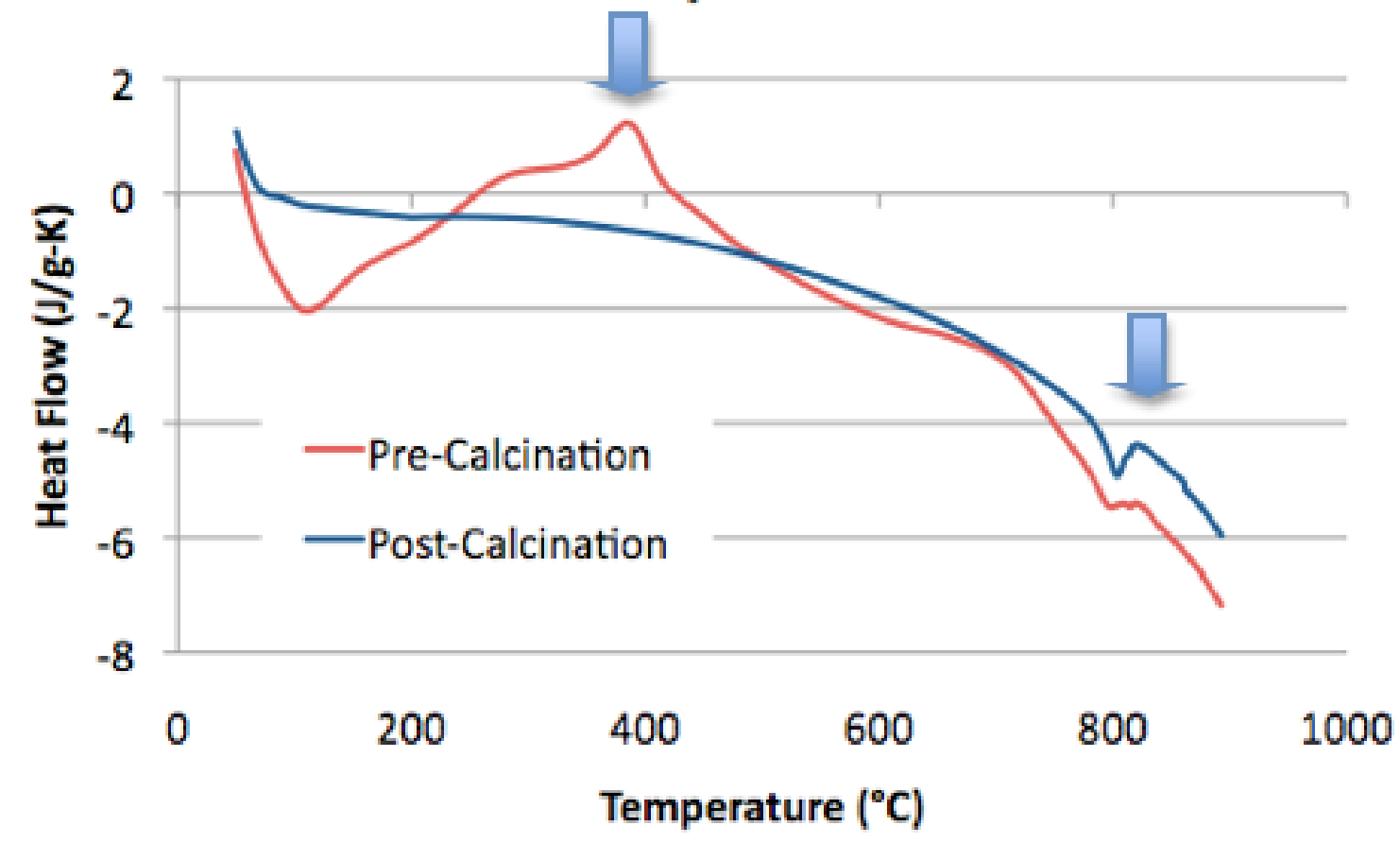

Figure 6.33. Differential Scanning Calorimetry heat flow measurements taken from the $\mathrm{TiO}_{2}$ photocatalyst before and after calcination at $700^{\circ} \mathrm{C}$ in air.

Table 6.6. Crystalinity and $\mathrm{TiO}_{2}$ phase determination for synthesized $\mathrm{TiO} 2$.

\begin{tabular}{|l|l|l|l|}
\hline & wt\% Amorphous & wt\% Anatase & wt\% Rutile \\
\hline Pre-Calcination & $20.4 \%$ & $79.6 \%$ & $0 \%$ \\
\hline Post-Calcination & $0 \%$ & $43.0 \%$ & $57.0 \%$ \\
\hline
\end{tabular}

The initial test of photocatalytic activity is the photo-oxidation of ethylene or carbon monoxide. Although both reactions can be photo-catalyzed, they each follow different mechanistic routes. To build towards photooxidation of hydrocarbons, work was started using ethylene. Prior to each test, the 2D plate reactor is packed with photocatalyst. The system is flushed with air for a minimum of 1 hour to remove impurities, such as water. The temperature of the reactor is then ramped to $400^{\circ} \mathrm{C}$ at $3^{\circ} \mathrm{C} / \mathrm{min}$ while the FTIR captures spectral information of the effluent stream. Previously, the mass spectrometer recorded this data. Each test is repeated at least twice: one test without the UV light on, and one test with the UV light on. This allows for baseline activity subtraction.

Experiments conducted using the mass spectrometer as an analytical instrument proved to have an unacceptable signal-to-noise ratio for $\mathrm{CO}_{2}$ concentration measurements. This persisted for experiments with and without UV irradiation. However, identical experiments that utilized a very small gas flow 
cell in the FTIR showed improved $\mathrm{CO}_{2}$ concentration measurement, albeit only at high reactor temperature $\left(T>350^{\circ} \mathrm{C}\right)$.

In order to maximize FTIR sensitivity to $\mathrm{CO}_{2}$, a gas flow cell was designed

to fully occupy the FTIR light path in the Bruker ${ }^{\mathrm{TM}}$ FTIR. The installation and testing of this gas flow cell showed drastically increased $\mathrm{CO}_{2}$ sensitivity.

\section{Conclusions}

The plate reactor has proven to work well for methane steam reforming. Using $10 \mathrm{wt} \% \mathrm{Ni} / \mathrm{CZO}$ catalyst (made previously in this lab), steam reforming products began to appear at catalyst temperatures above $400^{\circ} \mathrm{C}$, which is consistent with experimental data from other researchers.

Mass spectrum calibration has resulted in very stable and accurate effluent gas analysis. In addition, the current data collection technique allows the user to revisit old data to check for the presence of unexpected compounds. This is in stark contrast to the previous data collection technique, which required the user to guess in advance the gases to analyze and save.

The $2 \mathrm{D}$ reactor has proven capable of reaching autothermal reforming temperatures. More importantly, it can be used for photocatalytic reactions, as shown by the CO-Ox experiments completed on commercially available $\mathrm{TiO}_{2}$.

Titanium dioxide synthesis techniques are also improving. The most recent synthesis has produced anatase and rutile $\mathrm{TiO}_{2} ; \mathrm{CO}-\mathrm{Ox}$ tests need to be completed to determine photocatalytic activity of the synthesized material in comparison to commercially available Degussa P25.

The use of the Bruker FTIR as an analytical instrument showed enhanced sensitivity and a lower detection limit for $\mathrm{CO}_{2}$ than the previously used Hiden Analytical Mass Spectrometer. In addition, the FTIR was easily modified to further increase $\mathrm{CO}_{2}$ detection. As this new capability as been added to the photocatalytic characterization apparatus, it should be calibrated. 


\section{Effects of sulfur on reforming catalysts}

Deactivation of transition-metal catalysts due to sulfur poisoning remains a major challenge in processing feedstocks with even low sulfur contents. More detailed investigation of process conditions and catalyst properties is needed to define the limits of operation and identify new avenues for imparting sulfur tolerance. A series of investigations were conducted to determine the effect of different types of sulfur contaminants on the autothermal reforming of isooctane.

For these experiments $10 \mathrm{wt} \% \mathrm{Ni}$ supported on a ceria-zirconia support was used. The support was prepared via coprecipitation. The metal loading was performed using the incipient wetness impregnation method. The support and final precursor were both calcined at $900^{\circ} \mathrm{C}$. Prior to reaction the catalyst was reduced under an atmosphere of $5 \% \mathrm{H}_{2}$ at $600^{\circ} \mathrm{C}$.

The initial reaction conditions considered for these experiments were an oxygen-to-carbon ratio of 0.75 , a steam-to-carbon ratio of 1.0 , a gas hourly space velocity of $200,000 \mathrm{~s}^{-1}$, a fuel delivery rate of $0.4 \mathrm{~g} / \mathrm{min}$, and a total time-onstream of 24 hours. Experiments were performed with no sulfur present and then compared to runs contaminated with sulfur. Thiophene, $\mathrm{H}_{2} \mathrm{~S}$, and $\mathrm{SO}_{2}$ were considered to compare the effects of different types of sulfur contaminants. For the thiophene experiments the fuel was switched on-stream to fuel containing thiophene at a concentration of $100 \mathrm{ppmw}$ (comparable to commercial gasoline concentrations). For the $\mathrm{H}_{2} \mathrm{~S}$ and $\mathrm{SO}_{2}$ experiments the contaminants were fed in the gas phase such that there was an equivalent molar sulfur concentration in the gas phase feed to the reactor as the experiments involving thiophene.

The flow reactor used was equipped with rotary peristaltic pumps for delivery of the liquid reactants. Mass flow controllers controlled the delivery of gaseous reactants. The reactant stream was preheated to vaporize liquids before being fed to a $1 / 2$ " quartz tube in a furnace. The furnace preheated the feed to $500^{\circ} \mathrm{C}$ before it was exposed to the catalyst bed supported in the quartz tube by a plug of quartz wool. A thermocouple was placed within a $1 / 8$ " quartz placed in the center of the reactor tube to monitor the temperature through the vertical coordinate of the catalyst bed. The product gases from the experiment were fed to a GC with dual packed bed columns and TCDs for the analysis of $\mathrm{H}_{2}$, $\mathrm{O}_{2}, \mathrm{~N}_{2}, \mathrm{CO}, \mathrm{CO}_{2}, \mathrm{CH}_{4}$, ethylene, ethane, propylene, and propane.

Testing of the catalyst under each sulfur condition (no S, thiophene, $\mathrm{H}_{2} \mathrm{~S}$ or $\mathrm{SO}_{2}$ ) was conducted in triplicate. In order to quantify the performance of the catalyst a variable, termed Synthesis Gas Yield, was used. The Synthesis Gas Yield is the sum of $\mathrm{H}_{2}$ and $\mathrm{CO}$ produced divided by the maximum theoretical output from the originating hydrocarbon, isooctane in this case. Synthesis Gas Yields are possible in ranges over 1.0 in autothermal reforming due to the additional hydrogen produced from water in steam reforming reactions. The results for this study are shown for the no sulfur cases in Figure 6.34, for the thiophene cases in Figure 6.35, for the $\mathrm{H}_{2} \mathrm{~S}$ cases in Figure 6.36, and for the $\mathrm{SO}_{2}$ experiments in Figure 6.37. 


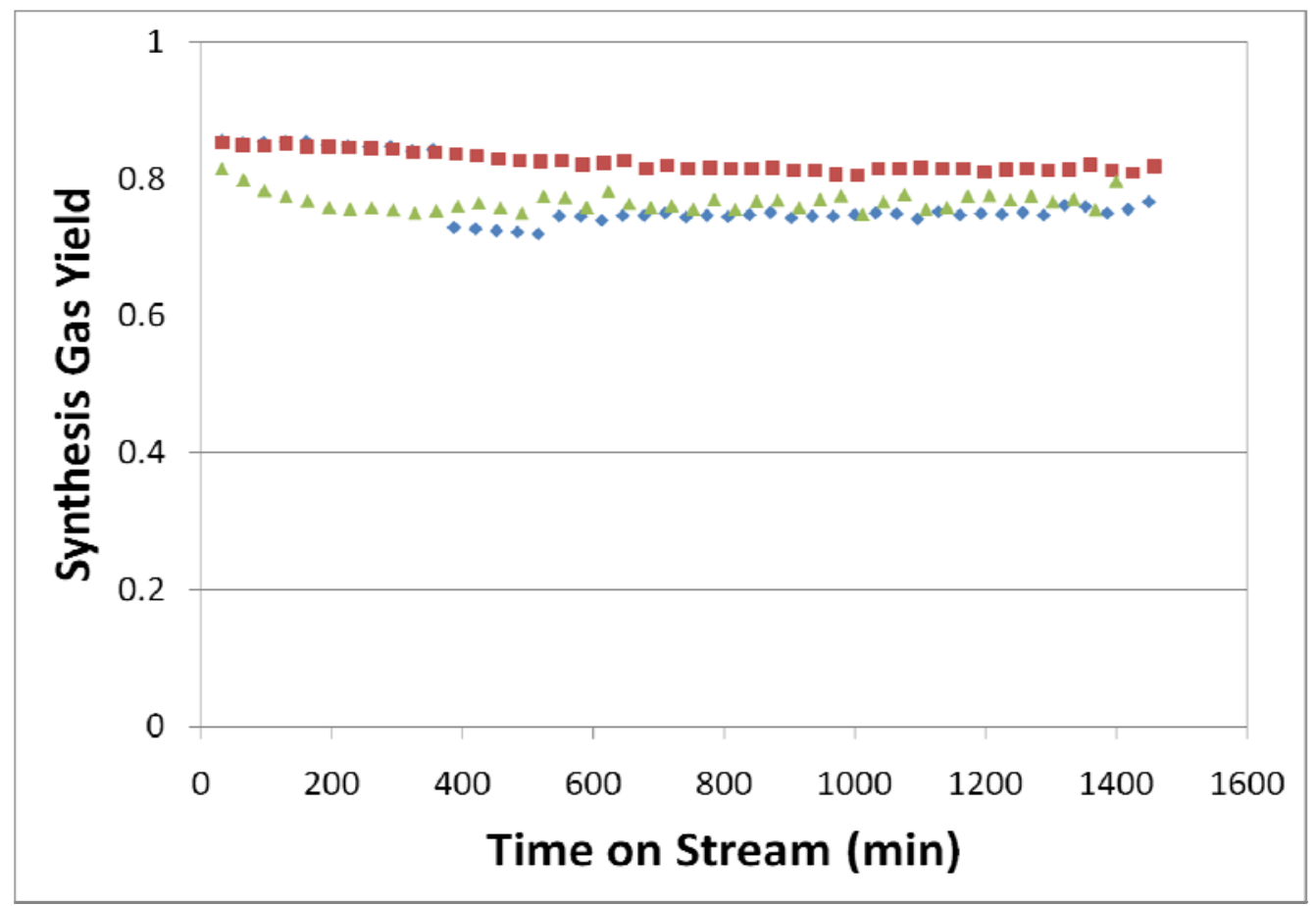

Figure 6.34. Results of isooctane autothermal reforming experiments performed over $\mathrm{Ni} / \mathrm{CZO}$ catalyst without the presence of sulfur.

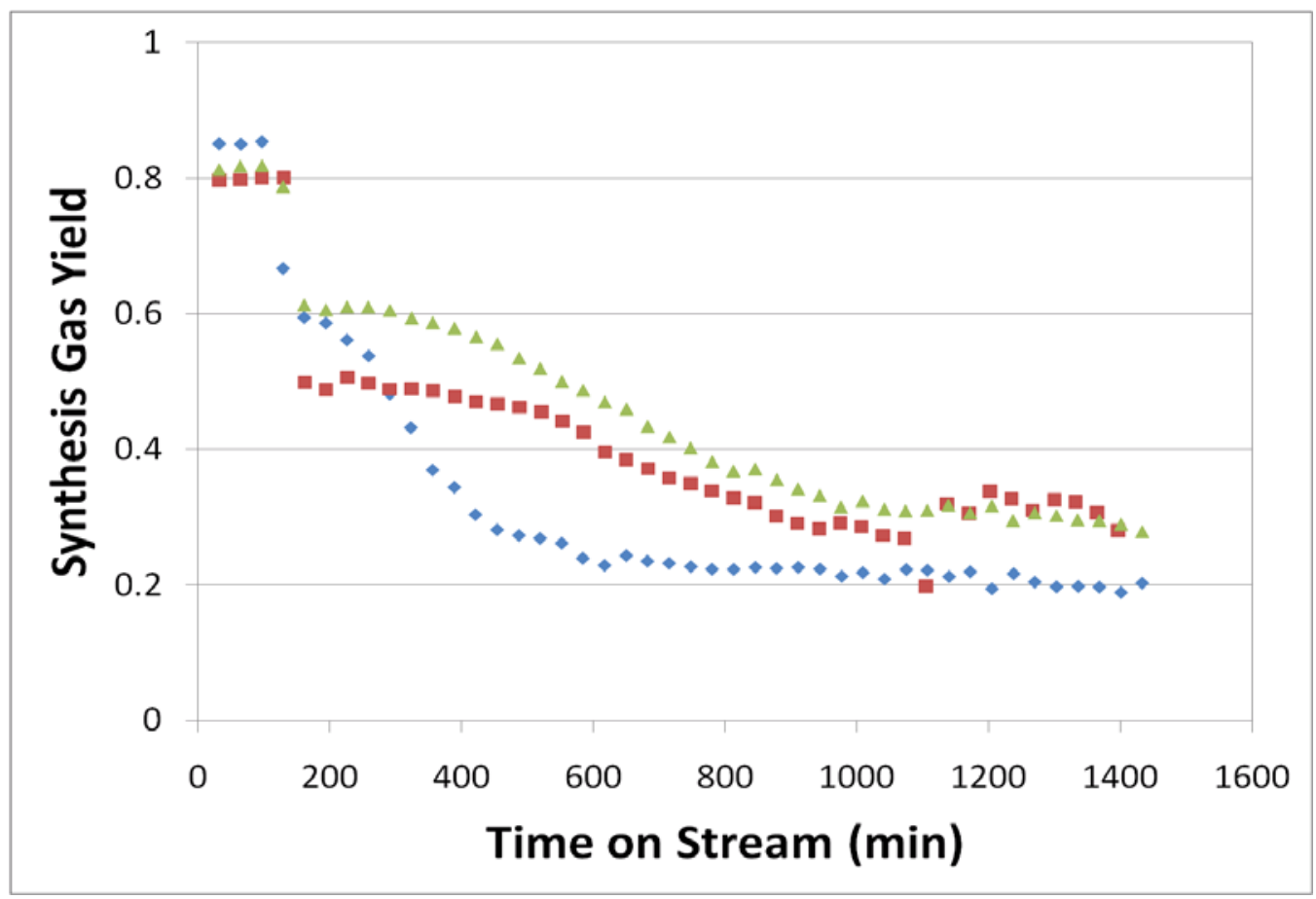

Figure 6.35. Results for isooctane ATR hot-switched to thiophene contaminated feed after two hours on stream. 


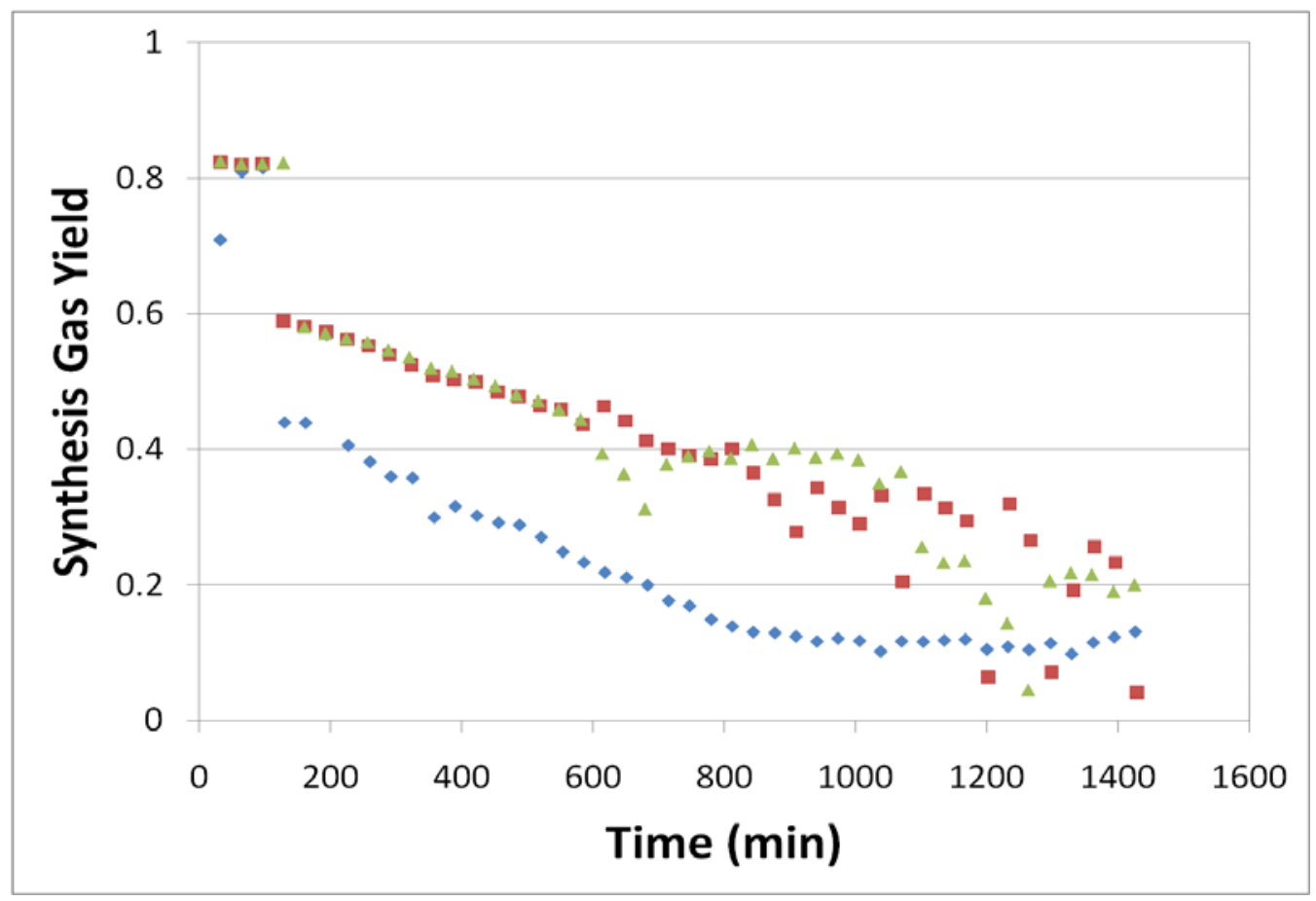

Figure 6.36. Results for isooctane ATR exposed to $\mathrm{H}_{2} \mathrm{~S}$ contaminated feed starting at two hours on stream.

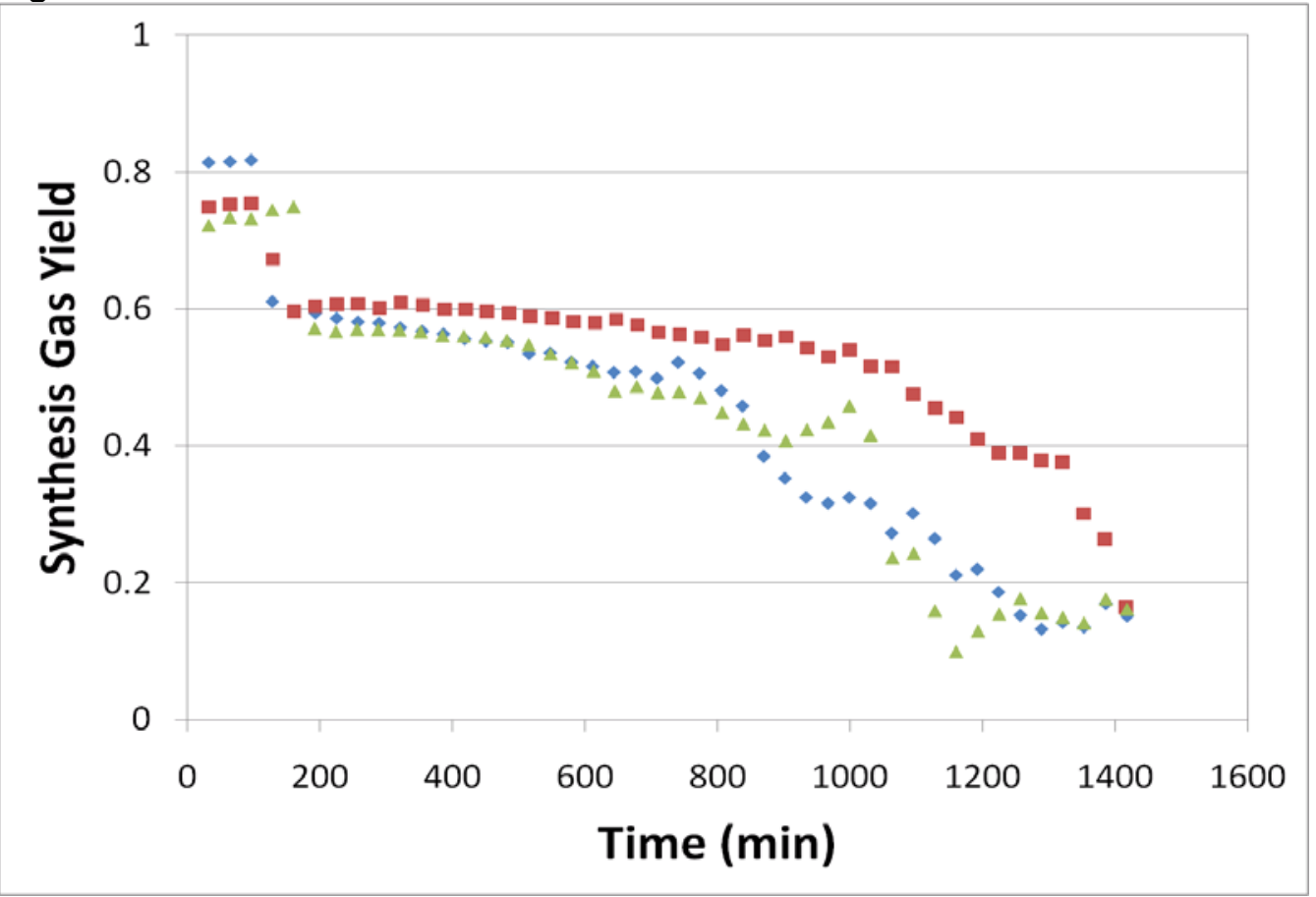

Figure 6.37. Results for isooctane ATR exposed to $\mathrm{SO}_{2}$ contaminated feed starting at two hours on stream. 
These results showed that the activity was eventually lost in all sulfur contaminated runs. These results were not in agreement with previous work performed in the NEC lab, which demonstrated that despite an initial drop-off in activity immediately following exposure, activity was quite stable, thereafter. Based upon the results of these experiments there were two goals for the direction of this research. First, there was a need to increase the repeatability between runs and second, it would be necessary to decrease the overall pressure drop across the catalyst bed. It was hypothesized that increased pressure drop played a major role in the discrepancies seen in the data.

Major changes to the flow reactor setup included the addition of a bypass line and a pressure transducer. The bypass line allowed for control of the catalyst environment prior to and immediately following reaction. A new standard operating procedure was developed to take advantage of the ability to start the reactant mixture separately from a controlled reduced catalyst environment.

The pressure transducer was used to track pressure drops throughout the reactor set-up and to track pressure changes in the system throughout a reaction run. To demonstrate the usefulness of this ability an example run is shown in Figure 6.38. In this experiment, thiophene doped isooctane was hot-switched into the reactant stream two hours into the run. This contamination led to an immediate drop in activity and increase in temperature in agreement with previous results. Eventually pressure drop in the reactor led to a premature failure of the experiment. This fact may have erroneously led to the hypothesis that thiophene poisoning had somehow increased the pressure drop across the reactor perhaps due to an increased deposition of carbon. However, it is clear from Figure 6.38 that the pressure in the reactor began to significantly increase before thiophene was added to the system. Therefore, it was clear that there were other sources of pressure drop to consider. 


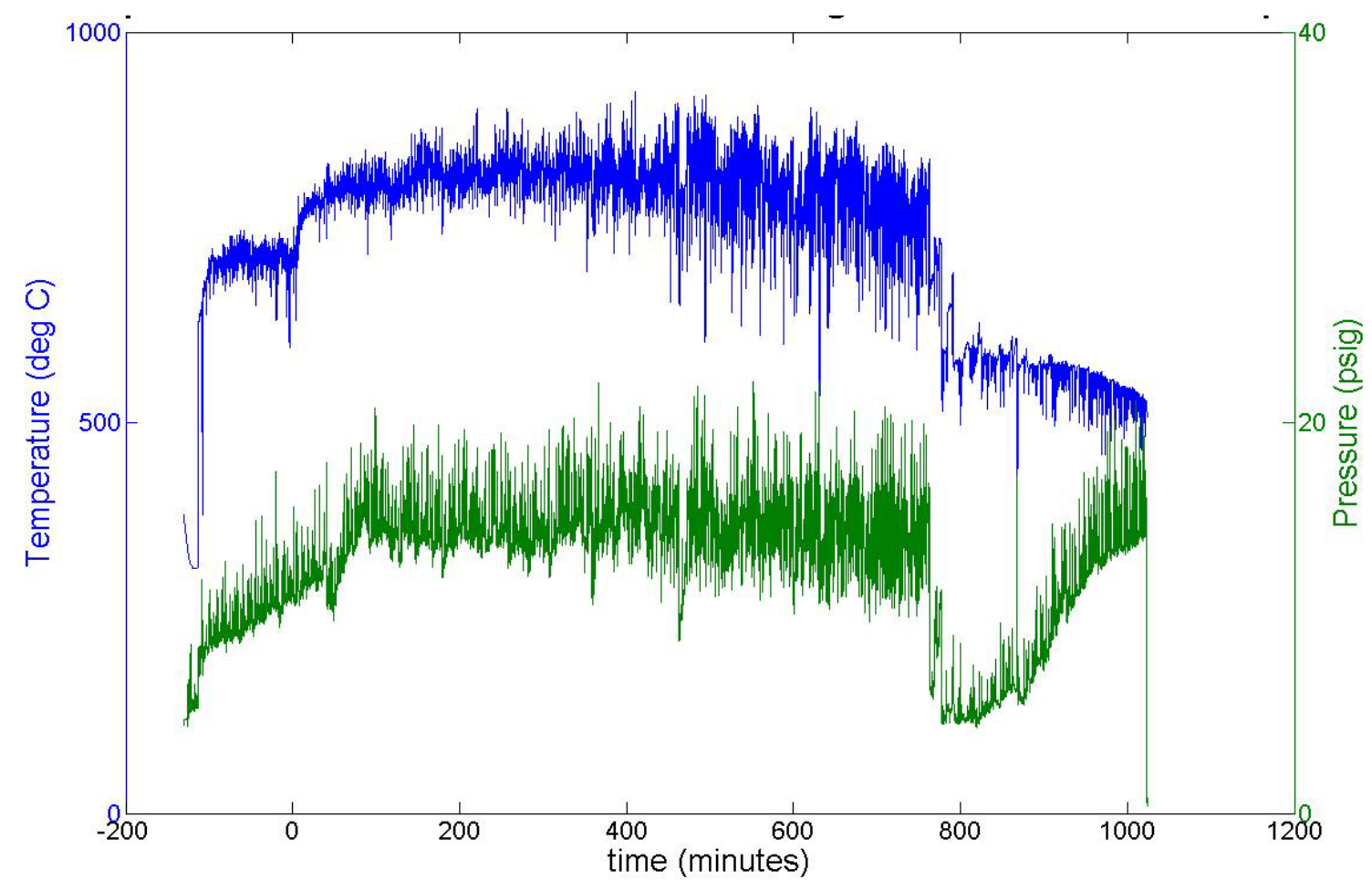

Figure 6.38. Temperature and pressure data for a thiophene exposed isooctane ATR experiment, time refers to time on stream after thiophene exposure.

The pressure drop across the reactor was clearly a major concern with the reactor set-up. Elevated pressures were responsible for reactor seal failures, catalyst blow-through, and likely contributed to erratic behavior observed in the peristaltic pumps. Pressure was measured throughout the reactor set-up in order to determine if there were any opportunities to decrease pressure drop. Minor modifications were made including using separate condenser units for the reactor and bypass lines and using $1 / 4$ " tubing wherever possible, as opposed to $1 / 8$ " lines. These changes led to a significant drop in pressure with a minimal increase in system dead space.

In order to further describe the interaction of sulfur with reforming reactions additional analytical capabilities were added to the instrumental setup described in the previous report. A Pulsed Flame Photometric Detector (PFPD) obtained from Varian was integrated into the existing Gas Chromatograph. The detector is capable of detecting $\mathrm{pg} / \mathrm{s}$ levels of sulfur.

The PFPD was used to analyze the breakthrough of $\mathrm{SO}_{2}$ on a typical ATR catalyst, ceria-zirconia supported nickel. This experiment is important to understand the typical sorption behavior of the catalyst and how this interacts with the complex ATR reaction framework.

For these experiments $10 \mathrm{wt} \% \mathrm{Ni}$ supported on a ceria-zirconia support was used. The support was prepared via coprecipitation. The metal loading was performed using the incipient wetness impregnation method. The support 
and final precursor were both calcined at $900^{\circ} \mathrm{C}$. Prior to study the catalyst was reduced under an atmosphere of $5 \% \mathrm{H}_{2}$ at $600^{\circ} \mathrm{C}$.

$\mathrm{SO}_{2}$ breakthrough was performed over the range of temperatures experienced in a typical ATR reaction experiment. At the low end, $500^{\circ} \mathrm{C}$, the preheat temperature, to $800^{\circ} \mathrm{C}$ at the high end, the temperature seen at the front edge of the catalyst bed. Following reduction the furnace was set to the desired experimental temperature under an inert $\mathrm{N}_{2}$ flow. An $\mathrm{SO}_{2}$ contaminated $\mathrm{N}_{2}$ stream was then passed over the catalyst at $10 \mathrm{ppm}$ and a space velocity of $200,000 \mathrm{hr}^{-1}$, both typical conditions of an ATR experiment. Due to the length of the GC analysis method there was a time resolution of approximately 11.5 minutes for data collection. The experiment was continued until the outlet composition matched the inlet conditions. Following $\mathrm{SO}_{2}$ treatment, the catalyst was cooled under $\mathrm{N}_{2}$.

Following treatment the samples were finely ground and analyzed by Diffuse Reflectance Infrared Spectroscopy (DRIFTS). A Bruker Tensor 27 system was used for this analysis. The spectra were collected over the range 4000 to $600 \mathrm{~cm}^{-1}$ at a resolution of $4 \mathrm{~cm}^{-1}$.

Figure 6.39 shows the breakthrough curves for $\mathrm{SO}_{2}$ through the catalyst at temperatures of 500,600 and $800^{\circ} \mathrm{C}$. These results showed that there is a decrease in the sulfur capacity of the catalyst as the temperature increases. An important implication of these results is that while the high temperature edge of the catalyst reaches equilibrium with $\mathrm{SO}_{2}$ in as quickly as 8 hours the lower temperature regions take as long as 24 hours to reach equilibrium surface concentration. It has been argued based upon previous results that the steam reforming activity of the catalyst which dominates at the cooler axial positions of the catalyst bed is more susceptible to sulfur poisoning than the exothermic partial oxidation mechanism. 


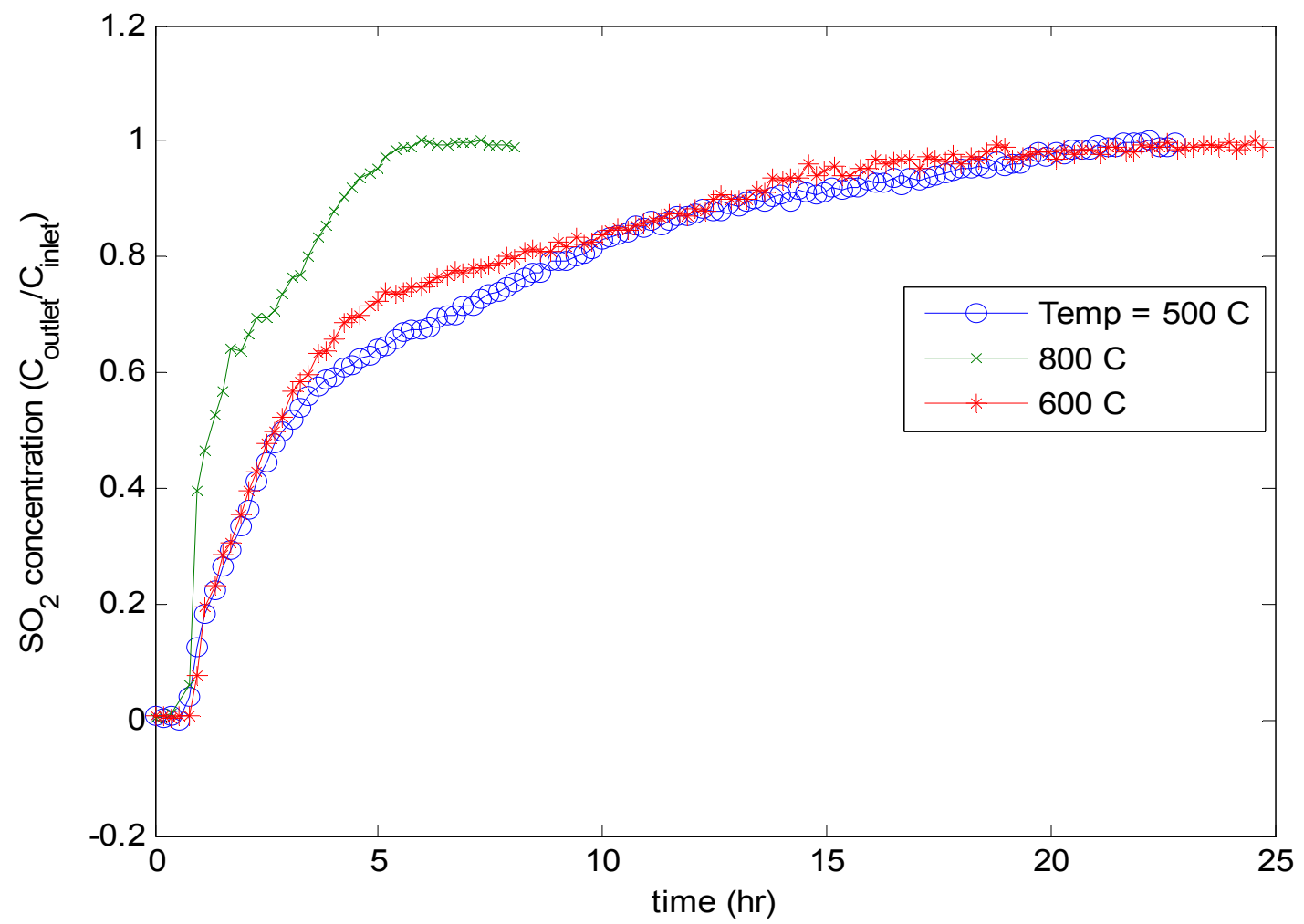

Figure 6.39. Breakthrough curves for $\mathrm{SO}_{2}$ through a Ni based ATR catalyst at 500,600 and $800^{\circ} \mathrm{C}$.

Figure 6.40 shows the DRIFTS spectrum obtained from the catalyst treated with $\mathrm{SO}_{2}$ at $500^{\circ} \mathrm{C}$. An examination of this data shows absorbance in bands associated with sulfate formation $\left(1000-1300 \mathrm{~cm}^{-1}\right)$. This is in agreement with previous XPS studies which suggested the reaction of the oxide support to form bulk-phase sulfates in addition to the more obvious surface nickel sulfide formation.

It has been shown that there is a dramatic decrease in sulfur capacity over the temperature range experienced in an ATR reactor. 


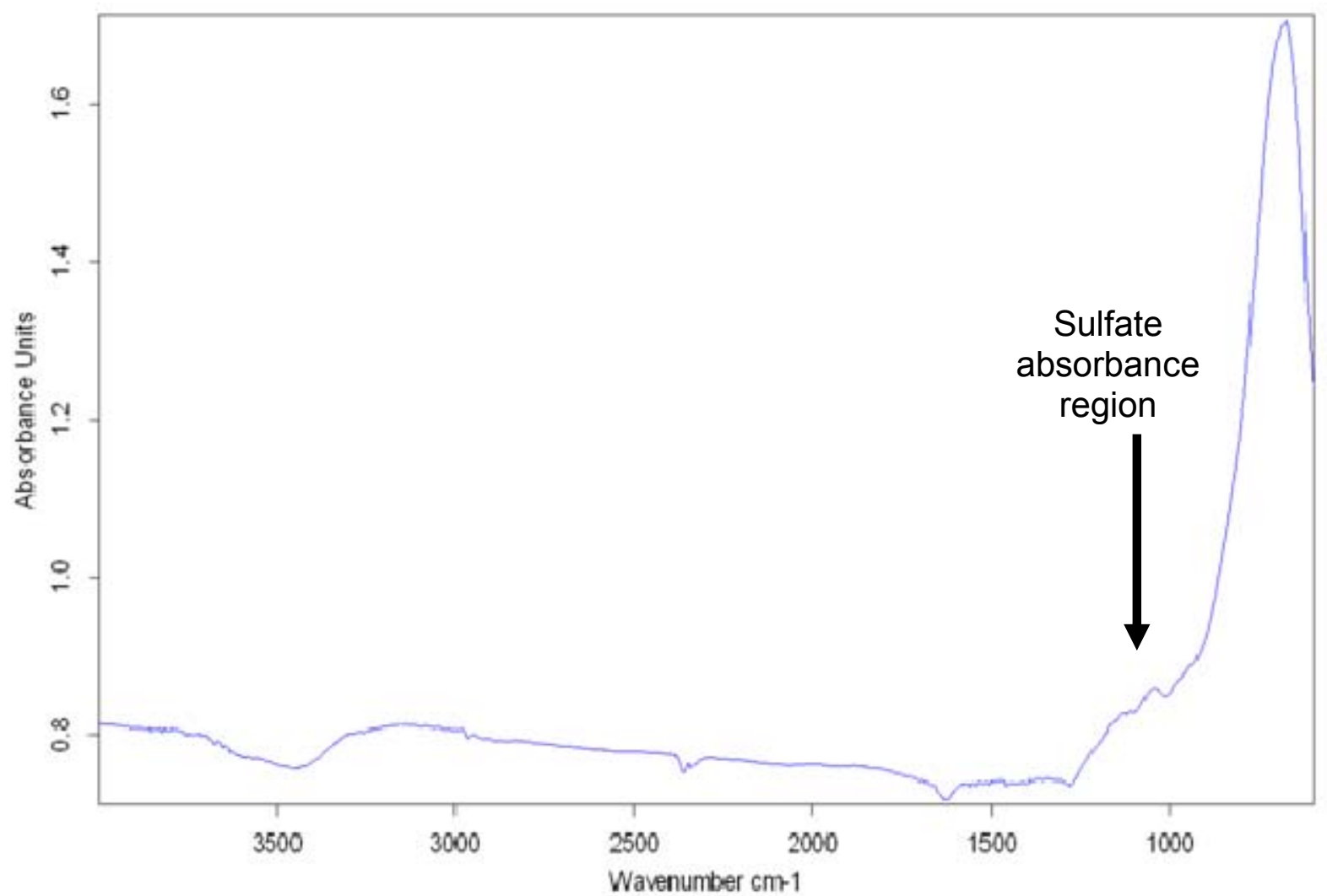

Figure 6.40. DRIFTS spectra of an $\mathrm{SO}_{2}$ treated catalyst. Breakthrough performed at $500^{\circ} \mathrm{C}$. 
In order to develop baseline DRIFTS behavior the DRIFTS patterns for $\mathrm{SO}_{2}$ treated samples were compared to patterns obtained in the same manner for a reduced sample of $\mathrm{Ni} / \mathrm{Ce}-\mathrm{Zr}-\mathrm{O}_{2}$, an unreduced sample of $\mathrm{NiO} / \mathrm{Ce}-\mathrm{Zr}-\mathrm{O}_{2}$, and a nickel-free $\mathrm{Ce}-\mathrm{Zr}-\mathrm{O}_{2}$.

Due to difficulties in obtaining good calibration curves for $\mathrm{H}_{2} \mathrm{~S}$ on the reactor system, it was deemed necessary to verify the inertness of the reactor transfer lines and fittings. Literature sources on the analysis of VSCs describe how the adsorptive losses of compounds such as $\mathrm{SO}_{2}$ and $\mathrm{H}_{2} \mathrm{~S}$ can lead to significant decreases in the concentration of VSC reaching the PFPD causing major issues in quantification. Therefore, an inert material was obtained from Restek. Their Sulfinert coating, a modified silica structure, has been demonstrated to be resistant to VSC adsorption and, according to their literature, results in near $100 \%$ VSC recovery in the ppb range. All of the reactor transfer lines and fittings were replaced with SS-316 materials coated with the Sulfinert coating. Once these modifications were complete it was confirmed that there was complete recovery of VSCs to the detection capability of the PFPD (about $0.1 \mathrm{ppm}$ with the current gas chromatograph set-up).

Figure 6.41 shows the DRIFTS patterns for the samples treated with $\mathrm{SO}_{2}$ at $500^{\circ} \mathrm{C}, 600^{\circ} \mathrm{C}, 700^{\circ} \mathrm{C}$ and $800^{\circ} \mathrm{C}$. For comparison, Figure 6.41 also shows the DRIFTS patterns for Ni/Ce-Zr- $\mathrm{O}_{2}$ untreated with $\mathrm{SO}_{2}$, an unreduced sample of $\mathrm{NiO} / \mathrm{Ce}-\mathrm{Zr}-\mathrm{O}_{2}$ and the blank support $\mathrm{Ce}-\mathrm{Zr}-\mathrm{O}_{2}$. These spectra show that sulfate species are produced at all $\mathrm{SO}_{2}$ exposure temperatures, while at higher temperatures other surface species are present. These presently unidentified species may be either sulfide species or the product of a bulk reaction with the mixed oxide support. Further work is needed to improve the DRIFTS data collection for these types of experiments. Data validation with $x$-ray photoelectron spectroscopy (XPS) can help identify unknown DRIFTS features. 


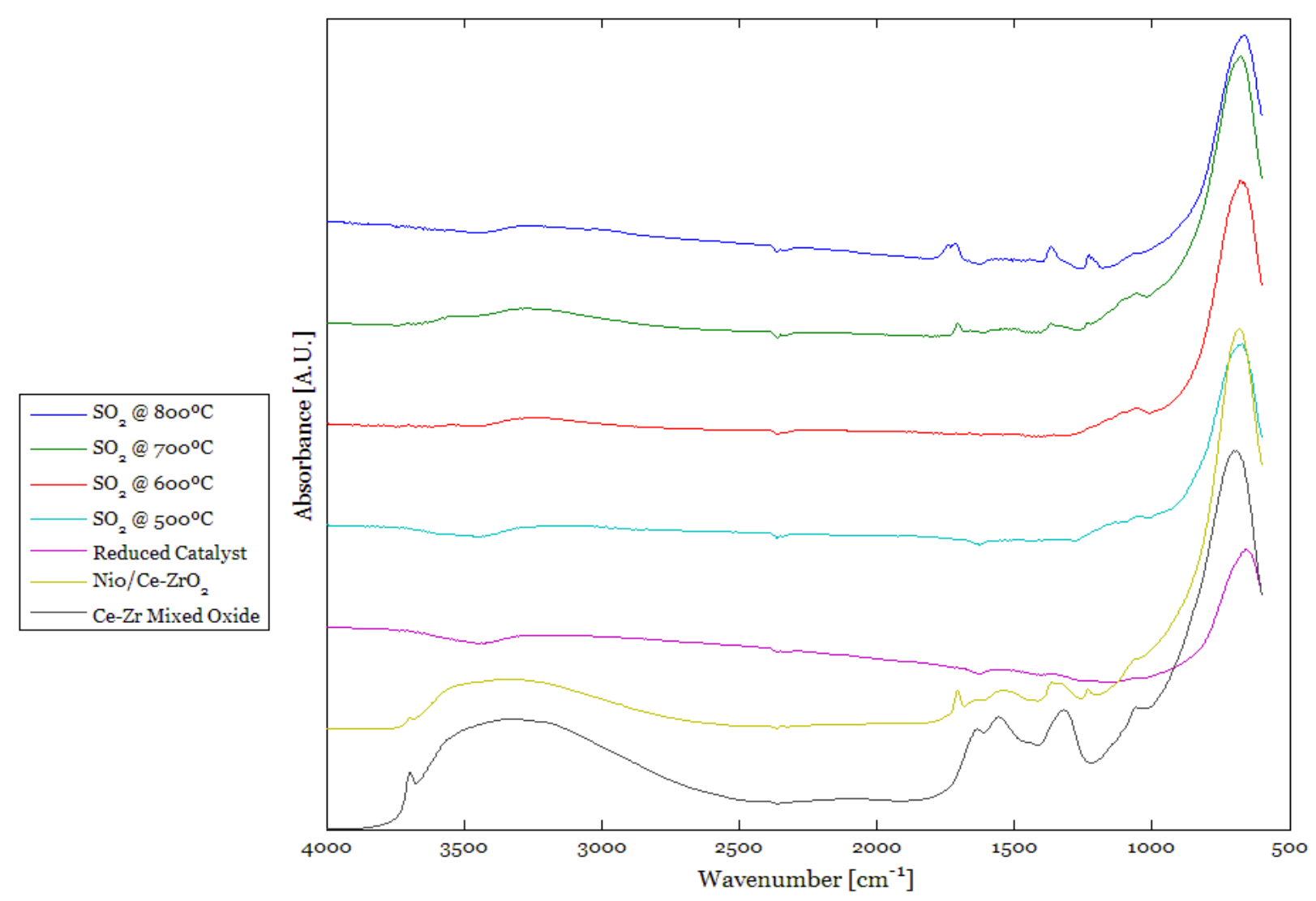

Figure 6.41. DRIFTS spectra for $\mathrm{Ce}-\mathrm{Zr}-\mathrm{O}_{2}$ mixed oxide, Ni impregnated catalyst, reduced catalyst, and catalyst treated with $\mathrm{SO}_{2}$ at $500,600,700$, and $800^{\circ} \mathrm{C}$. 
Having explored the effects of SO2 treatments on the catalyst and catalyst supports and modified the reactor system to achieve the desired accuracy in $S$ quantification, the research focus returned to the effects of $S$ during reforming. The influence of thiophene on the ATR activity of $10 \mathrm{wt} \% \mathrm{Ni}$ supported on $\mathrm{Ce}_{0.75} \mathrm{Zr}_{0.25} \mathrm{O}_{2}$ was compared for five different reforming scenarios. These conditions are given in Table 6.7, and shown graphically in Figure 6.42. Each scenario was performed twice under sulfur free conditions and twice using isooctane loaded with thiophene at a concentration of $30 \mathrm{ppmw} \mathrm{S}$, resulting in an inlet sulfur concentration given in the last column of Table 6.7.

Table 6.7. Reforming Scenarios Tested.

\begin{tabular}{|l|l|l|l|l|l|l|l|}
\hline Scenario & $\begin{array}{l}\mathrm{H}_{2} \mathrm{O} / \mathrm{C} \\
\text { Ratio }\end{array}$ & $\begin{array}{l}\mathrm{O} / \mathrm{C} \\
\text { Ratio }\end{array}$ & $\begin{array}{l}\mathrm{F}_{-} i-\mathrm{C}_{8} \mathrm{H}_{18} \\
(\mathrm{mmole} / \mathrm{min})\end{array}$ & $\begin{array}{l}\mathrm{F}_{-} \mathrm{H}_{2} \mathrm{O} \\
(\mathrm{mmole} / \mathrm{min})\end{array}$ & $\begin{array}{l}\mathrm{F}_{-} \mathrm{O}_{2} \\
(\mathrm{mmole} / \mathrm{min})\end{array}$ & $\begin{array}{l}\mathrm{F}_{-} \mathrm{N}_{2} \\
(\mathrm{mmole} / \mathrm{min})\end{array}$ & $\begin{array}{l}{[\mathrm{S}]_{0}} \\
(\mathrm{ppmv})\end{array}$ \\
\hline $\begin{array}{l}\text { Base } \\
\text { Case }\end{array}$ & 1 & 0.75 & 3.187 & 25.496 & 9.561 & 35.642 & 4.500 \\
\hline $\begin{array}{l}\text { Elevated } \\
\text { O }\end{array}$ & 1 & 1 & 2.644 & 21.150 & 10.576 & 39.426 & 3.736 \\
\hline $\begin{array}{l}\text { Pure } \\
\text { POX }\end{array}$ & 0 & 0.75 & 4.850 & - & 14.550 & 54.241 & 6.855 \\
\hline $\begin{array}{l}\text { Elevated } \\
\text { Steam }\end{array}$ & 3 & 0.75 & 1.822 & 45.172 & 5.466 & 20.377 & 2.667 \\
\hline Pure SR & 3 & 0 & 1.822 & 45.172 & - & 25.843 & 2.667 \\
\hline
\end{tabular}

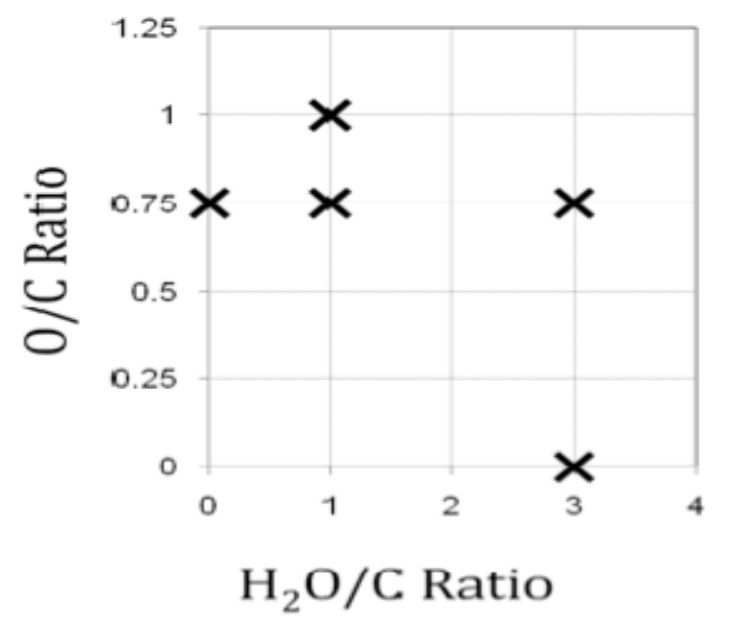

Figure 6.42. Reforming Conditions Tested. 
The results of these experiments demonstrated that thiophene interacts with the catalyst very differently depending upon the reforming conditions. Under the base case and elevated steam scenarios the reforming activity was diminished but remained stable for the duration of the experiment. In these experiments the thiophene was completely converted to $\mathrm{H}_{2} \mathrm{~S}$. In the other three scenarios the activity diminished significantly over the course of the experiment and the thiophene emerged from the reactor unconverted.

For these experiments $10 \mathrm{wt} \% \mathrm{Ni}$ supported on a ceria-zirconia (CZO) support was used. The support was prepared via coprecipitation. The metal loading was performed using the incipient wetness impregnation method. The support and final precursor were both calcined at $900^{\circ} \mathrm{C}$.

The reactor used for these experiments is equipped with gas mass flow controllers (MKS) for delivery of air, $\mathrm{N}_{2}, \mathrm{SO}_{2}, \mathrm{H}_{2} \mathrm{~S}$ etc. and liquid flow meters (Bronkhorst) and peristaltic pumps (Instech) for delivery and isooctane and water. For thiophene contaminated experiments the thiophene was added to the isooctane feed. The reactor transfer lines are coated with a protective coating (Restek, Silcotek) to assure that they are inert to volatile sulfur compounds (VSCs) down to the ppb range.

The Ni/CZO catalyst was size-fractioned to obtain 40-60 mesh powder samples for reactor studies. The catalyst was added to quartz wool packed quartz reactor tube inside a furnace (Thermolyne). Prior to reaction the catalyst was reduced in a $5 \% \mathrm{H}_{2}$ atmosphere at $600^{\circ} \mathrm{C}$.

The product gas from the reformer was passed to a condenser to remove most of the water vapor. The dry reformate was then fed to a Gas Chromatograph (Varian) for the quantification of $\mathrm{H}_{2}, \mathrm{~N}_{2}, \mathrm{O}_{2}, \mathrm{CO} \mathrm{CO}_{2}, \mathrm{CH}_{4}$, ethylene, ethane, propylene, propane, butane, $\mathrm{H}_{2} \mathrm{~S}, \mathrm{SO}_{2}$, and thiophene.

The results for this study are given in Figure 6.43, Figure 6.44, Figure 6.45, Figure 6.46, and Figure 6.47. On the left is a graphical representation of what reaction conditions are being considered. The center graph shows the activity with and without thiophene present. The graph on the right shows the yield of sulfur products for the each scenario when thiophene is present. For sake of brevity the temperature data is excluded here. In all cases the presence of sulfur increased the temperature bed of the catalyst. 


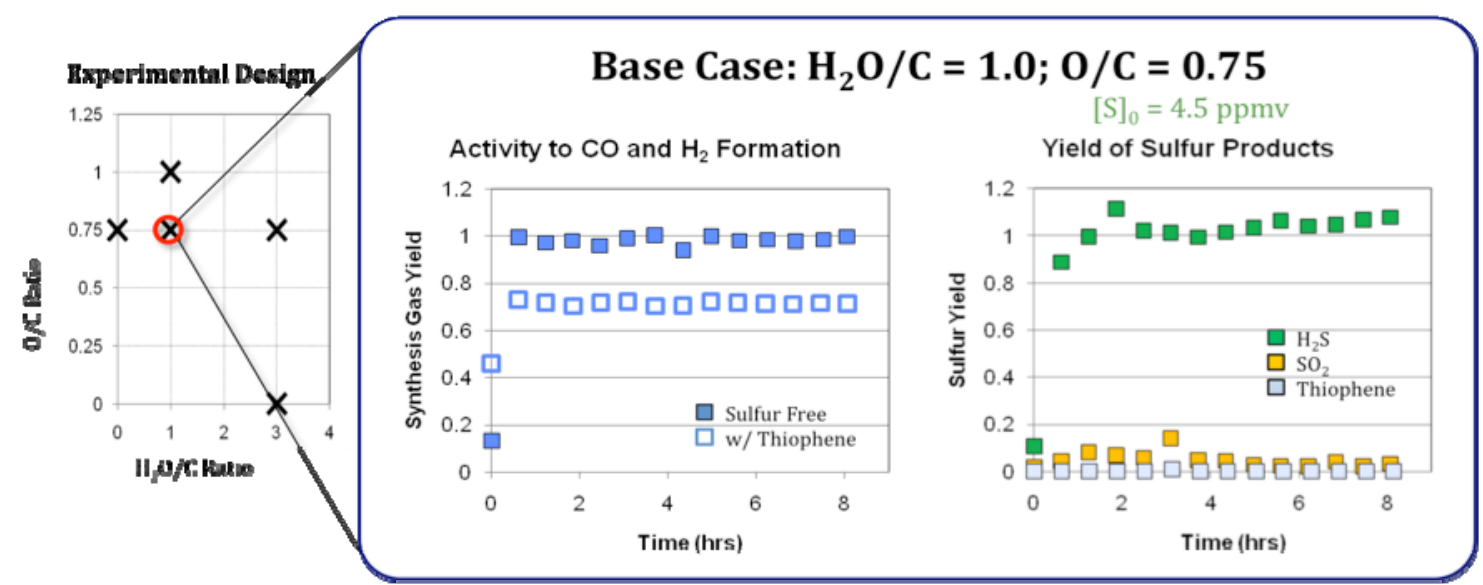

Figure 6.43. Base Case Scenario Results: Activity towards $\mathrm{CO}$ and $\mathrm{H}_{2}$ formation (center) and yield of sulfur products (right).

Figure 6.43 shows the results for the base case scenario. When sulfur is not present in the feed there is a steady and elevated production of $\mathrm{H}_{2}$ and $\mathrm{CO}$. When thiophene is present, the activity is still stable but is diminished by approximately $30 \%$. Due to the breakdown of products in the gas stream, it is presumed that the presence of sulfur leads to a deactivation of reforming activity. Under these conditions the thiophene is readily and completely converted to $\mathrm{H}_{2} \mathrm{~S}$. This is expected, due to the high hydrodesulfurization activity of nickel and the availability of $\mathrm{H}_{2}$ inside the reactor.

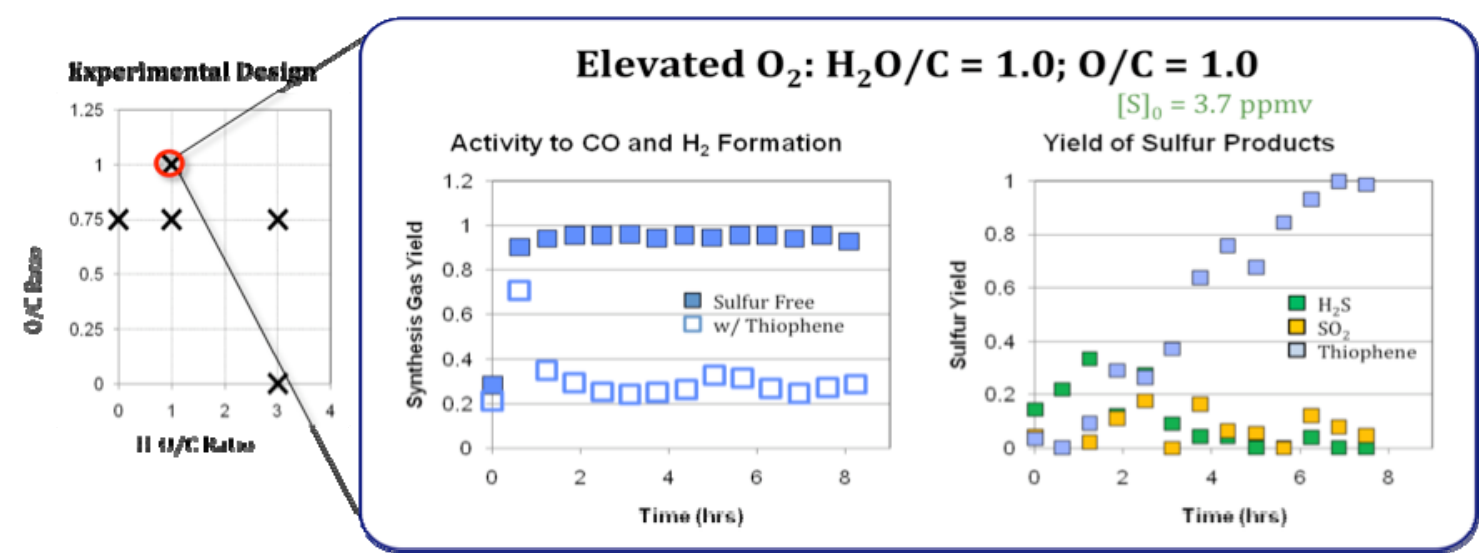

Figure 6.44. Elevated $\mathrm{O}_{2}$ Scenario Results: Activity towards $\mathrm{CO}$ and $\mathrm{H}_{2}$ formation (center) and yield of sulfur products (right).

Figure 6.44 shows the results for the elevated O/C scenario. Under these conditions there is a higher availability of oxygen in the reactor. The influence on sulfur free performance is a slightly lower selectivity towards $\mathrm{H}_{2}$ and $\mathrm{CO}$ production than the base case. When thiophene is present in the system the activity is no longer stable. The decrease in selectivity suggests the eventual loss of activity of many reforming sites. In this scenario the thiophene is no longer 
converted to $\mathrm{H}_{2} \mathrm{~S}$. This can either be attributed to a deactivation of HDS sites or an availability of $\mathrm{H}_{2}$ to clean off chemisorbed $\mathrm{S}$ species.

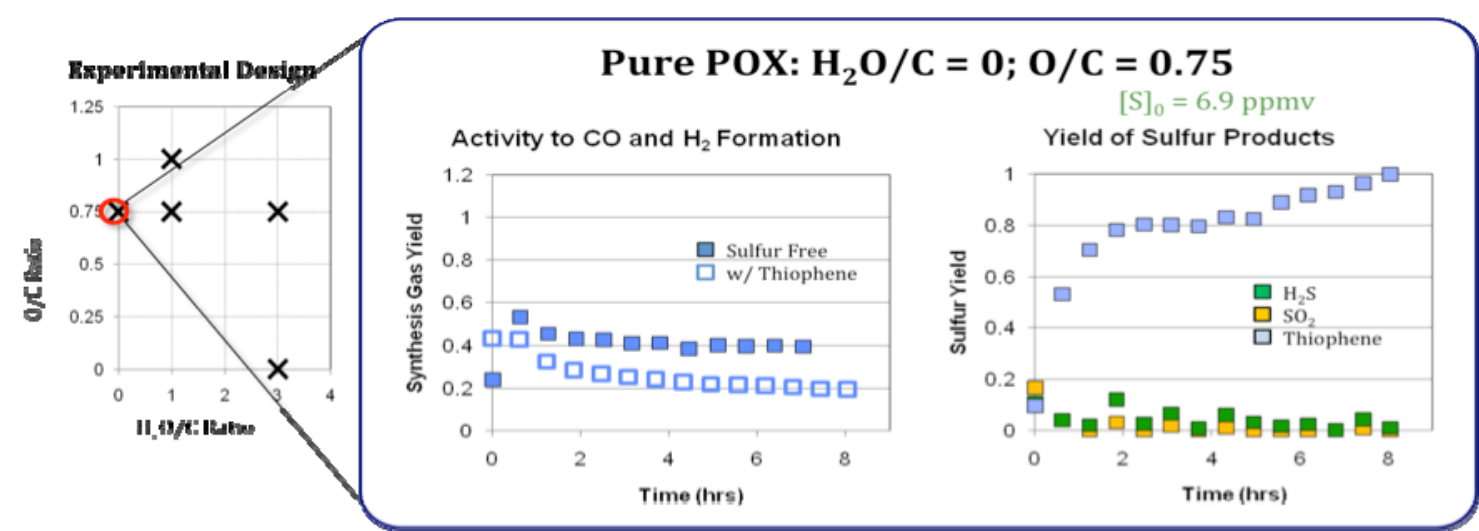

Figure 6.45. Pure POX Scenario Results: Activity towards $\mathrm{CO}$ and $\mathrm{H}_{2}$ formation (center) and yield of sulfur products (right).

Figure 6.45 shows the effect of thiophene upon pure POX conditions. Under sulfur free conditions the catalyst is considerably less selective towards $\mathrm{H}_{2}$ and $\mathrm{CO}$ production, and experiences slight deactivation due to the buildup of carbon on the surface. When thiophene is present there is an exponential dropoff in activity as was seen in the elevated O/C scenario. Similarly, the thiophene is not converted to $\mathrm{H}_{2} \mathrm{~S}$. This suggests a very similar behavior in elevated $\mathrm{O} / \mathrm{C}$ ratios and under pure $\mathrm{POX}$ conditions.

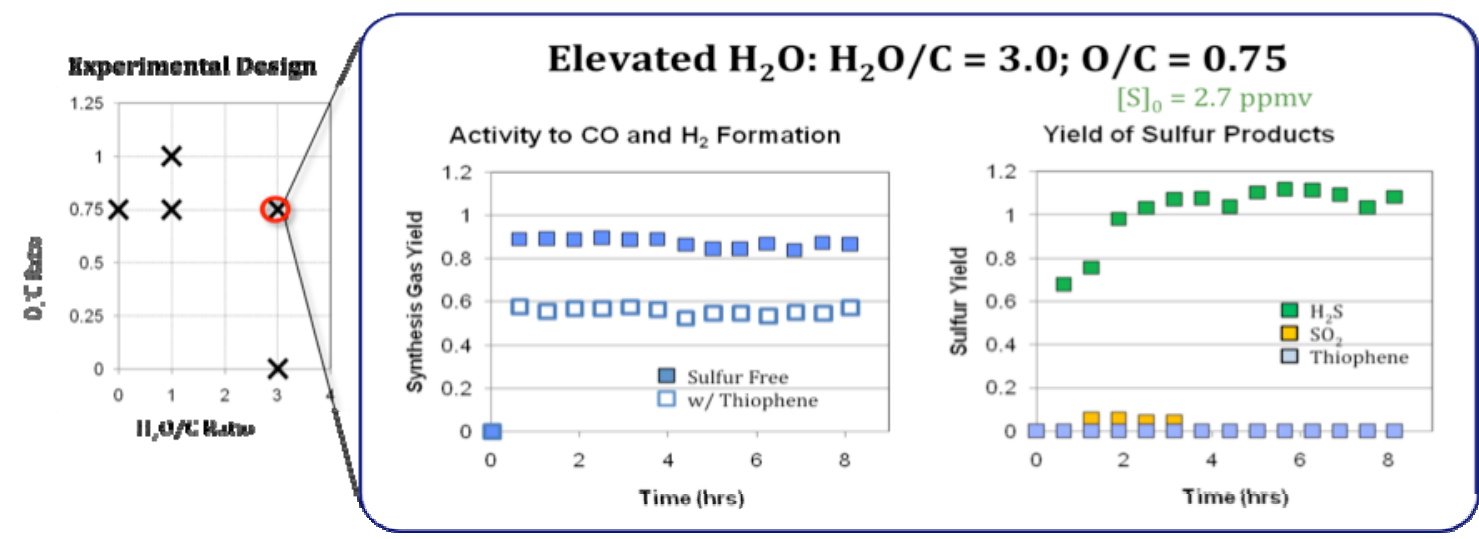

Figure 6.46. Elevated $\mathrm{H}_{2} \mathrm{O}$ Scenario Results: Activity towards $\mathrm{CO}$ and $\mathrm{H}_{2}$ formation (center) and yield of sulfur products (right).

Figure 6.46 shows the results for the elevated $\mathrm{H}_{2} \mathrm{O}$ scenario. Under these conditions there is less $\mathrm{H}_{2}+\mathrm{CO}$ selectivity than either the base case or the elevated $\mathrm{O} / \mathrm{C}$ scenario bur more than the pure POX case when there is no sulfur present. When thiophene is present, the behavior is very similar to the base case. There is diminished activity but the behavior is stable over time. The thiophene is converted to $\mathrm{H}_{2} \mathrm{~S}$, suggesting excellent HDS activity. The added 
availability of additional $\mathrm{H}_{2} \mathrm{O}$ in the system is linked to the ability of the system to rid itself of active site blocking sulfur atoms.

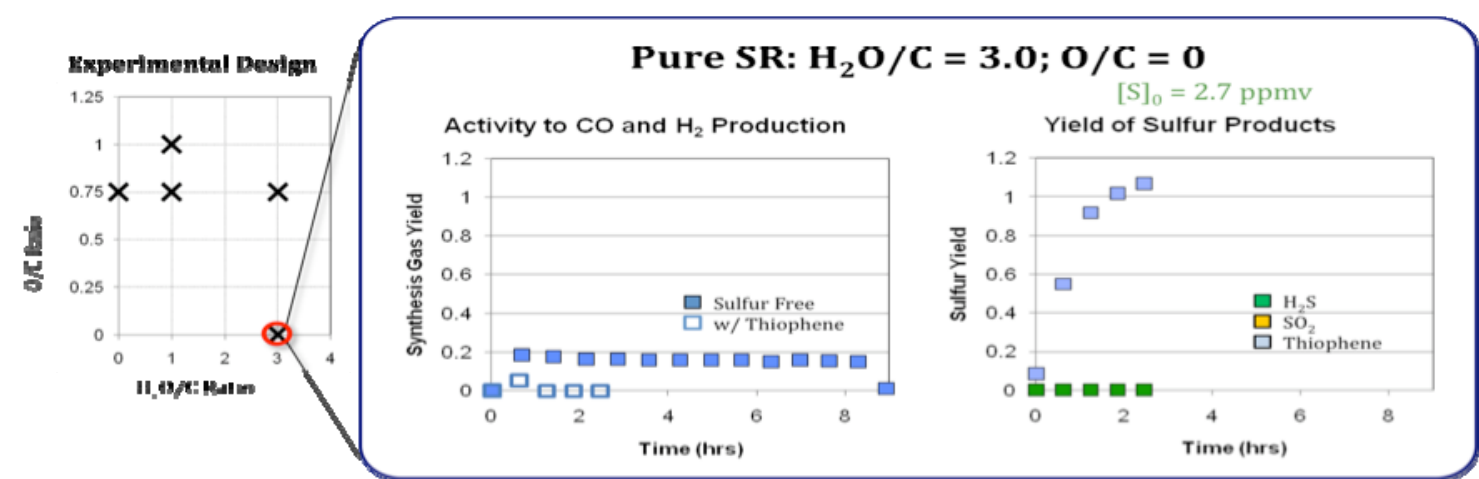

Figure 6.47. Pure SR Scenario Results: Activity towards $\mathrm{CO}$ and $\mathrm{H}_{2}$ formation (center) and yield of sulfur products (right).

This trend is not echoed in the pure steam reforming results seen in Figure 6.47. In this case there is a pronounced decrease in the availability of $\mathrm{H}_{2}$ even when there is no sulfur present. This leads to extremely low HDS activity and a complete loss of steam reforming activity in the system.

These results demonstrate that when sulfur is fed to a reforming system under various different conditions the resulting behavior can be quite unique depending upon the $\mathrm{H}_{2} \mathrm{O} / \mathrm{C}$ and $\mathrm{O} / \mathrm{C}$ ratios. There is also an important link between the reforming and hydrodesulfurization activity of Ni catalysts.

Perhaps the biggest shortcoming of the varied POX/ATR operation scenarios is the inability to separate temperature as a variable across the various reforming conditions. As determined by equilibrium calculations the adiabatic reaction temperature for the various experiments varied from $407^{\circ} \mathrm{C}$ for $\mathrm{SR}$ conditions to $1108^{\circ} \mathrm{C}$ for $\mathrm{POX}$ feed conditions. The relative rates of reforming reactions will vary greatly over that broad range of temperatures. Therefore, the experiments presented here are across a different range of conditions which showed the same adiabatic exit temperature, $650^{\circ} \mathrm{C}$. The conditions considered in this study are listed in Table 6.8. Table 6.8 shows the steam-to-carbon ratio and the oxygen-to-carbon ratio for each experiment. For each experiment the inlet sulfur concentration and the predicted $\mathrm{H}_{2}$ mole fraction, as calculated with ASPEN, is shown in Table 6.8. By running these six experiments, the effect of thiophene can be determined over a range of conditions while keeping the catalyst bed temperature roughly constant across all of the experiments. This experimental design offers a guide for the appropriate region of operating conditions in an autothermal reformer. 
Table 6.8. Reaction Conditions considered in this study.

\begin{tabular}{|l|l|l|l|l|l|}
\hline$\#$ & $\mathrm{H}_{2} \mathrm{O} / \mathrm{C}$ & $\mathrm{O} / \mathrm{C}$ & $\begin{array}{l}{[\mathrm{S}]_{\text {inlet }}} \\
(\mathrm{ppmv})\end{array}$ & $\begin{array}{l}\text { Predicted } \\
{\left[\mathrm{H}_{2}\right]_{\text {outlet }}} \\
(\mathrm{mole} \text { frac })\end{array}$ & $\begin{array}{l}\text { Predicted } \\
\text { Temp }\left({ }^{\circ} \mathrm{C}\right)\end{array}$ \\
\hline 1 & 0.500 & 0.503 & 7.185 & 0.330 & 649.95 \\
\hline 2 & 0.900 & 0.602 & 5.327 & 0.364 & 649.83 \\
\hline 3 & 0.125 & 0.626 & 4.781 & 0.368 & 648.24 \\
\hline 4 & 2.000 & 0.679 & 3.500 & 0.352 & 647.58 \\
\hline 5 & 2.500 & 0.699 & 3.055 & 0.335 & 649.82 \\
\hline 6 & 3.000 & 0.709 & 2.721 & 0.317 & 649.04 \\
\hline
\end{tabular}

For these experiments $10 \mathrm{wt} \% \mathrm{Ni}$ supported on a ceria-zirconia (CZO) support was used. The support was prepared via coprecipitation. The metal loading was performed using the incipient wetness impregnation method. The support and final precursor were both calcined at $900^{\circ} \mathrm{C}$.

Thermodynamic calculations within ASPEN give a reasonable prediction for both the outlet temperature and composition of an autothermal reforming experiment. In terms of visualizing the experimental conditions and results it can be useful to construct ternary diagrams that show the inlet condition in terms of the makeup of elemental carbon, oxygen, and hydrogen. An example of such a construction is shown in Figure 6.48, which shows the location of feed mixtures considered by various researchers in the reforming literature. In Figure 6.48, the line marked (i) refers to the steam reforming of isooctane at various steam-tocarbon ratios; (ii) refers to the gasification of elemental carbon; (iii) refers to the oxidation of isooctane (the bold region is the flammability region); and (iv) refers to synthesis gas. 


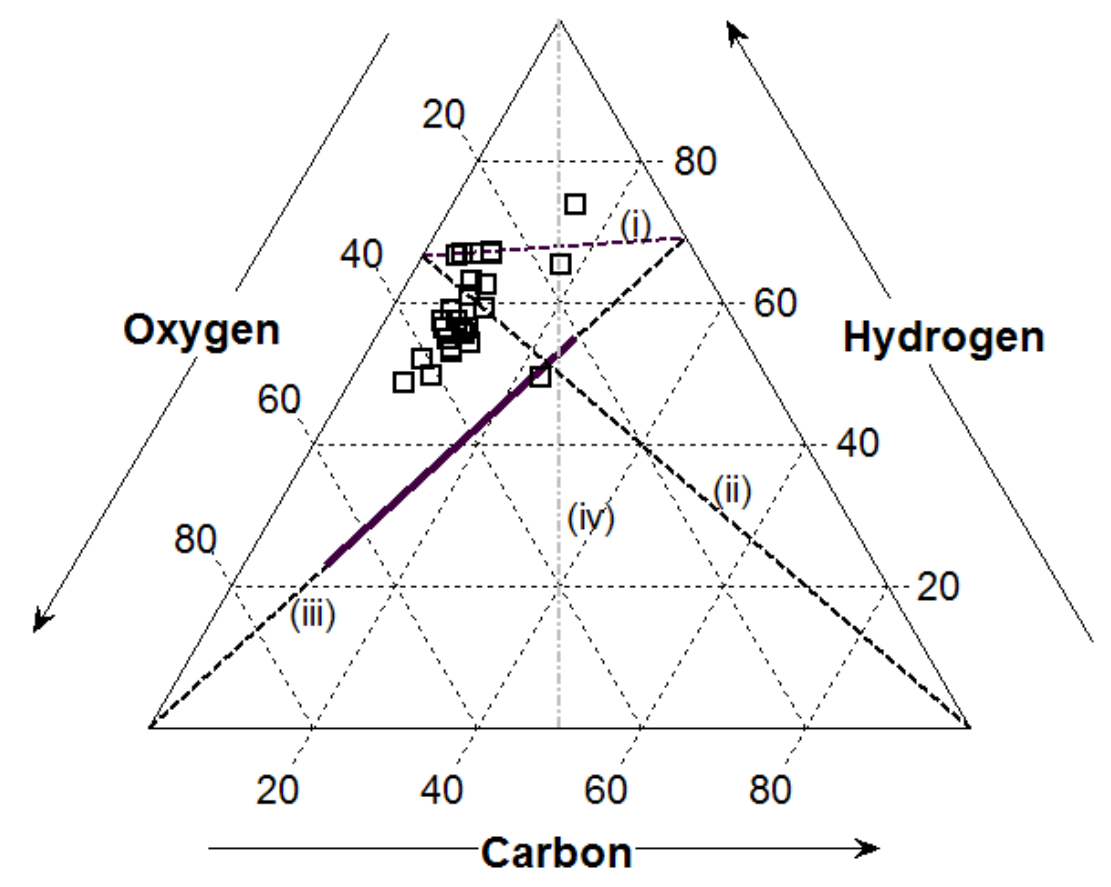

Figure 6.48. $\mathrm{C}-\mathrm{H}-\mathrm{O}$ ternary diagram based upon total feed composition showing typical reforming conditions considered by various researchers.

Each point on the $\mathrm{C}-\mathrm{H}-\mathrm{O}$ diagram can be interpreted as a potential feed composition in a reforming reactor, and therefore upon this diagram can be laid a contour map showing the predicted results of those conditions. Using ASPEN, such plots were constructed for the outlet temperature and hydrogen composition over a range of inlet conditions (steam-to-carbon ratios ranging from zero to 10 and oxygen-to-carbon ratios ranging from 0 to 2). These plots are shown in

Figure 6.49a and

Figure $6.49 \mathrm{~b}$ with the conditions considered in this study laid over the contours. Based upon these plots, it is shown that the conditions considered in this study span the region of highest hydrogen outlet composition. Compared to the conditions shown in Figure 6.48, the conditions considered in this study span the area where most reforming experiments are conducted as well as into a region of higher elemental carbon present. 


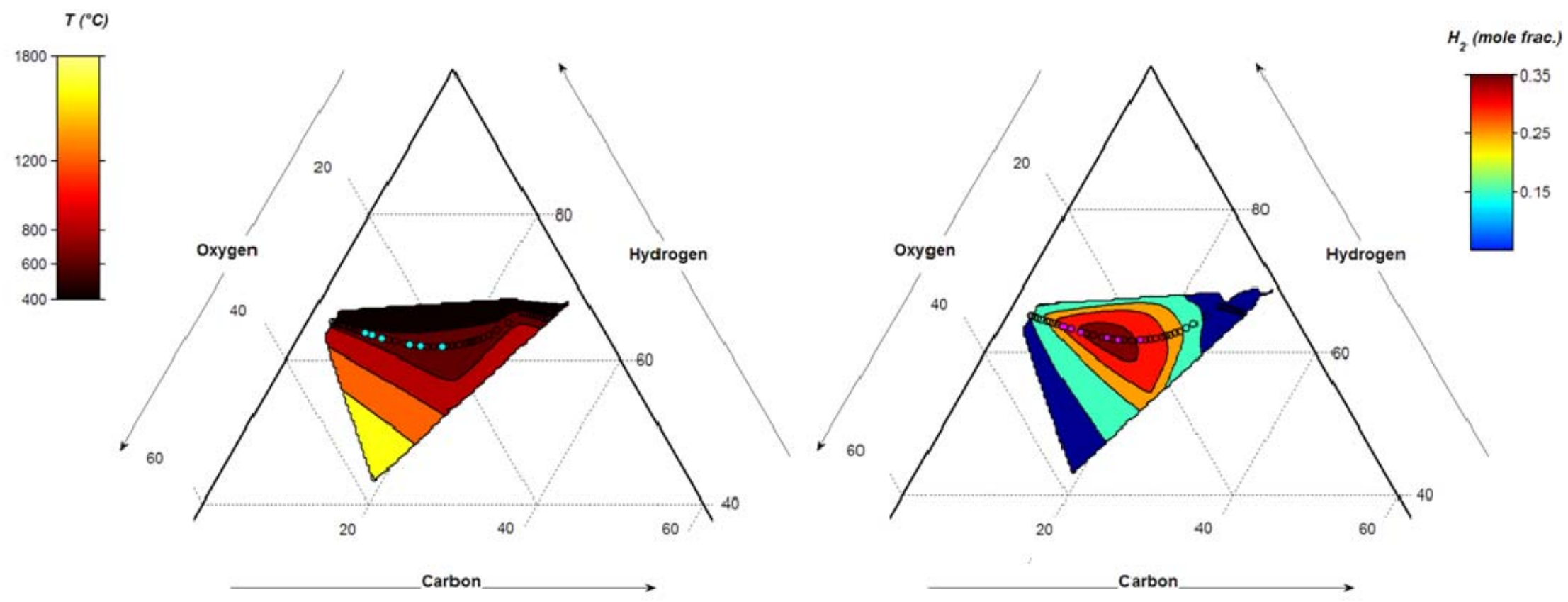

Figure 6.49. Contour plots in a zoomed region of the $\mathrm{C}-\mathrm{H}-\mathrm{O}$ ternary diagram showing (a, left) the adiabatic reaction temperature and (b, right) the predicted hydrogen mole fraction in the product gas. Upon both graphs are laid the conditions predicted to result in an effluent temperature of $650^{\circ} \mathrm{C}$, with the conditions used in this study highlighted. 
The results for the reactor experiments are shown in Figure 6.50. On the $x$-axis is the steam-to-carbon ratio for the experiments considered. On the $y$-axis is the average synthesis gas yield over the course of the each experiment. What is not shown in Figure 6.50 is the trend of how the synthesis gas yield changes over time. For Experiments Nos. 4, 5, and 6 the synthesis gas yield was stable over the course of the experiment. For Experiments Nos. 1, 2, and 3 the activity decreased over time. This trend was more apparent at lower steam-to-carbon ratios. In Experiment \#1, the reaction had completely failed in the first four hours of the experiment.

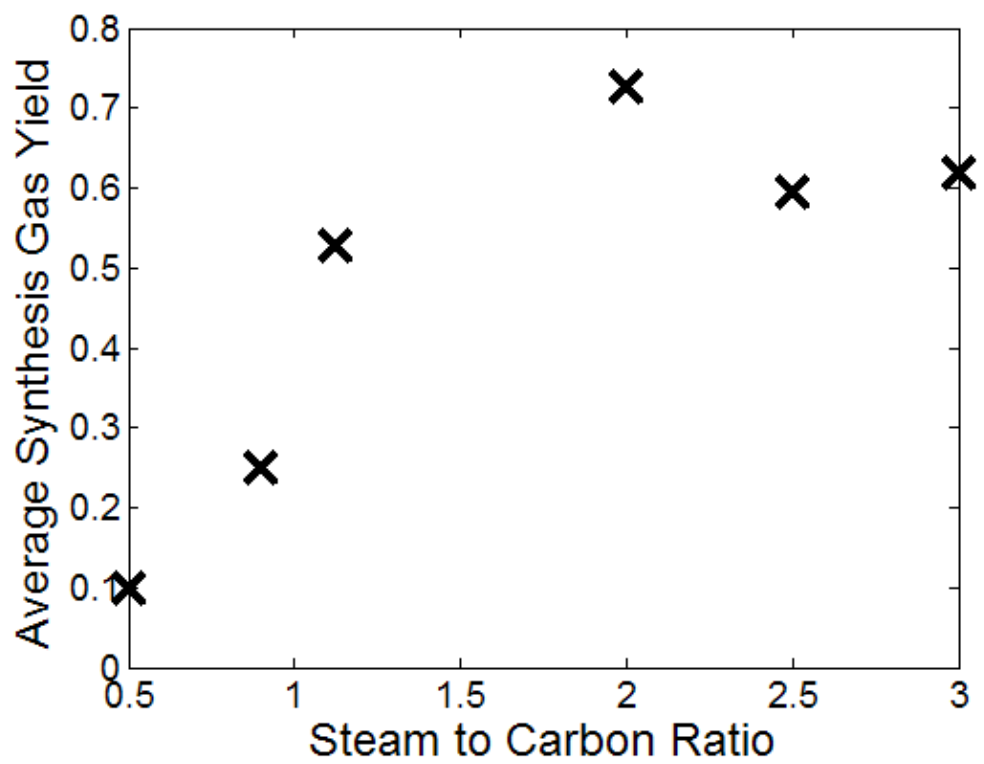

Figure 6.50. Results of the reactor experiments. Average yield of synthesis gas over the course of time-on-stream for the six different reaction conditions studied.

The results of these experiments did not support the initial hypothesis that the stability of the experiment would be related strongly to the predicted hydrogen composition. Based upon that hypothesis the highest average synthesis gas yield would have been expected for Experiment \#2, which based on the reactor studies had the second lowest. The explanation for this observation is the carbon deposition behavior. The amount of carbon deposited on the catalyst during the course of the experiment can be determined by analyzing Temperature Programmed Oxidation (TPO) curves. These were obtained using Thermogravimetric Analysis (TGA). The amount of carbon oxidized off the surface of the catalyst can be converted to an average carbon deposition rate over the course of the experiment. The minimum detectable rate of deposition using this method corresponds to about $0.3 \mathrm{mg}$ of carbon deposited per $\mathrm{g}$ of catalyst per hour. The results for the TPO analysis of the post-reaction samples are shown in Table 6.9. Results are omitted for Experiment \#1 due to the failure of the experiment due to large pressure drop, likely caused by excessive carbon deposition. 
Table 6.9. Carbon deposition rate as determined by TPO. Rate is given in units of $\mathrm{mg}$ of elemental carbon deposited per $\mathrm{g}$ of catalyst per hour of of time-on-stream.

\begin{tabular}{|l|l|}
\hline$\#$ & Average Rate \\
\hline 1 & N/A \\
\hline 2 & 53.6 \\
\hline 3 & 21.7 \\
\hline 4 & $\leq 0.3$ \\
\hline 5 & $\leq 0.3$ \\
\hline 6 & $\leq 0.3$ \\
\hline
\end{tabular}

The TPO results show that as the steam-to-carbon ratio is decreased the amount of carbon on the surface of the catalyst dramatically increased. This can be understood based upon the ternary diagram of

Figure 6.49, which shows that as the steam-to-carbon ratio is decreased there is less oxygen available in the reactor to oxidize carbon deposits as they form on the catalyst. Therefore, instead of refuting the original hypothesis related to sulfur deactivation depending upon the availability of hydrogen, there is additional information gained in this study, namely that the deactivation due to carbon deposition is highly dependent on the availability of oxygen.

This study has demonstrated the interconnectedness of deactivation routes of carbon and sulfur. Taken together these observations provide a basis for describing the optimum reaction conditions to consider for the autothermal reforming of isooctane within the presence of thiophene. Conditions should be considered which balance the need for elemental hydrogen and oxygen. Future work is required to understand the more fundamental interactions between sulfur contaminants and the catalyst structure. By understanding the chemical nature of how sulfur contamination blocks the reforming activity of nickel catalysts proper strategies may be developed for expanding the viable range of operating conditions. 
Alternate catalytic materials might offer improved tolerance to sulfur. Bimetallic materials have received considerable attention in the literature. The data presented here evaluates the catalytic properties and reforming performance of nickel based bimetallic catalysts.

The starting support material was synthesized by the coprecipitation of cerium and zirconium. Monometallic $10 \mathrm{wt} \% \mathrm{Ni}$ was prepared by the incipient wetness impregnation technique described in previous reports. Bimetallic materials were prepared by a co-precipitation of $\mathrm{Ni}$ and $\mathrm{X}$ metal precursor salts $\mathrm{X}=\mathrm{Cu}, \mathrm{Fe}, \mathrm{Sn}, \mathrm{Pt}$, and $\mathrm{Au})$. The final nominal loading of all bimetallic catalysts was $10 \mathrm{wt} \% \mathrm{Ni}$ and $0.5 \mathrm{wt} \% \mathrm{X}$.

Catalyst materials were characterized by their physical surface area (BET), metallic surface area $\left(\mathrm{H}_{2}\right.$ chemisorption), and reduction behavior (TPR). The microstructure of the catalysts was evaluated by scanning electron microscopy (SEM). The catalytic activity of all catalysts was compared under isooctane reforming using sulfur-free and thiophene contaminated $\left(\mathrm{H}_{2} \mathrm{O} / \mathrm{C}=1, \mathrm{O} / \mathrm{C}=0.75, \mathrm{GHSV}=200 \mathrm{k} \mathrm{hr}^{-1}\right)$.

The characterization of fresh monometallic and bimetallic catalysts showed that there was no significant difference in the physical surface area of any of the catalysts (Figure 6.51), however both the Ni-Sn and the Ni-Au systems demonstrated significant decreases in the amount of metallic surface area (Figure 6.52). SEM showed no significant differences in the bulk morphology of any of the catalysts(Figure 6.53). The $\mathrm{Ni}-\mathrm{Au}$ and $\mathrm{Ni}-\mathrm{Cu}$ systems showed essentially similar reduction features to the monometallic $\mathrm{Ni}$ systems. The Ni-Pt showed a new low-temperature reduction feature not seen in the monometallic catalyst. Both the Ni-Fe and Ni-Sn catalysts showed a shift in reduction toward a higher temperature (Figure 6.54 through Figure 6.59).

The activity for each catalyst was compared under sulfur-free and sulfur exposed conditions (Figure 6.59 through Figure 6.63). The Ni-Pt catalyst behaved very similarly to the $\mathrm{Ni}$ catalyst under both conditions. This catalyst should be tested at higher sulfur concentrations to determine which material is more sulfur tolerant. The Ni-Fe catalyst was not as active as $\mathrm{Ni}$ under sulfur free conditions but was not significantly affected by the presence of sulfur before the reaction was interrupted at 5 hours. The $\mathrm{Ni}-\mathrm{Cu}, \mathrm{Ni}-\mathrm{Au}$, and Ni-Sn catalysts all performed poorly under sulfur-free or thiophene-exposed conditions as compared to monometallic Ni catalysts. 


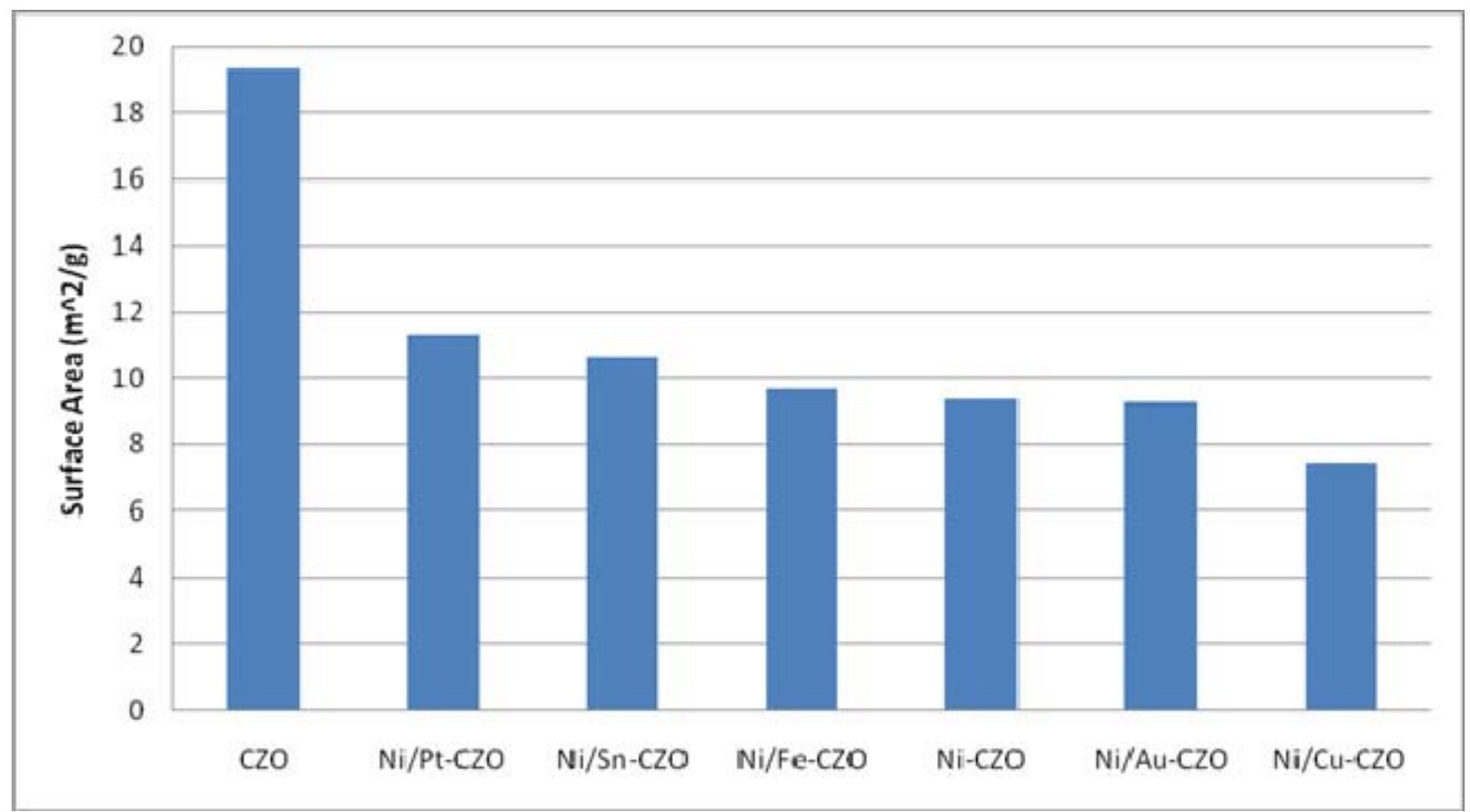

Figure 6.51. BET Surface area of catalysts

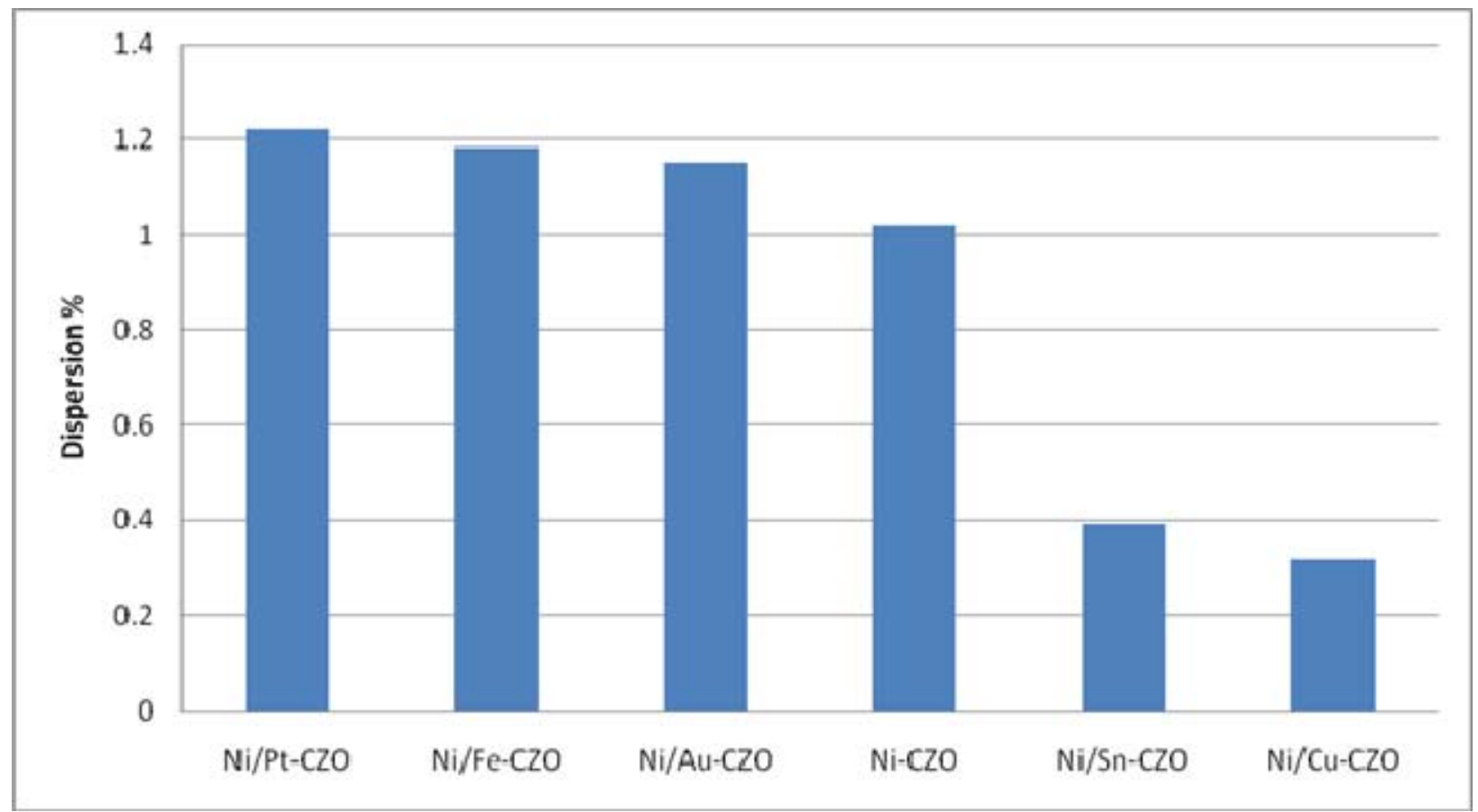

Figure 6.52. Results of $\mathrm{H}_{2}$ chemisorption 


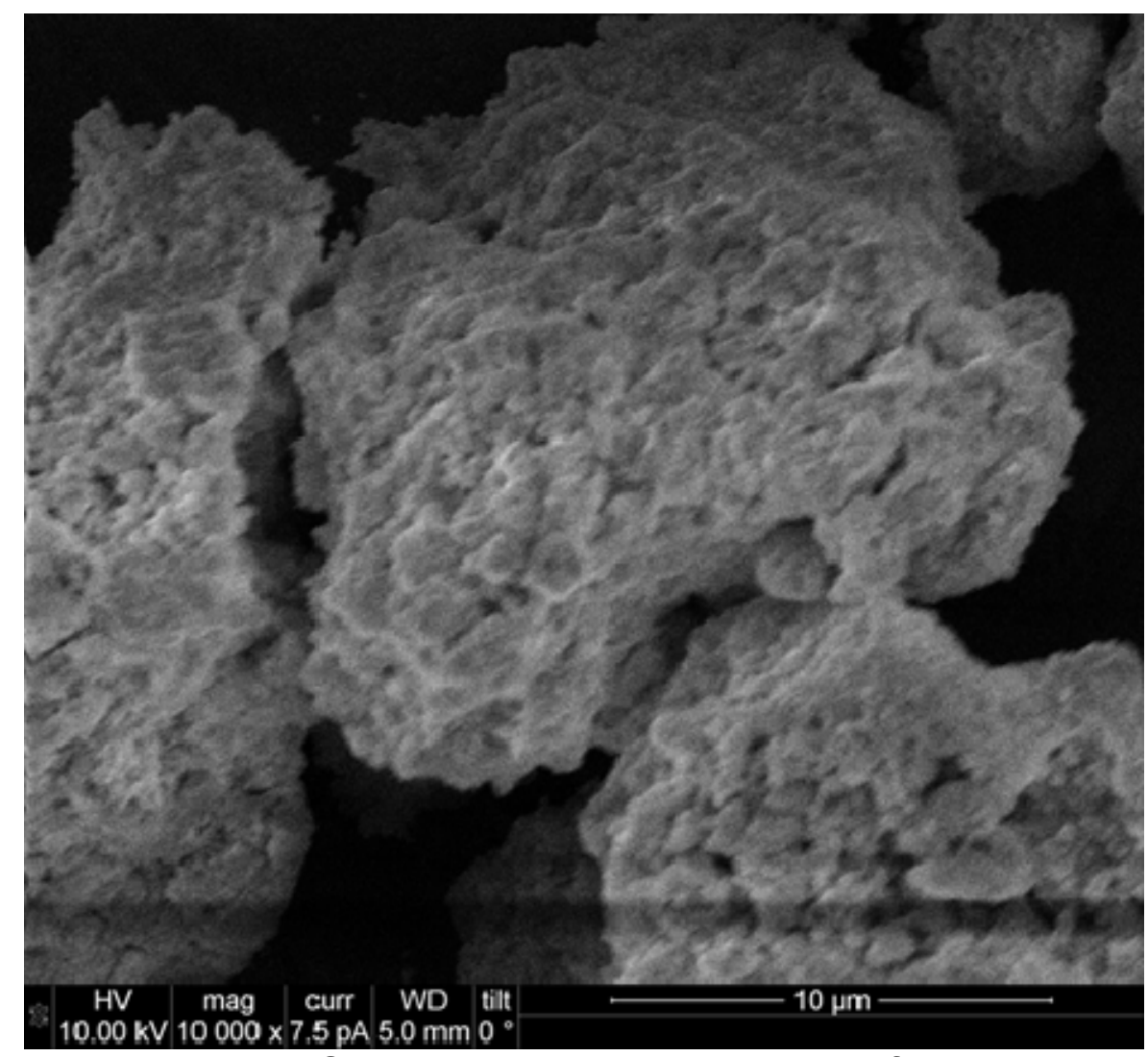

Figure 6.53. Representative Scanning Electron Micrograph of catalyst material

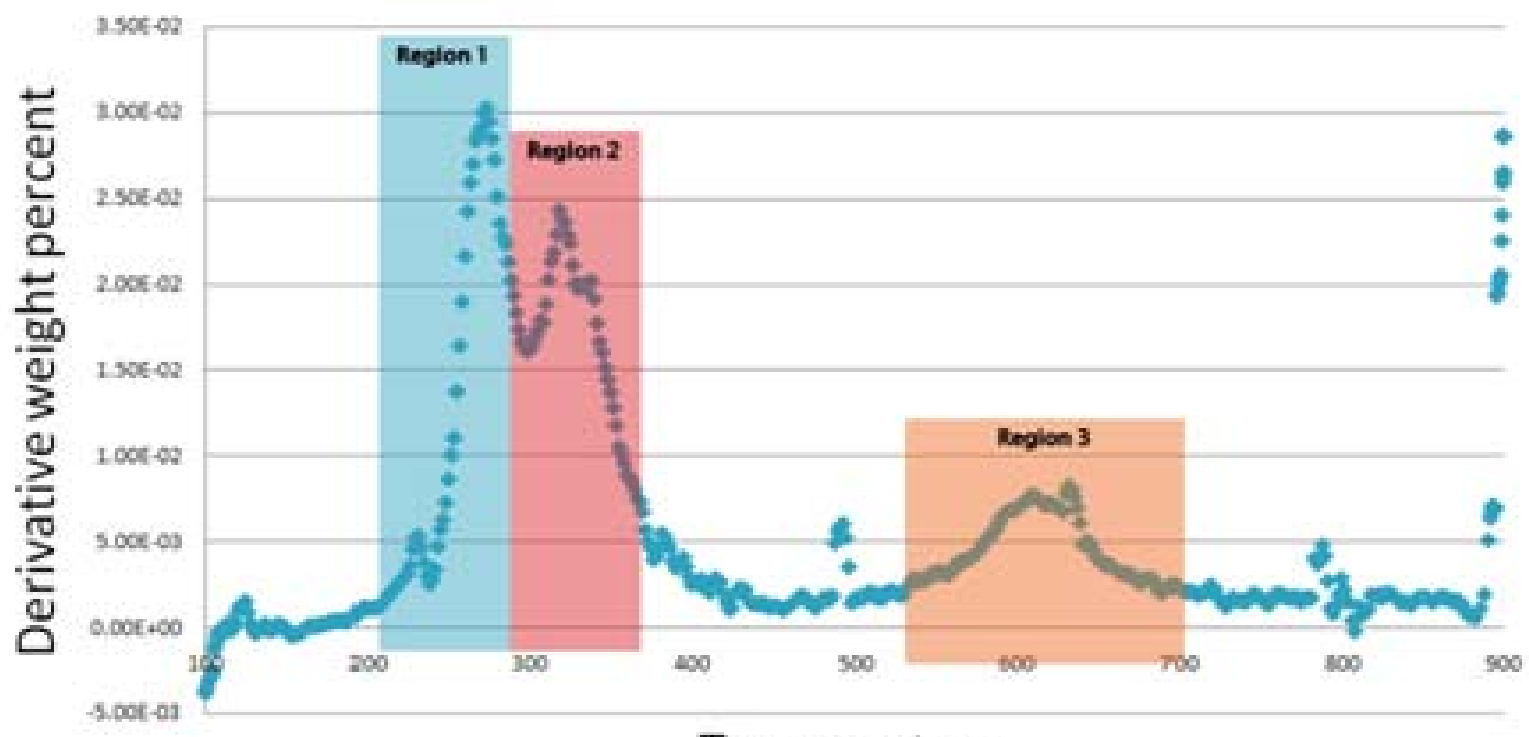

Temperature

Figure 6.54. Representative TPR dTGA curve for $\mathrm{Ni}, \mathrm{Ni} / \mathrm{Au}$ and $\mathrm{Ni} / \mathrm{Cu}$ samples showing the three reduction features 


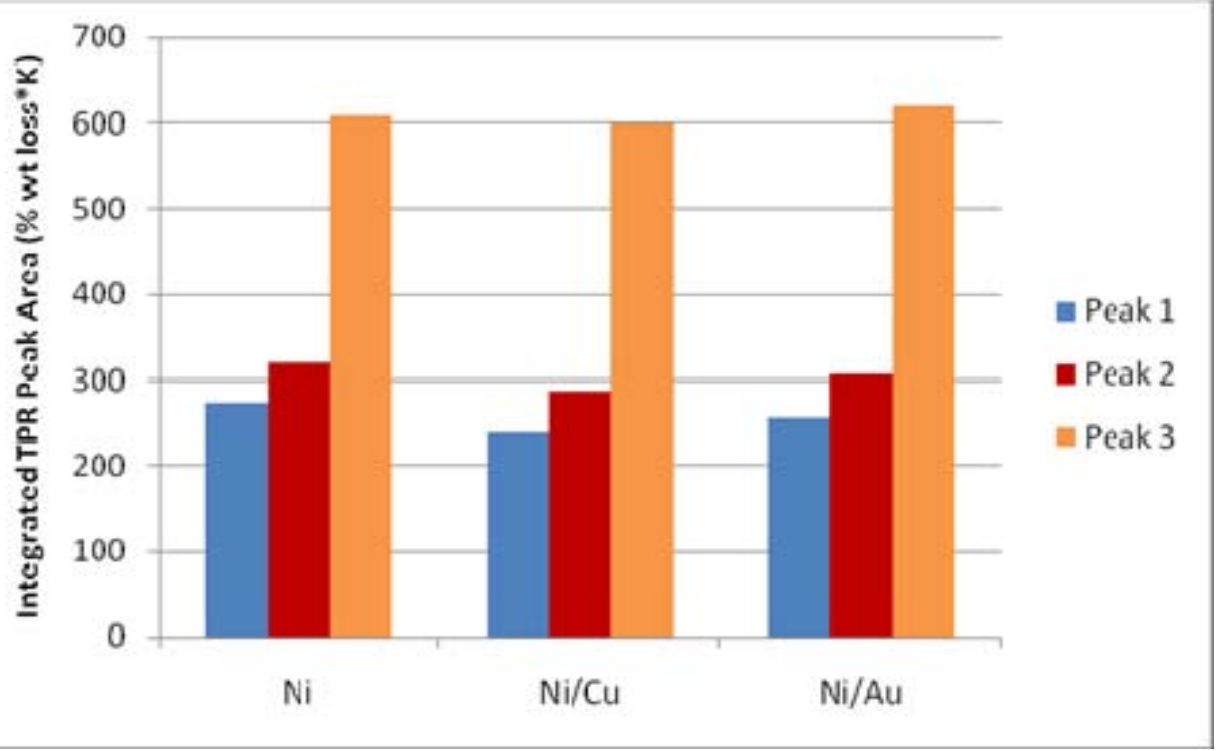

Figure 6.55. Numerical results from TPR of $\mathrm{Ni}, \mathrm{Ni} / \mathrm{Cu}$, and $\mathrm{Ni} / \mathrm{Au}$ samples

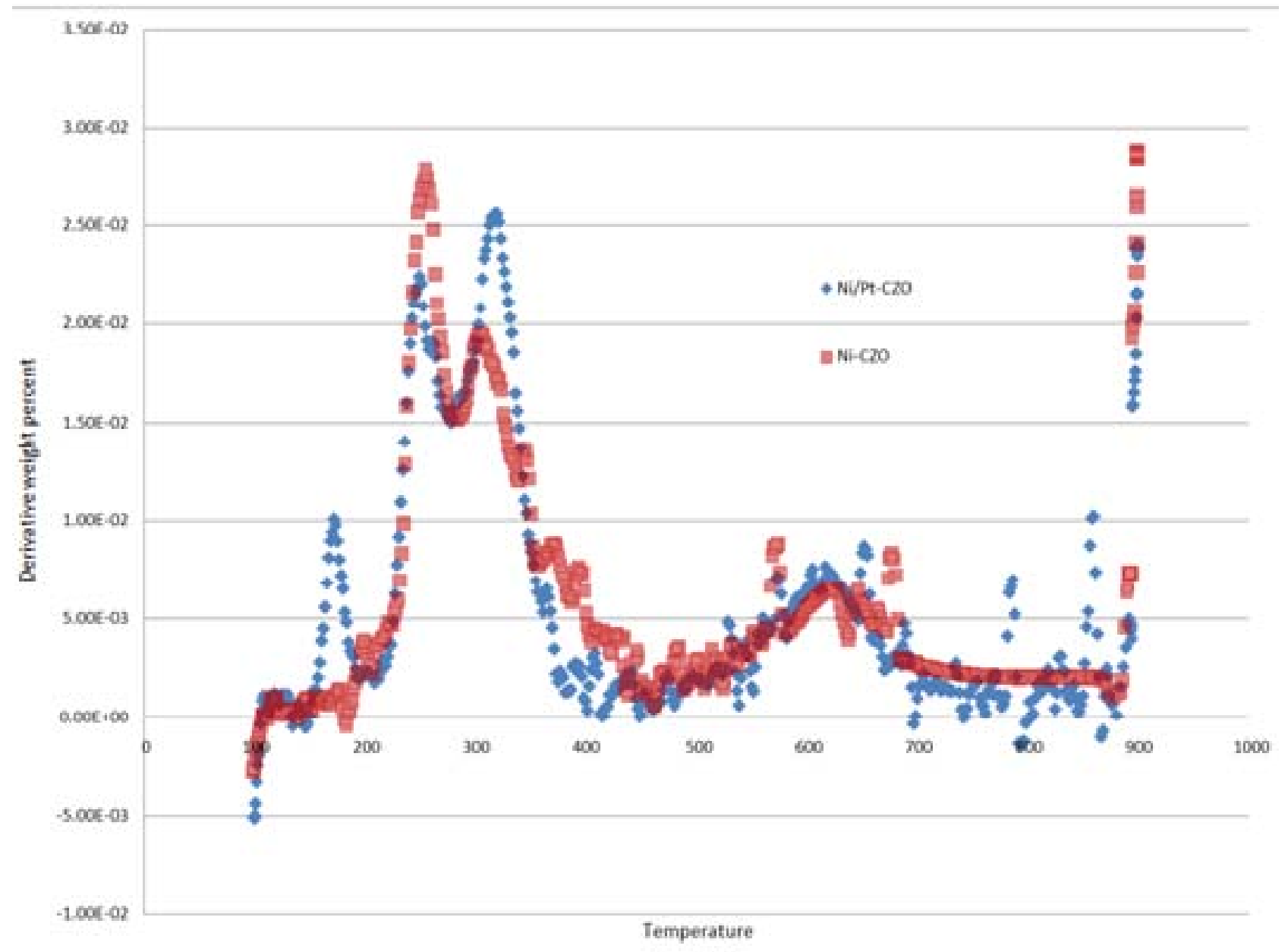

Figure 6.56. TPR comparison of $\mathrm{Ni}-\mathrm{Pt}$ and $\mathrm{Ni}$ 


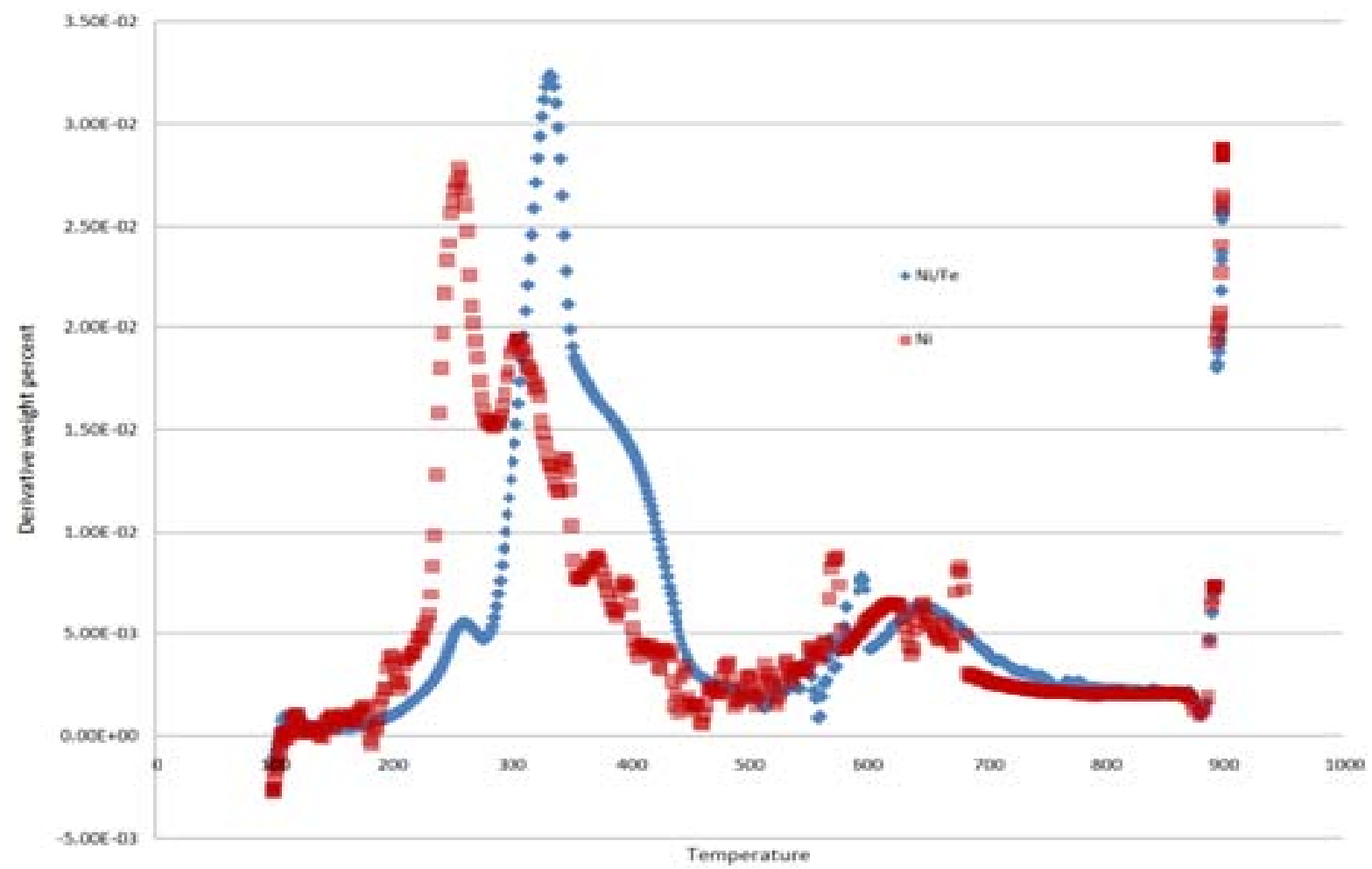

Figure 6.57. TPR Comparison of $\mathrm{Ni}-\mathrm{Fe}$ and $\mathrm{Ni}$ catalysts

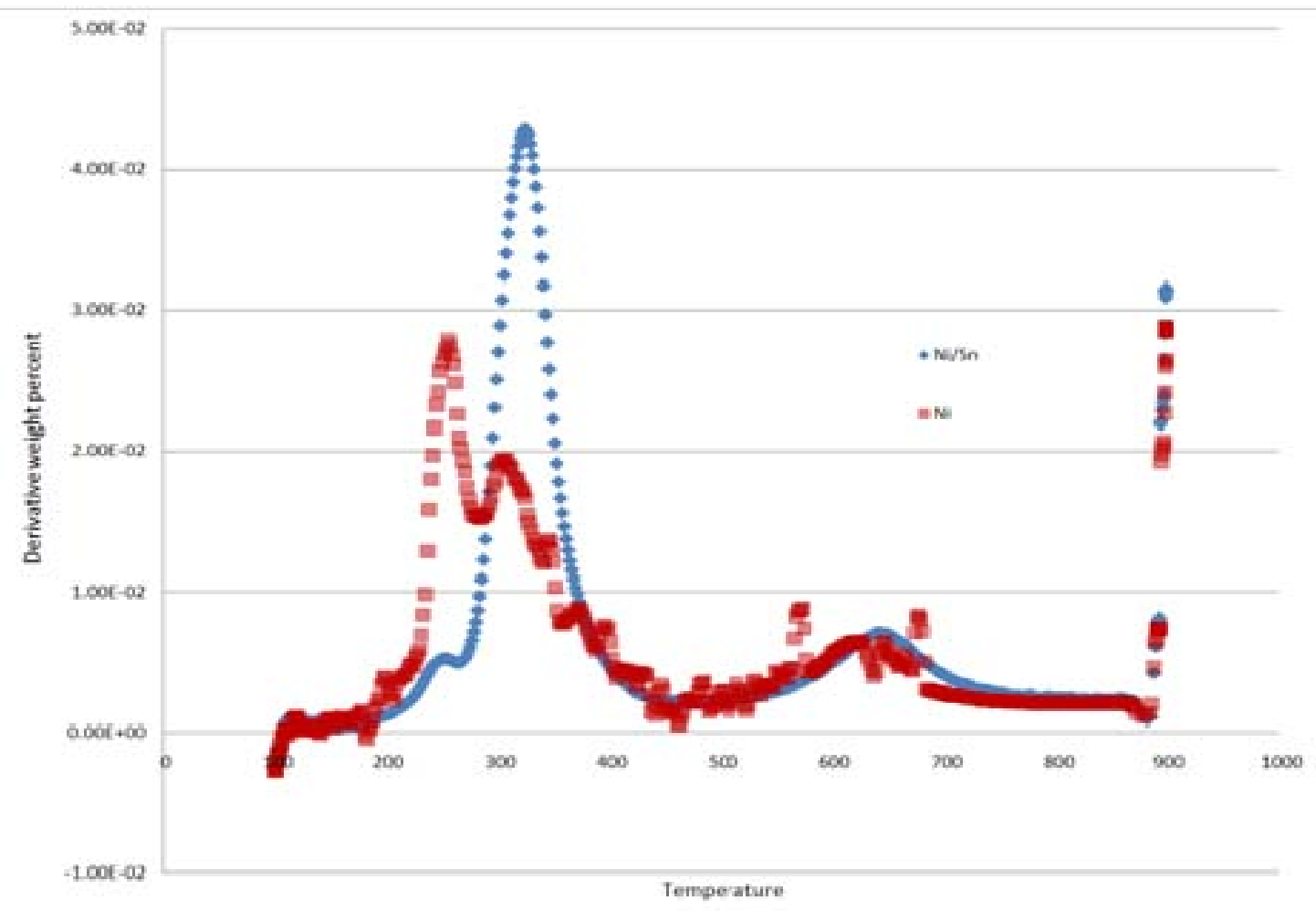

Figure 6.58. TPR comparison of $\mathrm{Ni}-\mathrm{Sn}$ and $\mathrm{Ni}$ catalysts 


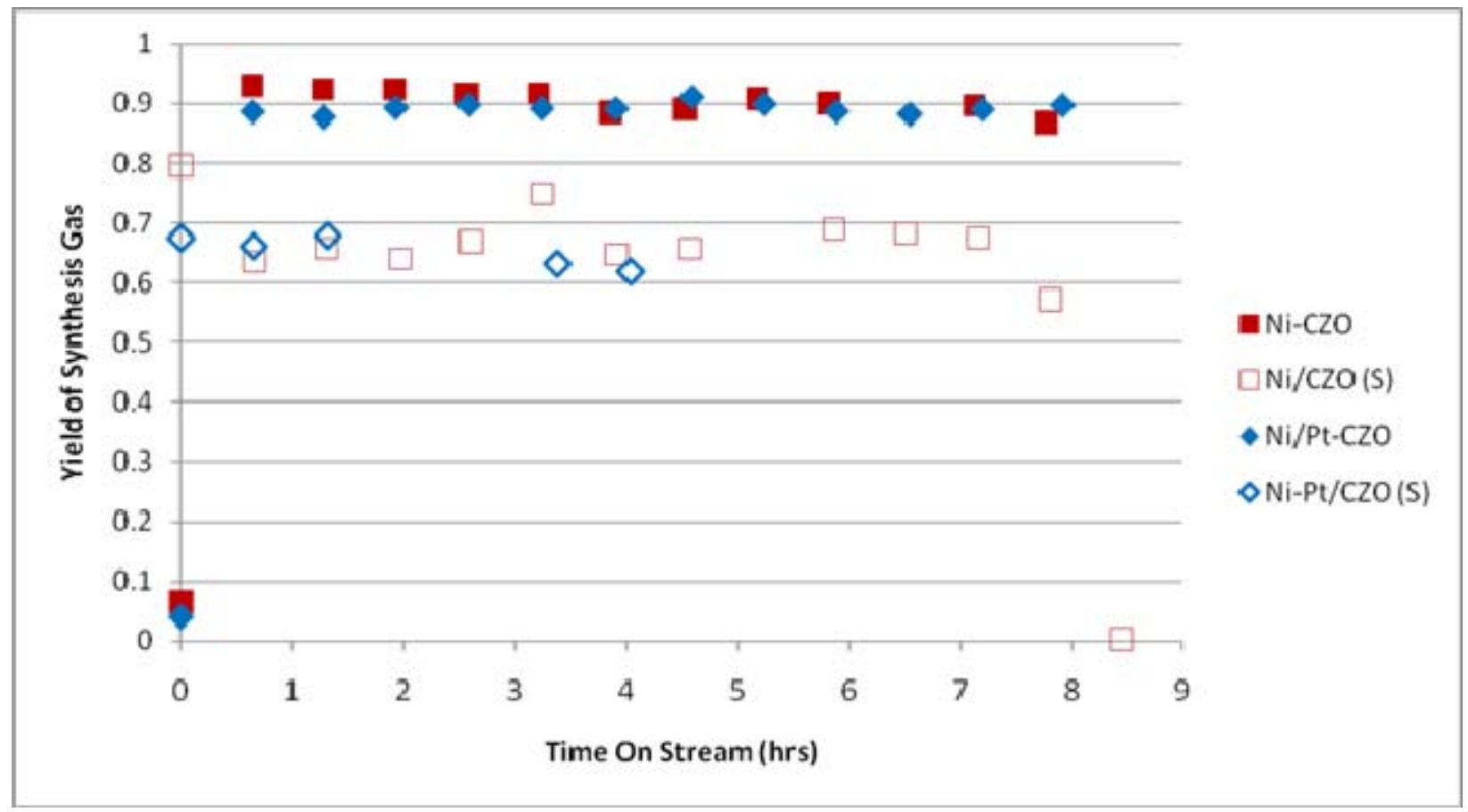

Figure 6.59. Activity of Ni-Pt compared to Ni. Closed symbols indicate sulfure-free, and open symbols indicate thiophene exposed experiments. 


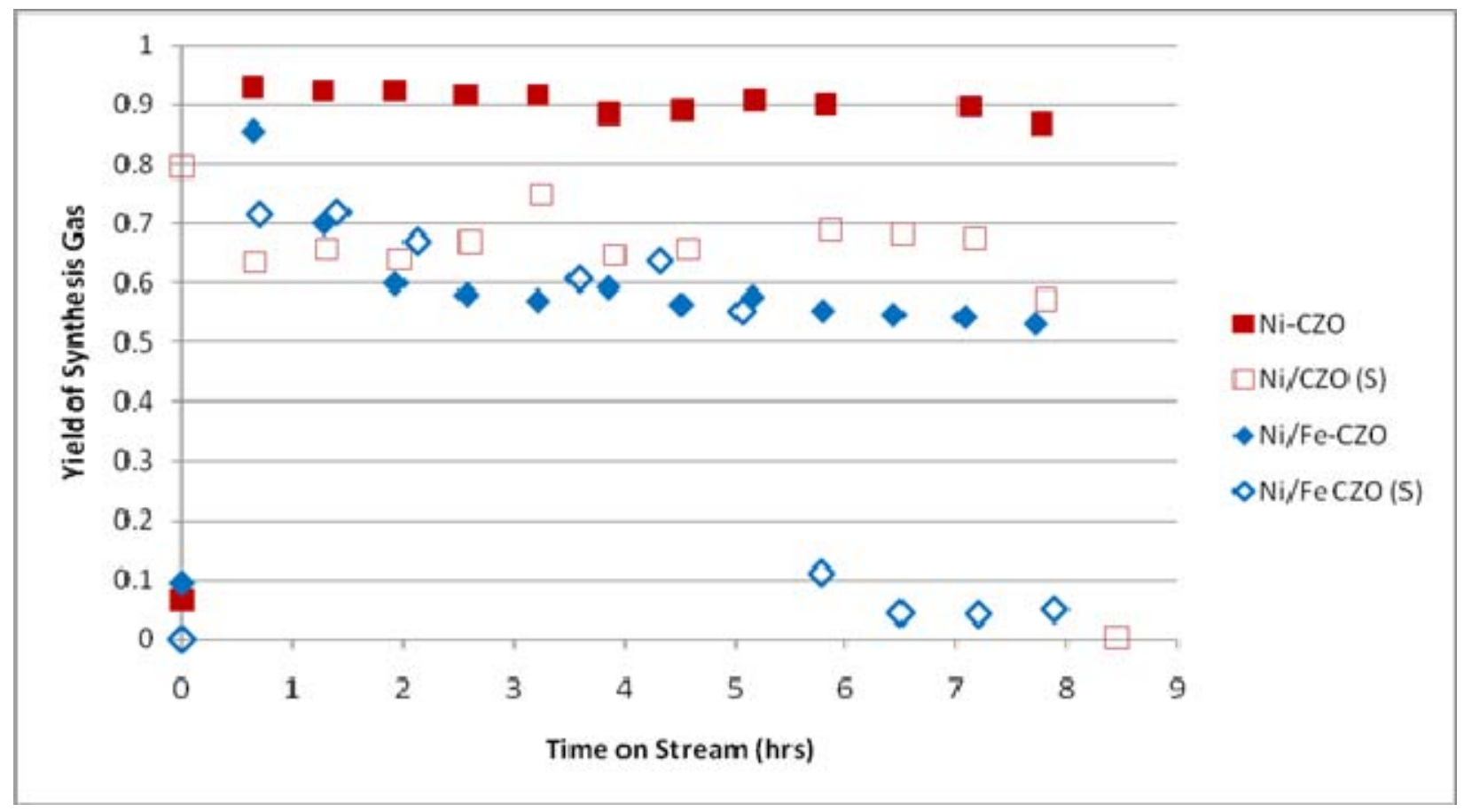

Figure 6.60. Activity of $\mathrm{Ni}-\mathrm{Fe}$ compared to $\mathrm{Ni}$. Closed symbols indicate sulfure-free, and open symbols indicate thiophene exposed experiments.

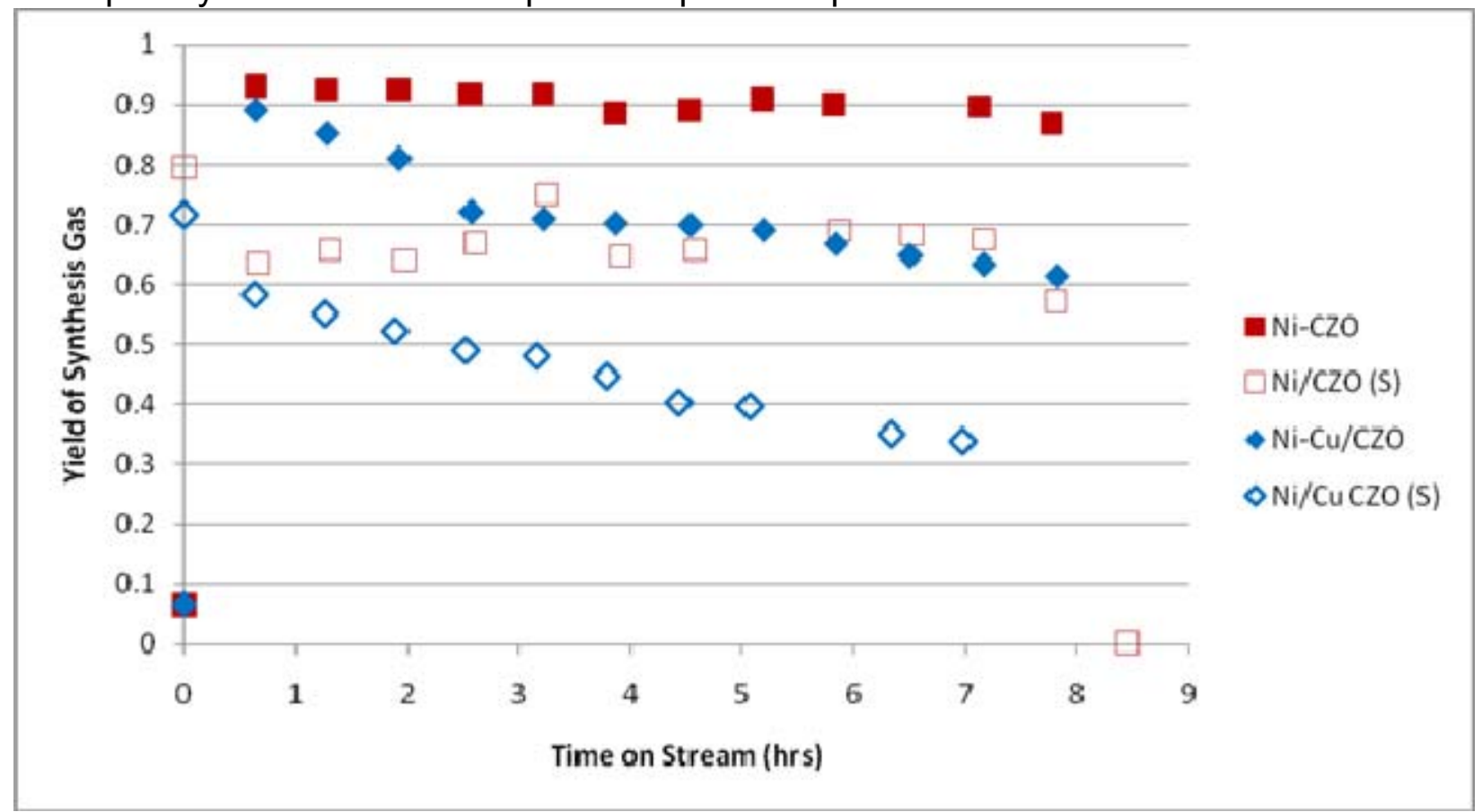

Figure 6.61. Activity of $\mathrm{Ni}-\mathrm{Cu}$ compared to $\mathrm{Ni}$. Closed symbols indicate sulfure-free, and open symbols indicate thiophene exposed experiments. 


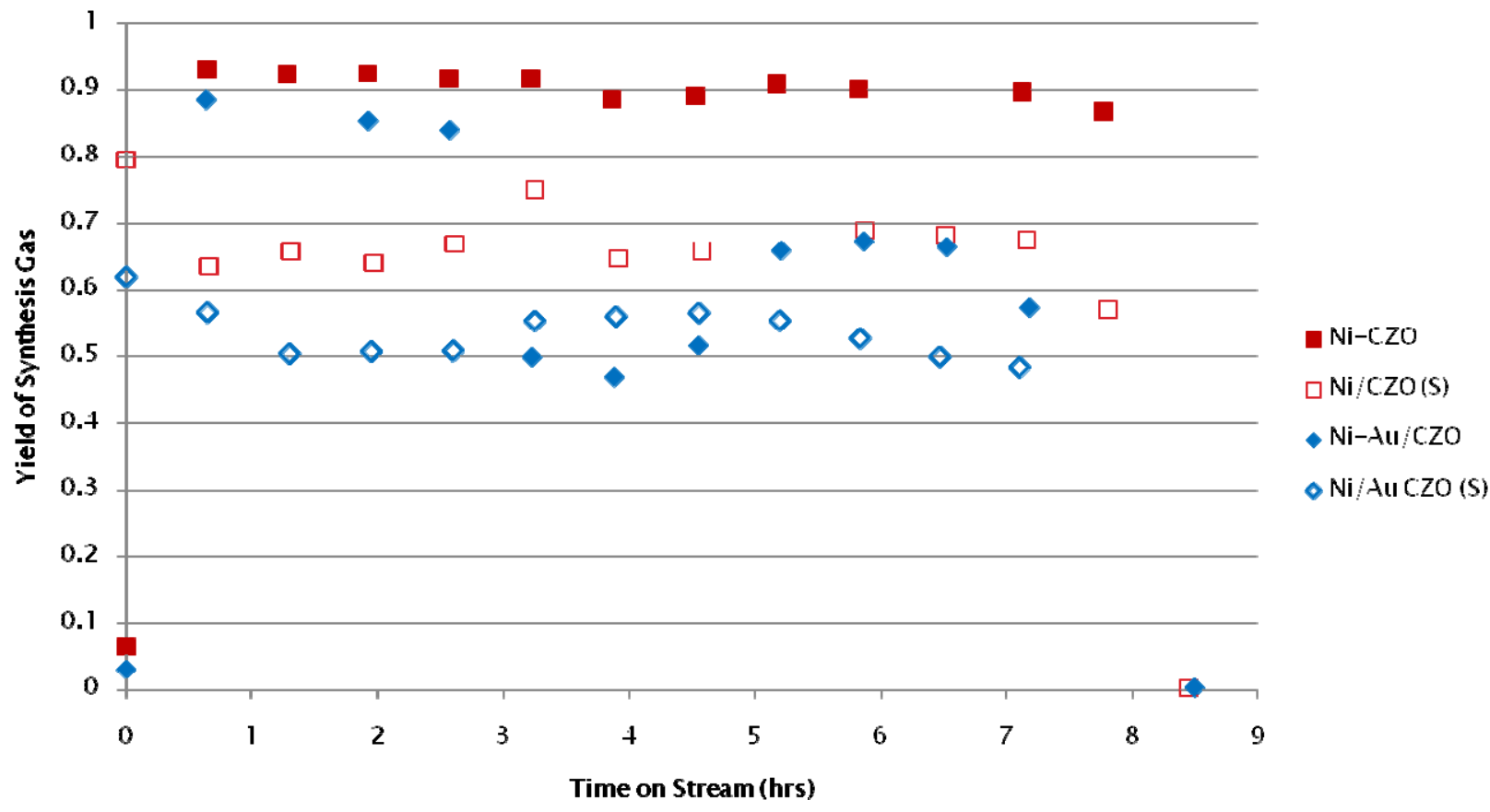

Figure 6.62. Activity of $\mathrm{Ni}-\mathrm{Au}$ compared to $\mathrm{Ni}$. Closed symbols indicate sulfure-free, and open symbols indicate thiophene exposed experiments.

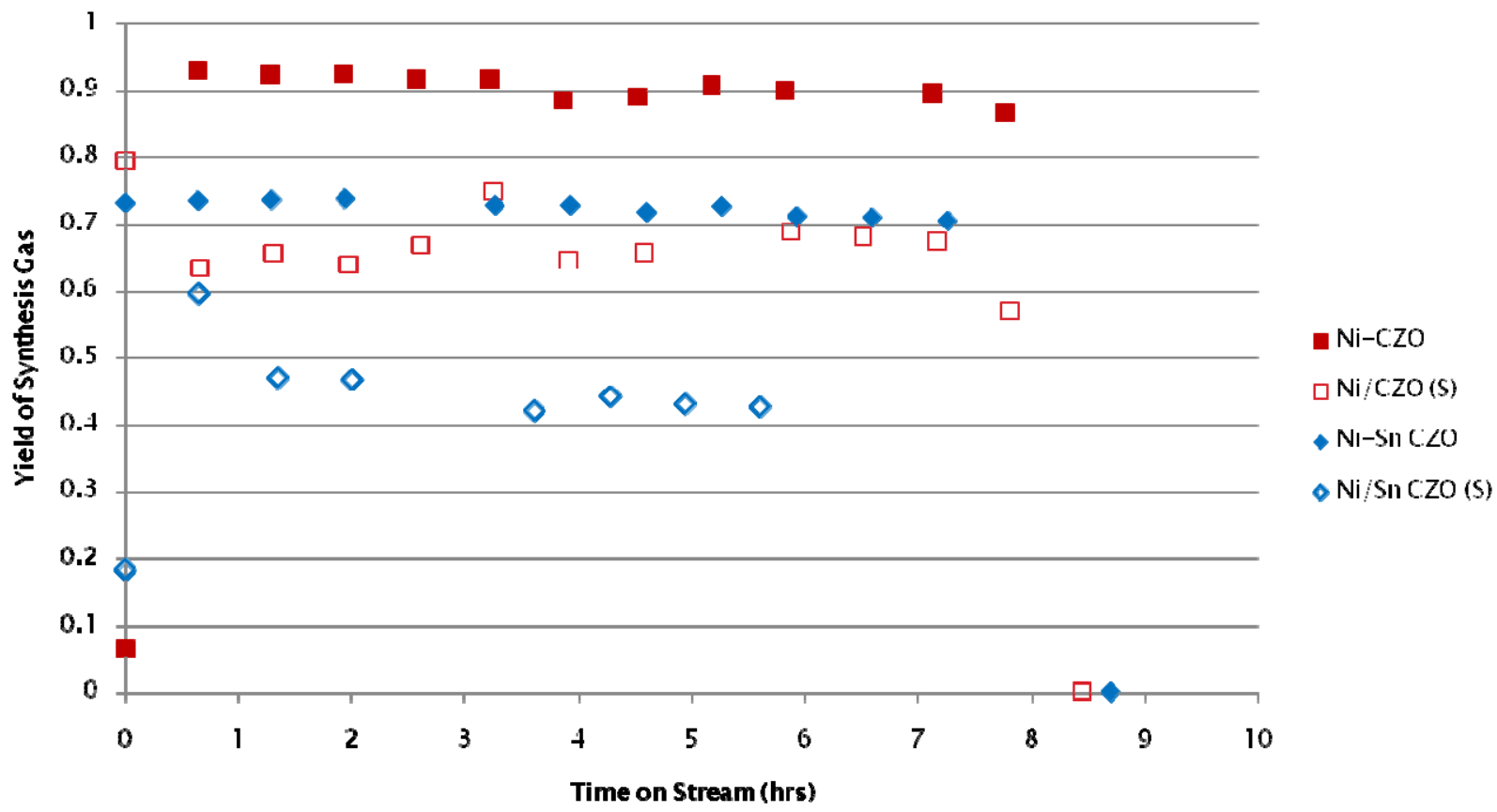

Figure 6.63. Activity of $\mathrm{Ni}-\mathrm{Sn}$ compared to $\mathrm{Ni}$. Closed symbols indicate sulfure-free, and open symbols indicate thiophene exposed experiments. 
A final thrust of investigation was to consider the effect of the properties of the catalytic metal particles. Historically, our group has been able to prepare Ni/CZO catalysts with varying mean nickel particle sizes by varying the nickel loading. We have found, however, that the total nickel surface area has also varied with the loading, leading to a confounding of effects. To isolate the effects of particle size, if any, on sulfur tolerance, a series of $\mathrm{Ni} / \mathrm{CZO}$ catalysts of various weight loadings was prepared. The samples with higher metal loadings were sintered under a steam/hydrogen atmosphere to reduce the active surface area and increase the metal particle size. This yielded a series of $\mathrm{Ni} / \mathrm{CZO}$ catalysts with the same active surface area but very different particle sizes (Figure 6.64 and Figure 6.65).

These catalysts were tested for autothermal reforming of isooctane with and without thiophene. The reaction conditions were chosen to avoid carbon deposition, which would interfere with elucidation of the effects of $\mathrm{S}$. $\mathrm{A} \mathrm{H}_{2} \mathrm{O} / \mathrm{C}$ ratio of 3 and an $\mathrm{O} / \mathrm{C}$ ratio of 0.75 were used at a GHSV of $200,000 \mathrm{hr}^{-1}$. For runs with S, a concentration of thiophene in the isooctane feed yielding a $S$ loading of $76 \mathrm{ppmw}$ was used.

Figure 6.66 and Figure 6.67 present the results of the reforming experiments. The initial hypothesis was that small nickel particles would result in the most active catalysts due the higher proportion of low-coordinated sites. In fact, under S-free conditions, the larger metal particles proved to be more active on an areal basis. Under reaction with $S$ in the fuel, the smallest nickel particles showed little change in performance, while the largest nickel particles showed a drop in performance. Initial characterization results suggest that the differences in activity and sulfur tolerance may be related to the oxidation state of the nickel, with small particles being less metallic than larger ones. 


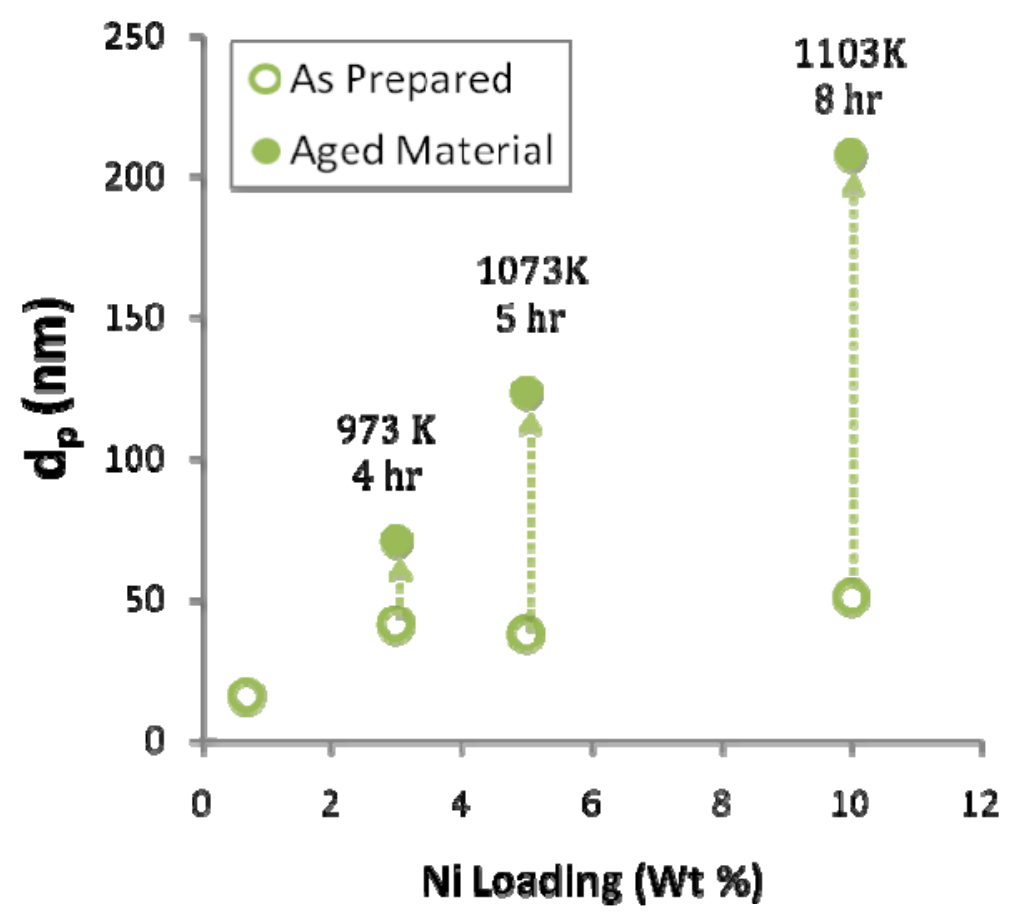

Figure 6.64. Nickel particle diameters as determined by $\mathrm{H}_{2}$ chemisorption for asprepared and sintered catalyst samples.

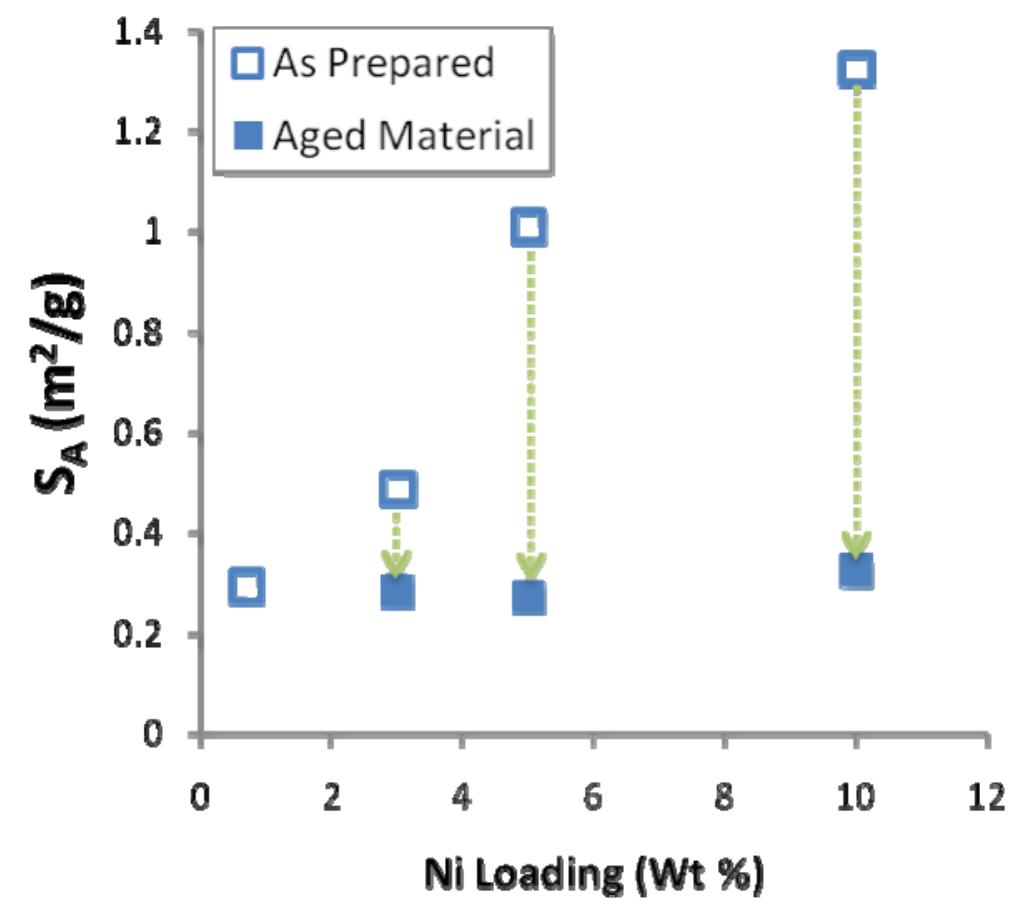

Figure 6.65. Nickel surface area as determined by $\mathrm{H}_{2}$ chemisorption for as-prepared and sintered catalyst samples. 


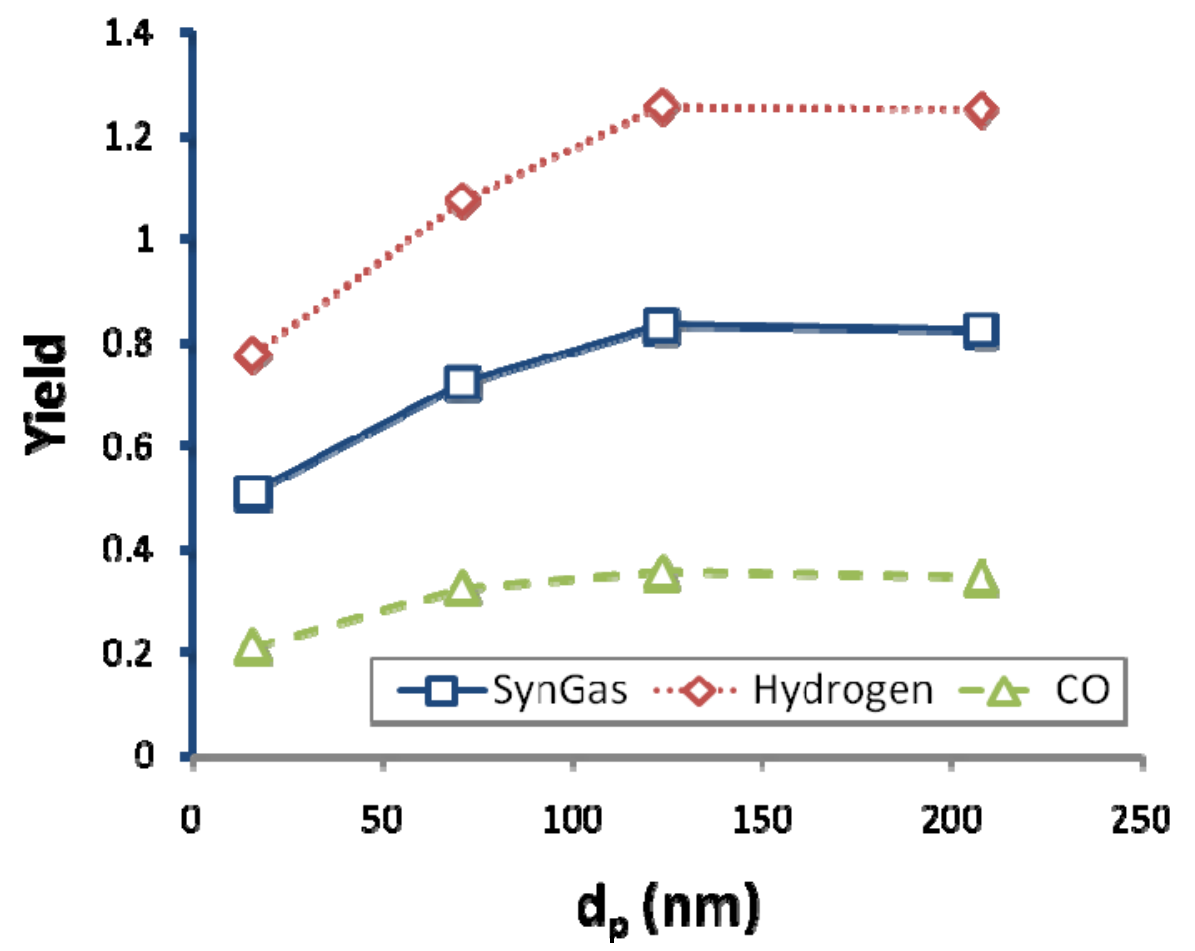

Figure 6.66. Product yields as a function of Ni particle diameter in S-free operation.

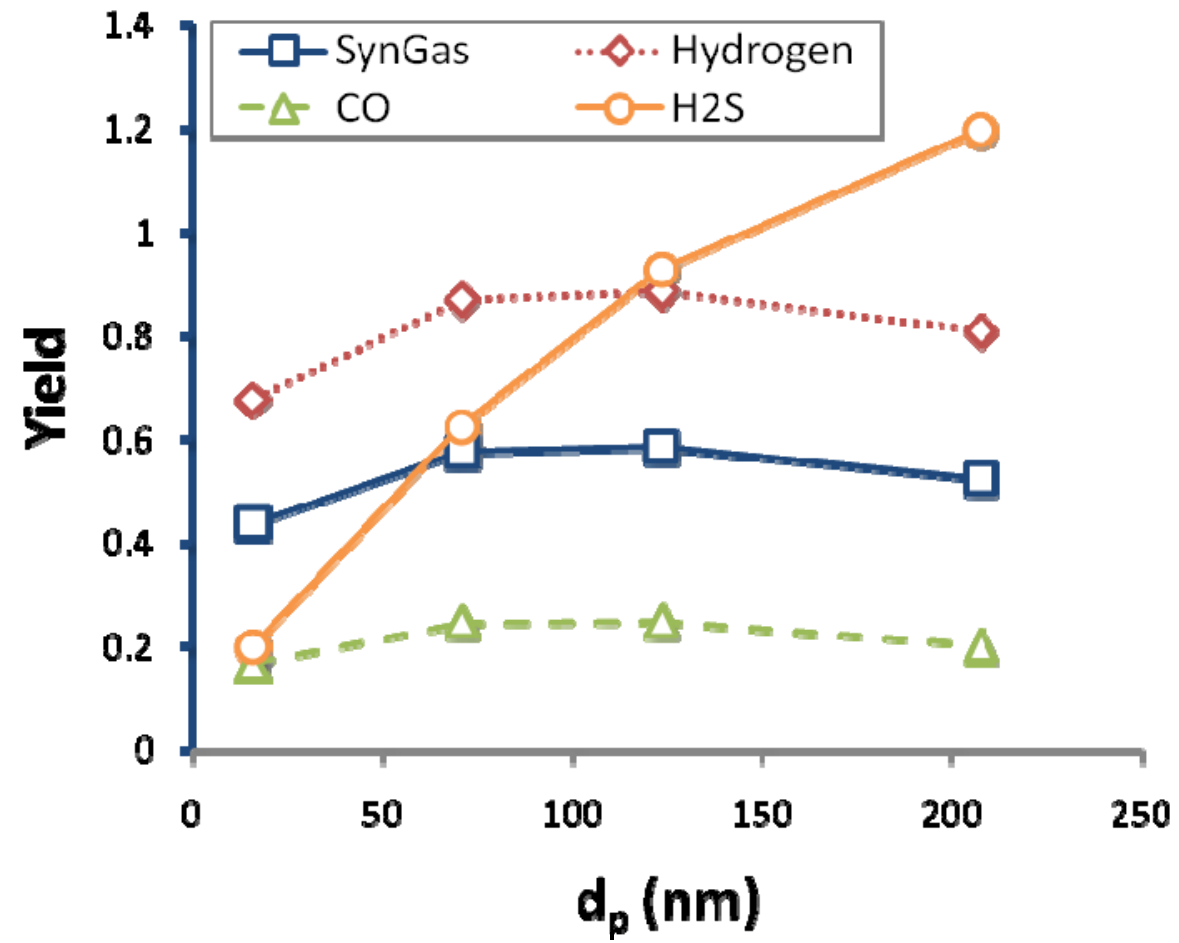

Figure 6.67. Product yields as a function of particle diameter at $76 \mathrm{ppmw} S$ in the fuel. 
Though it is known that biomass mainly consists of three macrocomponents; cellulose, hemicelluloses and lignin, every sample of biomass consists of different proportions of these and they control its decomposition. Hence, it is very important to quantify the amount of these macro-components present in a given sample of biomass.

Conventional methods exist for the determination of cellulose, hemicellulose and lignin. Biomass treated with $1 \%(\mathrm{w} / \mathrm{v}) \mathrm{NaOH}$ solution is known to undergo alkaline hydrolysis of hemicelluloses. Lignin can be quantified by the Klason method, which is basically an acid hydrolysis; and the amount of cellulose is obtained as a difference.

Characterization methods involving the analysis of TGA data also exist. The TG and the DTG peaks of the biomass samples as well as the pure macro-components are obtained. The DTG peaks of the biomass samples are approximated to that of the pure components as a weighted sum. Catalysts for biomass gasification have existed since the 1980s. Most of the catalysts have been developed with an intention of removal of tar from the products and reduction of methane content. The catalysts used have been broadly classified into two groups: primary (ones which are directly mixed with biomass prior to gasification) and secondary (ones used for post-gasification conversion).

Identification and analysis of the product gases evolved from the pyrolysis/gasification of biomass is of utmost importance in its usage as a source of both fuels and chemicals. Biomass decomposes over a wide temperature range. Whilst we are interested in the production of syn-gas, this work is also an attempt to understand the decomposition of biomass in different atmospheres and identify the products of the decomposition on the basis of their functional groups over the whole temperature range. This would provide a fingerprint of biomass decomposition and the products evolved at every stage. The effect of various catalysts in influencing product yields is also being considered. The ultimate aim would be to identify and recognize the volatiles being evolved at lower temperatures and evaluate the feasibility of usage of such products for this project.

Two different types of biomass samples were used for initial experiments. Oakwood and pinewood, which are easily available, were used. The biomass samples were milled to sizes around 40 mesh $(\approx 420 \mu \mathrm{m})$.

The catalysts used for this investigation were nickel on a ceria-zirconia mixed oxide (Ni/CZO) with $10 \%$ Ni-loading and $\mathrm{Pt}^{-} / \mathrm{Al}_{2} \mathrm{O}_{3}$ with $1 \% \mathrm{Pt}$ loading. Both these catalysts had been pre-synthesized and limited quantities were available for use.

A TA Q500 TGA was used for experiments described here. Samples of 10-20mg of biomass were heated at a ramp rate of $5^{\circ} \mathrm{C} / \mathrm{min}$ in different atmospheres to a final temperature of $800^{\circ} \mathrm{C}$ in gases $\left(\mathrm{N}_{2}\right.$ and Air) flowing at $30 \mathrm{ml} / \mathrm{min} .5^{\circ} \mathrm{C} / \mathrm{min}$ was chosen because it gives reasonable estimates for peak differentiation and optimum time required for an experiment. In experiments with catalysts, the biomass and the catalysts were physically mixed.

A simple flow reactor consisting of a glass U-tube placed in a furnace, with the inlet connected to a gas source and the outlet to either a sampling system or the vent was constructed. Different quantities of biomass samples were placed on a quartz wool support and a thermocouple was introduced to record the temperature changes. A soap film meter was used to measure the gas flow rates.

Various techniques were used in an attempt to identify the product gases. Gas sampling bulbs were used to trap the gaseous products were collected at different peak 
temperatures in gas sampling bulbs with sampling ports. Samples from the bulbs were taken in micro-syringes and analyzed by gas chromatography (GC). Solvent traps were also used. In order to concentrate the gaseous products from the flow reactor, they were passed through a vial of acetone dipped in an ice bath to dissolve the gases. This was then analyzed with a GC/MS. Since further concentration of the products was necessary, the product gases were taken to a U-tube dipped in liquid $\mathrm{N}_{2}$. The ends of the U-tubes were then sealed with septum ports and brought back to room temperature. The gases evolved were analyzed with the GC and the GC/MS was used to analyze liquid products.

The decomposition of oak is shown in Figure 6.68 along with the decomposition of the pure macro-components: cellulose, lignin and xylan (a hemicelluloses substitute) in an inert atmosphere. Though we are not interested in the exact percentage composition of the sample, the plots give us a fair idea about what biomass macrocomponent the peaks correspond to. It is well known that the shoulder is due to the hemicelluloses and the peak due to cellulose and lignin. Hence the results are in excellent agreement with literature.

Figure 6.69 shows the decomposition of oak in atmospheres of $\mathrm{N}_{2}$ and air. In nitrogen, it is observed that about $80 \%$ of the biomass is pyrolyzed at about $375^{\circ} \mathrm{C}$ and at the end of the experiment, about $15 \%$ of the total carbon in the biomass is left over as char. However, in air, we observe a sharp removal of the 14 carbon, with a loss of about $70 \%$ at temperatures of around $325^{\circ} \mathrm{C}$ and a further gradual loss of the remaining carbon to almost zero at about $480^{\circ} \mathrm{C}$. This indicates that the oxygen present in superstoichiometric amounts in the air combusts even the inactive carbon present as char. Also discernable in the DTG peaks are the pronounced shoulders and wider peaks for decomposition in $\mathrm{N}_{2}$. This is because the heating rate employed is low and pyrolysis, being an endothermic process, causes the biomass to lose mass slowly. Oxidation on the other hand is exothermic and hence causes a quick mass loss in the system. 


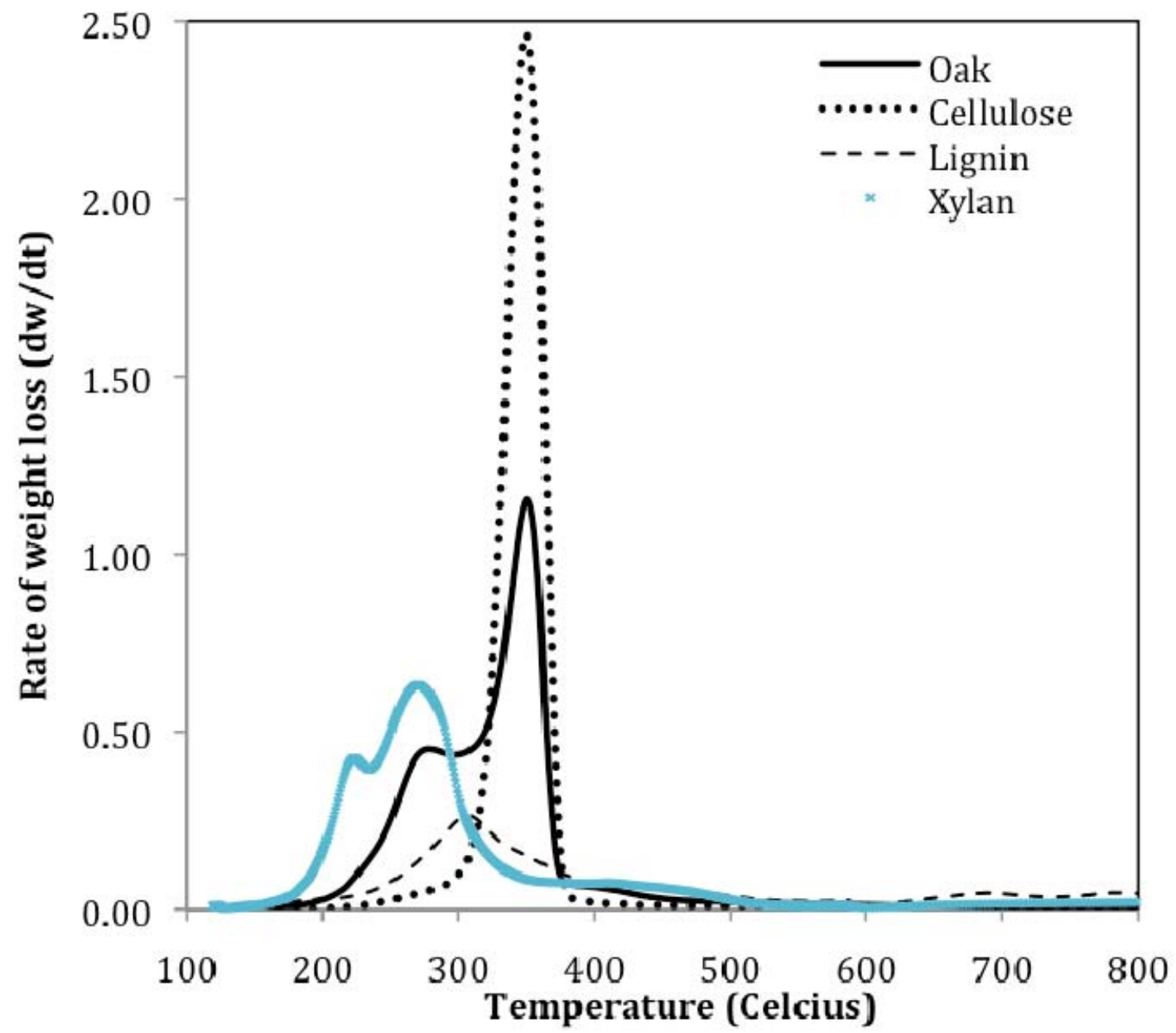

Figure 6.68. Pyrolysis of biomass and model components in air. 


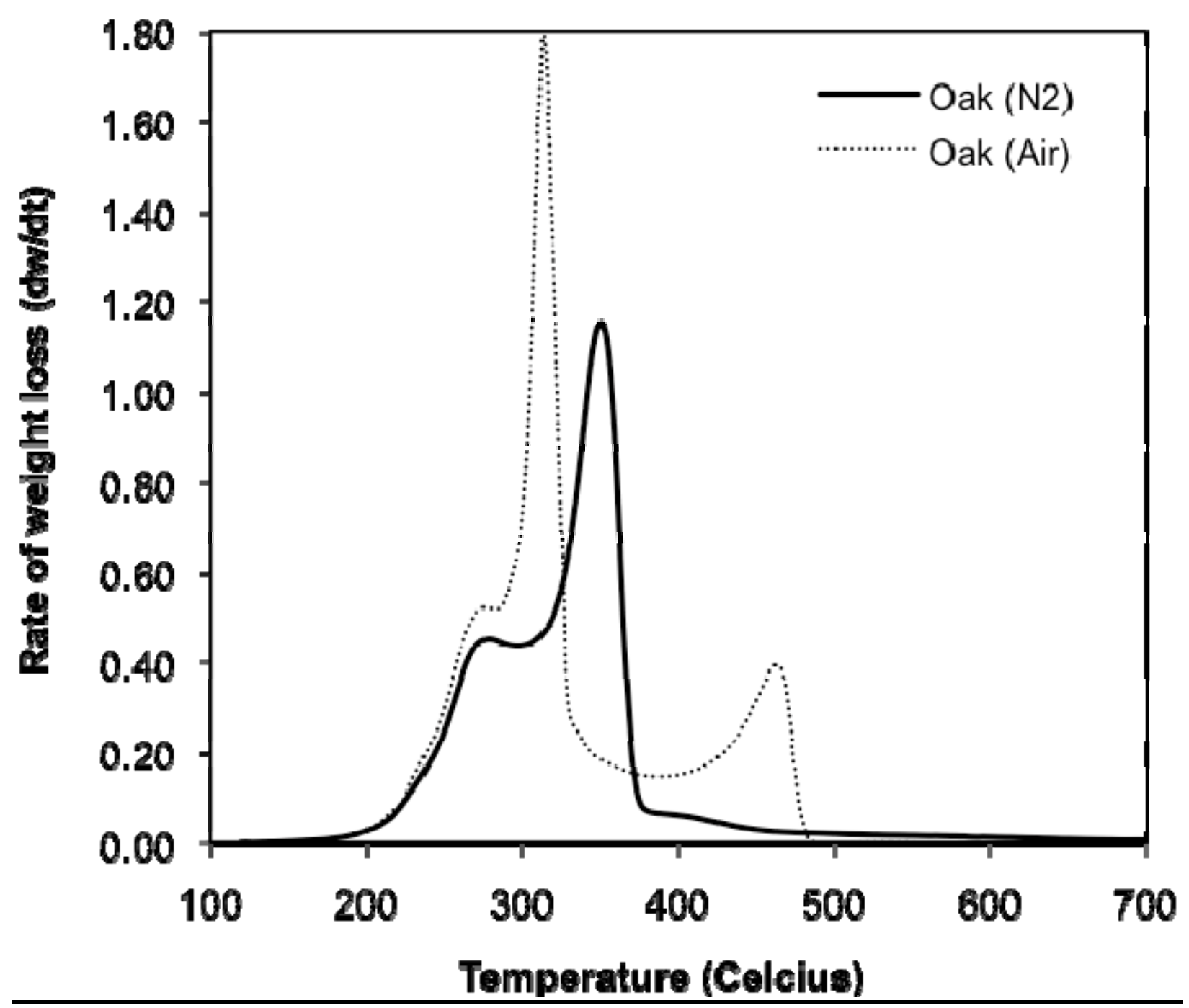

Figure 6.69. Pyrolysis of biomass and model components in $\mathrm{N}_{2}$.

The effects of both $\mathrm{Pt} / \mathrm{Al}_{2} \mathrm{O}_{3}$ and $\mathrm{Ni} / \mathrm{CZO}$ catalysts on the decomposition of biomass were studied in an atmosphere of air. In Figure 6.70, the results are compared to decomposition without a catalyst. Though $\mathrm{Ni}$ as a catalyst has been widely used in literature for biomass gasification, Ni/CZO does not seem to have any effect on the rate of decomposition. This is probably due to the fact that gasification conditions are never achieved in the TGA. There is always an excess amount of oxygen in the system, a constraint of the system, which probably oxidizes the active $\mathrm{Ni}$ surface to $\mathrm{NiO}$, thereby rendering the nickel catalyst inactive. $\mathrm{Pt} / \mathrm{Al}_{2} \mathrm{O}_{3}$ on the other hand, is a very well known combustion catalyst and is successful in shifting the weight loss curves to lower temperatures. 


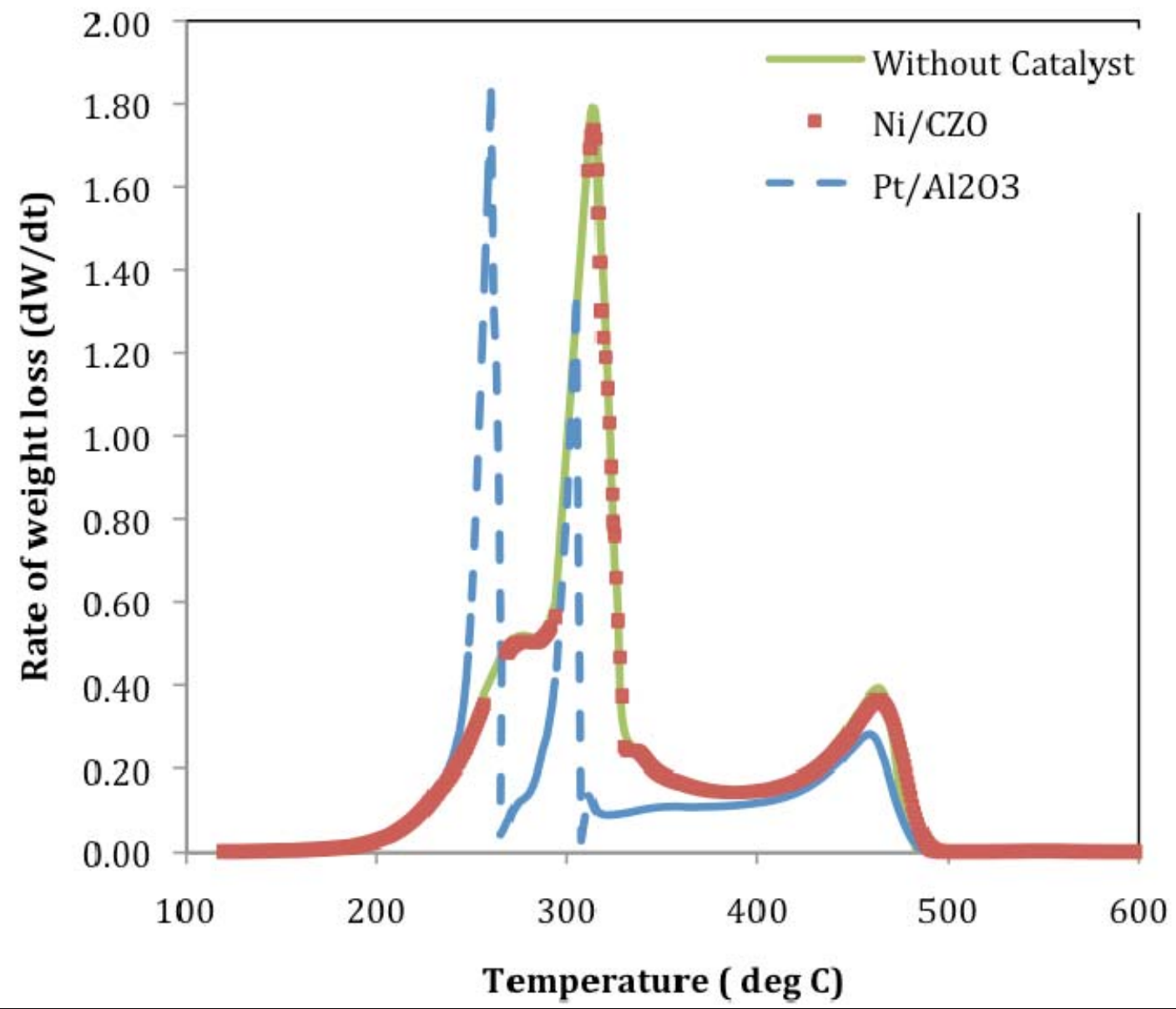

Figure 6.70. Pyrolysis of biomass in air with and without heterogeneous catalysts.

Both the TGA and the flow reactor were used in an attempt to identify product gases. Gas sampling bulbs were used with the TGA. But since the sample sizes were very small, no determinable results were obtained. The three techniques described earlier were used with the flow reactor.

The main reason for the unfruitfulness of the above experiments was the small amount of sample being used. The minimum amount of biomass sample, which has been experimented on as reported in literature was $10 \mathrm{gram}$, while our samples used in the TGA were substantially smaller. Another key observation was the deposition of substantial amounts of tarry substances towards the exit of the U-tube reactor. To overcome these constraints, a larger fixed bed reactor has been designed for future biomass pyrolysis and gasification. Larger reactors offer many advantages. Large amounts of samples can be used. This increases the amount of product gases being evolved and enables easier product identification and analysis. Reaction conditions are no longer limited by system size. Substoichiometric amounts of oxygen, which promote production of $\mathrm{CO}$ and $\mathrm{H}_{2}$ can be easily supplied and gasification conditions can easily be achieved. The system can be designed such that the residence time of the products in the system is very short. This can potentially decrease the accumulation of tarry substances in the reactor. 
Low temperature gasification and pyrolysis of biomass was carried out by ramping the temperature of the biomass to values between $200-300^{\circ} \mathrm{C}$ followed by an isothermal hold for a period of 2 hours. The weight change of the biomass was monitored during the heating period.

With regards to product analysis, a problem with the U-tube reactor was the clogging of the exit stream due to accumulation of tar. Tar is generally formed due to secondary reactions of the products. In the new packed bed flow reactor, the biomass loading was at the constricted end of the heated zone so that any product coming out would be in a cooler region as is seen in Figure 6.71 and that the product residence time was considerably short. This helped in the prevention of accumulation of tar and subsequent clogging.

A series of experiments were carried out to determine the optimum biomass loading and inert flowrate to ensure requisite product formation and collection. A biomass loading of $2 \mathrm{~g}$ with an inert He flowing at $1600 \mathrm{ml} / \mathrm{min}$ were found to be most effective in giving suitable results. A liquid nitrogen trap was used to collect the condensibles as shown in Figure 6.72. The uncondensed gases were fed to a GC equipped with two TCDs and an FID. The liquid products formed were analysed with a GC/MS. 


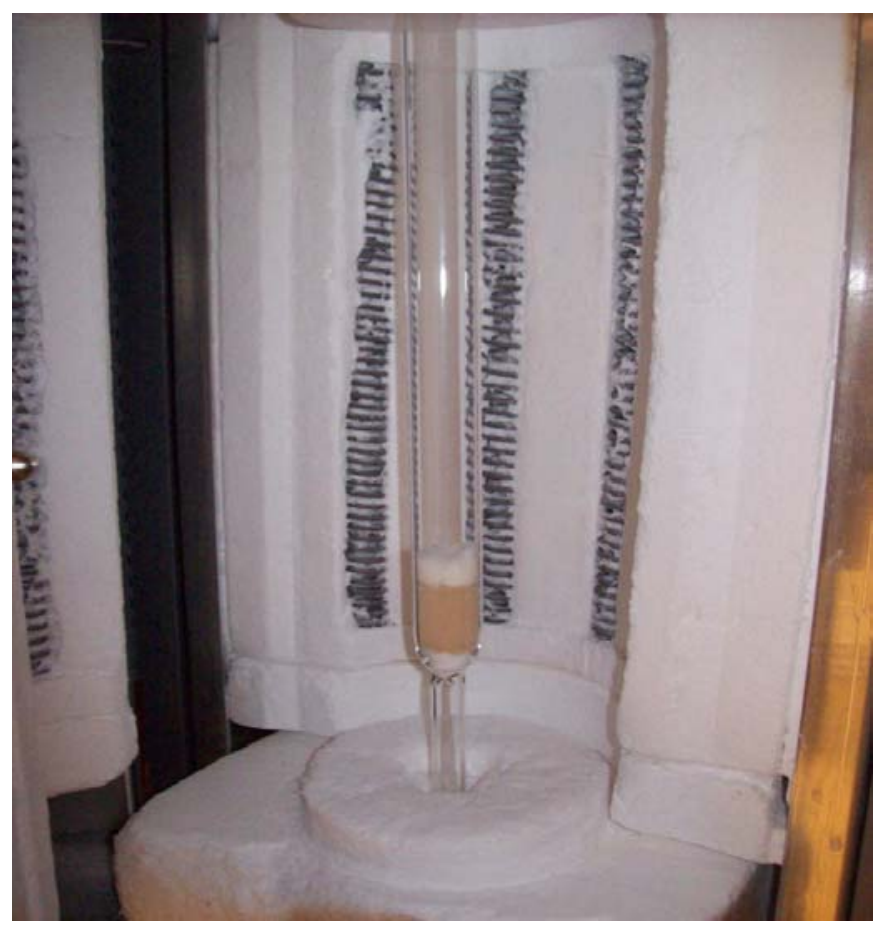

Figure 6.71. Reactor set up showing placement of biomass in the reactor.

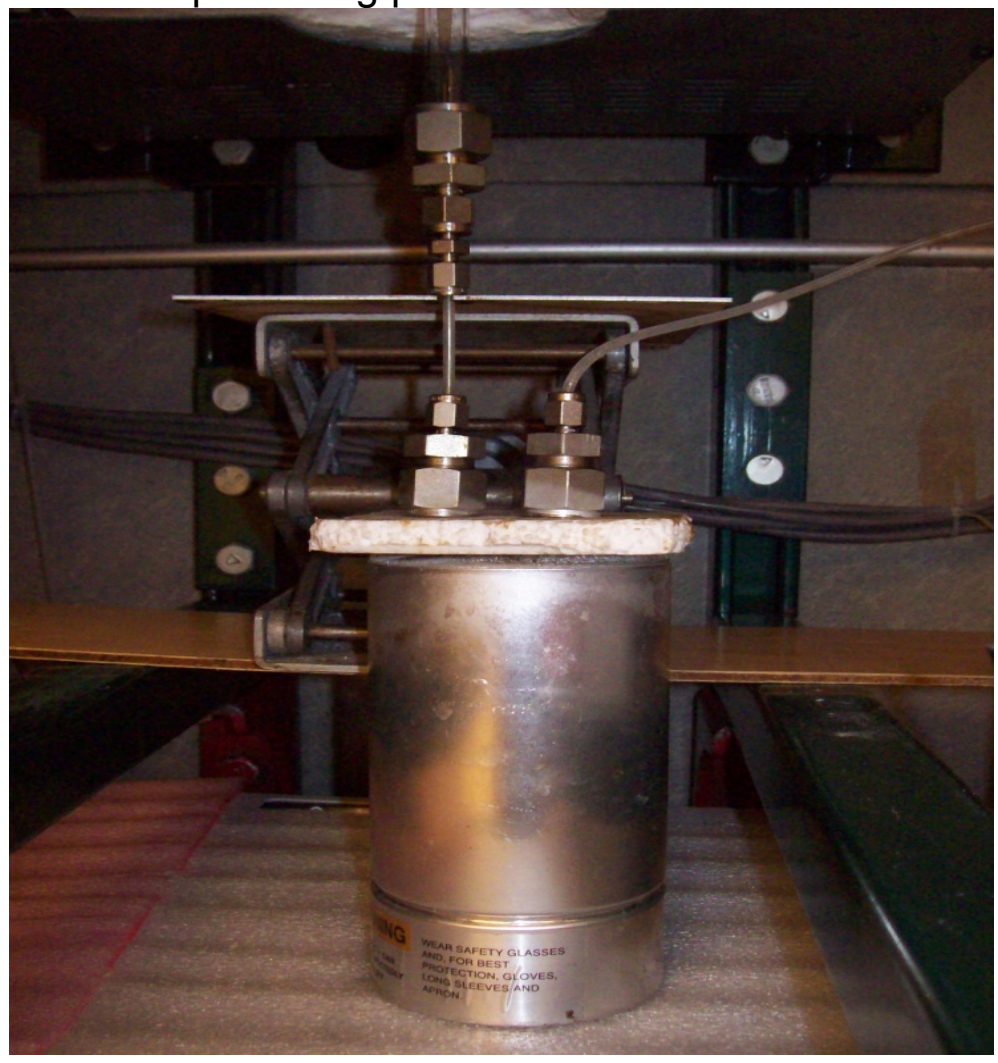

Figure 6.72: Liquid nitrogen trap used to trap products. 
Isothermal decomposition of biomass at low temperatures was carried out as described above. Figure 6.73 and Figure 6.74 show the results of these experiments. It has been found that at temperatures as low as $300^{\circ} \mathrm{C}$, about $80 \%$ of the mass is lost. This is substantial in that even at higher temperatures where biomass decomposition is classically studied, about $15 \%$ of the mass is left behind as char.

The TGA data reported in the previous report and the above results can be used as a guide to biomass decomposition. The time-temperature mass loss curves are essential for trapping the products of decomposition. A major challenge in this project has been the complete collection of pyrolysis products. Changes to the set up like change of liquid traps and associated fittings had to be made to overcome this difficulty. Analysis on the GC and the GC/MS carried out as described earlier showed numerous peaks corresponding to various products. The built-in database in the MS provides identification of the peaks.

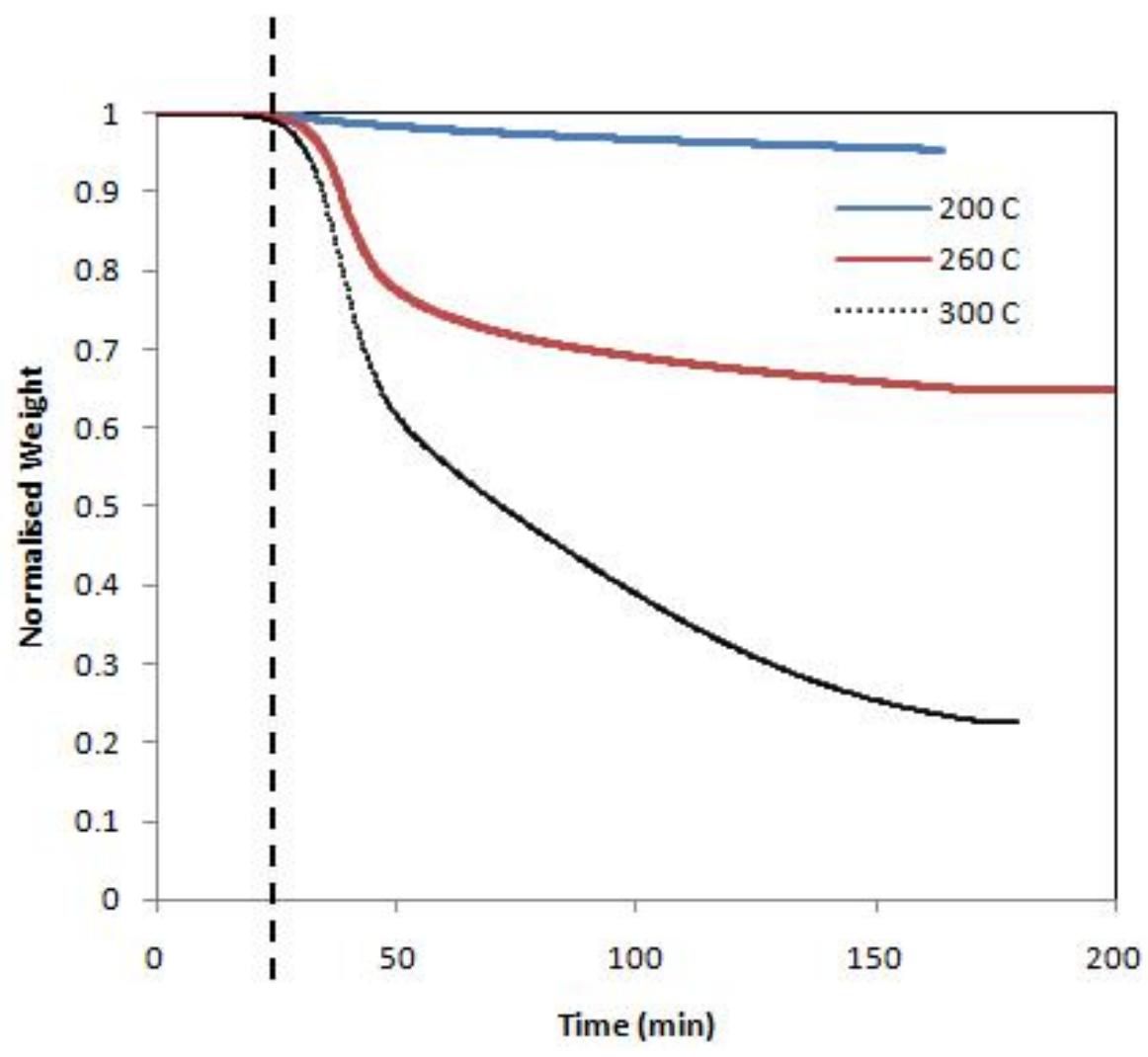

Figure 6.73: Isothermal decomposition of Oak in $\mathrm{N}_{2}$. 


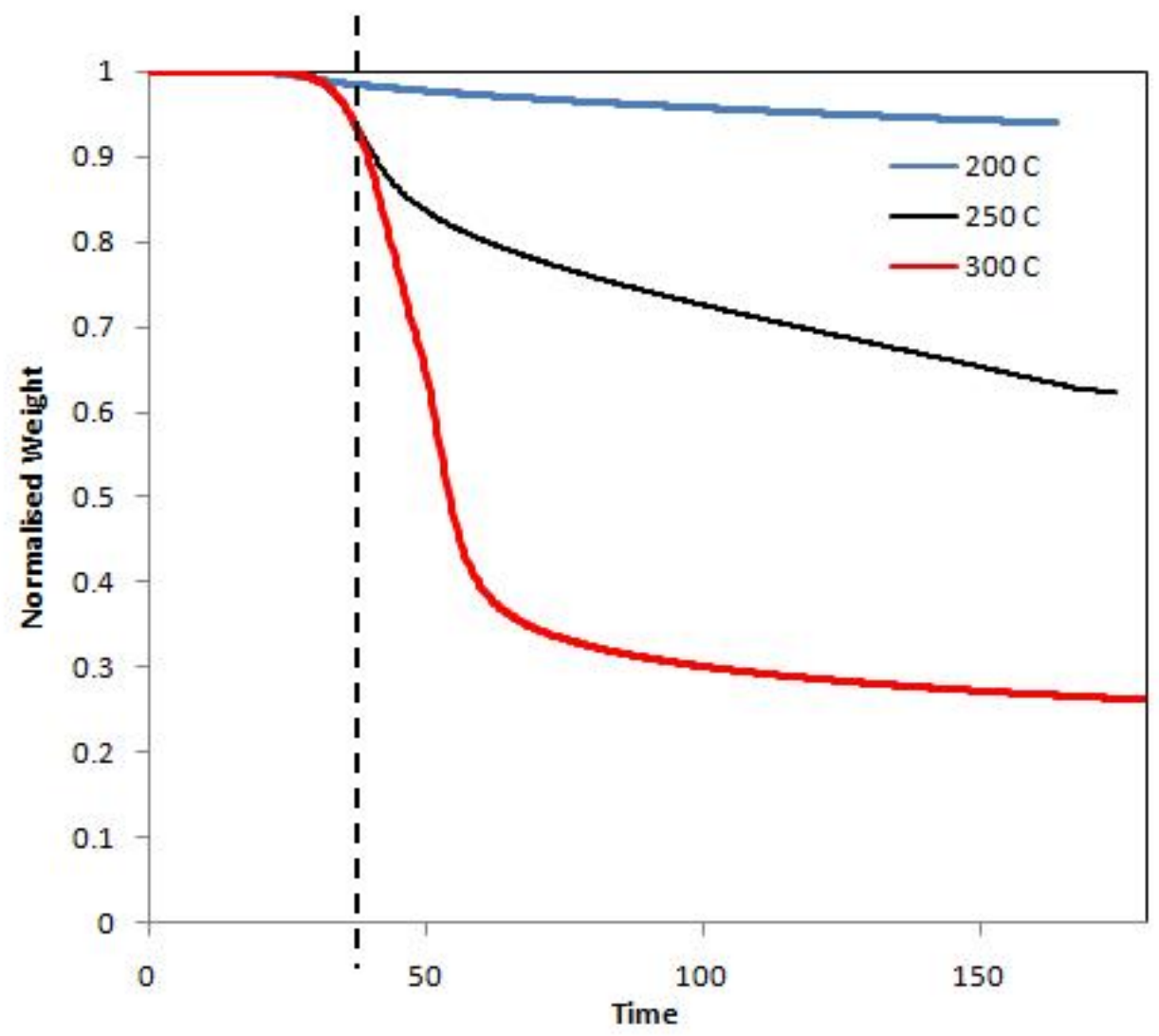

Figure 6.74. Isothermal Decomposition of Oak in Air.

Figure 6.75 compares the derivative weight loss peaks to the IR profiles of some gaseous species as a function of temperature. The IR profiles plot the integrated absorbance (IA) which is directly proportional to the concentration of the species in the gas phase. Though the calibration of these peaks can be complex, these peaks offer a qualitative picture of the different gases evolved in the pyrolysis of the biomass substances.

Since a majority of the volatiles are released in a narrow temperature range, it is difficult to identify individual species. Light gases like $\mathrm{CO}$ and $\mathrm{CO}_{2}$ however can easily be identified. Species with carbonyl groups like ketones, aldehydes and esters are grouped together as $\mathrm{C}=\mathrm{O}$. Hydrocarbons which have the characteristic $\mathrm{C}-\mathrm{H}$ bond stretching have been depicted as $\mathrm{CH}_{n}$. 

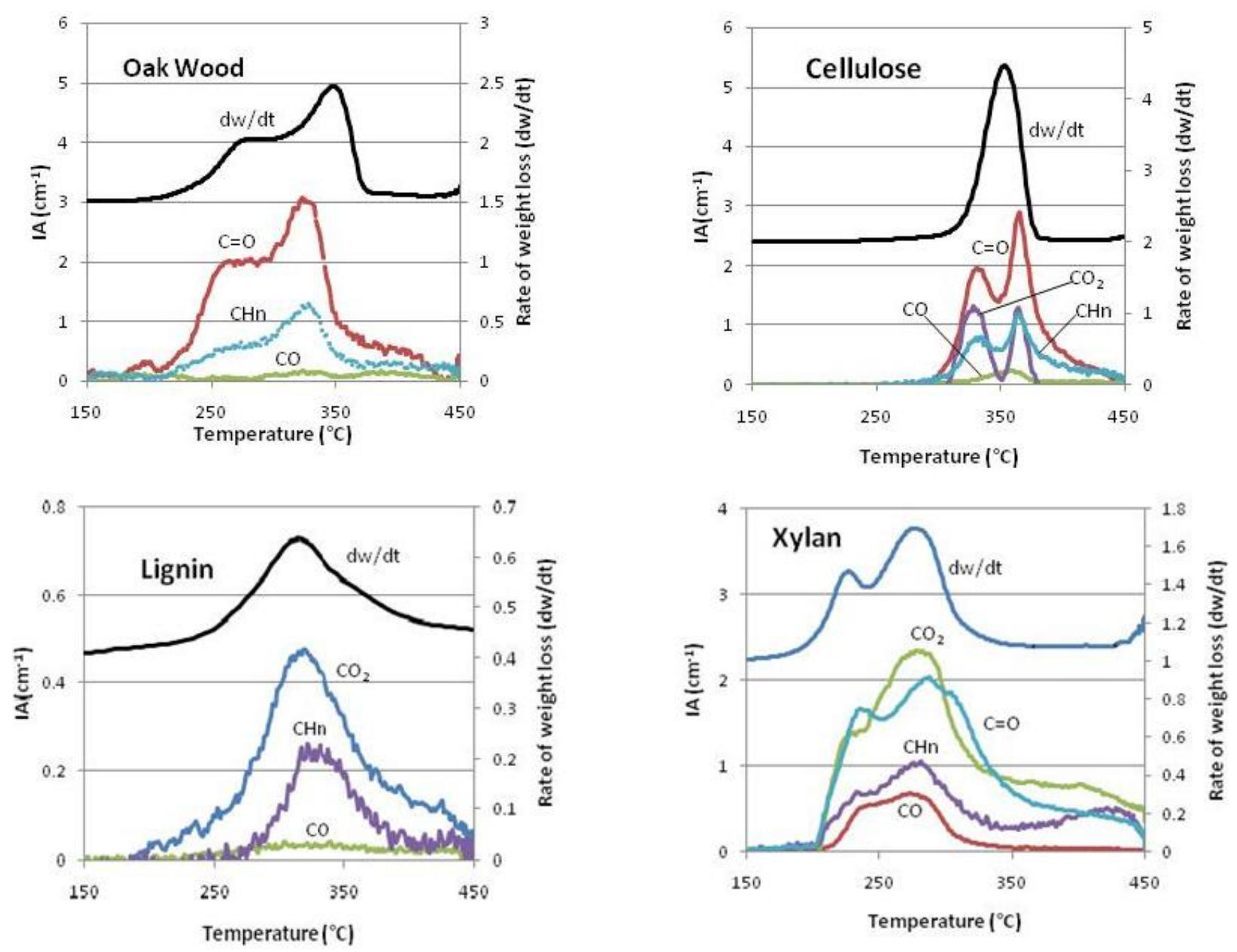

Figure 6.75. DTG profiles and FT-IR IA profiles of Oak and biomass pure components 
The above results show a direct correspondence between the weight loss peaks and IR profiles in both the biomass and the pure components. The maximum evolution of gases occurs during the primary volatilization stage.

Figure 6.76 shows the variation of some gaseous species like hydrocarbons, carbonyl-containing species, $\mathrm{CO}$ and $\mathrm{CO}_{2}$ with time at various temperatures. The plots show a clear trend in the evolution of gaseous species. An increased concentration of species like hydrocarbons and carbonyls is observed to be evolved at higher temperatures. Formation of $\mathrm{CO}$ is favored at higher temperatures.
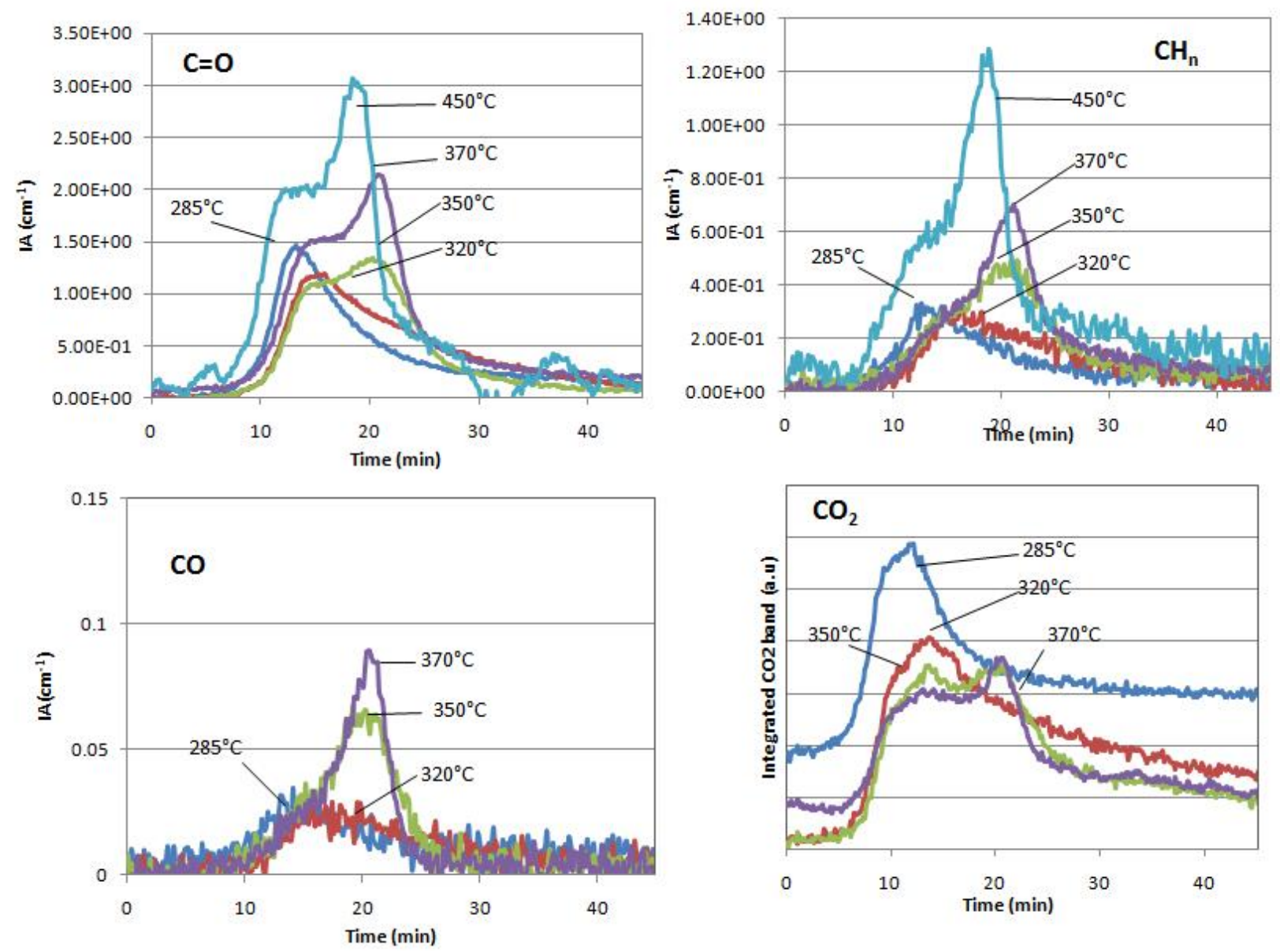

Figure 6.76. IR profiles of evolved species as a function of time at different temperatures of biomass

Having obtained qualitative continuous data and quantitative discrete data separately, it was necessary to try and obtain quantitative, continuous and real time data. Though having a mass spectrometer online downstream of the packed bed reactor is the logical way, in the absence of such equipment, an experimental methodology using available lab resources was developed.

A step towards continuous, real time data was to use the existing FT-IR spectrometer along with the GC in conjunction with each other in series 
downstream of the packed bed reactor. The following flow sheet (Figure 6.77) depicts the experimental setup, along with the benefits of each system.

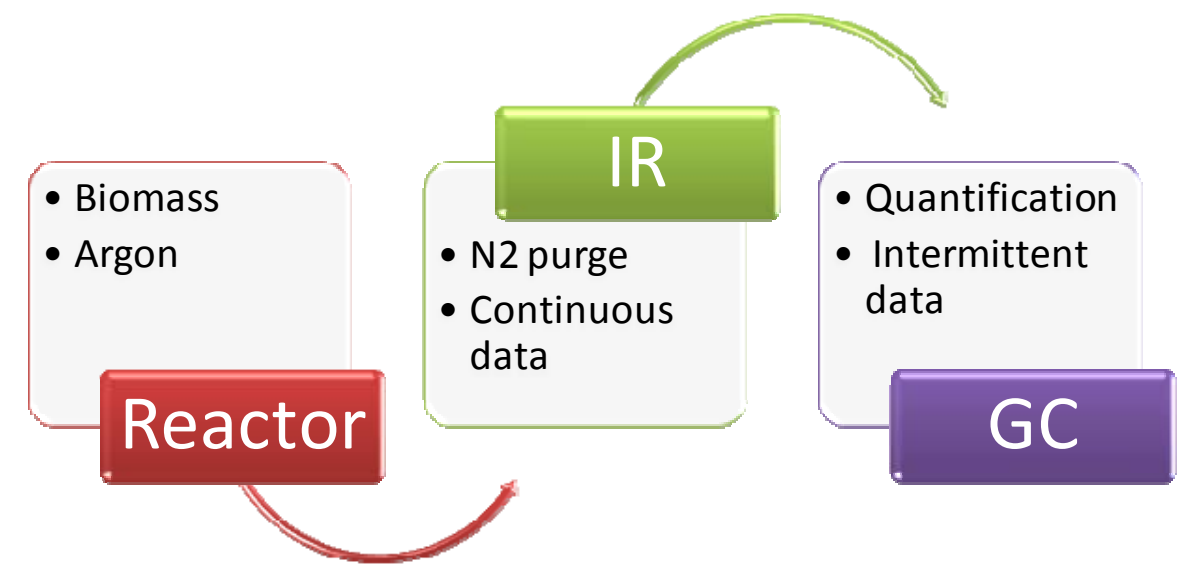

Figure 6.77. Experimental Scheme for real time, quantitative monitoring

The liquid products from partial pyrolysis of biomass, or 'bio-oil', are the precursors of tar that is formed at high temperatures. The composition of these bio-oils is of interest. To do this, liquid samples, previously collected in liquid $\mathrm{N}_{2}$ cooled condensers are injected into a GC-MS.

Previously, DTG peaks of biomass samples have been reported and the individual peaks have been associated with different pure components that make up woody biomass, viz. cellulose, lignin and hemicelluloses. By pyrolyzing biomass to different temperatures in the low temperature regime, we aim to control the composition of both the evolved liquid and gaseous products, as well as the remaining solids. DTG peaks of the remaining solids have been correlated with the DTG peaks of pure biomass samples.

Figure 6.78 and Figure 6.79 show the gaseous products evolved from two different experiments on the GC and the IR respectively. Both figures show evolution of $\mathrm{CO}, \mathrm{CO}_{2}$, along with $\mathrm{C}_{1}$ and $\mathrm{C}_{2}$ hydrocarbons. They are in very good correlation with each other as well as with independent observations performed previously. 


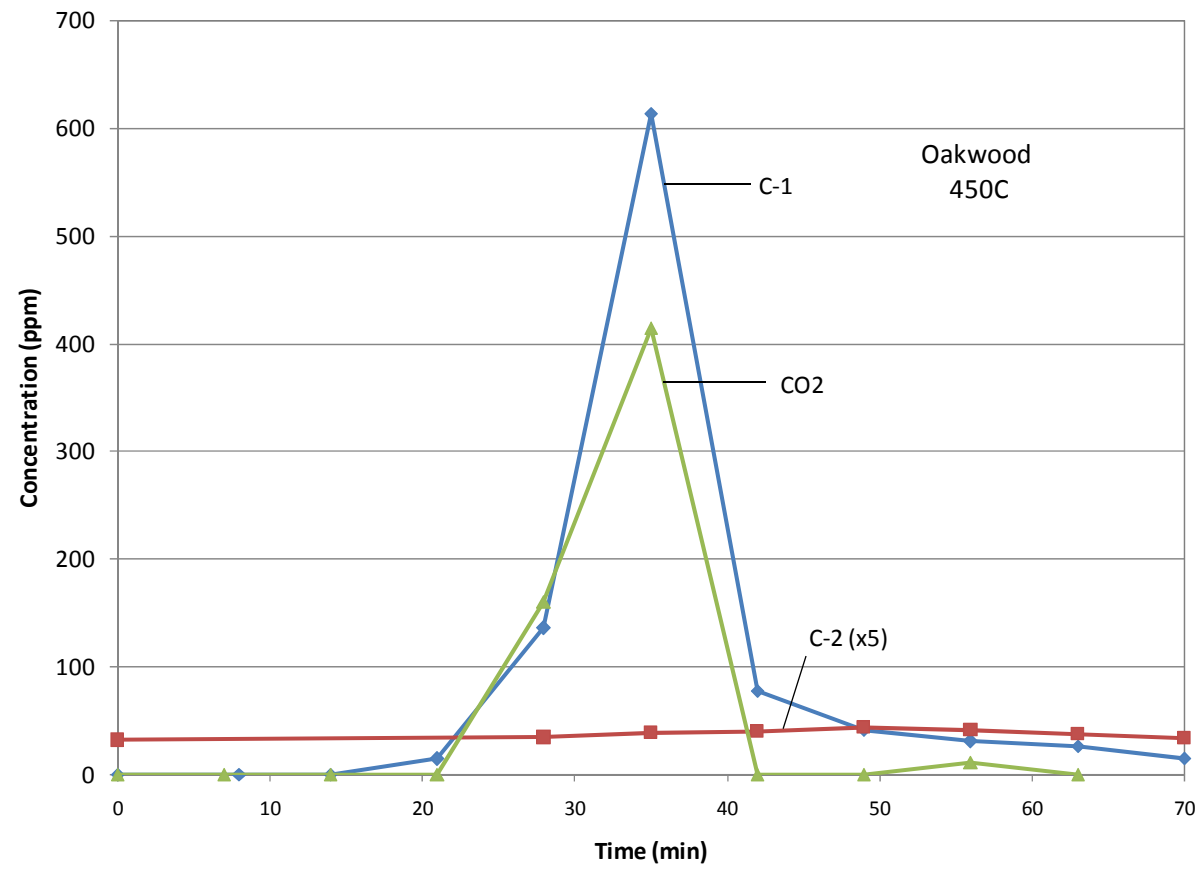

Figure 6.78. Gas evolution from biomass pyrolysis (GC)

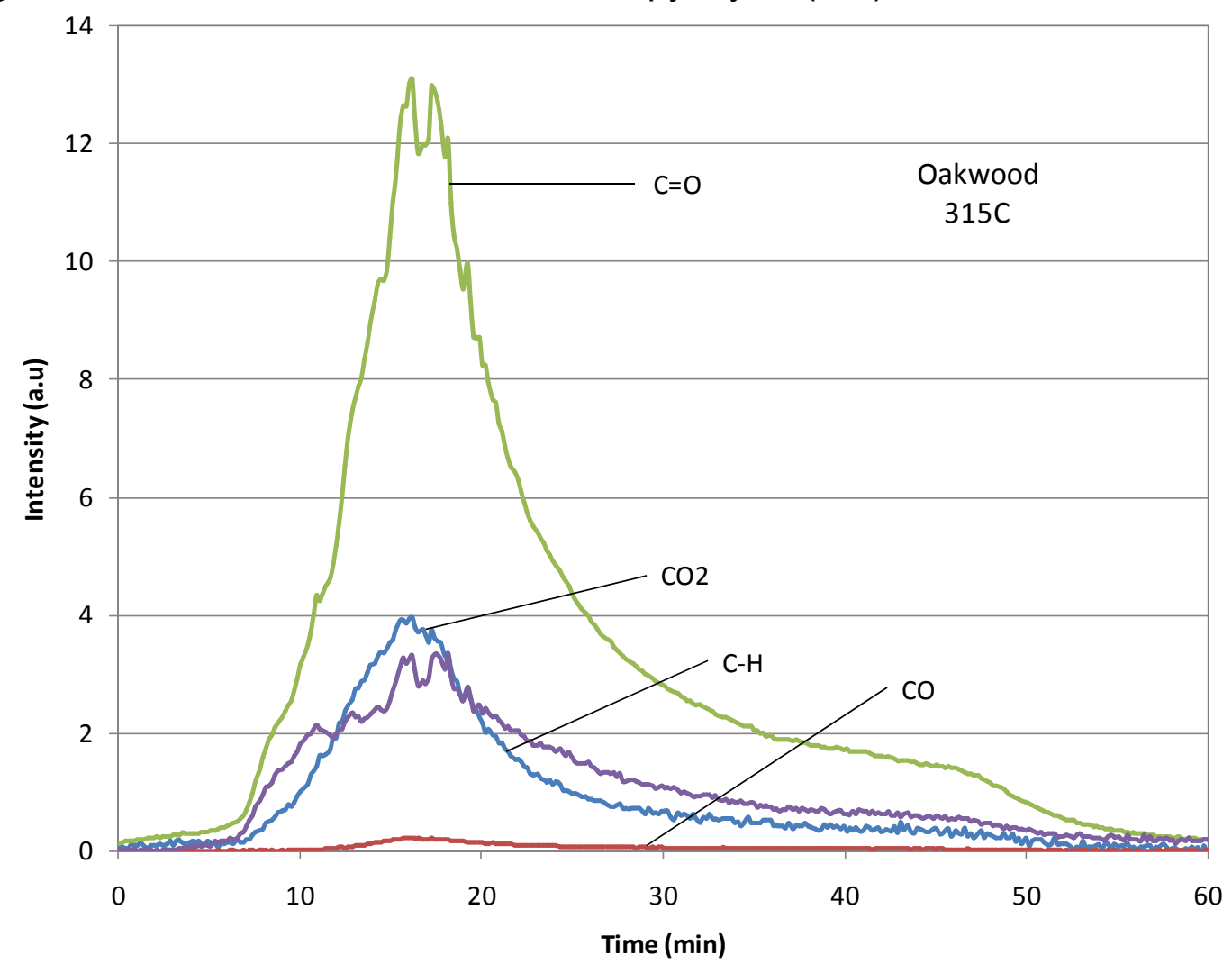

Figure 6.79. IR profile of evolved species from biomass pyrolysis

Figure 6.80 shows the MS trace of a 'bio-oil' sample. Also depicted on the trace are some of the aromatic species identified by the MS. 


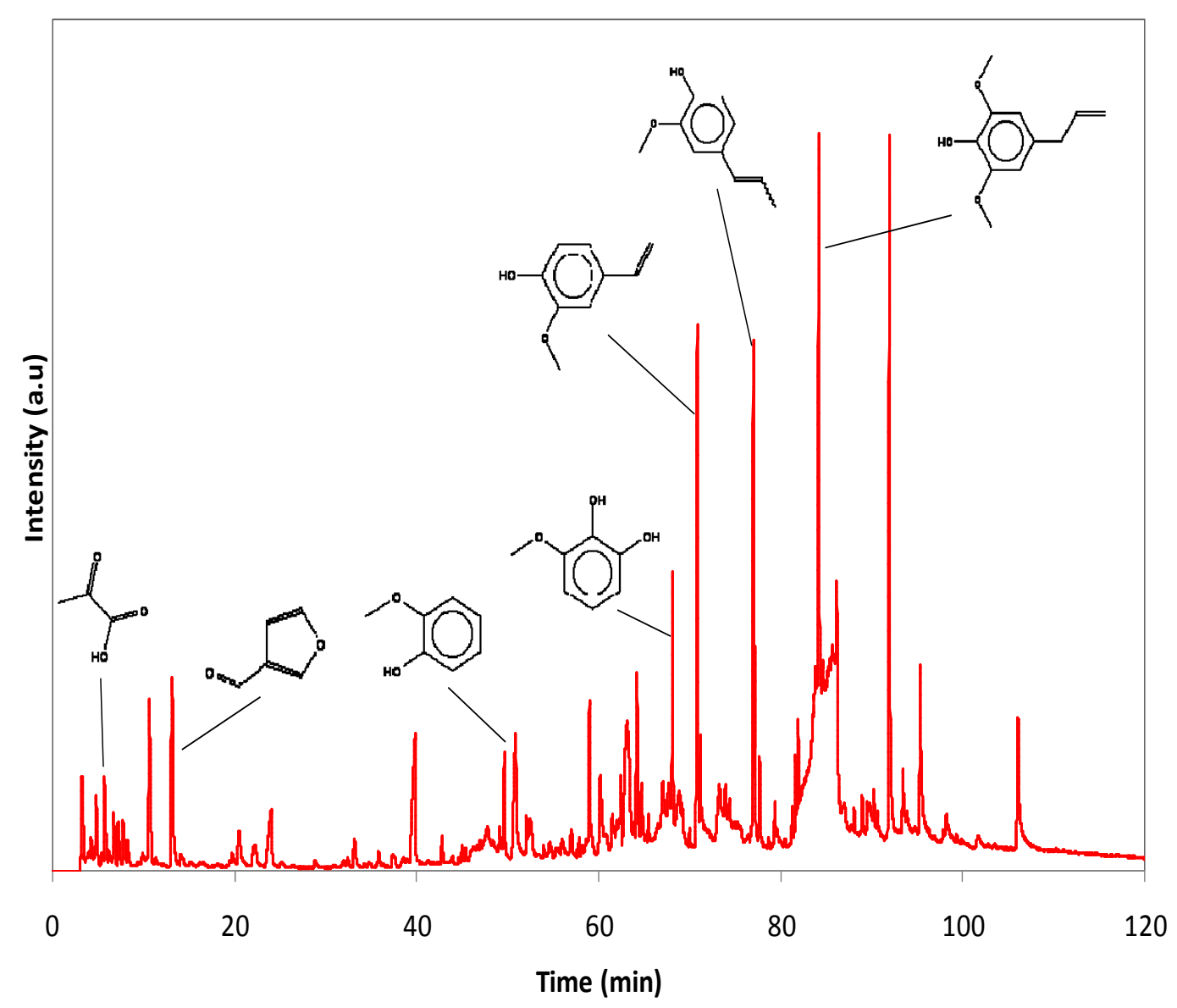

Figure 6.80. MS trace of bio-oil from biomass pyrolysis

As can be seen, the MS identified about 120 different compounds. Observations reveal them to be substituted phenols and other aromatics that could be formed by the breakage of bonds in cellulose, lignin and hemicellulose polymers.

Figure 6.81 shows the DTG peaks of samples that have already been pyrolyzed to different temperatures. Visual observation reveals that just by controlling the temperature of pyrolysis, some degree of control in composition has been achieved. For example, samples pyrolyzed to $285^{\circ} \mathrm{C}$ do not show the shoulder (due to hemicelluloses) observed in pure biomass samples and samples pyrolyzed to $350^{\circ} \mathrm{C}$ undergo a massive loss in weight between $315^{\circ} \mathrm{C}$ and $350^{\circ} \mathrm{C}$ and do not exhibit the main peak (due to cellulose) observed in pure, un-pyrolyzed biomass samples. 


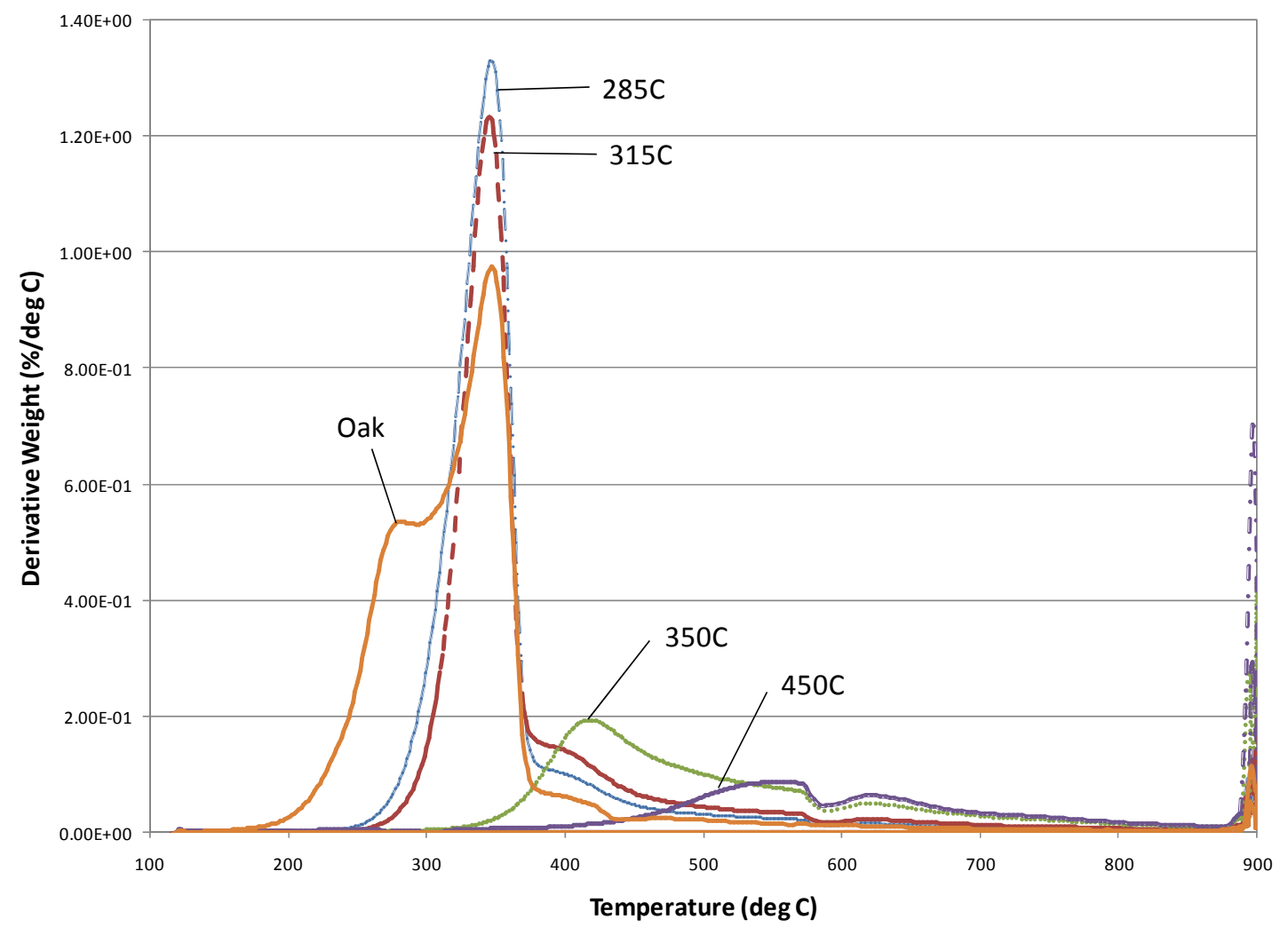

Figure 6.81. DTG peaks comparing pure biomass sample to samples partially pyrolyzed to different temperatures.

DTG studies indicated that we were able to control the composition of the solid biomass residues by varying the pyrolysis temperature alone. In order to confirm and quantify this, the following experimental protocol was devised to determine the cellulose, lignin and hemicelluloses content in biomass.

The procedure was adapted from an NREL Laboratory Analytical Procedure. In order to determine the amount of hemicellulose in the biomass, the hemicellulose was removed from the biomass and then the remaining biomass was weighed. The difference in the initial sample weight and the remaining biomass gives the weight of hemicellulose. Hemicellulose is soluble in $\mathrm{NaOH}$ solution following the procedure above, while cellulose and lignin remains insoluble and thus was trapped by the filter paper.

After drying, lignin and cellulose remain. By adding acid, the acid soluble cellulose was removed via filtration, leaving only acid-insoluble lignin. Since there is a small percent of lignin that is acid-soluble, the percentages will be only of the acid-insoluble lignin.

There are some differences between the NREL procedure and the procedure used. One is that the extraction of 'extractives' or material that is not cellulose, hemicellulose or lignin, was not included. Since extractives make up a very small portion $(5 \%)$ of the total biomass, this should not have a large effect, but should still be kept in mind when considering the values determined. 
Additionally, lignin is composed of acid soluble and acid insoluble types. Acid soluble lignin is found in biomass at a much lower amount than acid insoluble lignin, and so is ignored when determining the lignin concentration. To find the actual total lignin concentration a UV spectrophotometer would need to be used.

Optimizing the procedure consisted of varying the different steps to find what gave the best separation of the components, keeping in mind the literature values of each component. The concentration of base used in the hemicellulose determination step was decreased as it seemed to be damaging the biomass in some way, allowing less to be captured by the filter. An easier problem to explain was the issue of what concentration of sulfuric acid to use for the lignin test. Papers discussing Klason lignin extraction recommended using $76 \%$ sulfuric acid, although whether this was $\mathrm{v} / \mathrm{v}$ or $\mathrm{w} / \mathrm{w}$ with water differed in the literature sources. Both methods were tested on normal oak, where w/w is a lower molar concentration because of the high specific gravity of sulfuric acid. The lower molar concentration did not give good results, as the material after filtration was not a similar color to lignin, and also gave a much higher percent of lignin than is typically found in biomass. Using $\mathrm{v} / \mathrm{v}$ allowed the extraction of a material that was physically similar to pure lignin found in the lab, and also was much closer to the approximately $20 \%$ of lignin typically found in biomass.

This procedure was first applied to the raw biomass and the results were compared to values from literature to test its veracity. The procedure was then extended to the biomass residues pyrolysed to different temperatures. This gives a clear idea of the behavior of the pure components in actual biomass with increasing pyrolysis temperatures.

Figure 6.82 shows the gaseous products evolved from the pyrolysis of oak wood under an inert atmosphere at relatively low pyrolysis temperatures of $450^{\circ} \mathrm{C}$. 


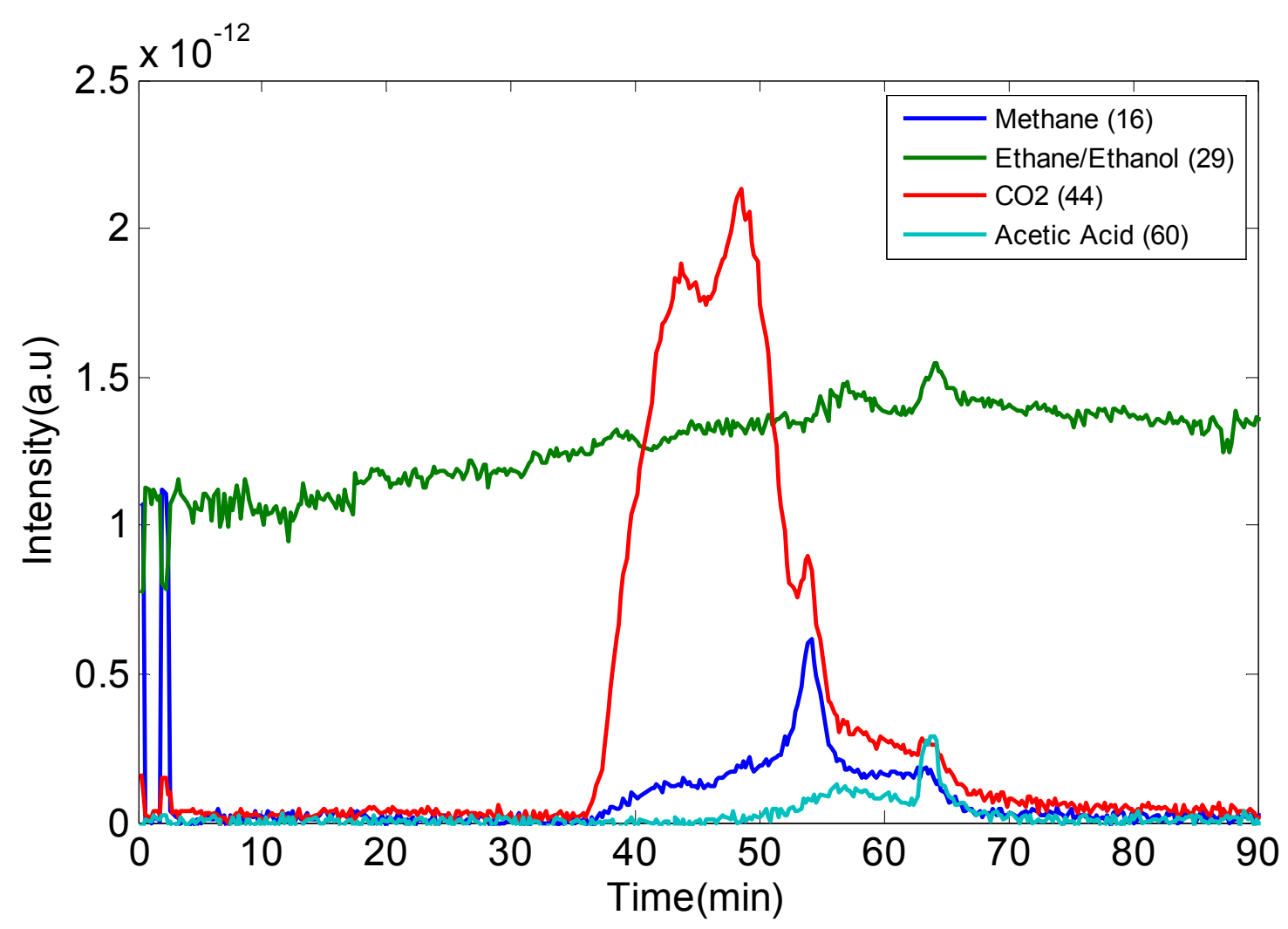

Figure 6.82: Product evolution from Oak pyrolysis (Mass Spec profiles)

The evolution of $\mathrm{CO}_{2}, \mathrm{CH}_{4}$ and acetic acid are clearly seen. A mass spectrometer background signal consistent with $\mathrm{C}_{2} \mathrm{H}_{5}$ species (either ethane or ethanol) is also observed. However, careful observation of the profiles leads to the conclusion that this $\mathrm{C}_{2} \mathrm{H}_{5}$ signal was not due to a product evolved from the pyrolysis, but stemmed from an impurity that was in the reactor system's plumbing or in the transfer lines (most probably from the calibration gases used in earlier experiments on the system). Also not observed are evolution profiles for carbon monoxide. Since $\mathrm{N}_{2}$ was used as the carrier gas for the experiments at Next Energy, CO, which has the same $\mathrm{m} / \mathrm{z}$ as $\mathrm{N}_{2}$ could not be distinguished in the mass spectrometer.

The procedure explained in the above sections were first applied to raw biomass and compared with literature values for percentage compositions in oak. Figure 6.83 and Table 6.10 report these values. 


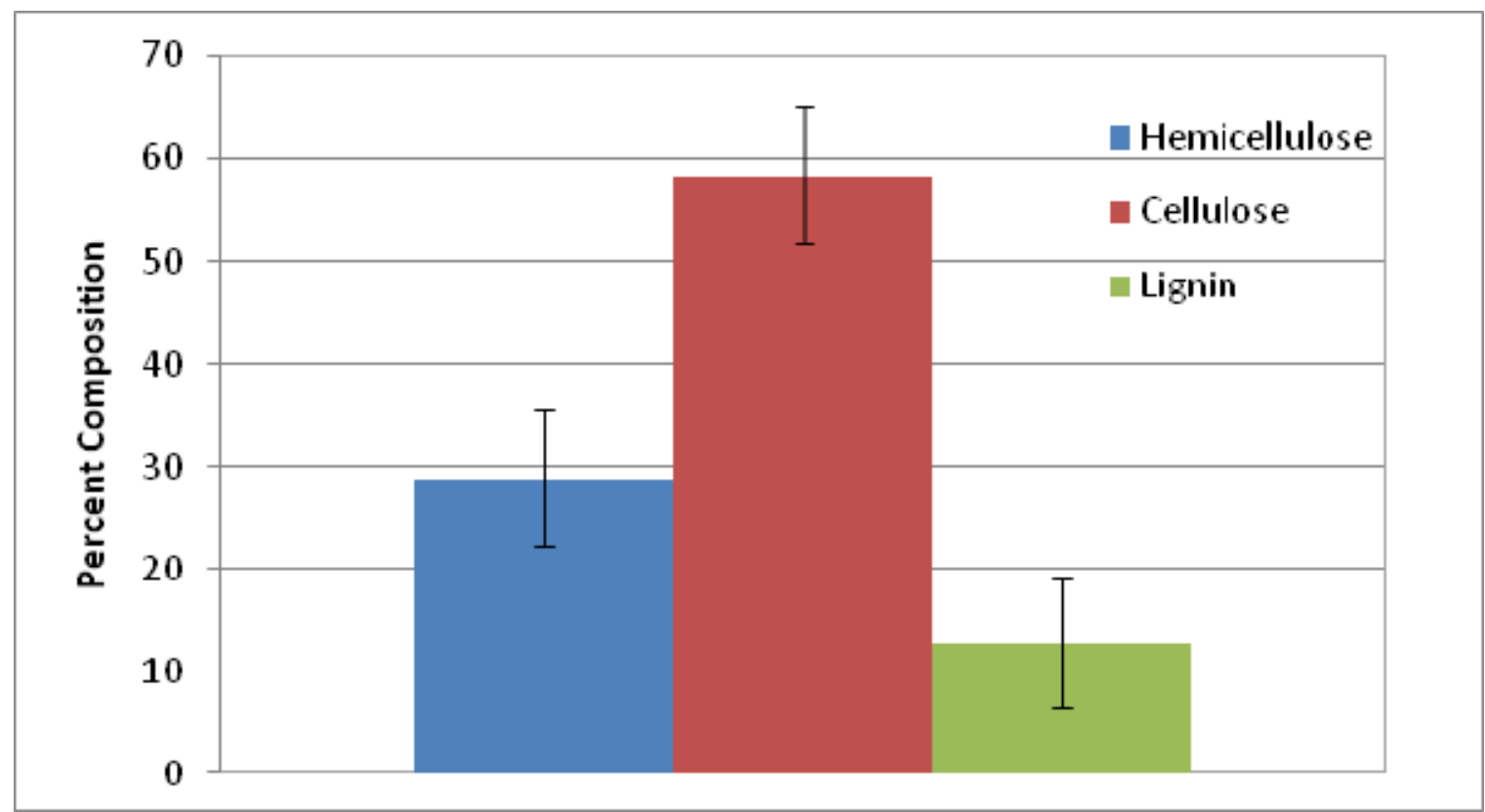

Figure 6.83. Percentage composition of Oak.

Table 6.10. Percentage composition of Oak (as reported in literature)

\begin{tabular}{ll}
\hline Component & Percent (From Literature) \\
Hemicellulose & 30 \\
Lignin & 20 \\
Cellulose & 45 \\
\hline
\end{tabular}

As can be observed, the values reported in literature and the values from our experiments are quite agreeable. The above procedure was also applied to prepyrolyzed biomass samples and the behavior of the pure components, hemicelluloses, cellulose and lignin was charted as a function of temperature (Figure 6.84, Figure 6.85, Figure 6.86). 


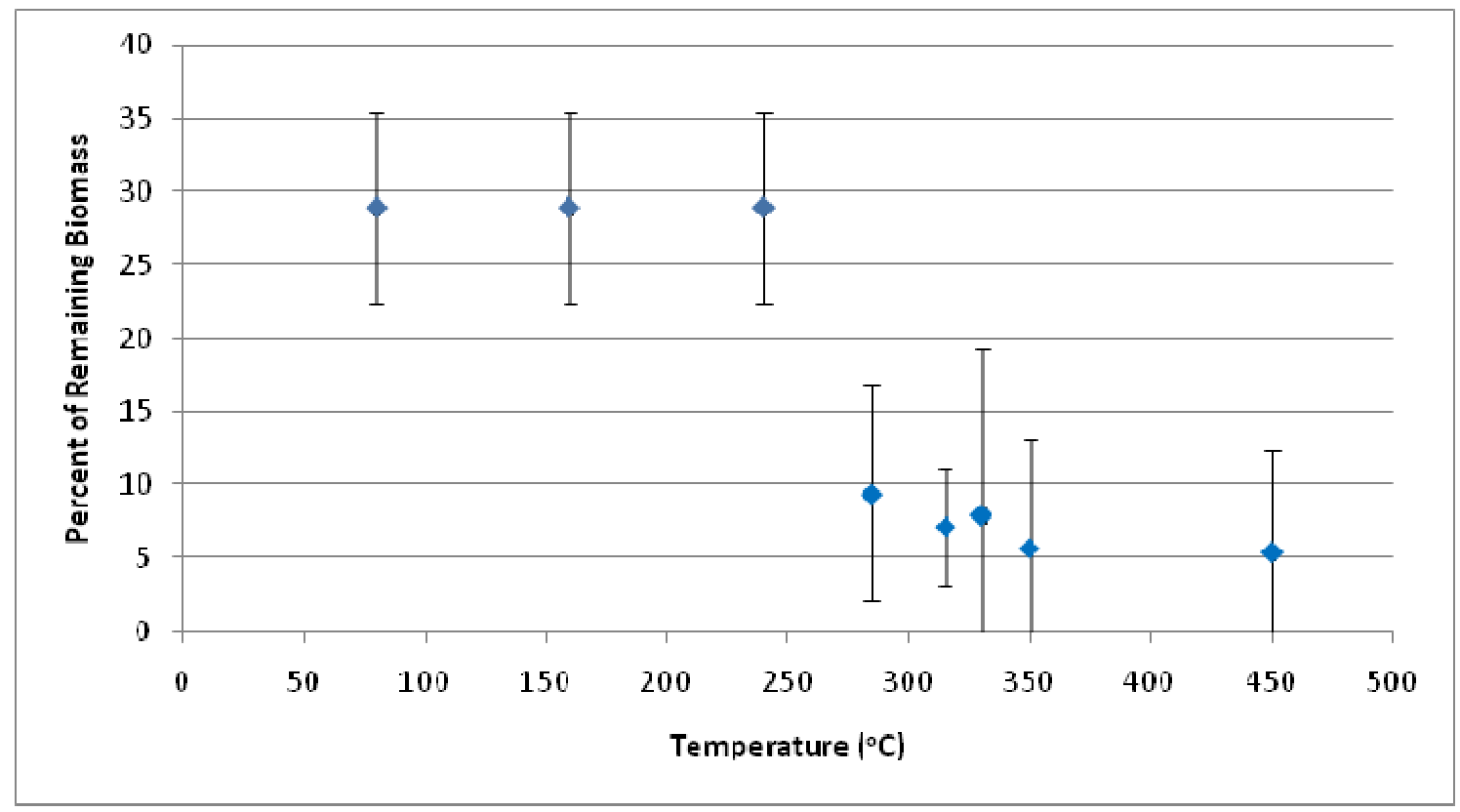

Figure 6.84. \% hemicellulose as a function of pyrolysis temperature

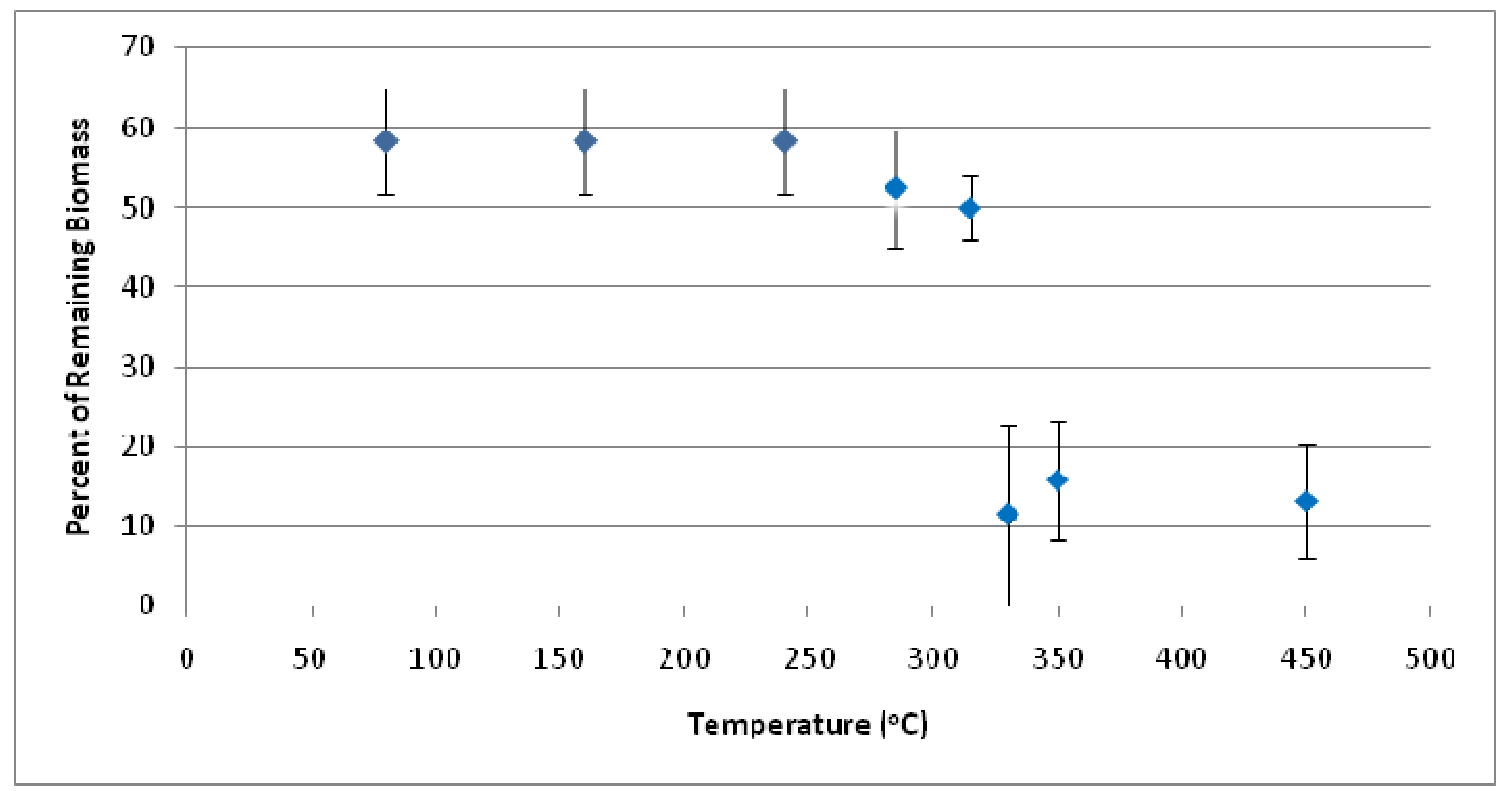

Figure 6.85. \% cellulose as a function of pyrolysis temperature 


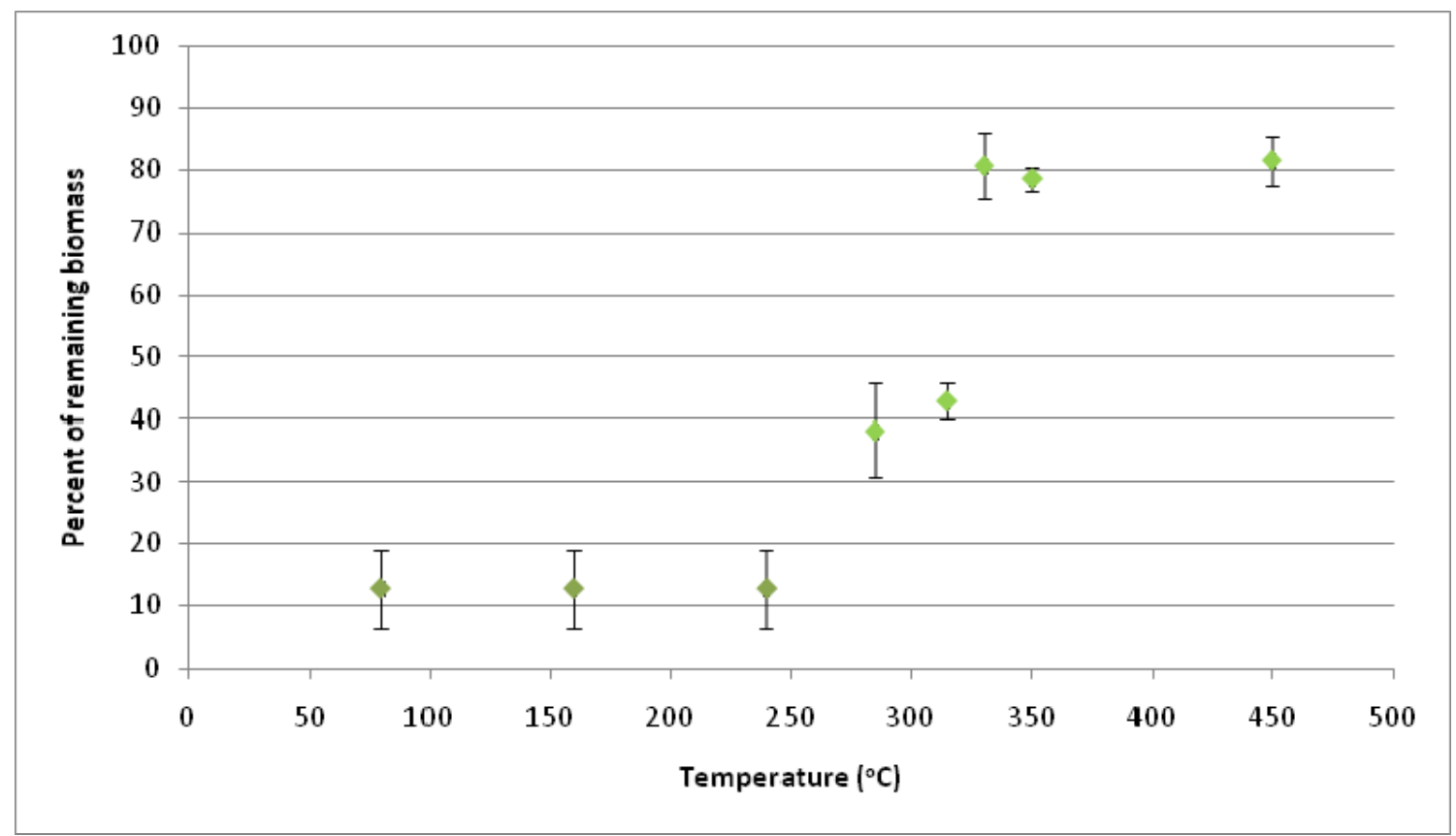

Figure 6.86. \% lignin as a function of pyrolysis temperature

As can be seen, the amount of hemicellulose and cellulose decreases as temperature decreases. This is reasonable behavior that can be explained by the fact that as the temperature increases and pyrolysis proceeds, more bonds are broken and each of the components starts decomposing. However, lignin exhibits the opposite trend. The hypothesis behind this is that as the temperature increases, there is an increasing build up of char. The procedure dictates that the amount of lignin be determined as a difference from the amount of hemicelluloses and cellulose, and not individually. So even though, the amount of lignin decreases with increasing temperature, the increasing amount of char in the samples at these higher temperatures causes this.

GC-MS analysis of the liquid fraction of products from biomass decomposition has been reported to consist of a myriad of aromatic hydrocarbons that could possibly be valuable. The difficulty in the analysis of the liquid phase is twofold: the sheer number of components of different classes present and the low concentration in which they are present. This causes a difficulty in assigning the peaks in the GC-MS trace to a particular species. The presence of a large number of structurally similar components also causes spectrometric profile to be convoluted. The separation of the different compounds in the bio-oil is therefore essential, not only for the analysis of the pyrolysis products and the understanding of the pyrolysis process itself, but also for the adaption of bio-oil as a future source of chemicals. The general feature of all these different schemes is the use of an organic solvent to separate the bio-oil into an aqueous phase and an organic phase. Some of the different solvents that have been reported are: n-pentane, n-hexane, benzene, toluene, chloroform, ethyl acetate, ether and combinations of them along with inorganic acids and 
bases like sodium hydroxide and phosphoric acid. The main drawbacks of most of these processes have been solvent recovery. As with any organic solvent, these are volatile, so in addition to the problem of losing solvents, there is also the issue of releasing potentially harmful chemicals into the atmosphere. Additionally, some of the solvents are also products of biomass pyrolysis. So the presence of these species would only serve to compound the problem of accounting for and quantifying the products. While identifying the true products of decomposition is important in this case, quantitative estimation of the products might not be as important. The true emphasis would be on relative quantification of the products, as the major mass fractions would dictate the behaviour of the liquid.

The search for an effective solvent that can be used for bio-oil fractionation led us to consider ionic liquids. Ionic liquids are organic salts that have a melting point lower than $100^{\circ} \mathrm{C}$. These salts are composed generally of a large organic cation and a smaller inorganic anion. Ionic liquids are a class of compounds whose physical and chemical properties are very easily tuneable. By choosing the correct ionic liquid, it is possible to obtain high product yields with minimal waste production. They possess most of the desired properties for use not only as a solvent for bio-oil fractionation, but also for the upgrading of bio-oil and its components to useful chemicals.

One of the most studied ionic liquid systems is the di-alkylimidazolium system. These ILs are very easy to prepare and their properties can also be tuned by altering the functional groups. Most importantly, several researchers have reported that these ILs dissolve significant mass fractions of large macromolecules like cellulose. It is hypothesised that if these ILs can dissolve high molecular weight compounds like cellulose, smaller molecules like biomass derivatives should also be reasonably soluble in them, thus making them suitable solvents for bio-oil fractionation.

The choice of the correct ionic liquid is instrumental for the analysis of biomass derived systems. The thermal stability of ILs is an important property for our work since it dictates the maximum operable temperature for our pyrolysis experiments. The other important aspect to consider in choosing an ionic liquid for study is its ability to dissolve biomacromolecules. Based on available literature, three ionic liquids have been selected for preliminary experiments. Though the focus of this research is also on bio-oil fractionation, raw biomass pyrolysis presents the most complex of all the systems under study. Studying this system provides a better understanding of the ionic liquids as solvents for the other applications. The ionic liquids chosen were commercially available and were purchased from SigmaAldrich. The ionic liquids and their properties as reported in literature have been shown in Table 6.11 below: 
Table 6.11. Ionic Liquids chosen and some of their properties

\begin{tabular}{|c|c|c|c|c|c|c|}
\hline $\begin{array}{l}\text { Sl. } \\
\text { No. }\end{array}$ & Ionic Liquid & Abb. & $\begin{array}{l}T_{m} \\
\left({ }^{\circ} \mathrm{C}\right)\end{array}$ & $\begin{array}{l}\mathrm{T}_{\mathrm{d}} \\
\left({ }^{\circ} \mathrm{C}\right)\end{array}$ & $\begin{array}{l}\text { Conditions } \\
\text { for } \\
\text { dissolution }\end{array}$ & $\begin{array}{l}\% \\
\text { dissolution }\end{array}$ \\
\hline 1. & $\begin{array}{l}\text { 1-butyl-3- } \\
\text { methylimidazolium } \\
\text { chloride }\end{array}$ & {$[\mathrm{bmim}] \mathrm{Cl}$} & 41 & 264 & $110^{\circ} \mathrm{C}, 8 \mathrm{~h}$ & 8 \\
\hline 2. & $\begin{array}{l}\text { 1-butyl-3- } \\
\text { methylimidazolium } \\
\text { hexafluorophosphate }\end{array}$ & {$\left[\mathrm{bmim} \mathrm{PF}_{6}\right.$} & 11 & 373 & - & - \\
\hline 3. & $\begin{array}{l}\text { 1-allyl-3- } \\
\text { methylimidazolium } \\
\text { chloride }\end{array}$ & [amim]Cl & 17 & 273 & $\begin{array}{l}80^{\circ} \mathrm{C}, 24 \mathrm{~h} \\
110^{\circ} \mathrm{C}, 8 \mathrm{~h}\end{array}$ & $\begin{array}{l}5 \\
8\end{array}$ \\
\hline
\end{tabular}

Legend: $T_{m}=$ Melting point; $T_{d}=$ Decomposition temperature;

Prior to biomass pyrolysis experiments, it was essential to carry out a parametric study to determine suitable reaction conditions. Preliminary experiments performed here have shown that the dissolution time could be cut down massively from what has been shown in the table above by mild preheating of the ionic liquid to $80^{\circ} \mathrm{C}$ before introduction of the biomass. Dissolution of biomass increases the viscosity of the ILs. To determine the maximum operable viscosity, dissolution studies were carried out in $1 \%, 2 \%, 5 \%$ and $8 \%$ biomass. On this basis, it was found that a solution of $5 \%$ biomass in IL was the most suitable for further experiments.

The object of the initial pyrolysis experiments was to test the effect of the cationic and anionic moieties on pyrolysis of raw biomass with respect to the product evolution. In order to do this, a $5 \%$ solution in each of the ILs was prepared in a semi-batch reactor with a continuous purge stream of $\mathrm{N}_{2}$. Once the temperature is stabilized, the reactor temperature is ramped up to $250^{\circ} \mathrm{C}$, which is very close to the decomposition temperature of two of the three ILs. This temperature is also close to the shoulder of the DTG peak of pure oak wood. The reactor temperature is monitored with the help of a thermocouple. After the temperature reaches the set point, the reactants are maintained at that temperature for $30 \mathrm{~min}$ to allow the decomposition to complete. The protocol is similar to the one followed during the fixed bed experiments and have been based on observations made during the thermogravimetric studies on raw biomass. Throughout the temperature ramp and isothermal phase, the effluent gases are monitored by an online mass spectrometer (MS). The MS collects mass/charge values from 1 to 60 . 
Figure 6.87 shows the gaseous products evolved on gasification in [amim] Cl, along with the temperature profile in the reactor. The legend labels the species with the detected $\mathrm{m} / \mathrm{z}$ ratios in brackets. Evolution of $\mathrm{C}-2, \mathrm{C}-3$ and $\mathrm{C}-4$ hydrocarbons is clearly seen along with $\mathrm{CO}$ and $\mathrm{CO}_{2}$. Similar observations can also be made in the gasification in [bmim] $\mathrm{Cl}$ (Figure 6.88).

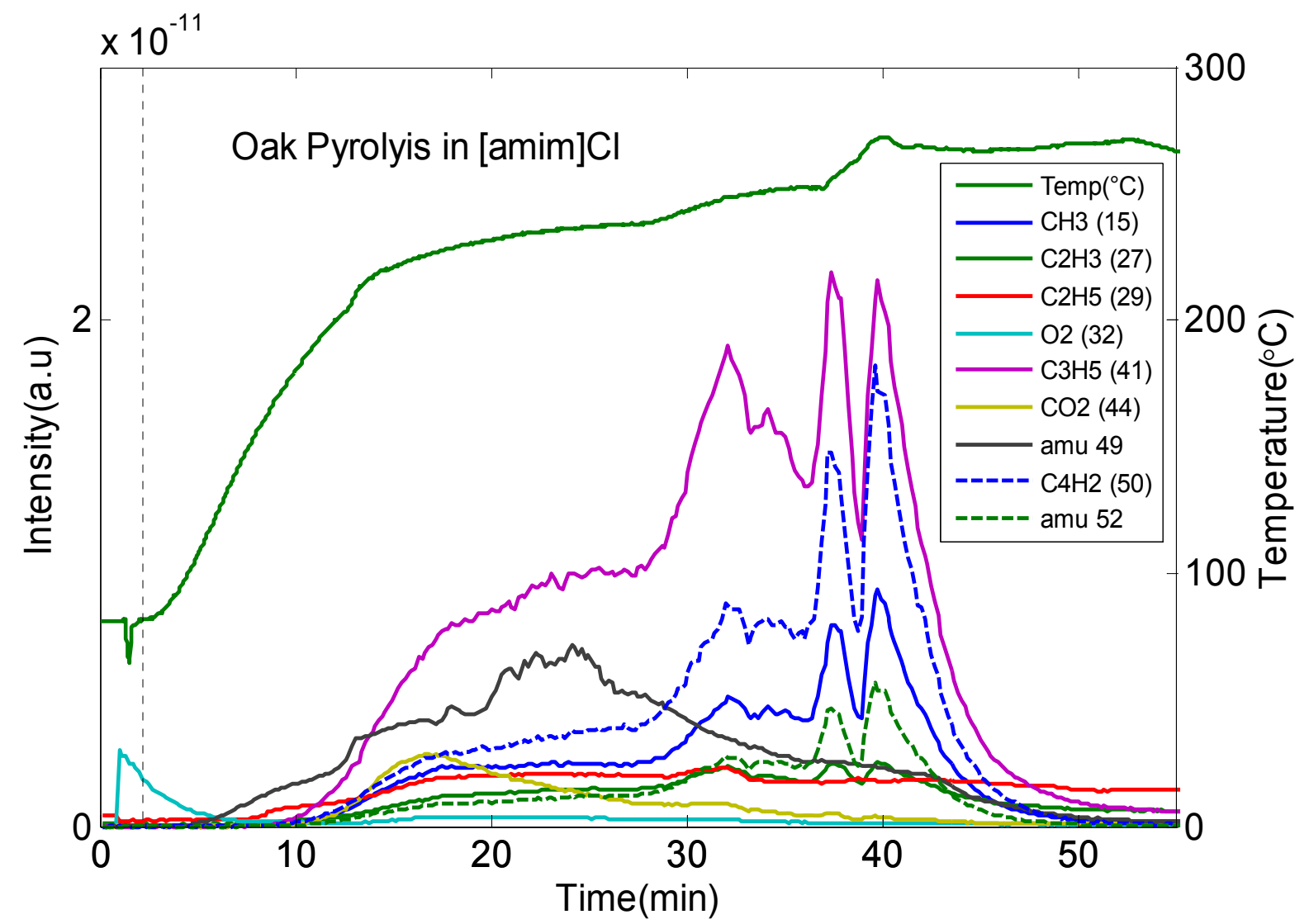

Figure 6.87. Gas evolution from oak pyrolysis in [amim] $\mathrm{Cl}$ 


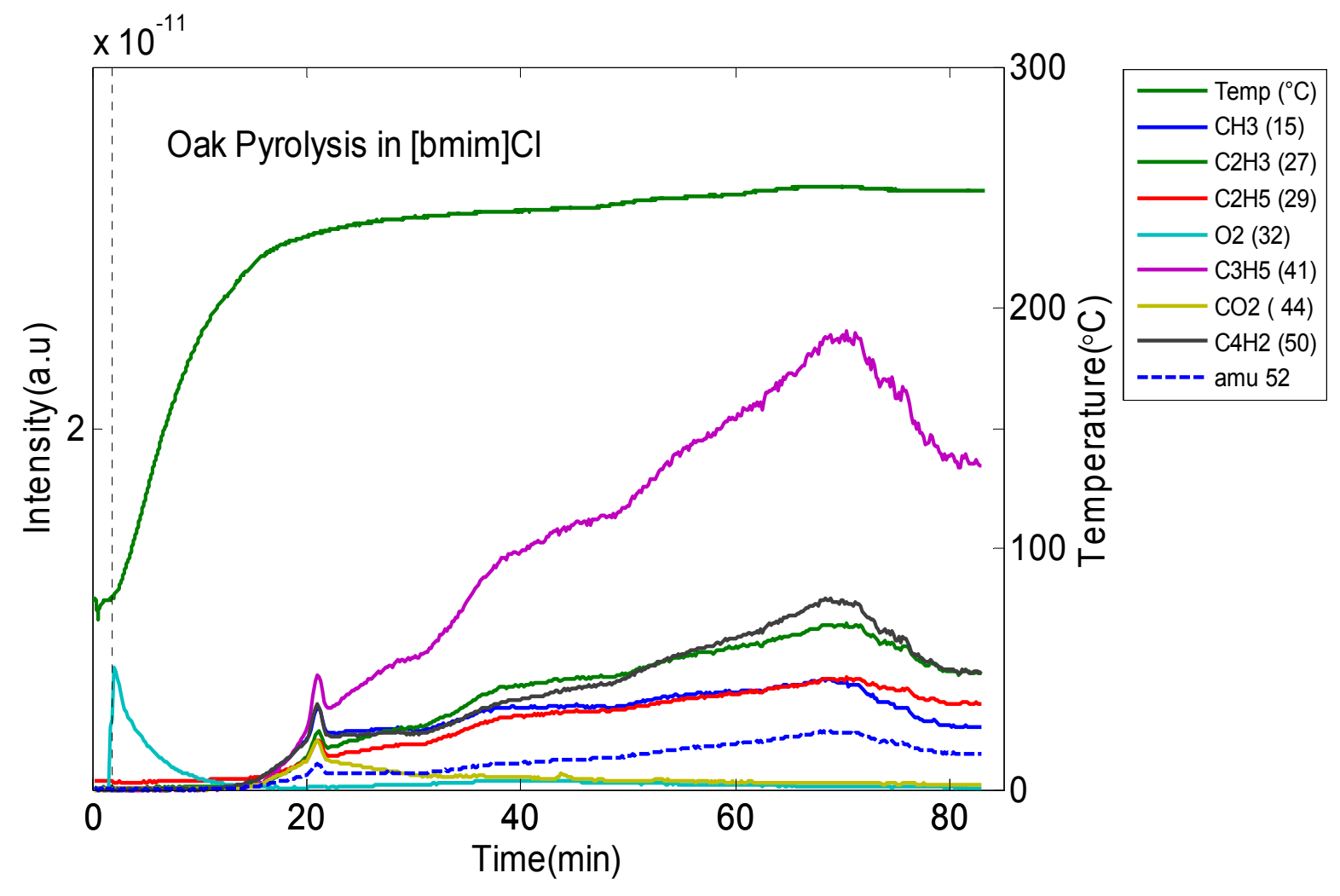

Figure 6.88. Gas evolution from oak pyrolysis in [bmim] Cl

\section{Effect of cation and anion:}

In order to compare the effect of the solvents on pyrolysis, the evolution of a particular species is observed in different media. Figure 6.89, Figure 6.90, and Figure 6.91 compare the evolution of methane, $\mathrm{CO}_{2}$ and $\mathrm{C}-3$ in the three different ionic liquids. It is observed that for all three species, the evolution in [amim] $\mathrm{Cl}$ is quicker than in [bmim] Cl, though the intensity of the MS peaks are about the same. However, [bmim] $\mathrm{PF}_{6}$ shows much lower activity than the other ILs.

This difference in activity can be explained by considering the structures of the ionic liquids. The allyl group is considerably smaller than the butyl group. Researchers have previously found that increasing the length of the alkyl chain in the functional group on the imidazolium ring decreases the solubility of cellulose in the IL. Therefore, the smaller [amim] ${ }^{+}$has stronger interactions with the biomass than the bigger [bmim $]^{+}$. Also, the allyl group has a double bond while the butyl group doesn't. Thus there are also stronger $\pi$ interactions with the biomass in [amim] Cl than in [bmim] Cl. Hence the stronger cationic interactions of $[\mathrm{amim}]^{+}$versus the $[\mathrm{bmim}]^{+}$, which causes the $[\mathrm{amim}] \mathrm{Cl}$ dissolve to biomass faster than $[\mathrm{bmim}] \mathrm{Cl}$, causing the biomass to undergo decomposition more readily and hence form products more readily.

As far as the anion is concerned, [PF 6$]$ - is a larger moiety than $\mathrm{Cl}^{-}$. The $\mathrm{Cl}^{-}$ breaks the hydrogen bonds present in biomass more easily than $\left[\mathrm{PF}_{6}\right]$-. Hence $[\mathrm{bmim}] \mathrm{Cl}$, which dissolves biomass better than $[\mathrm{bmim}] \mathrm{PF}_{6}$, is also a better solvent 
with regard to gaseous product evolution and causes an early evolution of these products.

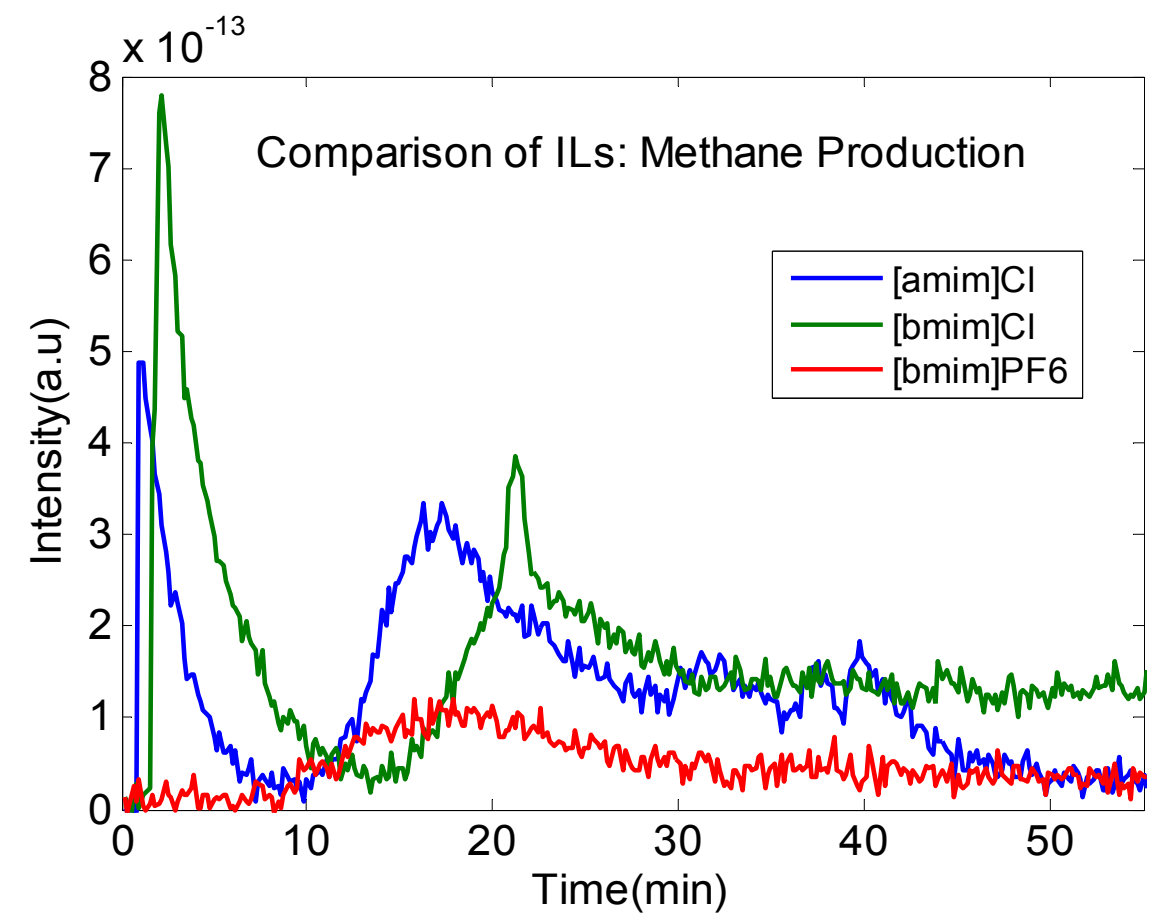

Figure 6.89. Comparison of $\mathrm{CH}_{4}$ production in different ILs

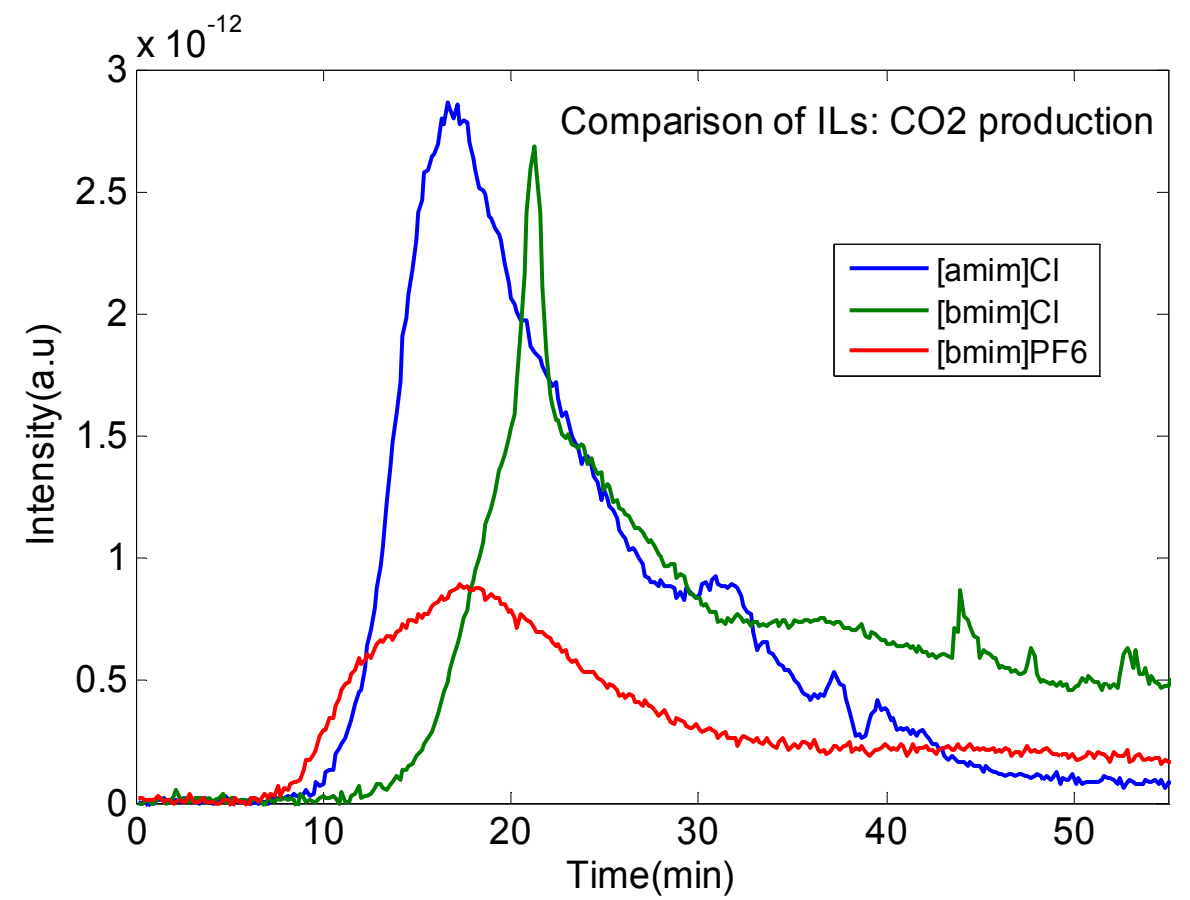

Figure 6.90. Comparison of $\mathrm{CO}_{2}$ production in different ILs 


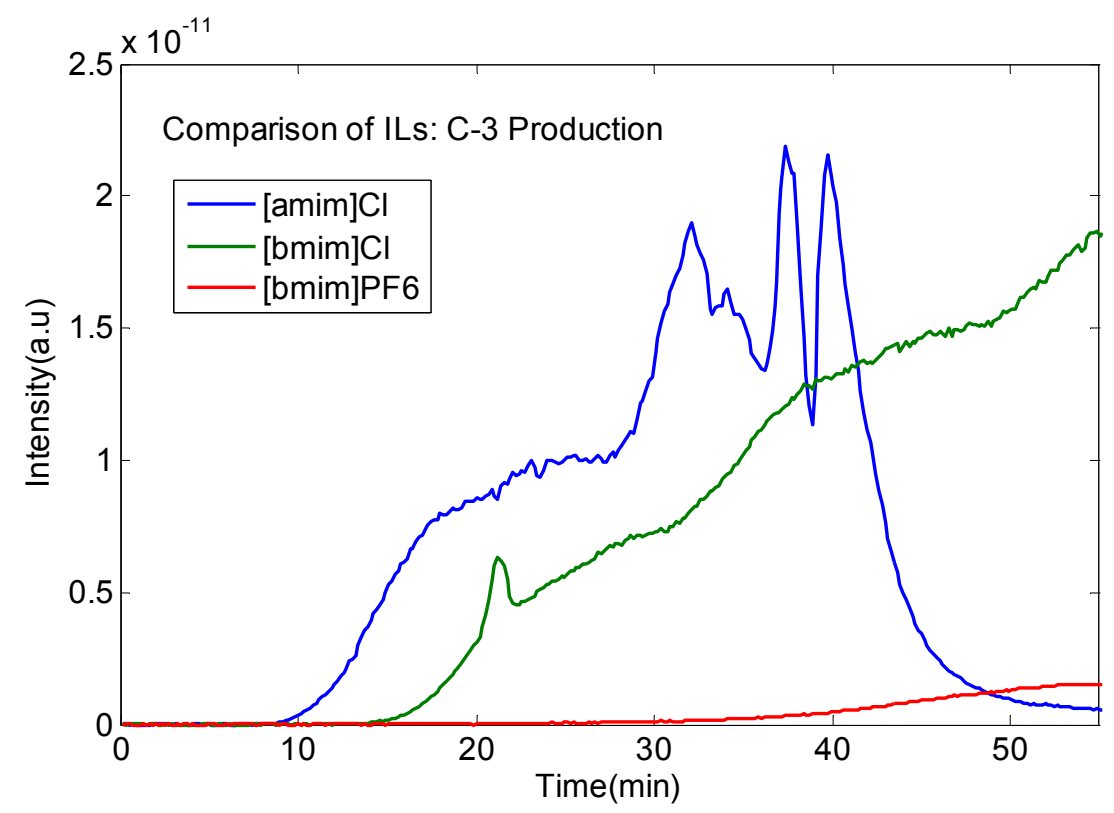

Figure 6.91. Comparison of C-3 production in different ILs

We followed up on our previous preliminary investigation of biomass gasification/pyrolysis in imidizolium-based ionic liquids by developing the concept further and conducting experiments with alternate, less expensive ionic liquids.

Clearly, biomass represents a tremendous opportunity in terms of renewable energy and chemicals production. Many methods of utilization have been proposed, but for cellulosic materials such as waste wood saccharification and fermentation to ethanol or gasification are the most touted. Gasification avoids the challenges of cellulose breakdown and lignin removal. However, gasification only leverages the $\mathrm{C}$ - and $\mathrm{H}$-fixing functions of biomass, not the structural arrangements. Figure 6.92 shows the rough pricing of several chemicals plotted against the rough number of functional groups, and points out the advantages of capitalizing on the structural arrangements inherent in biomass. 


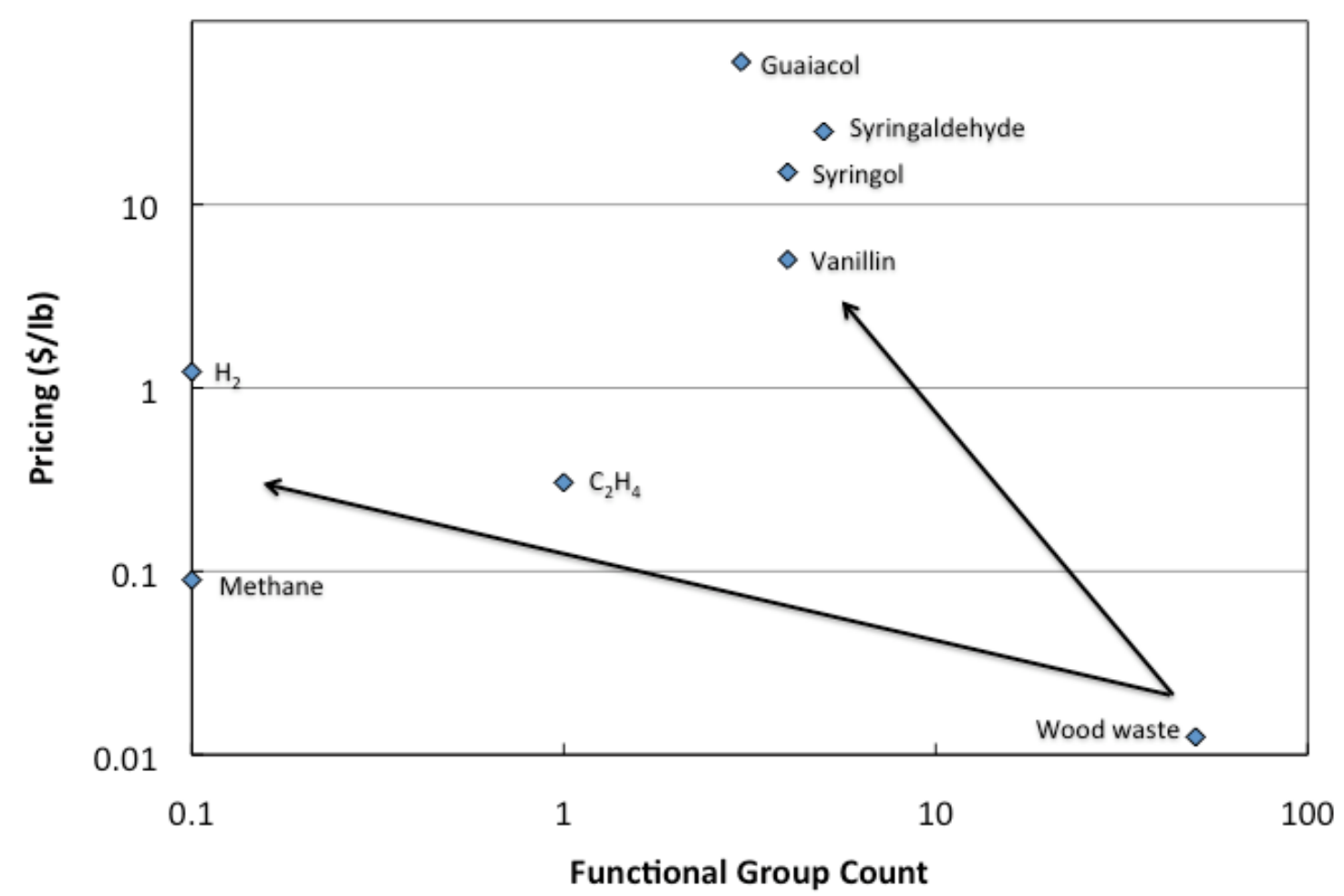

Figure 6.92. Approximate pricing versus chemical complexity based on functional groups for various potential products of biomass conversion.

While the mechanism of solubility has not been clearly established, it has been proposed that the ability of these materials to dissolve cellulose is linked to their combination of chloride ion and hydrogen bonding. This suggests that other ionic liquids, perhaps inorganic salts, may have some ability to dissolve cellulose. To avoid complete decomposition through pyrolysis, however, the solvent melting point must be sufficiently low.

While the community has so far focused mainly on biomass solubility, we have begun to investigate higher temperatures that will facilitate mild pyrolysis. Many of the imidazolium-based ionic liquids are thermally stable to $250-300{ }^{\circ} \mathrm{C}$. Similarly, mixtures of nitrates with low melting points are stable to $300-350{ }^{\circ} \mathrm{C}$. In solvent-free mild pyrolysis experiments (gas-solid reactions), we encountered difficulty removing initial, often condensable, reaction products from the reaction zone prior to further decomposition. The use of a solvent system opens up entirely new reactor designs, such as a CSTR, for use in biomass conversion. We also hypothesize that IL's that can solvate biomass will be able to solvate intermediate breakdown products, leading to more efficient and rapid separations.

IL's also offer the opportunity to engage catalysis much more directly than in gas-solid systems. Homogeneous catalysts such as metal complexes may be added to the solvent system to facilitate reactions on the raw biomass or on the 
intermediate pyrolysis products. Heterogeneous catalysts may also be used, since the solvent can deliver intermediate products with low or negligible vapor pressures, such as sugars, to the catalyst surface.

The low melting inorganic ionic liquids are potentially much less expensive than the organic-based systems. They might also be expected to have a much lower environmental footprint when accounting for solvent preparation, replacement, and disposal.

Low melting inorganic IL mixtures are water soluble. This might afford a clean separation route to recover water-soluble pyrolysis products, such as sugars, from organic-soluble products. The amount of water added might need to be carefully considered so as to avoid significant energy costs in reconstituting the dry IL for recycling. Establishing the effect and acceptable threshold of water concentration may shed light on this problem. Similar to supercritical fluids, where partial depressurization is used to affect solubility, a modest addition of water might be sufficient to achieve the desired fractionation.

We have so far tested the thermal stability of alternate IL's, particularly choline chloride-urea mixtures, as well as nitrate salt mixtures. We have found, as in literature, that choline chloride readily dissolves biomass at reasonable temperatures. The inorganic salt IL's do not appear to dissolve raw biomass, but we are investigating pyrolysis and the solubility of smaller model compounds, which might be analogous to breakdown products from mild gasification/pyrolysis products. 


\section{TASK 7.0: Post-Reaction Characterization of Catalysts}

Recipient shall conduct a post-reaction analysis of the spent catalysts, specifically evaluating characteristics that could result in catalyst deactivation. Causes for catalyst deactivation will be diagnosed by examining the catalyst using a wide range of state-of-the-art catalyst characterization methods available at the University of Michigan, including, but not limited to, thermogravimetric analysis, surface area analysis, pore size analysis, electron microscopy and X-ray photoelectron spectroscopy.

Results of this task are presented in concert with results in Task 6 and Task 8. 


\section{TASK 8.0: DEMONSTRATION OF REFORMING OF A SIMULATED FLEXIBLE-FEEDSTOCK DERIVED GASIFIER PRODUCT STREAM}

Recipient shall test and evaluate the reforming of simulated gasifier product streams in the compact reformer reactor. Experiments will be conducted using gas and condensable mixtures with compositions simulating product streams from coal and biomass gasification. The purpose of this task is to evaluate feedstock sensitivities, operability and other parameters. The stability and reliability of the system will be tested by keeping the catalyst on stream over extended periods of time, and the composition of the syngas product will be continuously monitored to assure SOFC-grade quality.

\section{Introduction}

Reforming catalysts typical of those used in UM's prior reforming work were prepared by co-precipitation and impregnation. A ceria-zirconia mixedoxide support material $\left(\mathrm{Ce}_{0.75} \mathrm{Zr}_{0.25} \mathrm{O}_{2}\right.$, hereafter $\left.\mathrm{CZO}\right)$ was prepared by coprecipitation of $\mathrm{Ce}\left(\mathrm{NO}_{3}\right)_{3} \cdot 6 \mathrm{H}_{2} \mathrm{O}$ and $\mathrm{ZrOCl}_{2} \cdot 8 \mathrm{H}_{2} \mathrm{O}$ from solution. The precipitate was filtered, redispersed in a fresh quantity of the precipitation solvent, filtered again and dried. Following drying, supports were calcined in air at $900{ }^{\circ} \mathrm{C}$. Catalysts were prepared by loaded nickel onto the calcined $\mathrm{CZO}$ via wet impregnation with $\mathrm{Ni}\left(\mathrm{NO}_{3}\right)_{2} \cdot 6 \mathrm{H}_{2} \mathrm{O}$ dissolved in de-ionized water. The nickel nitrate was fixed by calcination in air first to $600{ }^{\circ} \mathrm{C}$ to decompose the nitrate, then to $900{ }^{\circ} \mathrm{C}$ in air to stabilize the catalyst. The entire batch was crushed and classified into size fractions. The reactor was loaded with $1.00 \mathrm{~g}$ of $40-60$ mesh size catalyst particles.

\section{Reforming Experiments}

Initial runs were undertaken to check out the FFRS. In each run catalyst was loaded in the reactor system, reduced in-situ under a $\mathrm{H}_{2} / \mathrm{N}_{2}$ atmosphere, and used for reforming of a simulated gasifier product stream, typical of a switchgrass feedstock, at a feed temperature of $500{ }^{\circ} \mathrm{C}$. After reaching $500{ }^{\circ} \mathrm{C}$, the full reactant mixture was fed at the composition given above. The flowrate was increased at 30 minute intervals to study reaction at space velocities of $155 \mathrm{~K}$, $232 \mathrm{~K}, 310 \mathrm{~K}$, and $387 \mathrm{~K} \mathrm{hr}^{-1}$. This run was stopped shortly after the halfway point due to a rapidly increasing pressure drop. The second run, a repeat of the first, was aborted shortly after startup due to problems with catalyst retention in the bed. 
Table 8.12. Feed composition for simulated gasifier reforming runs. $\mathrm{O} / \mathrm{C}$ and $\mathrm{H}_{2} \mathrm{O} / \mathrm{C}$ determined on basis of $\mathrm{CH}_{4}, \mathrm{C}_{2} \mathrm{H}_{4}$, and $\mathrm{C}_{7} \mathrm{H}_{8}$ in feed stream.

\begin{tabular}{ll} 
Component & Vol \% \\
\hline $\mathrm{H}_{2}$ & 12.59 \\
$\mathrm{CO}$ & 20.44 \\
$\mathrm{CO}_{2}$ & 7.75 \\
$\mathrm{CH}_{4}$ & 7.13 \\
$\mathrm{C}_{2} \mathrm{H}_{4}$ & 3.03 \\
$\mathrm{C}_{7} \mathrm{H}_{8}$ & 0.60 \\
$\mathrm{~N}_{2}$ & 24.54 \\
$\mathrm{O}_{2}$ & 6.53 \\
$\mathrm{H}_{2} \mathrm{O}$ & 17.40 \\
& \\
$\mathrm{O} / \mathrm{C}$ & 0.75 \\
$\mathrm{H}_{2} \mathrm{O} / \mathrm{C}$ & 1.00
\end{tabular}

The reaction started immediately as evidenced by the rapid increase of the catalyst temperature (Figure 8.93). The pressure drop across the catalyst bed also increased at this point, due to the increase in total flow rate through the bed (Figure 8.94). Subsequent increases in flowrates (see Figure 8.95 for actual system flowrates) produced further increases in pressure drop, with the final flowrate increase leading to a dramatic runaway pressure drop - at this point the experiment was terminated. Initially this was thought to be due to carbon deposition, a common cause of pressure drop in reforming systems. On further inspection, however, this is likely due to incomplete water vaporization prior to the reactor entrance. Figure 8.93 shows a dropping Pre-Reactor 2 temperature this temperature dips below $100{ }^{\circ} \mathrm{C}$ at the same point where the pressure drop increases dramatically. Increasing the heat tracing temperature from $150{ }^{\circ} \mathrm{C}$ to $200{ }^{\circ} \mathrm{C}$ will remedied this problem in future experiments. 


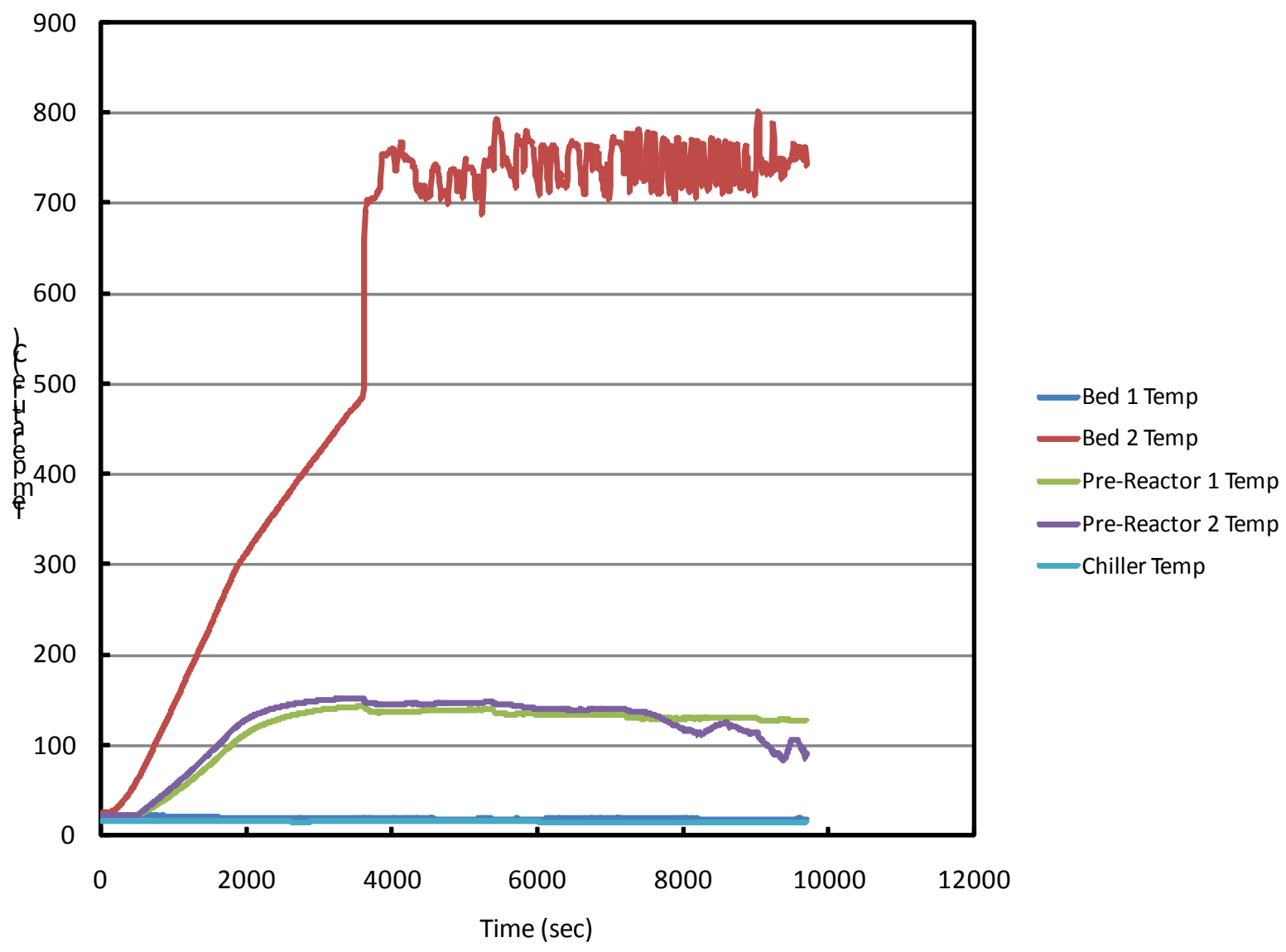

Figure 8.93. Reactor and feed stream temperatures for reforming run. (Bed 1 unused in this experiment.) 


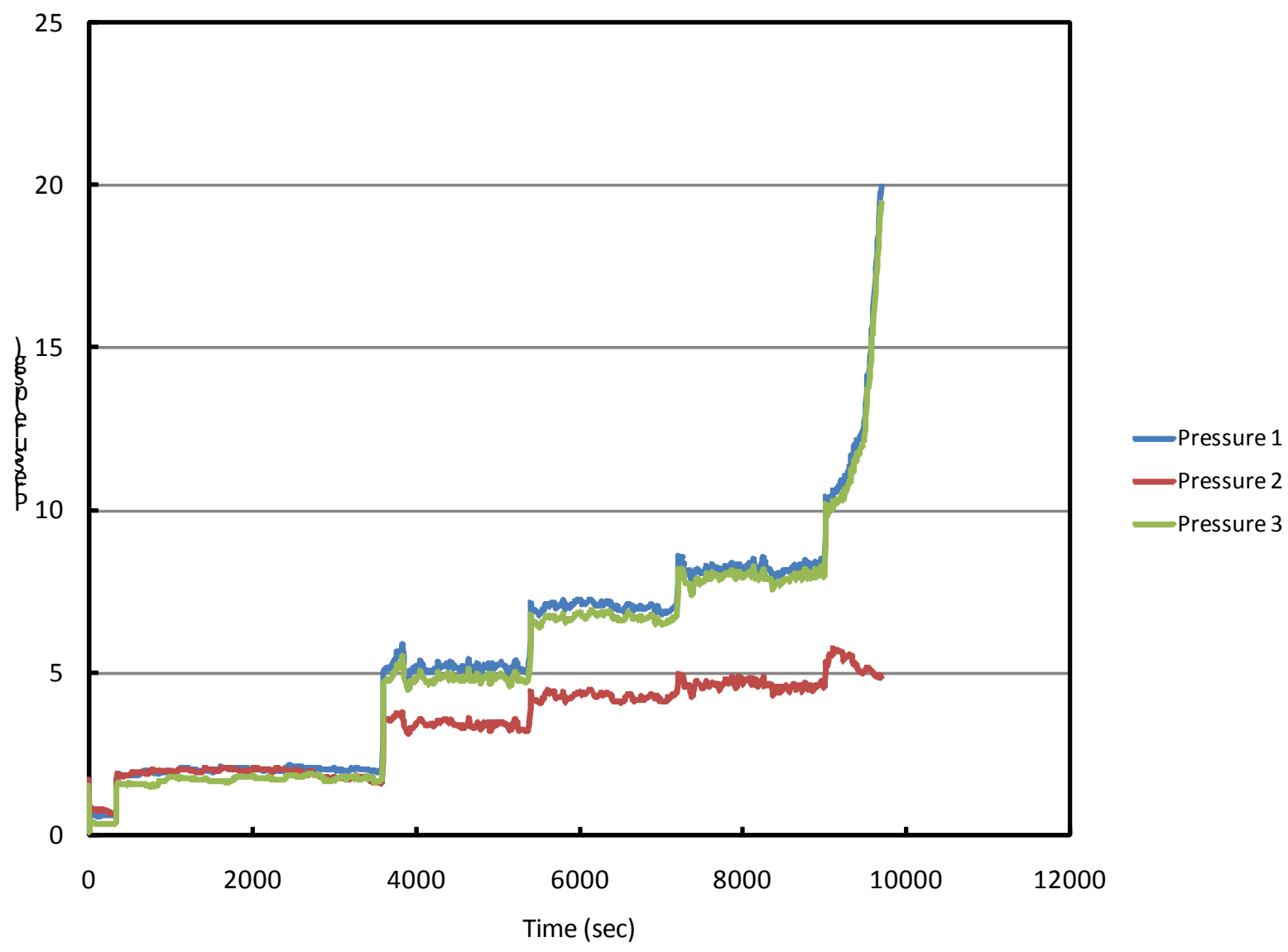

Figure 8.94. System pressure during reforming run. (Pressure drop across Bed 2 is Pressure 3 - Pressure 2.) 


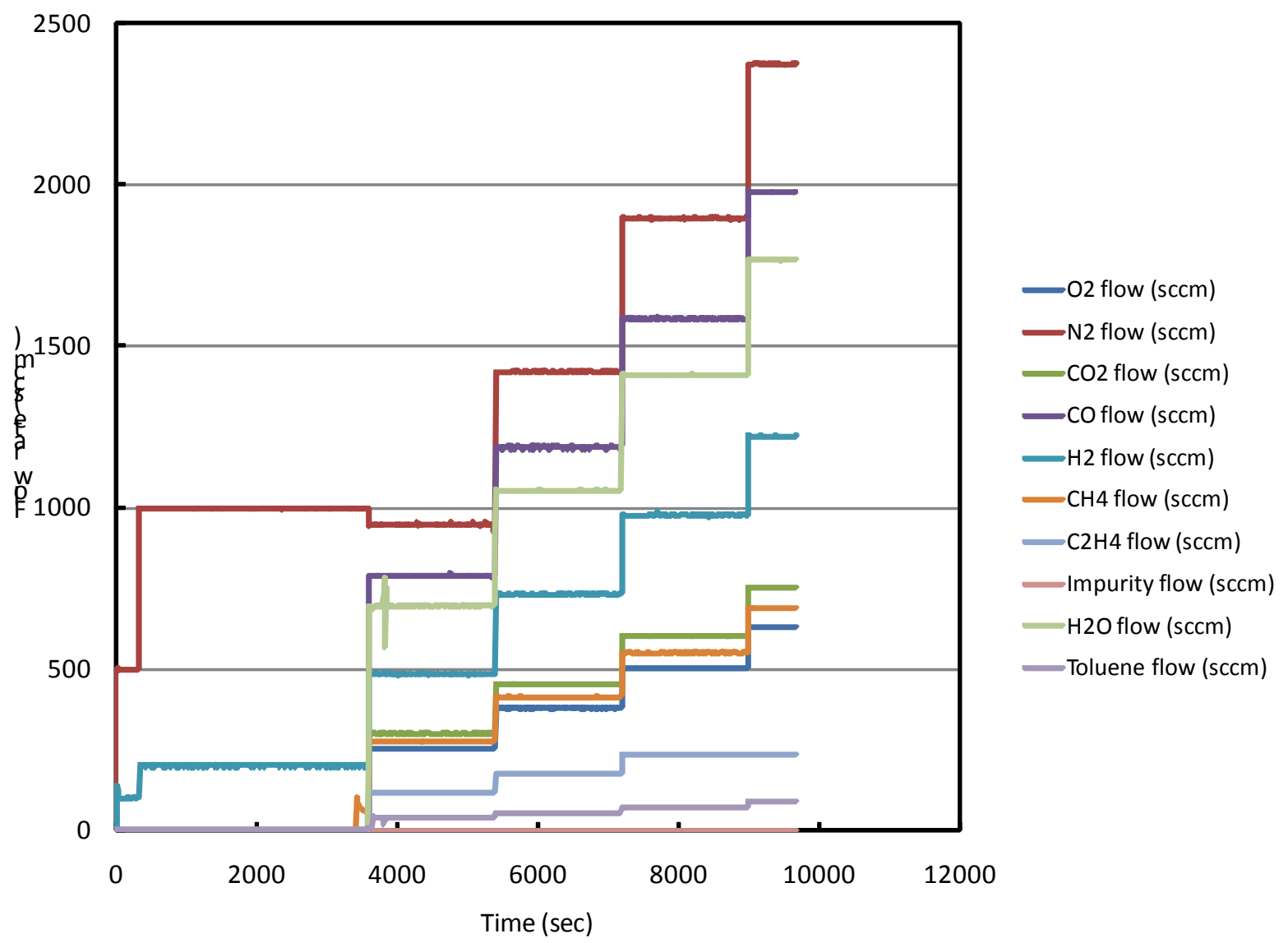

Figure 8.95. System flowrates during reforming run up to point of termination.

Despite its early termination, this run provided significant information. Figure 8.96 shows the raw MS data for products of the reforming reaction. The gaps are where data from the two reactor feed streams have been removed for clarity. Both ethylene $\left(\mathrm{C}_{2} \mathrm{H}_{4}\right)$ and toluene $\left(\mathrm{C}_{7} \mathrm{H}_{8}\right)$ are completely converted at all space velocities. Previous results during experiments at UM suggested that ethylene would be easily converted under ATR conditions. There has been some concern expressed in literature that aromatics in reforming feeds lead to carbon deposition. This has clearly been demonstrated to be problematic under steam reforming conditions, but in our results under ATR conditions there do not appear to be obvious indications of carbon deposition. The catalyst was recovered as a free flowing mixture with no evidence of agglomeration usually associated with carbon deposition. Oxygen was also completely converted, as would be expected under these conditions. While somewhat scattered, the data for methane does suggest that increasing space velocity leads to increased methane slip in the product (Figure 8.97). Methane is the hardest hydrocarbon to reform, and decreased contact time should be expected to lead to decreased conversion. 


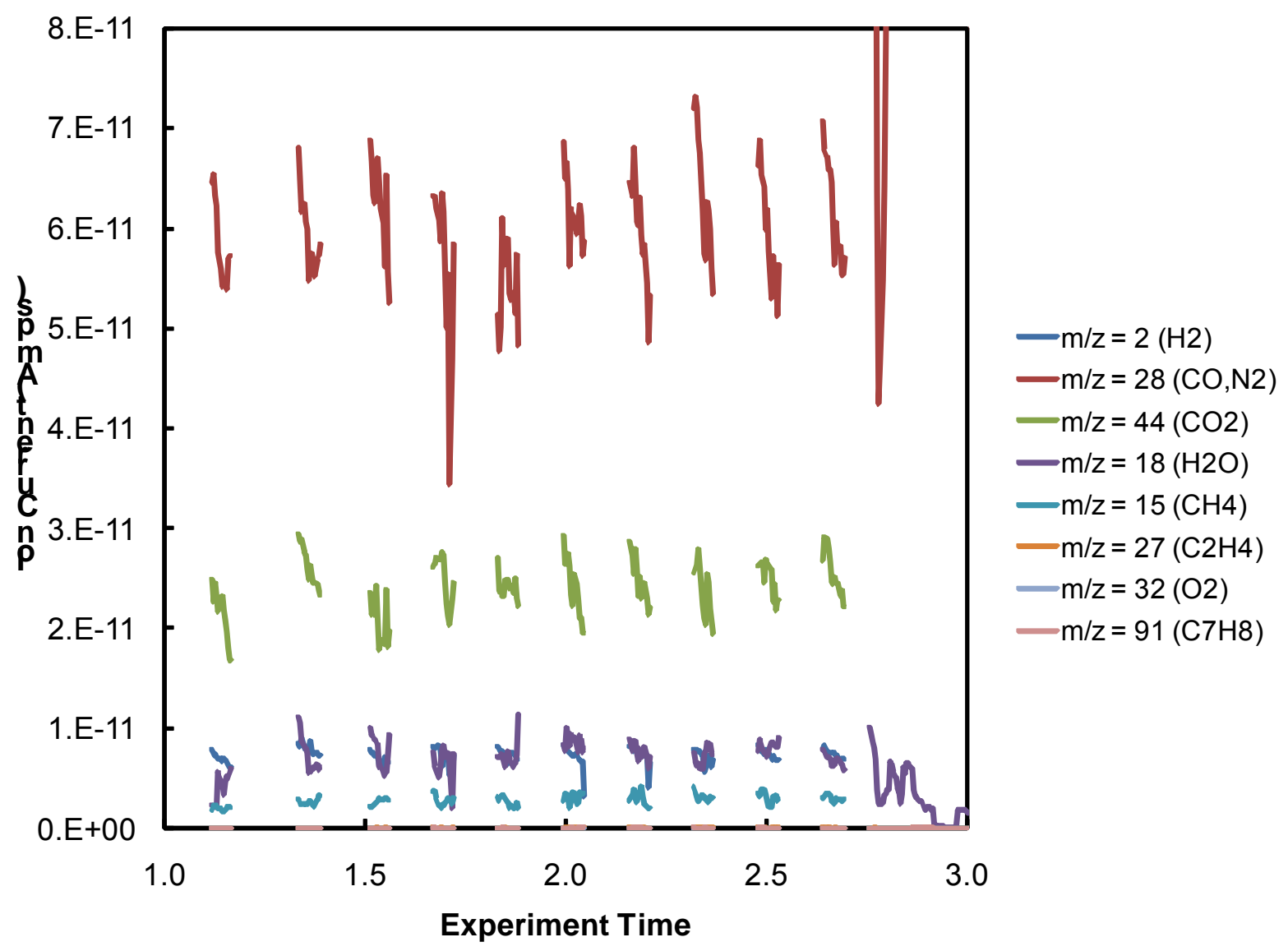

Figure 8.96. MS data for product stream during reforming run. Legend indicates $\mathrm{m} / \mathrm{z}$ values and species associated with that $\mathrm{m} / \mathrm{z}$ value. 


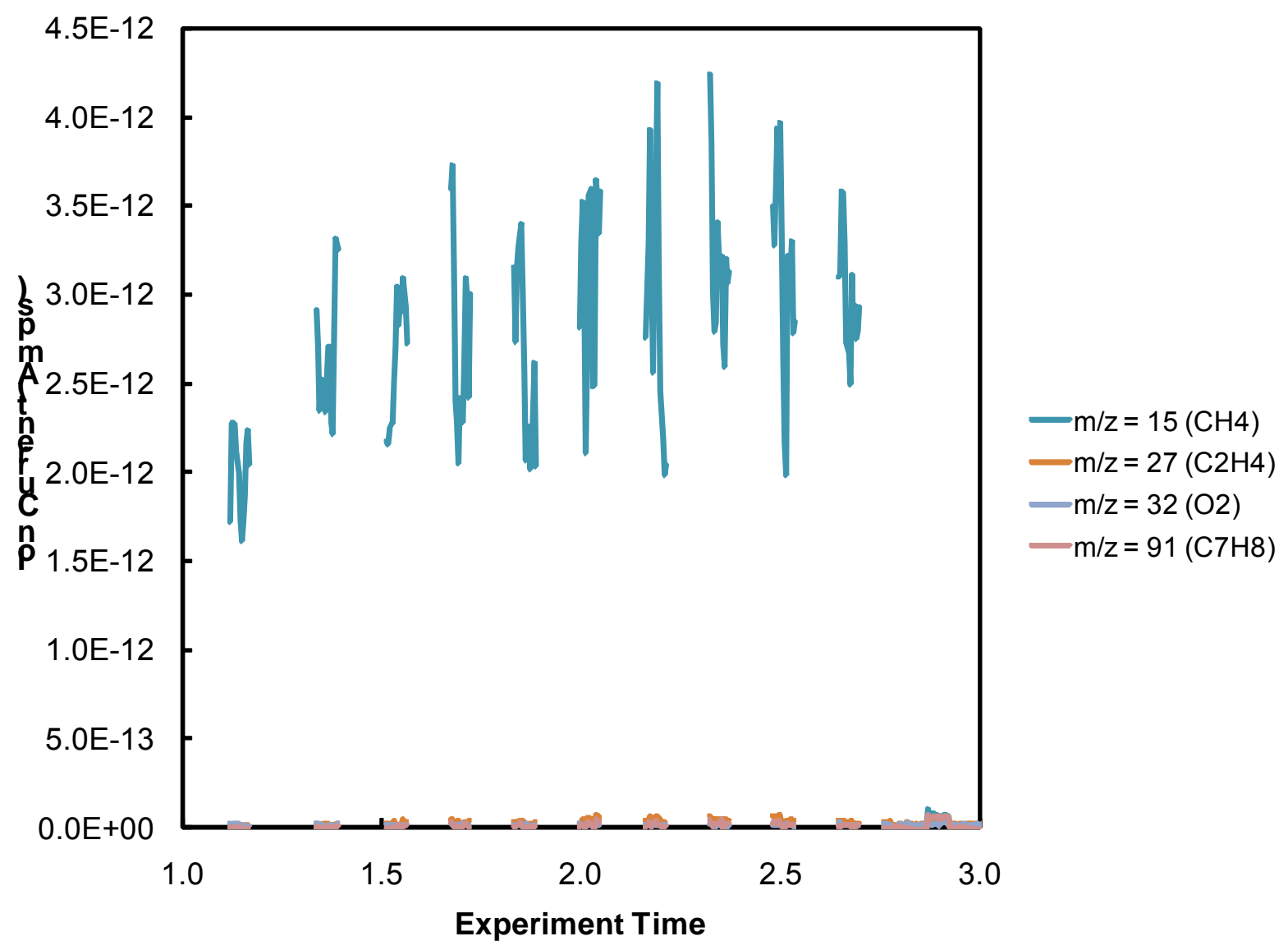

Figure 8.97. Enlargement of Figure 8.96 showing just $\mathrm{CH}_{4}$. 
Following initial experiments, a complete set of experiments comparing and contrasting the performance of two reforming catalysts, $5 \mathrm{Ni} / \mathrm{CZO}$ and $0.3 \mathrm{Sn}-$ $5 \mathrm{Ni} / \mathrm{CZO}$, under the same reaction conditions with and without $\mathrm{H}_{2} \mathrm{~S}$ as an impurity are presented. Previous work demonstrated that doping of nickel catalysts with $\mathrm{Sn}$ decreased $\mathrm{C}$ deposition and loss of activity during reforming. The inclusion of a $\mathrm{Sn}-\mathrm{Ni}$ catalyst here was to evaluate whether $\mathrm{Sn}$ might have any beneficial effects on $\mathrm{S}$ tolerance. The product distribution using each catalyst is presented, along with the effects of sulfur addition on performance. Temperature profiles of the catalyst bed region during operation are given, as well as characterization results for the catalysts before and after reaction.

The addition of sulfur to the feed stream as $\mathrm{H}_{2} \mathrm{~S}$ has a strong influence on $\mathrm{H}_{2}$ and $\mathrm{CO}$ production and $\mathrm{CH}_{4}$ and $\mathrm{C}_{2} \mathrm{H}_{4}$ conversion. $\mathrm{CO}_{2}$ production, however, is not strongly affected. All catalysts showed decreased metal dispersions following reaction, but reaction with $\mathrm{H}_{2} \mathrm{~S}$ in the feed stream led to much lower nickel dispersions.

Characterization of fresh catalysts revealed important differences between $\mathrm{Ni}$ and $\mathrm{Sn}-\mathrm{Ni}$ catalysts. All catalysts showed decreased hydrogen uptake following reaction, but especially so after reaction with sulfur in the feed stream.

Two catalysts were prepared for comparison under reaction conditions. The first was $5 \mathrm{wt} \% \mathrm{Ni}$ supported on $\mathrm{Ce}_{0.75} \mathrm{Zr}_{0.25} \mathrm{O}_{2}$ (5Ni/CZO). The second was $5 \mathrm{Ni} / \mathrm{CZO}$ doped with $0.3 \mathrm{wt} \% \mathrm{Sn}(0.3 \mathrm{Sn}-5 \mathrm{Ni} / \mathrm{CZO})$. The $\mathrm{CZO}$ was first prepared by co-precipitation of $\mathrm{Ce}\left(\mathrm{NO}_{3}\right)_{3}-6 \mathrm{H}_{2} \mathrm{O}$ and $\mathrm{ZrOCl}_{2}-8 \mathrm{H}_{2} \mathrm{O}$ from aqueous solution using $4 \mathrm{M} \mathrm{NH}_{4} \mathrm{OH}$. The precipitate was filtered, dried, and calcined in air at $900^{\circ} \mathrm{C}$ for one hour. After calcination, nickel was added via incipient wetness using aqueous nickel nitrate. This pre-catalyst was dried, then calcined in air at $900^{\circ} \mathrm{C}$ for one hour. To prepare the $0.3 \mathrm{Sn}-5 \mathrm{Ni} / \mathrm{CZO}$ catalyst, $\mathrm{SnCl}_{2}$ dissolved in isopropyl alcohol was added to a quantity of $5 \mathrm{Ni} / \mathrm{CZO}$, the solid dried, and calcined at $900^{\circ} \mathrm{C}$ for one hour.

Reforming experiments were carried out in the Feedstock Flexible Reformer System (FFRS) at NextEnergy using a standard feed mixture given in Table 8.13. A simulated gasifier product mixture composition was assumed based on review of literature. It contained hydrogen, carbon monoxide, carbon dioxide, and light hydrocarbons. Both methane and ethylene would be expected in gasifier products, and toluene is added as a surrogate for tars. The desired reactions are autothermal reforming of methane, ethylene, and toluene, along with water gas shift to bring the mixture to an equilibrium composition. The oxygen and water feed rates were determined using an $\mathrm{O} / \mathrm{C}$ ratio of 0.75 and a $\mathrm{H}_{2} \mathrm{O} / \mathrm{C}$ ratio of 2.0 , based only on the hydrocarbons in the feed mixture. Nitrogen was added at the same ratio to oxygen as in air, $4.76 \mathrm{~N}_{2}$ to $\mathrm{O}_{2}$. 
Table 8.13. Feed composition for autothermal reforming experiments.

\begin{tabular}{|c|c|c|c|c|c|c|}
\hline Species & $\begin{array}{l}\text { Simula } \\
\text { sccm }\end{array}$ & $\begin{array}{l}\text { gasifier feed } \\
\text { vol \% }\end{array}$ & $\begin{array}{l}\text { Reform } \\
\text { sccm }\end{array}$ & $\begin{array}{l}\text { Add } \\
\text { vol \% }\end{array}$ & $\begin{array}{l}\text { Total input } \\
\text { sccm }\end{array}$ & vol $\%$ \\
\hline $\mathrm{H}_{2}$ & 720 & 24 & & & 720 & 11.66 \\
\hline $\mathrm{CO}$ & 1200 & 40 & & & 1200 & 19.43 \\
\hline $\mathrm{CO}_{2}$ & 450 & 15 & & & 450 & 7.29 \\
\hline $\mathrm{CH}_{4}$ & 420 & 14 & & & 420 & 6.80 \\
\hline $\mathrm{C}_{2} \mathrm{H}_{4}$ & 150 & 5 & & & 150 & 2.43 \\
\hline $\mathrm{C}_{7} \mathrm{H}_{8}$ & 60 & 2 & & & 60 & 0.97 \\
\hline $\mathrm{O}_{2}$ & & & 428 & 13.46 & 428 & 6.92 \\
\hline $\mathrm{N}_{2}$ & & & 1607 & 50.63 & 1607 & 26.03 \\
\hline $\mathrm{H}_{2} \mathrm{O}$ & & & 1140 & 35.91 & 1140 & 18.46 \\
\hline Total & 3000 & & 3175 & & 6175 & \\
\hline $\mathrm{O} / \mathrm{C}$ & & & & & 0.75 & \\
\hline $\mathrm{H}_{2} \mathrm{O} / \mathrm{C}$ & & & & & 2.00 & \\
\hline
\end{tabular}

All experiments were started by loading the catalyst in a $1 / 2$ " stainless steel tube on top of a quartz wool plug. The reactor was fitted with a $1 / 8$ " stainless steel thermowell along the tube centerline, within which was placed a 1/16" Ktype thermocouple, which could be moved up and down to record a temperature profile during reaction. The catalyst bed was topped with another quartz wool plug and sealed. An additional 1/16" K-type thermocouple was placed into the gas stream well above the catalyst to measure the gas feed temperature $\sim 1 / 3$ of the distance into the heated zone. The steel reactor tube was placed in an electrically heated furnace. Pressure transducers above and below the catalyst bed provided a measurement of pressure drop during reaction.

All reactions were carried out using the same protocol on the FFRS. The catalyst was heated to $500^{\circ} \mathrm{C}$ in the reactor under $1000 \mathrm{sccm}$ of $5 \% \mathrm{H}_{2}$ balance $\mathrm{N}_{2}$ and held for 6 minutes at $500^{\circ} \mathrm{C}$. Flow of all reactants was then started simultaneously. For runs without sulfur, reaction was continued until 10 hours on stream. For runs that included $\mathrm{H}_{2} \mathrm{~S}$, the reaction was started sulfur-free and allowed to proceed for 1 hour, at which time the $\mathrm{H}_{2} \mathrm{~S}$ flow was started. The reaction was then allowed to proceed an additional 9 hours for a total of 10 hours on stream.

The physical surface area of the catalysts was determined by $\mathrm{N}_{2}$ physisorption at $77 \mathrm{~K}$ using an ASAP 2020 instrument (Micromeritics, USA). Active surface area was measured by $\mathrm{H}_{2}$ chemisorption using the ASAP 2020, assuming a $\mathrm{H}: \mathrm{Ni}$ ratio of 1 and an adsorption temperature of $30^{\circ} \mathrm{C}$. Post reaction 
samples were analyzed for active surface area by $\mathrm{H}_{2}$ chemisorption and for carbon deposition by thermogravimetric analysis. Prior to chemisorption, the post reaction samples were calcined at $650^{\circ} \mathrm{C}$ under air for 30 minutes to remove any carbon. Temperature programmed reduction was carried out using a ChemBET 3000 (Quantachrome) and $5 \% \mathrm{H}_{2} / \mathrm{N}_{2}$ as the reducing gas.

$\mathrm{Ni} / \mathrm{CZO}$ catalysts of varied weight loadings have previously been shown to be very effective at autothermal reforming of liquid fuels. High nickel loadings, however, have shown tendencies towards carbon deposition and decreases in performance as a result. Reforming light hydrocarbons such as methane and ethylene in the presence of $\mathrm{H}_{2}, \mathrm{CO}$, and $\mathrm{CO}_{2}$ is a new challenge.

Figure 8.98 shows the product output from $5 \mathrm{Ni} / \mathrm{CZO}$ during ATR of a simulated gasifier product. There is a slight drop off of $\mathrm{H}_{2}$ and $\mathrm{CO}$ production during the course of the run. This is accompanied by a slight increase in methane over the same time period. The $\mathrm{CO}_{2}$ production rate is constant throughout the reaction. Ethylene is completely converted throughout the entire run.

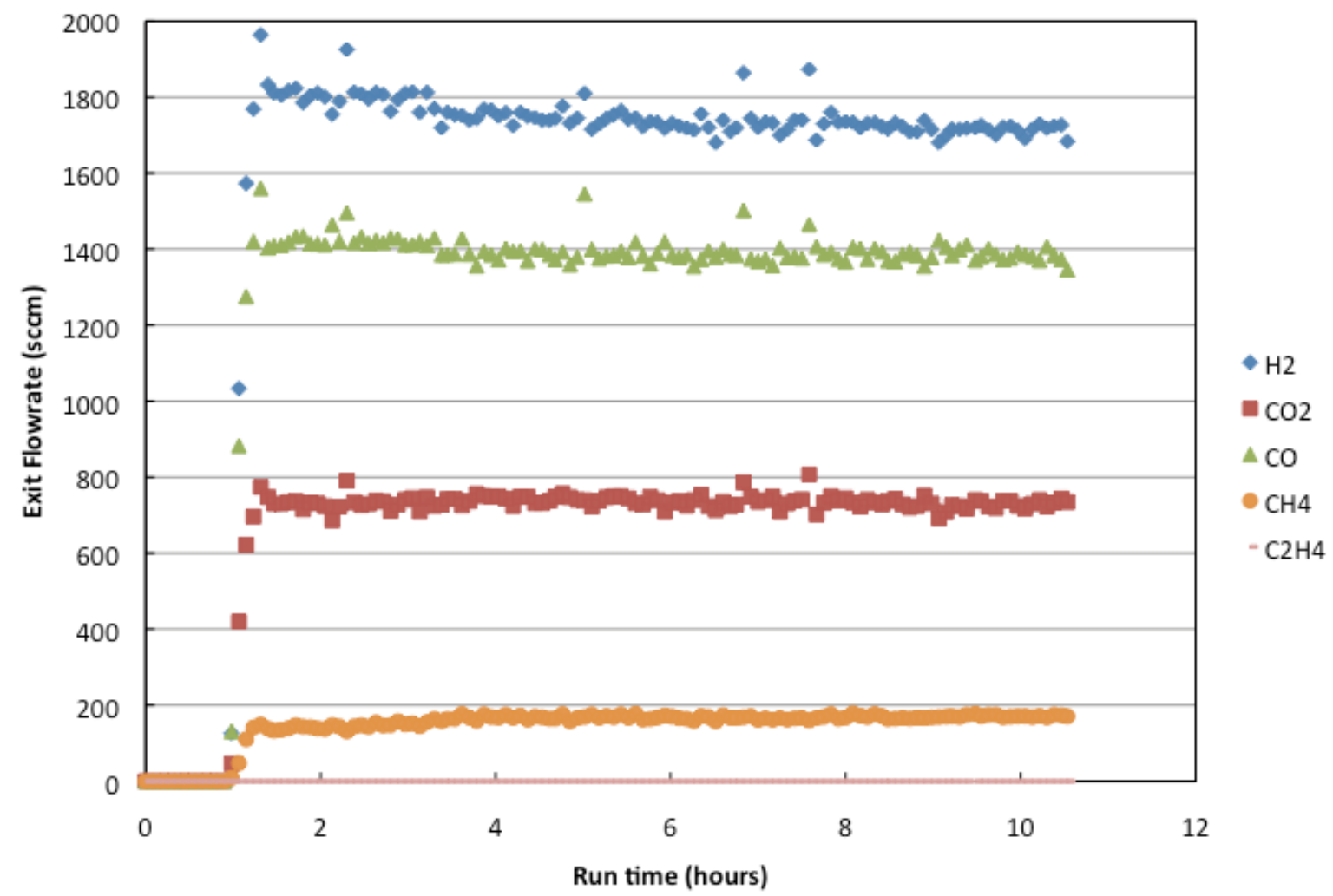

Figure 8.98. Product flowrates for ATR over $5 \mathrm{Ni} / \mathrm{CZO}, 1 \mathrm{~g}$ catalyst, $3 \mathrm{slpm}$ gasifier feed, feed temperature of $500{ }^{\circ} \mathrm{C}$, no $\mathrm{H}_{2} \mathrm{~S}$. 
Figure 8.99 shows the product output from $0.3 \mathrm{Sn}-5 \mathrm{Ni} / \mathrm{CZO}$ under the same conditions. There is a much more pronounced initial drop off in $\mathrm{H}_{2}$ and $\mathrm{CO}$ production as well as a slight steady increase in methane. Again, the $\mathrm{CO}_{2}$ production is constant and ethylene is completely converted over the course of the run.

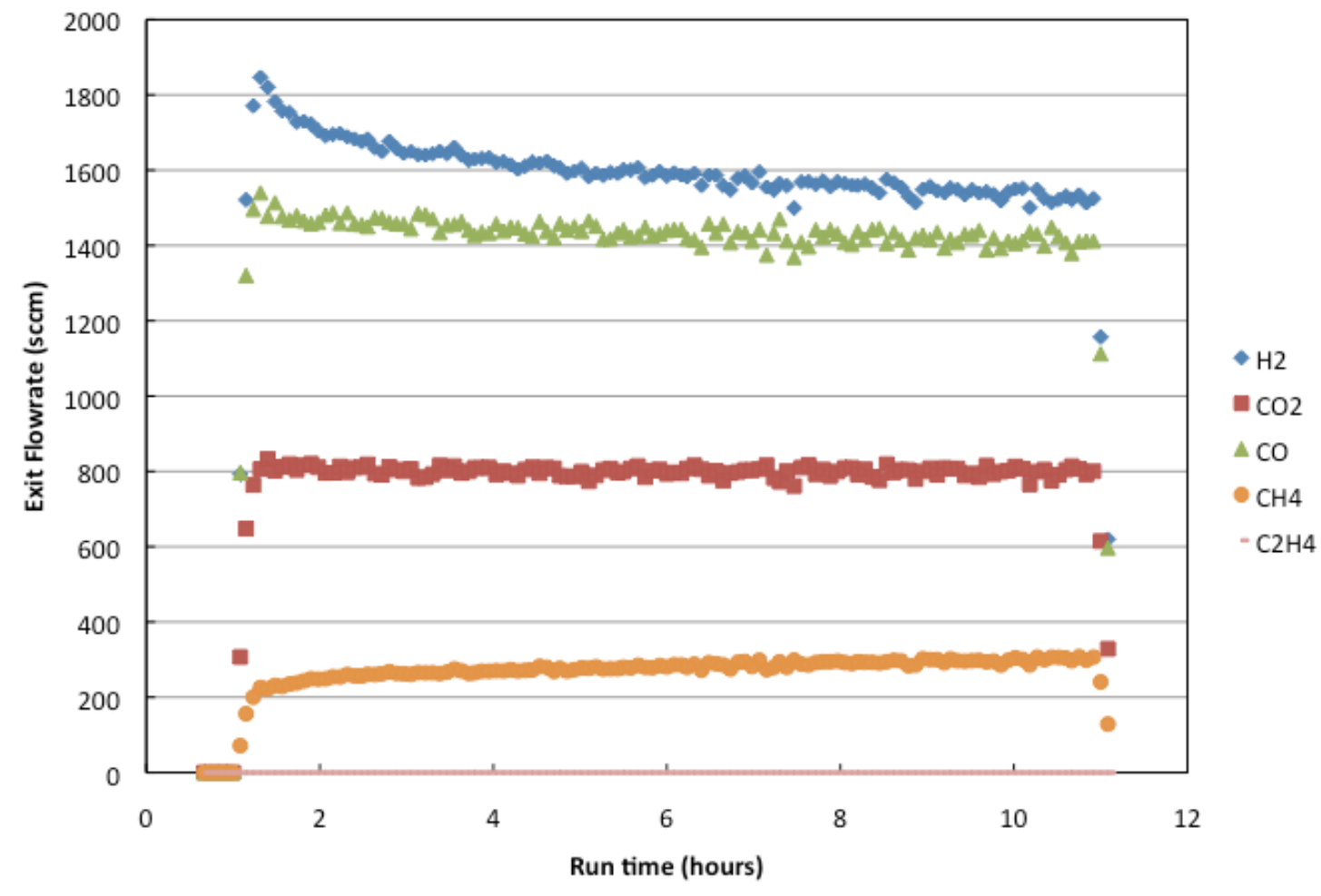

Figure 8.99. Product flowrates for ATR over $0.3 \mathrm{Sn}-5 \mathrm{Ni} / \mathrm{CZO}, 1 \mathrm{~g}$ catalyst, $3 \mathrm{slpm}$ gasifier feed, feed temperature of $500{ }^{\circ} \mathrm{C}$, no $\mathrm{H}_{2} \mathrm{~S}$. 
Performance over both catalysts is significantly affected by the addition of $\mathrm{H}_{2} \mathrm{~S}$. Figure 8.100 shows product output from $5 \mathrm{Ni} / \mathrm{CZO}$ with 250 ppmv $\mathrm{H}_{2} \mathrm{~S}$ added to the gasifier feed. There is a sharp drop in $\mathrm{H}_{2}$ and $\mathrm{CO}$ production upon $\mathrm{H}_{2} \mathrm{~S}$ addition. There is a slight uptick in methane exit flow at the same time, but not enough to account for the large drop in $\mathrm{H}_{2}$ and $\mathrm{CO}$. At the addition of $\mathrm{H}_{2} \mathrm{~S}$, ethylene breaks through. The ethylene conversion is approximately $75 \%$ throughout the remainder of the run. The $\mathrm{CO}_{2}$ production rate is unaffected by the addition of $\mathrm{H}_{2} \mathrm{~S}$.

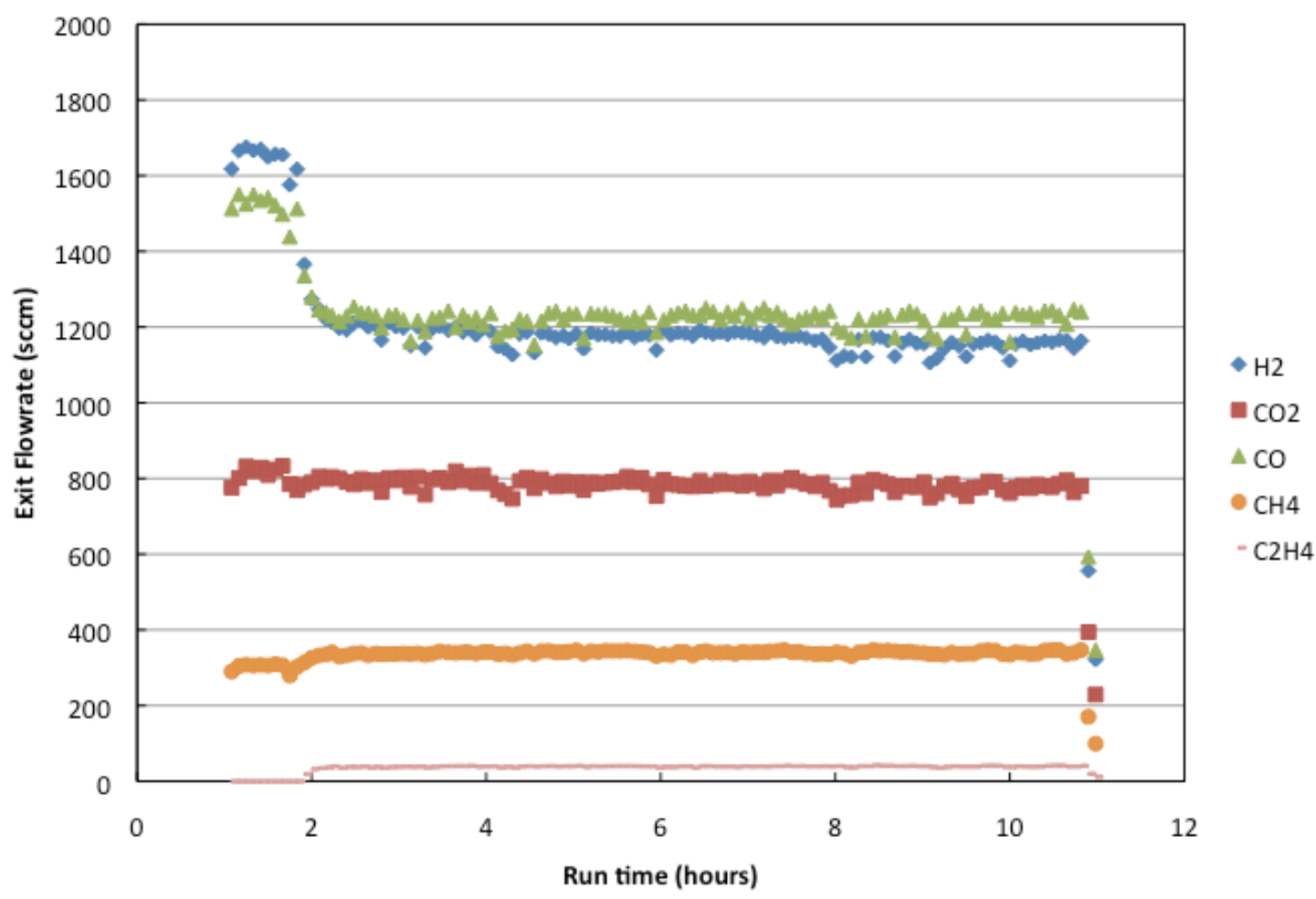

Figure 8.100. Product flowrates for ATR over 5Ni/CZO, $1 \mathrm{~g}$ catalyst, $3 \mathrm{slpm}$ gasifier feed, feed temperature of $500{ }^{\circ} \mathrm{C}, 250 \mathrm{ppmv} \mathrm{H}_{2} \mathrm{~S}$ added at 2 hour mark. 
Figure 8.101 shows the product output from $0.3 \mathrm{Sn}-5 \mathrm{Ni} / \mathrm{CZO}$ with the addition of $\mathrm{H}_{2} \mathrm{~S}$. As with $5 \mathrm{Ni} / \mathrm{CZO}$, there is a drop in $\mathrm{H}_{2}$ and $\mathrm{CO}$ along with a small increase in methane slip and a drop in ethylene conversion from $100 \%$ to approximately $76 \%$. Again, $\mathrm{CO}_{2}$ is unaffected by the addition of $\mathrm{H}_{2} \mathrm{~S}$.

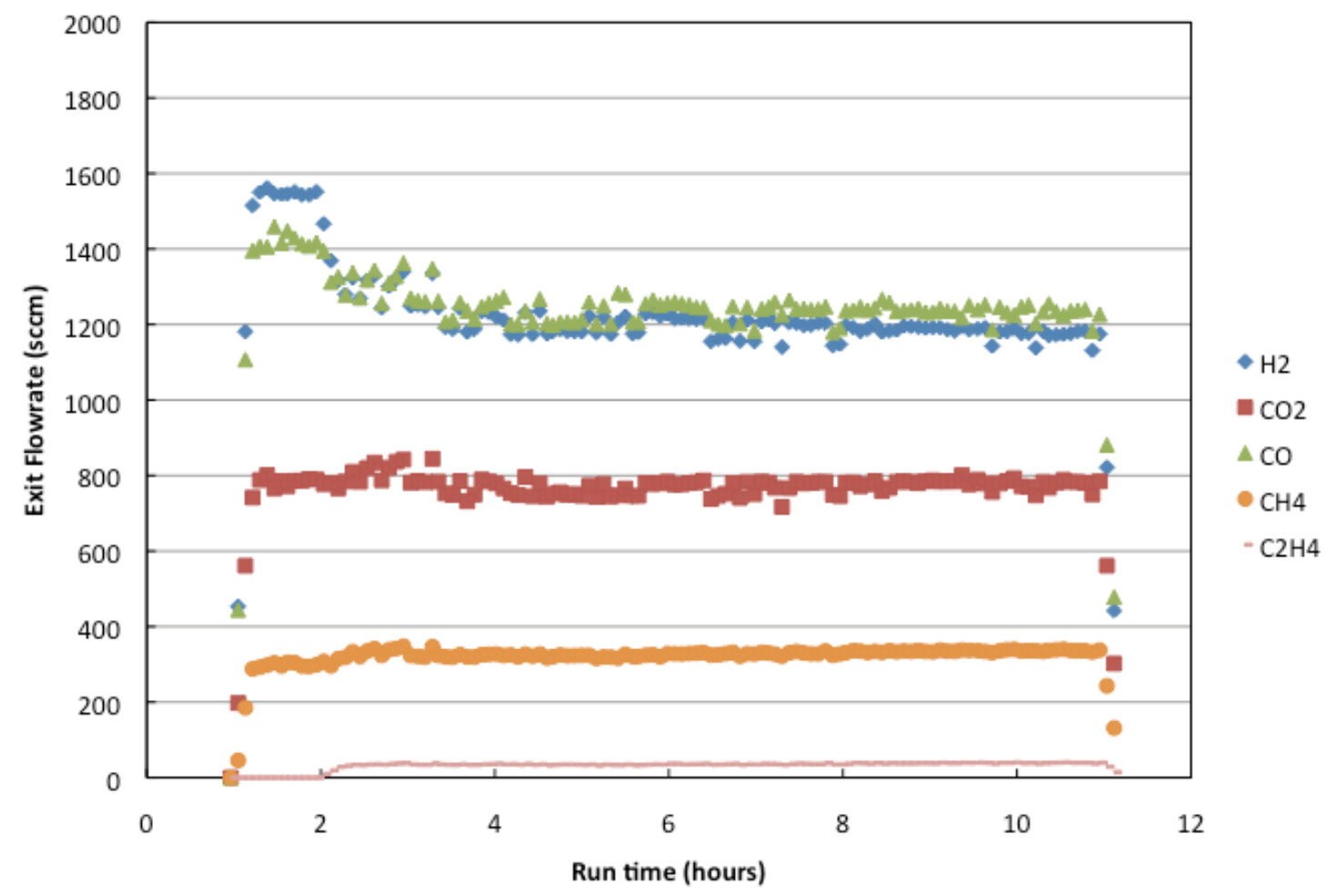

Figure 8.101. Product flowrates for ATR over $0.3 \mathrm{Sn}-5 \mathrm{Ni} / \mathrm{CZO}, 1 \mathrm{~g}$ catalyst, 3 slpm gasifier feed, feed temperature of $500{ }^{\circ} \mathrm{C}, 250 \mathrm{ppmv} \mathrm{H}_{2} \mathrm{~S}$ added at 2 hour mark.

Measurement of catalyst bed profiles reveals additional differences between the catalysts and their response to $\mathrm{H}_{2} \mathrm{~S}$ addition. Figure 8.102 shows the temperature profile along the reactor axis for $5 \mathrm{Ni} / \mathrm{CZO}$ and $0.3 \mathrm{Sn}-5 \mathrm{Ni} / \mathrm{CZO}$ catalysts with a S-free feed. The Sn-doped catalyst shows higher temperatures throughout the bed and a significantly higher peak temperature. Figure 8.103 compares the temperature profiles of $5 \mathrm{Ni} / \mathrm{CZO}$ before and after the addition of $\mathrm{H}_{2} \mathrm{~S}$ in the feed. The peak temperature observed increases and moves downstream. Due to the axial resolution of the temperature measurements, it is possible that the peak temperature in the bed lies between the available data points and is actually higher than the values observed. The temperatures in the downstream portion of the bed increase by approximately $50^{\circ} \mathrm{C}$. Figure 8.104 shows the same comparison for $0.3 \mathrm{Sn}-5 \mathrm{Ni} / \mathrm{CZO}$. As with the Ni-only catalyst, the downstream bed temperatures are higher once $\mathrm{H}_{2} \mathrm{~S}$ is added. The peak temperature observed does not increase significantly. 


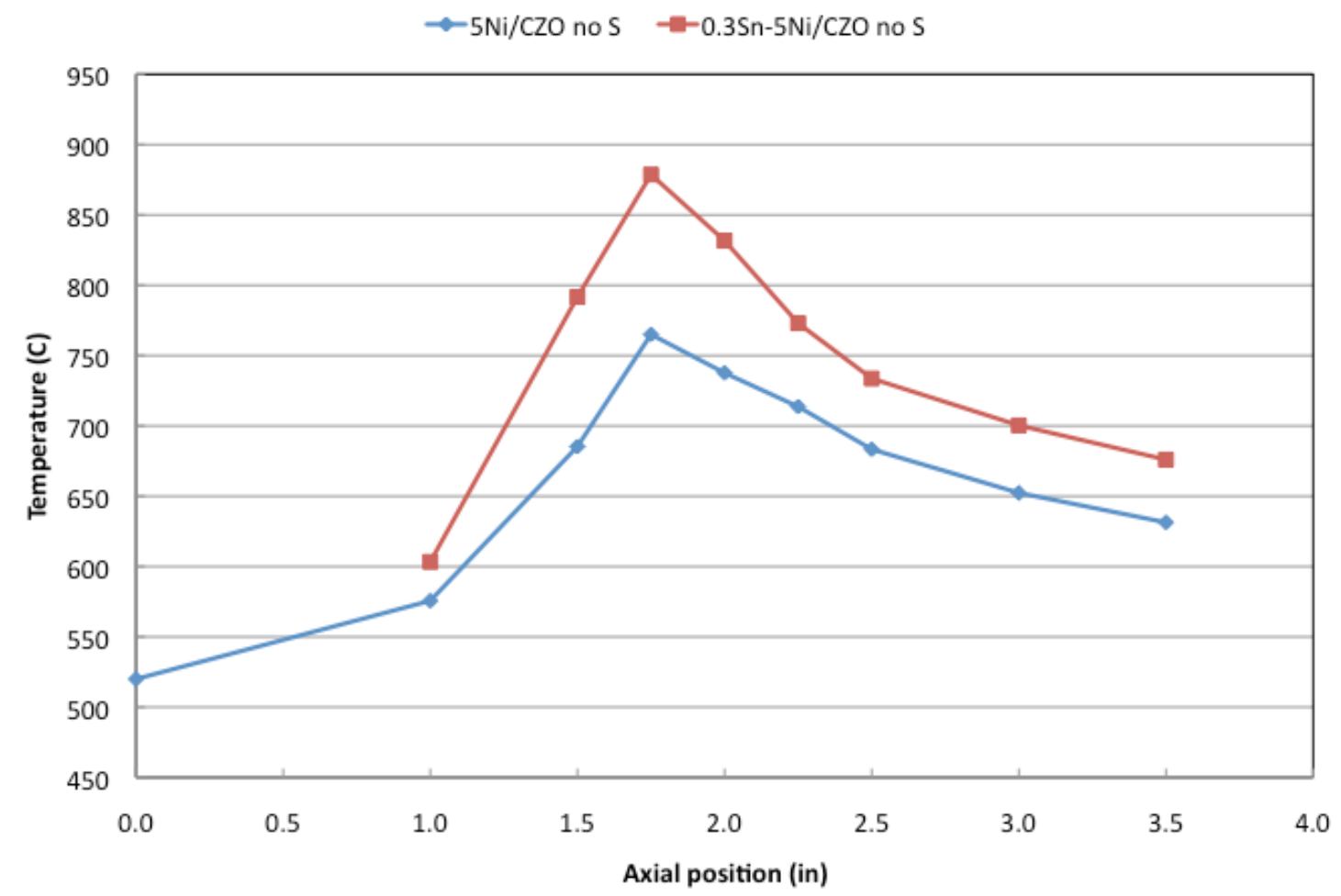

Figure 8.102. Axial temperature profiles for $5 \mathrm{Ni} / \mathrm{CZO}$ and $0.3 \mathrm{Sn}-5 \mathrm{Ni} / \mathrm{CZO}$ during ATR of sulfur free gasifier product. 


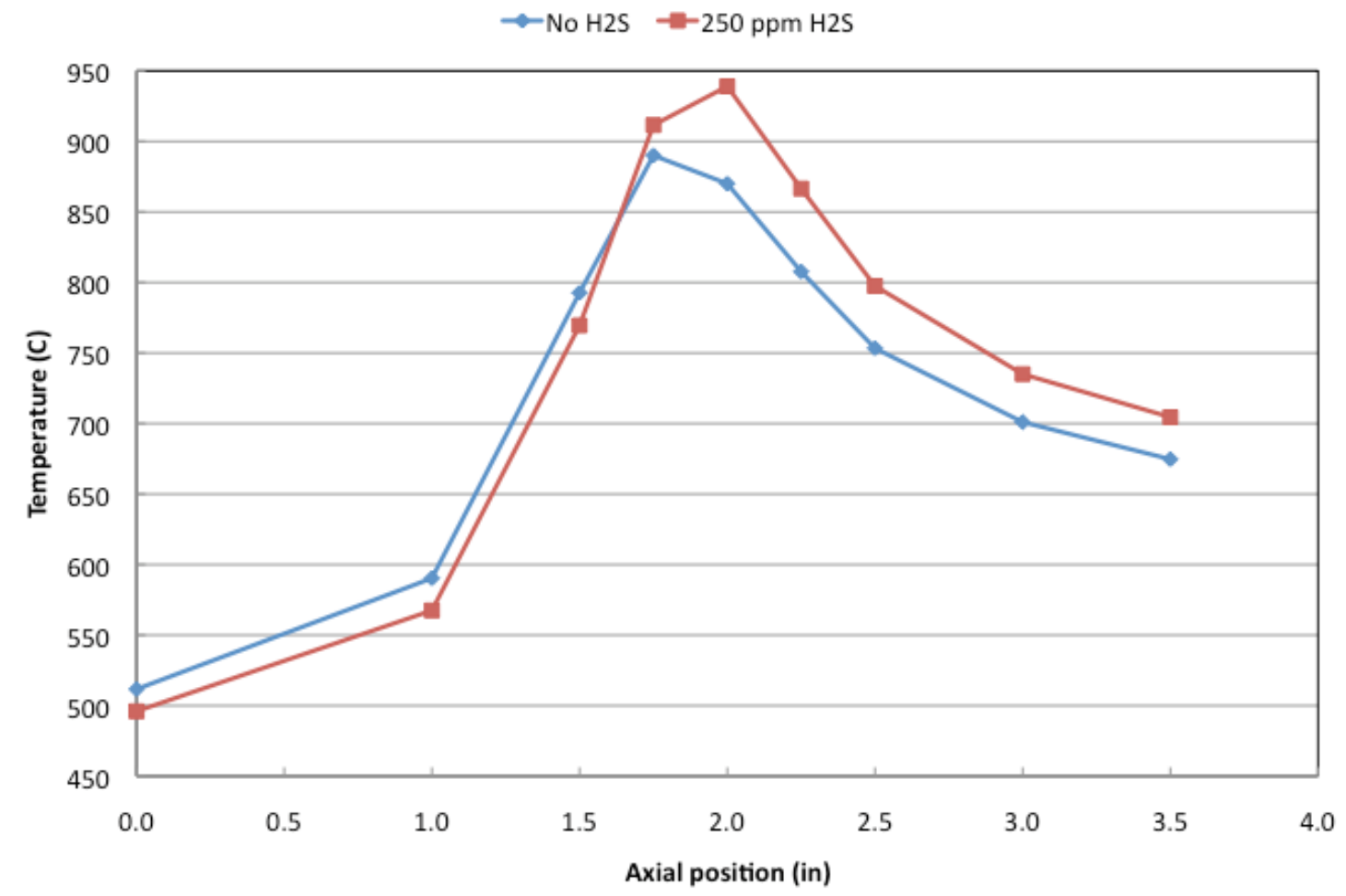

Figure 8.103. Axial temperature profiles for $5 \mathrm{Ni} / \mathrm{CZO}$ before and after addition of 250 ppmv $\mathrm{H}_{2} \mathrm{~S}$.

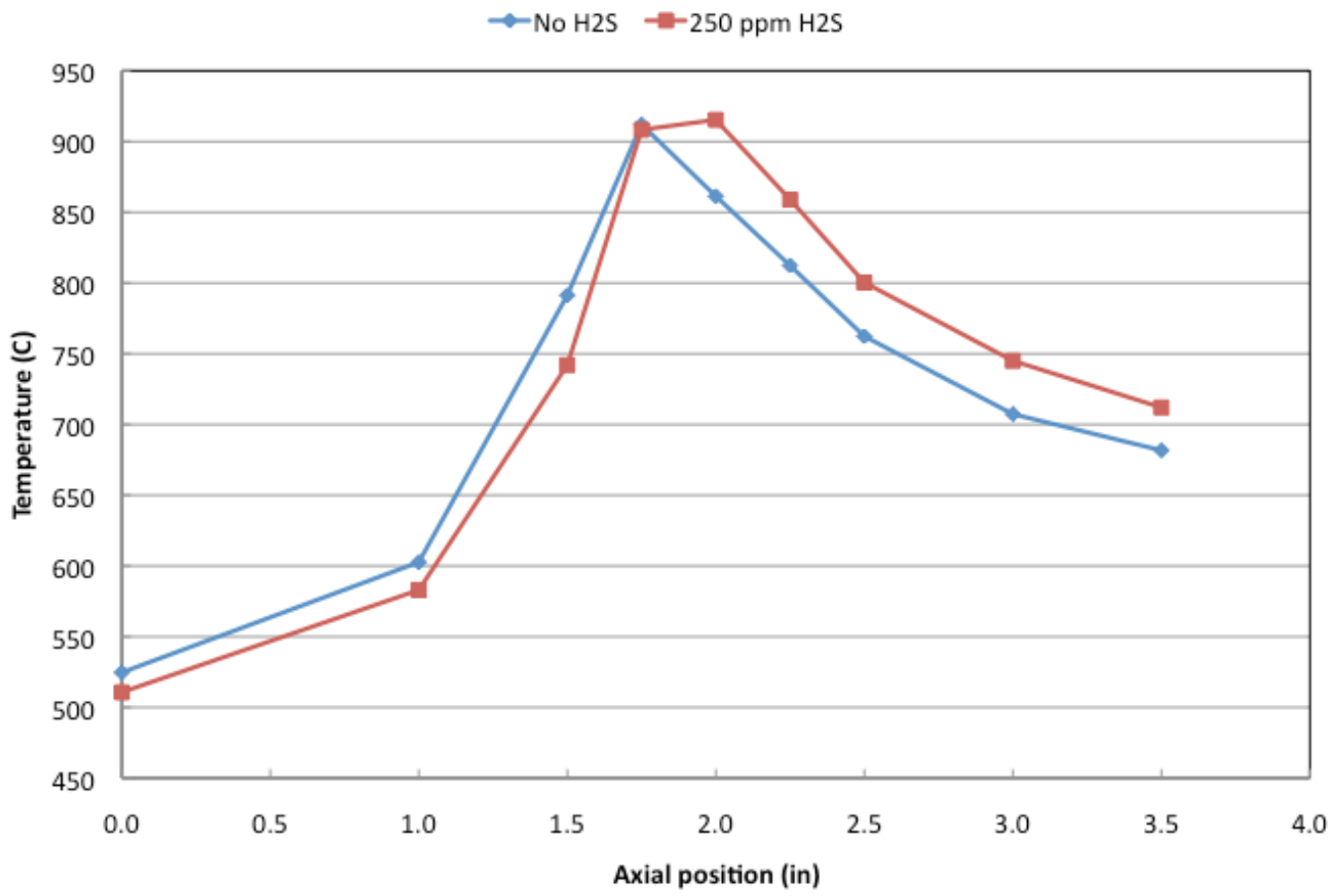

Figure 8.104. Axial temperature profiles for $0.3 \mathrm{Sn}-5 \mathrm{Ni} / \mathrm{CZO}$ before and after addition of 250 ppmv $\mathrm{H}_{2} \mathrm{~S}$. 
Figure 8.105 presents an overlay of all the temperature profiles, with and without $S$ in the feed stream. This shows that in general, there is little difference in the gas temperature above the catalyst bed, but there are higher peak temperatures and higher temperatures downstream from the peak with $\mathrm{H}_{2} \mathrm{~S}$ in the feed. Two profiles stand out as being significantly lower in temperature than the others these are from $5 \mathrm{Ni} / \mathrm{CZO}$ runs.

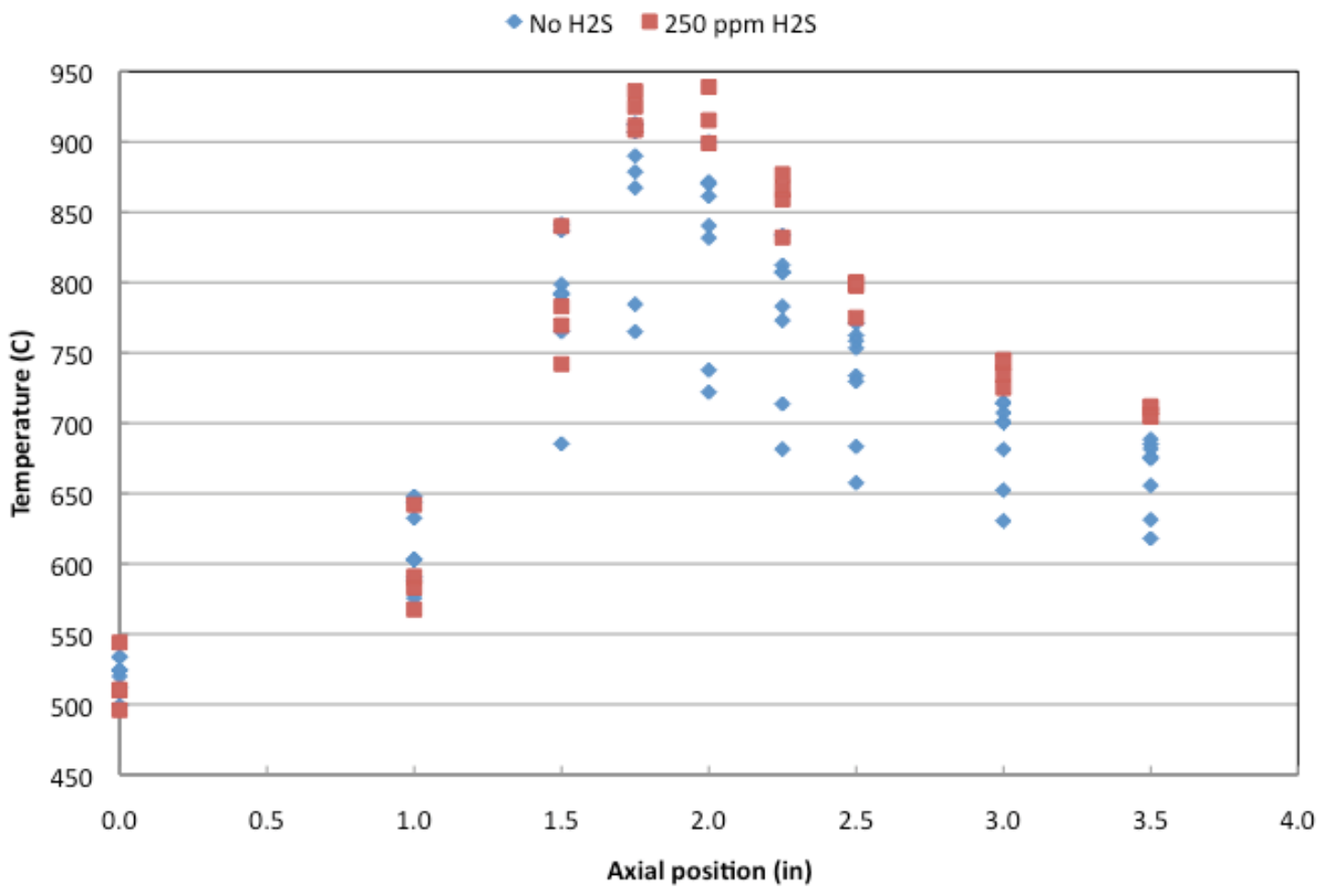

Figure 8.105. Master composite of all temperature profiles taken with and without $\mathrm{H}_{2} \mathrm{~S}$ in feed stream for both catalysts.

Results for nickel dispersion, specific surface area, and average metal particle diameter are given in Table 8.14 . The fresh $5 \mathrm{Ni} / \mathrm{CZO}$ catalyst has a nickel dispersion of $2.39 \%$, typical for $\mathrm{Ni} / \mathrm{CZO}$ catalysts of this loading and preparation method. This corresponds to a nickel surface area of $0.797 \mathrm{~m}^{2} / \mathrm{g}_{\text {cat }}$. The addition of $\mathrm{Sn}$ to the $5 \mathrm{Ni} / \mathrm{CZO}$ catalyst significantly reduces the $\mathrm{H}_{2}$ uptake, leading to a lower reported nickel dispersion and much larger mean particle diameter than the Sn-free catalyst. The effect of Sn may in fact be to cause significant nickel agglomeration, but based on other work in the literature it seems more likely that $\mathrm{Sn}$ forms a surface alloy with $\mathrm{Ni}$ and disrupts chemisorption without significantly altering the nickel particle size. Figure 8.106 presents the X-ray diffraction patterns of the $5 \mathrm{Ni} / \mathrm{CZO}$ and $0.3 \mathrm{Sn}-5 \mathrm{Ni} / \mathrm{CZO}$ catalysts. Significantly larger nickel particles would be apparent by sharper, narrower nickel reflection peaks. There are no significant differences between the 
XRD patterns of the two catalysts, and no extra peaks in the Sn-doped catalyst that would indicate formation of new phases.

Table 8.14. Chemisorption results for fresh and used catalysts.

\begin{tabular}{lllll} 
Sample & Exp \# & disp & $\mathrm{m}^{2} / \mathrm{g}_{\mathrm{cat}}$ & $\mathrm{dp}(\mathrm{nm})$ \\
\hline 5Ni/CZO Lot 4 & $\mathrm{N} / \mathrm{A}$ & 2.39 & 0.797 & 42.3 \\
5Ni/CZO Lot 4 Post ATR no S & 1 & 1.20 & 0.399 & 84.4 \\
5Ni/CZO Lot 4 Post ATR no S & 6 & 0.90 & 0.299 & 112.7 \\
5Ni/CZO Lot 4 Post ATR 250 ppmv S & 5 & 0.07 & 0.024 & 1392.7 \\
5Ni/CZO Lot 4 Post ATR 250 ppmv S & 8 & 0.10 & 0.033 & 1031.1 \\
& & & & \\
0.3Sn-5Ni/CZO Lot 4 & $\mathrm{N} / \mathrm{A}$ & 0.68 & 0.227 & 148.2 \\
0.3Sn-5Ni/CZO Lot 4 Post ATR no S & 2 & 0.22 & 0.073 & 459.5 \\
0.3Sn-5Ni/CZO Lot 4 Post ATR no S & 7 & 0.10 & 0.033 & 1017.1 \\
0.3Sn-5Ni/CZO Lot 4 Post ATR 250 & 4 & 0.09 & 0.030 & 1121.9 \\
ppmv S & & & & \\
0.3Sn-5Ni/CZO Lot 4 Post ATR 250 & 9 & 0.0066 & 0.0022 & 15358 \\
ppmv S & & & &
\end{tabular}




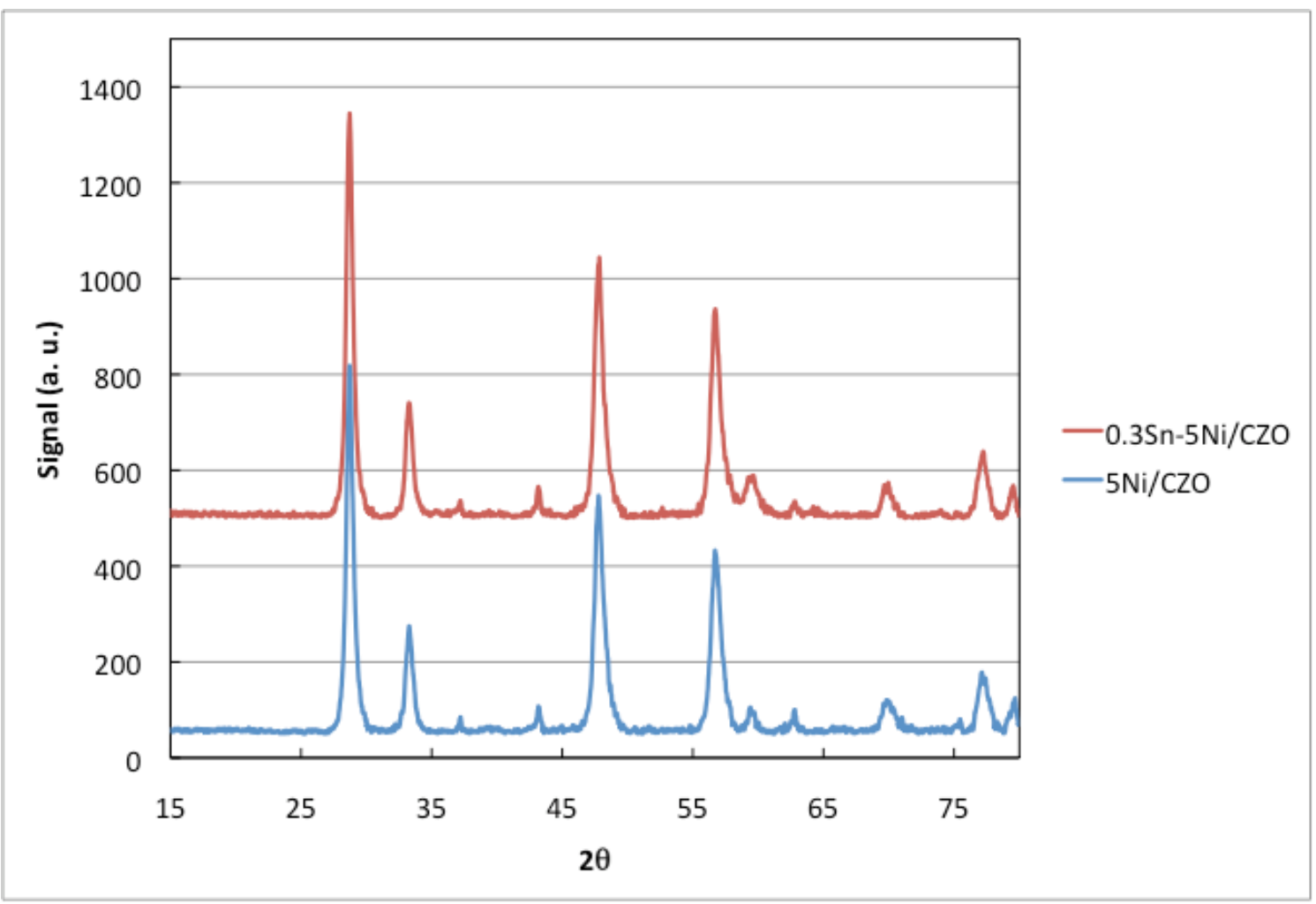

Figure 8.106. X-ray diffraction patterns for $5 \mathrm{Ni} / \mathrm{CZO}$ and $0.3 \mathrm{Sn}-5 \mathrm{Ni} / \mathrm{CZO}$ catalysts prior to reduction or reaction.

Results from temperature-programmed reduction are shown in Figure 8.107. $5 \mathrm{Ni} / \mathrm{CZO}$ shows a low temperature reduction peak typically seen in low loading $\mathrm{Ni} / \mathrm{CZO}$ catalysts with dispersions in the $2-4 \%$ range. It also exhibits a medium temperature reduction feature usually assigned to reduction of bulk-like nickel. The high temperature reduction feature is due to bulk reduction of the CZO support. The addition of $\mathrm{Sn}$ to the $5 \mathrm{Ni} / \mathrm{CZO}$ catalyst has no significant effects on the reduction behavior. 


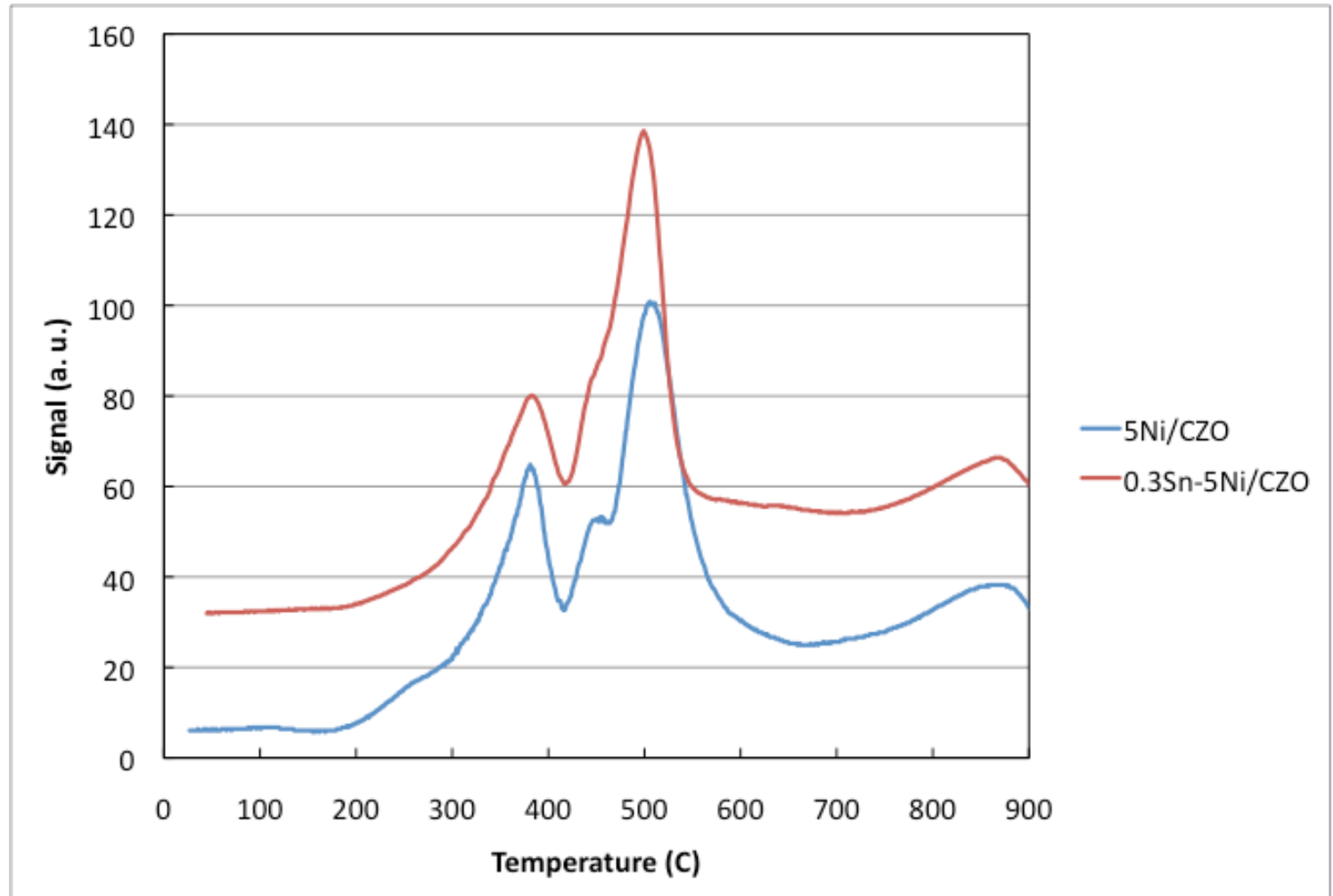

Figure 8.107. Temperature programmed reduction profiles for $5 \mathrm{Ni} / \mathrm{CZO}$ and $0.3 \mathrm{Wn}-5 \mathrm{Ni} / \mathrm{CZO}$.

Autothermal reforming of a simulated gasifier output is a complex combination of multiple reactions, with most of them occurring on the reforming catalyst but with some potentially occurring in the gas phase. In typical single hydrocarbon ATR studies, there is only one target for oxygen and steam to react with. In these experiments, hydrogen and carbon monoxide may also react with oxygen (or $\mathrm{CO}$ with steam), although these are not the desired reactions.

Several important observations may be made based on the results given above. First, $5 \mathrm{Ni} / \mathrm{CZO}$ and $0.3 \mathrm{Sn}-5 \mathrm{Ni} / \mathrm{CZO}$ have similar reforming activities despite large differences in hydrogen uptake on the fresh catalysts. Second, the effect of $\mathrm{H}_{2} \mathrm{~S}$ addition impacts reforming performance as evidenced by decreases in $\mathrm{H}_{2}$ and $\mathrm{CO}$ production and ethylene conversion. This performance reduction, however, is an offset followed by constant long-term performance, rather than a steady decline in performance leading eventually to inactivity. Third, $\mathrm{CO}_{2}$ production is similar over both catalysts, and is unaffected by the addition of $\mathrm{H}_{2} \mathrm{~S}$ to the feed stream.

Clearly, reforming performance of these two catalysts is not related to hydrogen uptake in a simple manner. The XRD data, while admittedly inferior to microscopy for nickel particle size estimation, does not indicate large differences between $\mathrm{Sn}$-free and Sn-doped $5 \mathrm{Ni} / \mathrm{CZO}$. Similar Sn doping levels of Ni/YSZ have been shown in the literature to form $\mathrm{Sn}-\mathrm{Ni}$ surface alloys. This surface enrichment could be expected to alter the chemisorption behavior of the catalyst 
without grossly changing the nickel particle size. The question remains, however, if $\mathrm{Sn}$ addition can increase the barrier to $\mathrm{H}_{2}$ activation and subsequent chemisorption, should it not affect $\mathrm{C}-\mathrm{C}$ bond breaking, $\mathrm{O}_{2}$ adsorption, and other key reaction steps assumed to be operative in reforming?

The addition of $\mathrm{H}_{2} \mathrm{~S}$ negatively impacts reforming performance, and it does so on both the Sn-free and Sn-doped catalysts. Doping of Ni/YSZ catalysts with $\mathrm{Sn}$ has been shown to decrease carbon deposition experimentally, with computational chemistry results providing a detailed understanding of the underlying mechanism. One hypothesis posed during this project was that Sndoping might alter the catalytic behavior of nickel to impart some tolerance of sulfur. This hypothesis must be rejected given that the presence of Sn did not provide an improvement in performance when $\mathrm{H}_{2} \mathrm{~S}$ was added to the feed stream. The addition of $\mathrm{H}_{2} \mathrm{~S}$ to the feed at such a high level might have been expected to completely deactivate the catalyst fairly quickly. Assuming a site density for nickel of $1 \times 10^{15}$ sites $/ \mathrm{cm}^{2}$, and a metal surface area of $0.797 \mathrm{~m}^{2} / \mathrm{g}_{\text {cat, }}$, there would be approximately $7.97 \times 10^{18}$ sites in a typical catalyst load. The flow rate of $\mathrm{H}_{2} \mathrm{~S}$ in to the system is approximately $3.35 \times 10^{-5} \mathrm{moles} / \mathrm{min}$, or $2.02 \mathrm{x}$ $10^{19} \mathrm{molecules} / \mathrm{min}$. Assuming a Ni:S stoichiometry of $1: 1$, enough sulfur was admitted to the system in the first 30 seconds of flow to completely cover the available nickel. In fact, the catalyst continues to perform, albeit at a lower $\mathrm{H}_{2}$ and $\mathrm{CO}$ production rate. So the sulfur coverage on the catalyst surface during operation reaches equilibrium with sulfur species in the gas phase and stable performance is observed. This lack of deactivation may be a result of the specific reaction conditions chosen. A change in the hydrogen, water, or oxygen concentration may lead to progressive deactivation and ultimate cessation of activity.

While $\mathrm{H}_{2}$ and $\mathrm{CO}$ production are decreased upon $\mathrm{H}_{2} \mathrm{~S}$ addition, $\mathrm{CO}_{2}$ production is unaffected over both catalysts. The immediate conclusion to be drawn from this observation is that $\mathrm{H}_{2}$ and $\mathrm{CO}$ are formed via different paths than $\mathrm{CO}_{2}$. If both are produced by catalytic reactions, then different sites must be involved, with those active for $\mathrm{CO}_{2}$ production unaffected by $\mathrm{S}$ poisoning. Sources of $\mathrm{CO}_{2}$ in the system are oxidation of $\mathrm{CO}$, total oxidation of hydrocarbons $\left(\mathrm{CH}_{4}, \mathrm{C}_{2} \mathrm{H}_{4}\right.$, or $\left.\mathrm{C}_{7} \mathrm{H}_{8}\right)$, and reverse water gas shift. It is unlikely that $\mathrm{CO}_{2}$ would be a secondary product derived from oxidation of $\mathrm{CO}$ produced first by reforming - its production rate would necessarily be decreased upon $\mathrm{H}_{2} \mathrm{~S}$ addition. CZO is not an inert support - in other studies CZO has been shown to catalyze hydrocarbon oxidation with a higher yield to $\mathrm{CO}_{2}$ than $\mathrm{CO}$. As the support surface area exceeds the nickel surface area by a factor of 10-14, even a low activity to hydrocarbon oxidation might compete with reforming. It is also possible that homogeneous oxidation of hydrocarbons occurs and leads to $\mathrm{CO}_{2}$ formation. $\mathrm{CO}_{2}$ production via a homogeneous path would be unaffected by the addition of $\mathrm{H}_{2} \mathrm{~S}$. Additional experiments will almost certainly be needed to test different hypothetical reaction networks given the complexity of the feed stream and the many possible reactions that take place.

The large changes in $\mathrm{H}_{2}$ uptake by the catalysts following reaction are not fully explainable at this point. Operation at high temperatures in reducing 
environments can lead to sintering of nickel particles, reducing the active surface area and the $\mathrm{H}_{2}$ uptake during chemisorption. The greater decrease in uptake found after operation with $\mathrm{H}_{2} \mathrm{~S}$ might be due to residual $\mathrm{S}$ not removed during calcination prior to analysis, or could simply be a result of the higher bed temperatures during operation, which were observed in the temperature profiles. Additional characterization verifying the nickel particle sizes calculated by chemisorption might rule out residual sulfur.

ATR of mixed hydrocarbons in the presence of $\mathrm{H}_{2}$ and $\mathrm{CO}$ is a complex reaction system. While significant portions of the reactions are catalytic, as evidenced by their sensitivity to the introduction of a catalyst poison, some reaction paths may be homogeneous (for example $\mathrm{CO}_{2}$ production) or proceed on different types of sites. The addition of $\mathrm{Sn}$ to the $5 \mathrm{Ni} / \mathrm{CZO}$ catalyst did not provide for improved sulfur tolerance as had been hypothesized. In fact, it appears to have yielded a catalyst more susceptible to deactivation under our reaction conditions.

Results of reforming simulated gasifier products with and without $\mathrm{H}_{2} \mathrm{~S}$ over $\mathrm{Ni} / \mathrm{CZO}$ and $\mathrm{Sn}-\mathrm{Ni} / \mathrm{CZO}$ catalysts have been previously reported. In this period the effects of $\mathrm{H}_{2} \mathrm{~S}$ on catalyst performance over longer periods have been investigated.

FIGURE 8.108 presents the results from approximately 30 hours of reforming a simulated gasifier mixture. The feed composition is given in Table 1. Sulfur was added as $\mathrm{H}_{2} \mathrm{~S}$ at the 5-hour mark and removed at 25.5 hours. The $\mathrm{H}_{2}$ and $\mathrm{CO}$ concentration drop immediately upon addition of $\mathrm{H}_{2} \mathrm{~S}$ - this effect has been observed previously. Over the 20 hours of reforming with $\mathrm{H}_{2} \mathrm{~S}$, the $\mathrm{H}_{2}$ level drops steadily, while the $\mathrm{CO}$ and $\mathrm{CO}_{2}$ levels nearly return to their $\mathrm{S}$-free values. The $\mathrm{CH}_{4}$ slip increases slightly, while the $\mathrm{C}_{2} \mathrm{H}_{4}$ slip increases more significantly. Prior to $\mathrm{H}_{2} \mathrm{~S}$ addition, the $\mathrm{CH}_{4}$ and $\mathrm{C}_{2} \mathrm{H}_{4}$ conversions were approximately 23 and $90 \%$ respectively. After $\mathrm{H}_{2} \mathrm{~S}$ addition, the $\mathrm{CH}_{4}$ conversion is relatively unchanged at $21 \%$, but the $\mathrm{C}_{2} \mathrm{H}_{4}$ conversion drops to $62 \%$.

Removing the $\mathrm{H}_{2} \mathrm{~S}$ recovers some $\mathrm{H}_{2}$ production as well as some of the $\mathrm{C}_{2} \mathrm{H}_{4}$ conversion, but complete recovery of performance is not obtained. This points to either some irreversible poisoning of the catalyst by $\mathrm{S}$, or some physical changes that decreased activity in addition to a recoverable loss when $\mathrm{H}_{2} \mathrm{~S}$ is present in the feed stream. 


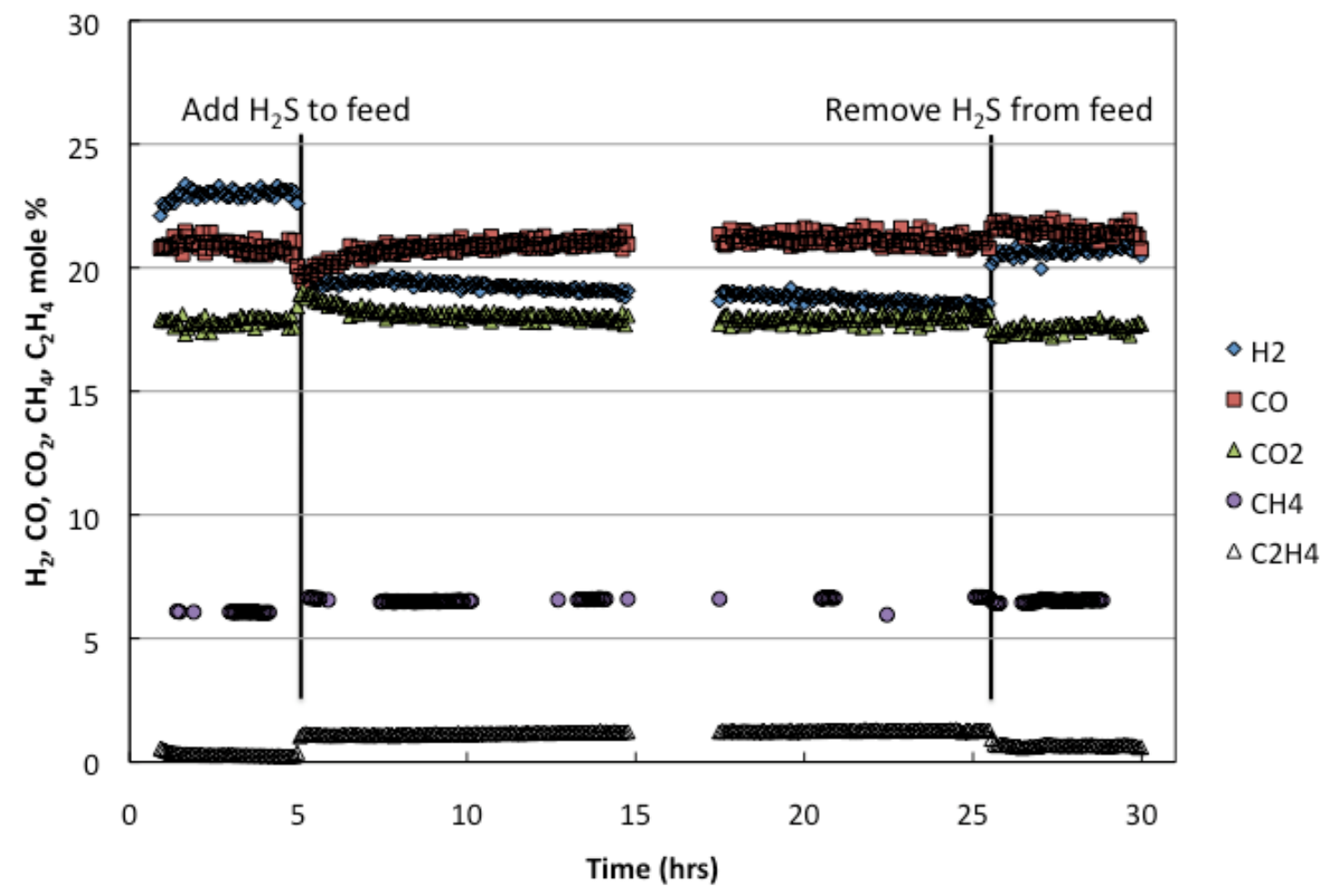

Figure 8.108. $\mathrm{H}_{2}, \mathrm{CO}, \mathrm{CO}_{2}, \mathrm{CH}_{4}$, and $\mathrm{C}_{2} \mathrm{H}_{4}$ concentrations during ATR of a simulated gasifier product. 


\section{TASK 9.0: SOFC TESTING}

Recipient shall evaluate the performance of the reformed syngas product in an existing Solid Oxide Fuel Cell (SOFC). The objective will be to evaluate efficiencies of operation and to identify any problems associated with contaminants in the syngas generated by the proposed reformer. The focus will be on optimizing thermodynamic efficiency (including both electrical and thermal energy contributions) and the sensitivity of the SOFC electrolyte and catalyst(s) to poisoning or other adverse effects as a consequence of any remaining contaminants in the gas stream.

No work is required on this task as it was an optional task that DOE-NETL advised not to pursue. 